\title{
PROPOSTA DE UM MODELO DE REFERÊNCIA PARA PLANEJAMENTO E CONTROLE DA PRODUÇÃO EM EMPRESAS VIRTUAIS
}

Christiane Peres Goulart

Dissertação apresentada à Escola de Engenharia de São Carlos da Universidade de São Paulo, como parte dos requisitos para obtenção do título de Mestre em Engenharia de Produção.

ORIENTADOR: Prof. Dr. Carlos Frederico Bremer

São Carlos

2000 
Dedico este trabalho aos meus pais pelo constante apoio à realização dos meus objetivos. 


\section{Agradecimentos}

Ao Prof. Bremer pelas oportunidades e orientação.

Ao Prof. Rozenfeld pela amizade e conselhos, ao Prof. João Fernando pelo exemplo de bom humor e de como tratar as pessoas e ao Prof. Silvio Pires pela atenção e conversa sobre algumas dúvidas conceituais.

À Fundação de Amparo à Pesquisa do Estado de São Paulo (FAPESP) pela bolsa concedida.

À todo o pessoal do Núcleo de Manufatura Avançada (NUMA) pelo convívio e troca de experiências. Em especial àqueles que participaram diretamente na realização deste trabalho (fosse dando sugestões, revendo o texto ou apenas escutando as minhas dúvidas e explicações): Ana Paula, Domingos, Elaine, Flávia, Gislaine, Favareto, Jairo, Kamarão, Luciane, Levon, Márcio, Mateus, Rodrigo, Rogério e Tiago.

Ao que sempre quebram os meus galhos: Renata, Cris, André, Fernandinho e Francis. Ao Mike pela força na reta final e concepção do produto para o exemplo.

Às queridas amigas, Maira, Luciana e Tutu, que mesmo distantes estão sempre presentes.

Ao Mário pela total apoio, paciência e muitas revisões e sugestões.

À minha família, em especial aos meus pais, minha irmã, meu irmão e meus avôs pelo carinho que amenizou a distância. 


\section{SUMÁRIO}

LISTA DE FIGURAS

LISTA DE TABELAS

IX

LISTA DE ABREVIATURAS E SIGLAS ...X

RESUMO XIII

ABSTRACT. XIV

1 INTRODUÇÃ

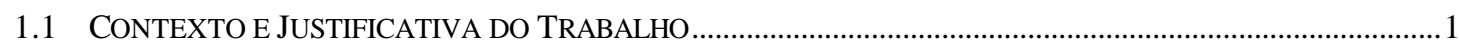

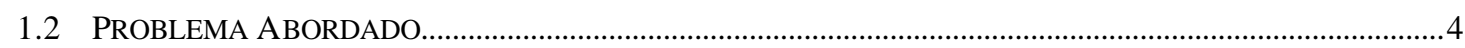

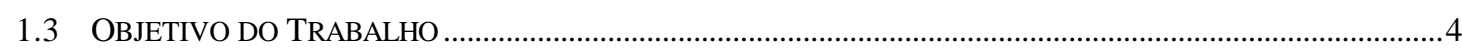

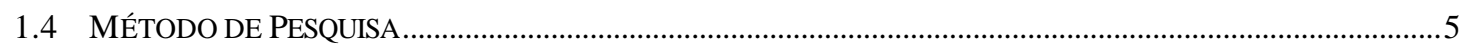

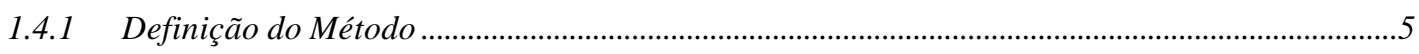

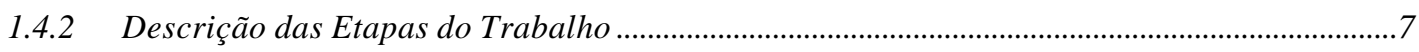

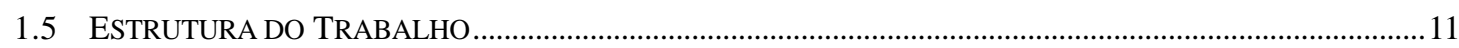

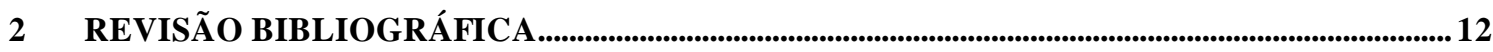

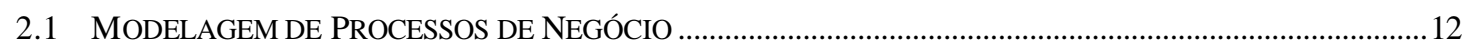

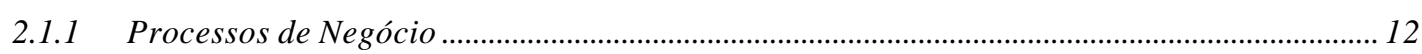

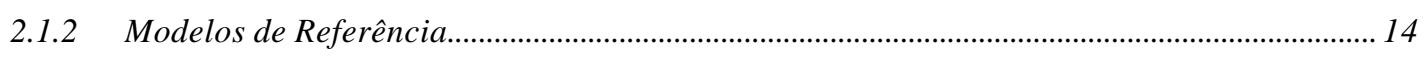

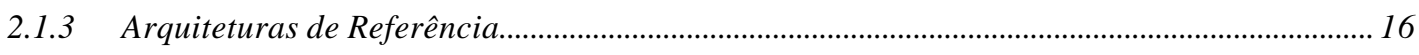

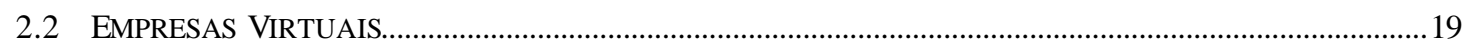

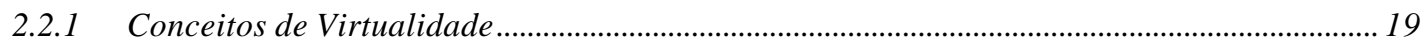

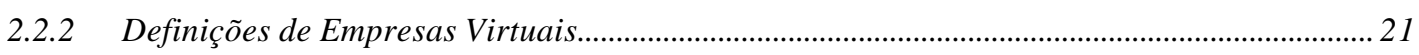

2.2.3 Características de Empresas Virtuais ......................................................................................... 22

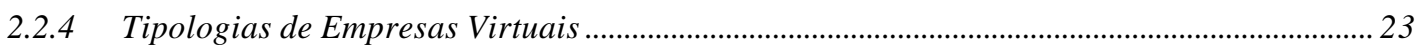

2.2.5 Comparação com outras Formas de Cooperação .......................................................................... 26

2.2.6 Propostas para a Formação de Empresas Virtuais ......................................................................... 32

2.3 PlANEJAMENTO E CONTROLE DA PRODUÇÃo ..............................................................................................39

2.3.1 Atividades do Planejamento e Controle da Produção .................................................................... 40

2.3.2 Classificação dos Sistemas Produtivos............................................................................................ 43

2.3.3 Abordagens de Planejamento e Controle da Produção ................................................................ 48 


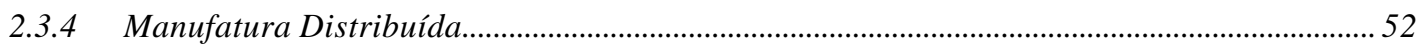

2.3.5 Projetos relacionados à Gestão da Produção em Empresas Virtuais........................................ 54

\section{PROPOSTA DE UM MODELO DE REFERÊNCIA PARA PLANEJAMENTO E} CONTROLE DA PRODUÇÃ̃ EM EMPRESAS VIRTUAIS ...............................................................................65

3.1 DETERMINAÇÃO DAS CARACTERÍSTICAS DE EMPRESA VIRTUAL ABORDADAS NO TRABALHO .........65

3.2 ESTUdo dos PROJETOS RELACIONADOS À GESTÃo DA PRODUÇÃO EM EMPRESAS VIRTUAIS...........67

3.3 DETERMINAÇÃO DAS CARACTERÍSTICAS DA GESTÃo DA PRODUÇÃO EM EMPRESAS VIRTUAIS........71

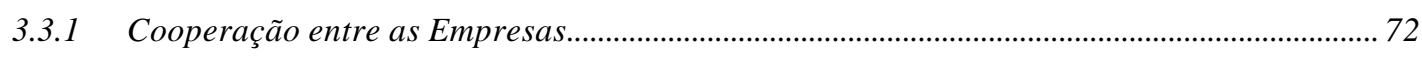

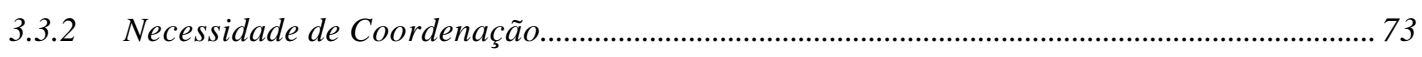

3.3.3 Existência de duas Dimensões de Planejamento....................................................................... 74

3.3.4 Planejamento para Oportunidades Específicas ............................................................................. 76

3.3.5 Necessidade de Troca de Informações.............................................................................................. 76

3.4 IDENTIFICAÇÃO DOS PROCESSOS DE NEGÓCIO DE UMA EMPRESA VIRTUAL .........................................79

3.5 DETERMINAÇÃO DO ESCOPO E REQUISITOS DO MODELO DE REFERÊNCIA ............................................84

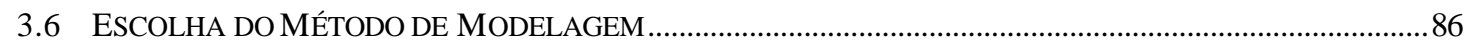

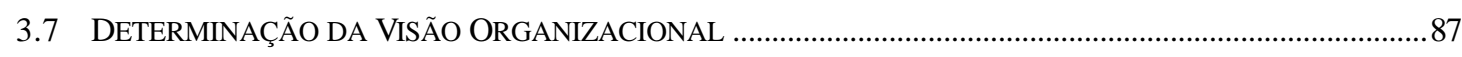

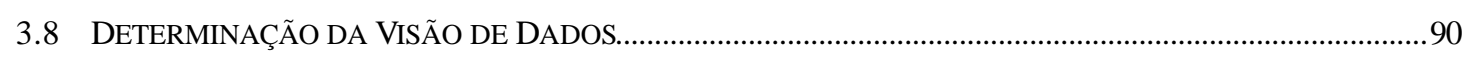

3.8.1 Entidades do Modelo Entidade-Relacionamento ........................................................................ 92

3.8.2 Relacionamentos do Modelo Entidade-Relacionamento ............................................................. 95

3.9 DETERMINAÇÃO DA VISÃO DE FUNÇÕES...................................................................................................97

3.9.1 Pré-Planejar Produção da EV ................................................................................................. 100

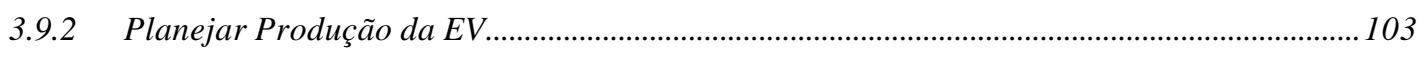

3.9.3 Inserir Planejamento nas Empresas Parceiras.................................................................... 106

3.9.4 Programar e Controlar Produção ........................................................................................... 107

ElabORAÇÃO DA VISÃo DE CONTROLE …….................................................................................110

4 ELABORAÇÃO DE UM EXEMPLO DE APLICAÇÃO DO MODELO PROPOSTO .............113

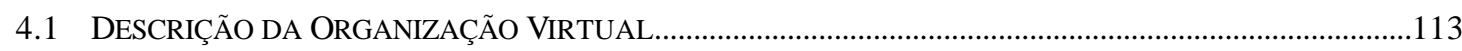

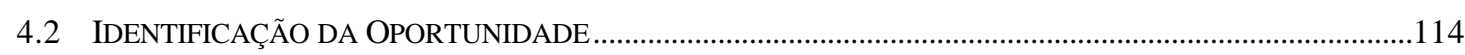

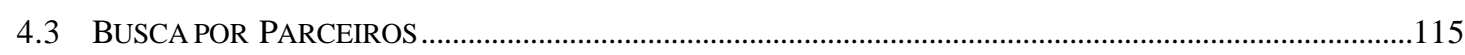

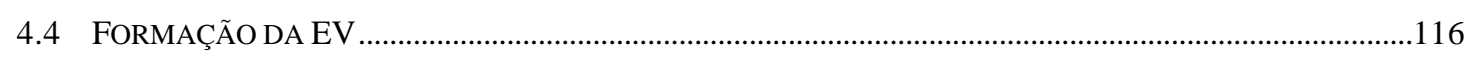

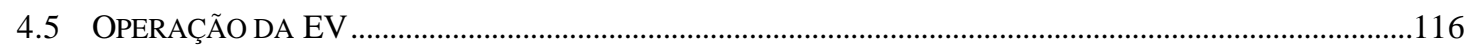

4.5.1 Pré Planejar Produção da EV .................................................................................................. 117

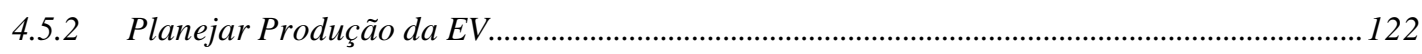

4.5.3 Inserir Planejamento nas Empresas Parceiras..................................................................... 124 
4.5.4 Programar e Controlar Produção ........................................................................................... 126

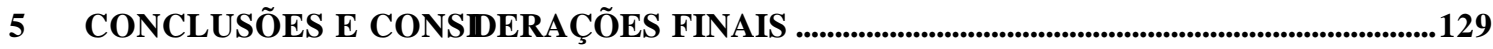

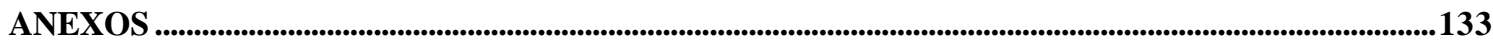

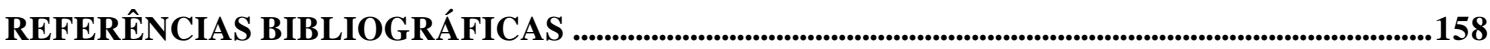

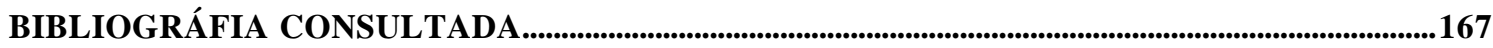




\section{LISTA DE FIGURAS}

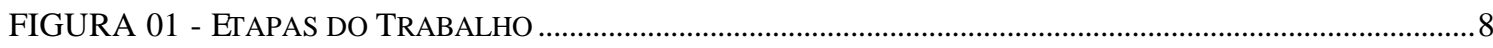

FIGURA 02 - FRAMEWORK DE CLASSIFICAÇÃO DE PROCESSOS DE NEGÓCIO_...................................................13

FIGURA 03 - VISÕES DE UM MODELO DE PROCESSO DE NEGÓCIO......................................................................17

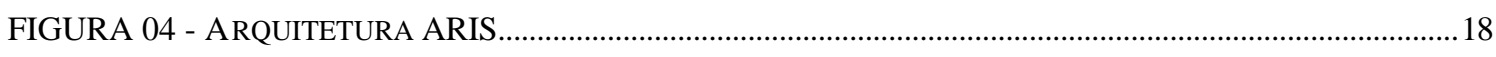

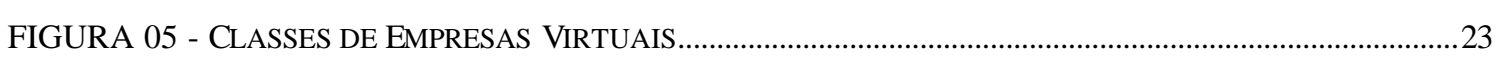

FIGURA 06 - RELAÇÕES ENTRE COOPERAÇÕES DE EMPRESAS........................................................................

FIGURA 07 - REDES DE EMPRESAS E RELACIONAMENTO BILATERAL …………………………………….......32

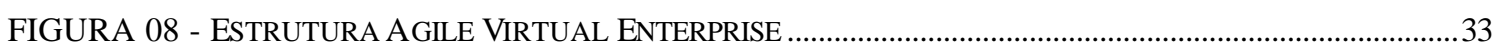

FIGURA 09 - CICLO DE VIDA DE UMA EMPRESA VIRTUAL - AMMRC..........................................................36

FIGURA 10 - RELACIONAMENTOS NO AMBIENTE DE NEGÓCIOS VIRTUAIS GLOBAIS.........................................37

FIGURA 11 - FoRMAÇÃO DE EMPRESAS VIRTUAIS A PARTIR DE UMA ORGANIZAÇÃO VIRTUAL ....................39

FIGURA 12 - A TIVIDADES BÁSICA DO PLANEJAMENTO E CONTROLE DE PRODUÇ̃̃o .........................................41

FIGURA 13 - VOLUME DE PRODUÇÃO X VARIEDADE DE PRODUTOS....................................................................4

FIGURA 14 - NÚMERO DE COMPONENTES, LEAD-TIMEE TIPOS DE SISTEMAS DE PRODUÇÃO.............................45

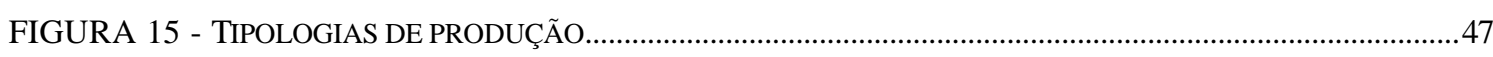

FIGURA 16 - CICLO DE VIDA DE UMA EMPRESA VIRTUAL - PRODNET II......................................................55

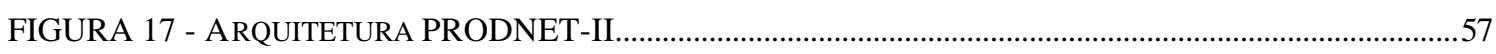

FIGURA 18 - RECONFIGURAÇÃO OU DISSOLUÇÃO DA EMPRESA VIRTUAL.......................................................67

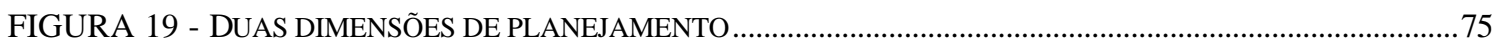

FIGURA 20 - CICLO DE VIDA DE UMA EMPRESA VIRTUAL ......................................................................... 80

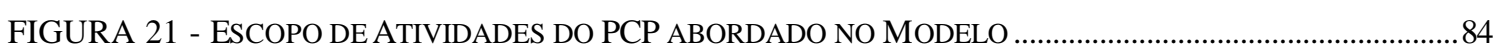

FIGURA 22 - ESCOPO DO PROCESSO PRODUZIR ……………………………………………………..... 85

FIGURA 23 - OBJETOS DA VISÃO ORGANIZACIONAL ……….................................................................... 87

FIGURA 24 - ORGANOGRAMA SIMPLIFICADO DA ORGANIZAÇÃO VIRTUAL .....................................................8

FIGURA 25 - ORGANOGRAMA SIMPLIFICADO DA EMPRESA VIRTUAL............................................................8

FIGURA 26 - ORGANOGRAMA DE GESTÃo DA PRODUÇÃO DA EMPRESA VIRTUAL ………..............................90

FIGURA 27 - REPRESENTAÇÃO GRÁFICA DE UM MER …………………………………………………...91

FIGURA 28 - MODELO ENTIDADE-RELACIONAMENTO DA VISÃO DE DADOS...................................................93

FIGURA 29 - ClASSIFICAÇÃO DA ESTRUTURA DO PRODUTO POR ITEM .........................................................94 


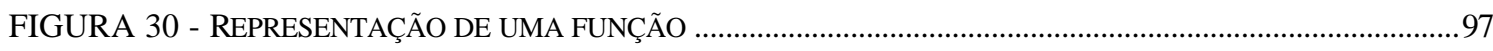

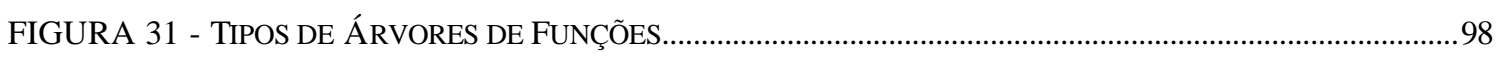

FIGURA 32 - SUB-PROCESSOS DO PROCESSO PRODUZIR .......................................................................................99

FIGURA 33 - ÁRVORE DE FUNÇÕES DO SUB-PROCESSO PRÉ-PLANEJAR PRODUÇÃO DA EV..........................100

FIGURA 34 - ÁRVORE DE FUNÇÕES DO SUB-PROCESSO PLANEJAR PRODUÇÃO DA EV ..................................104

FIGURA 35 - ÁRVORE DE FUNÇÕES DO SUB-PROCESSO INSERIR PLANEJAMENTO NAS EMPRESAS...............106

FIGURA 36 - DESDOBRAMENTO DE UMA ORDEM DE PRODUÇÃO DA EV EM ORDENS DA EP .......................107

FIGURA 37 - ÁRVORE DE FUNÇÕES DO SUB-PROCESSO PROGRAMAR E CONTROLAR PRODUÇÃO ...............108

FIGURA 39 - REPRESENTAÇÃO DE UM EVENTO .......................................................................................111

FIGURA 40 - REPRESENTAÇÃO DE UM DATA CLUSTER ...............................................................................11

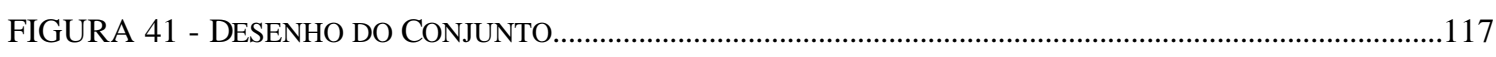

FIGURA 42 - GRÁFICO DE GANTT: QUANTIDADES E PRAZOS .......................................................................120

FIGURA 43 - GRÁFICO DE GANTT: PLANEJAMENTO DA EV ………...............................................................124

FIGURA 44 - ESTRUTURA DO MÓDULO MECÂNICO E ROTEIRO DE PRODUÇÃO ...............................................125

FIGURA 45 - INSERÇÃO DA ORDEM DE PRODUÇÃO DA EV NA EP.....................................................................126

FIGURA 46 - LBERAÇÃO DAS ORDENS DE PRODUÇÃO ...............................................................................127 


\section{LISTA DE TABELAS}

TABELA 01 - COMPARAÇÃO ENTRE CADEIA DE SUPRIMENTO E EMPRESA VIRTUAL .....................................28

TABELA 02 - PRINCIPAIS DIFERENÇAS ENTRE EMPRESA ESTENDIDA E EMPRESA VIRTUAL ...........................30

TABELA 03 - ATRIBUTOS PARA CARACTERIZAR RELACIONAMENTOS BILATERAIS.........................................31

TABELA 04 - PROCESSO DE DECISÃO NO PLANEJAMENTO DA PRODUÇÃO......................................................43

TABELA 05 - DIFERENÇAS SIGNIFICATIVAS ENTRE EV E A ABORDAGEM PLENT ...........................................62

TABELA 06 - Estudo dos PROJETOS RELACIONAdOs À GeSTÃo DA PRODUÇÃo EM EMPRESAS ViRTUAIS

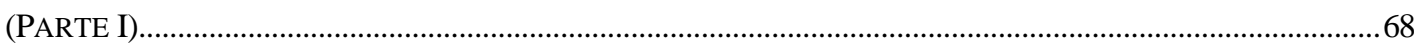

TABELA 07 - ESTUdo dos PROJETOS RELACIONAdOS À GESTÃo DA PRODUÇÃO EM EMPRESAS VIRTUAIS

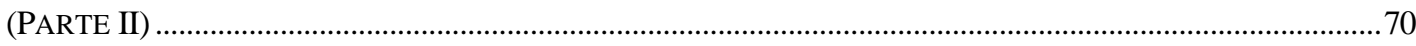

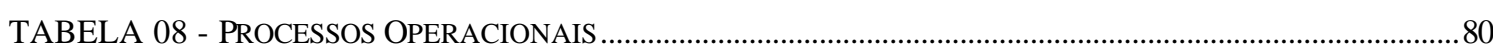

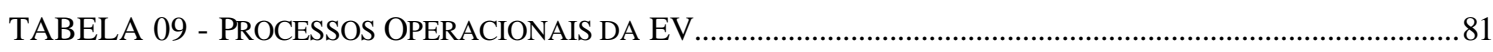

TABELA 10 - SÍMBOLO E DESCRIÇÃO DOS CONECTORES ................................................................................111

TABELA 11 - MATRIZ DE PARTICIPAÇÃO ……….......................................................................................115

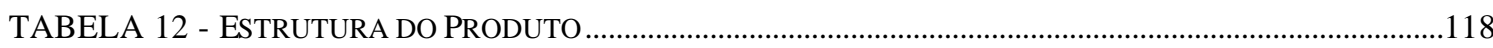

TABELA 13 - PEDIDOS EM CARTEIRA ………......................................................................................118

TABELA 14 - MATERIAIS E TEMPOS NECESSÁRIOS.............................................................................................119

TABELA 15 - CONFIRMAÇÃO DOS DADOS DE PRODUÇÃO.............................................................................120

TABELA 16 - CÁLCULO DA NECESSIDADE LÍQUIDA E CAPACIDADE NECESSÁRIA.........................................121

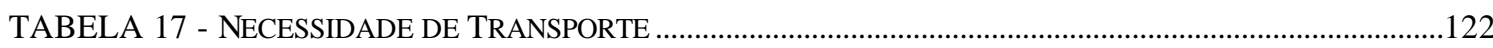

TABELA 18 - ORDENS DE PRODUÇÃO E TRANSPORTE ....................................................................................123

TABELA 19 - USO DE TI PARA A GESTÃO DA PRODUÇÃO NA EMPRESAS DO PROJETO VIRTEC ..................131

TABELA 20 - PROCESSOS DO GRUPO VIRTUAL DE INDÚSTRIA .........................................................................133

TABELA 22 - LEVANTAMENTO DO USO DE TI NAS EMPRESAS DO PROJETO VIRTEC (PARTE I) .................156

TABELA 23 - LEVANTAMENTO DO USO DE TI NAS EMPRESAS DO PROJETO VIRTEC (PARTE II)................157 


\section{LISTA DE ABREVIATURAS E SIGLAS}

\begin{tabular}{|c|c|c|}
\hline AAMRC & - & Agile Aerospace Manufacturing Research Center \\
\hline AEV & - & Agenciador de Empresas Virtuais \\
\hline AMEF & - & Agile Manufacturing Enterprise Forum \\
\hline APQC & - & American Productivity \& Quality Center \\
\hline APS & - & Advanced Planning and Scheduling \\
\hline ARIS & - & Architecture for integrated Information System \\
\hline ASP & - & Application Service Provider \\
\hline ATO & - & Assemble to Order \\
\hline AVE & - & Agile Virtual Enterprise \\
\hline CAD & - & Computer Aided Design \\
\hline CORBA & - & Common Object Request Brokers Architecture \\
\hline CPEV & - & Coordenador de Produção da Empresa Virtual \\
\hline CRM & - & Customer Relationship Management \\
\hline CS & - & Cadeias de Suprimentos \\
\hline CSCW & - & Computer-Supported Co-operative Work \\
\hline EDI & - & Eletronic Data Interchange \\
\hline EE & - & Empresas Estendidas \\
\hline EL & - & Empresa Líder \\
\hline EM & - & Empresa-Membro \\
\hline
\end{tabular}




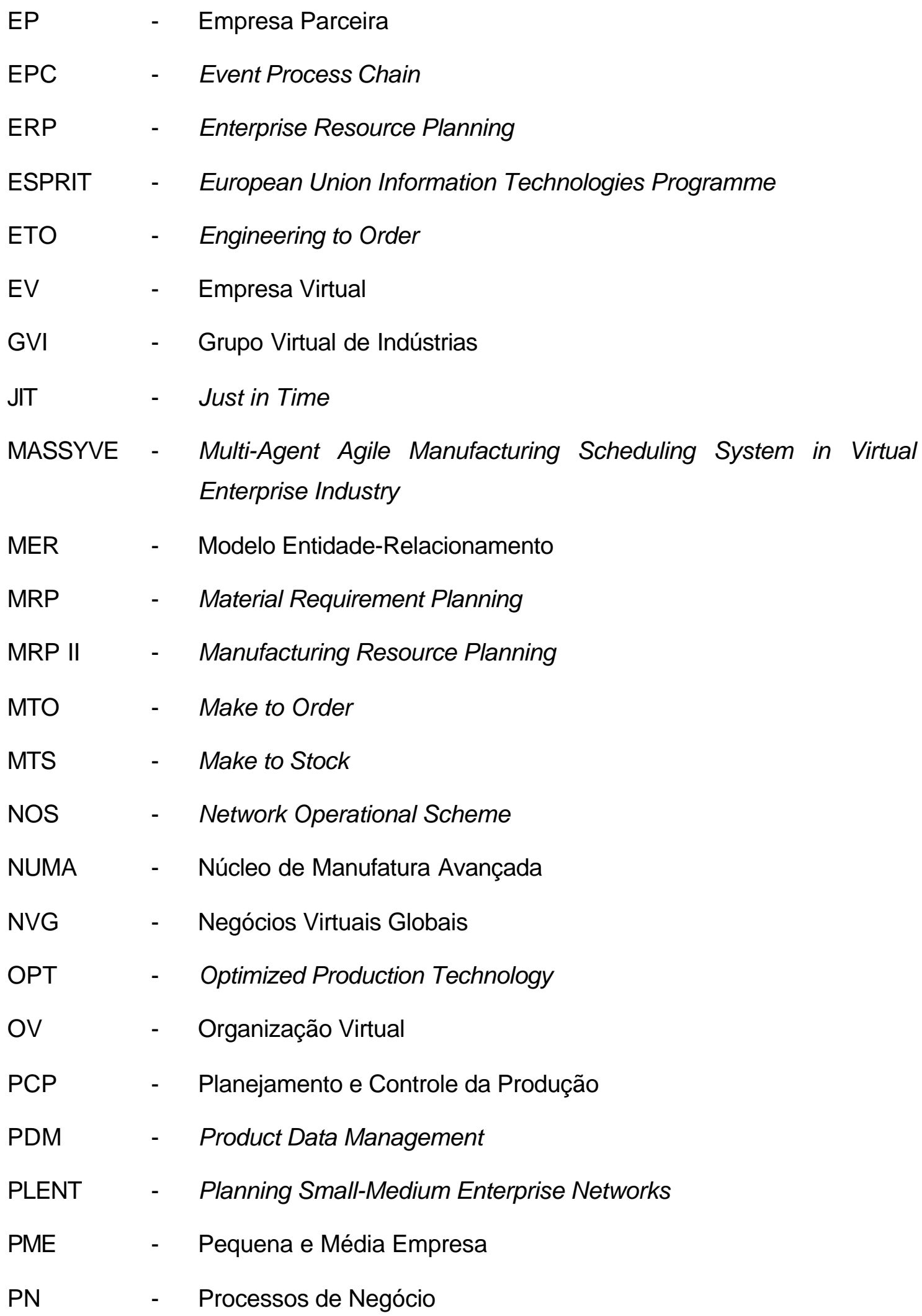


PND - Processo de Negócio Distribuído

PRODNET - Production Planning and Management in an Extended Enterprise

REP - Representante da Empresa Parceira

SCM - Supply Chain Management

SDAI - Standard Data Access Interface

$\mathrm{SMH} \quad$ - Sistema de Manufatura Holônico

SQL - Structure Query Language

STEP - Standard for the exchange of process and product model data

$\mathrm{TI} \quad$ - Tecnologia de Informação

TPEV - Time de Produção da Empresa Virtual

X-CITTIC - Planning and Control System for Semiconductor Virtual Enterprises 


\section{RESUMO}

Goulart, C. P. Proposta de um Modelo de Referência para Planejamento e Controle da Produção em Empresas Virtuais. São Carlos, 2000. 180p. Dissertação (Mestrado) Escola de Engenharia de São Carlos, Universidade de São Paulo.

O conceito de Empresas Virtuais vem sendo amplamente discutido no atual contexto de globalização dos mercados e da produção. Uma Empresa Virtual (EV) é uma rede temporária de entidades que se unem para explorar uma oportunidade de negócio, compartilhando competências, custos e acesso ao mercado. Apesar da EV ser composta por várias empresas diferentes, é fundamental gerenciar essa rede como se fosse uma única empresa. No entanto, para formação de EVs voltadas a produtos manufaturados existe uma lacuna na sua fase de operação: a carência de métodos adequados para executar o planejamento e controle da produção. O objetivo deste trabalho é propor um modelo de referência para o planejamento e controle da produção em EV, visando dar suporte a sua operação distribuída, porém de forma integrada. Esse modelo define um conjunto de atividades para o planejamento e controle da produção em EVs, as informações necessárias para realizá-las e a estrutura organizacional responsável pela execução das mesmas. Para elaborar o modelo, são determinadas as características de EVs e de sua gestão da produção, e considerados os processos envolvidos no ciclo de vida de uma EV. Por fim, um exemplo do planejamento e controle da produção em uma EV fictícia é elaborado para ilustrar a utilização do modelo proposto.

Palavras-chave: Empresa Virtual; Planejamento e Controle da Produção; Modelo de Referência. 


\section{ABSTRACT}

The concept of Virtual Enterprises has been widely discussed in the current context of market and production globalization. A Virtual Enterprise (VE) is a temporary enterprise network that joint themselves to exploit a business opportunity by sharing competences, costs and market share. Even though a VE is composed by different enterprises, it is fundamental to manage this network like a single company. However, while forming a VE for manufacturing sector, there is a gap in the operational phase: the lack of appropriated methods to execute the production planning and control. The goal of this work is to propose a reference model for production planning and control in VE, in order to support its distributed operation, but in an integrated way. This model defines a set of activities for the production planning and control in a VE, the required information to perform them and also the organizational model responsible for their execution. To elaborate the model, it was determined the features of VEs and its production management, and also considered the VE lifecycle processes. An example of production planning and control in a fictitious VE is elaborated to illustrate the proposed model utilization.

Keywords: Virtual Enterprise; Production Planning and Control; Reference Model. 


\section{Introdução}

Este capítulo apresenta o contexto no qual se insere o trabalho, as justificativas que motivaram o seu desenvolvimento, assim como o objetivo estabelecido. Também são expostos o método de pesquisa adotado, as etapas do trabalho e a forma como estão organizados os capítulos deste texto.

\subsection{Contexto e Justificativa do Trabalho}

As organizações voltadas a processos produtivos estão sendo pressionadas a adotar novos conceitos diante da crescente competição global, da redução do ciclo de vida dos produtos e da customização em massa (WIENDAHL \& HÖBIG, 1998).

Segundo PREISS et al. (1998), entre as forças propulsoras destas mudanças estão: a difusão mundial da cultura e da tecnologia, que intensifica a competição, tornando-a global e com taxas crescentes de mudanças mercadológicas; a fragmentação contínua dos mercados de massa, transformados em nichos de mercado; clientes mais exigentes, com expectativas mais elevadas; a difusão de uma produção colaborativa, com fornecedores e consumidores que compreendem a cadeia de valor e o impacto crescente de valores sociais em constante alteração, tais como considerações quanto ao ambiente de trabalho ou quanto à criação de empregos, sobre a tomada de decisão das empresas.

Esse cenário expõe as empresas a um ambiente altamente dinâmico, forçandoas a se tornarem ágeis. Em NAGEL \& DOVE ${ }^{1}$ apud JAGDEV \& BROWNE (1998), temse que agilidade, no contexto de manufatura, requer a integração de tecnologias flexíveis de produção com a habilidade baseada no conhecimento dos trabalhadores e

\footnotetext{
${ }^{1}$ NAGEL, R.; DOVE, R. (1991). $21^{\text {st }}$ Century Manufacturing Enterprise Strategy. lacocca Institute/ Lehigh University.
} 
estruturas flexíveis de gerenciamento que estimulem iniciativas de cooperação entre as empresas.

Atualmente, as empresas têm optado por cooperações e entre os fatores que impulsionam essa opção estão a concentração em competências essenciais e o desenvolvimento de tecnologias de informação.

As empresas, visando tornarem-se mais competitivas, estão focando os seus negócios em suas competências essenciais ${ }^{2}$, precisando cooperar para complementar as suas competências necessárias, a fim de oferecer produtos ou soluções para o mercado.

Quanto ao crescente avanço das tecnologias de informação e de comunicação, esse permite uma redução nos custos de transação ${ }^{3}$ das atividades econômicas migrando a coordenação das atividades de um modelo hierárquico e interno às empresas para um modelo regido pelos mecanismos de mercado aumentando o número de cooperações entre empresas (WIGAND et al.,1997).

Entre os extremos institucionais: o mercado e as estruturas empresariais hierárquicas surgem o conceito de Empresa Virtual (EV) como um tipo organizacional intermediário (TUMA, 1998). Segundo BYRNE (1993), uma EV é uma rede temporária de empresas que se unem rapidamente para explorar oportunidades, compartilhando custos, habilidades e acesso ao mercado, na qual cada empresa parceira contribui com o que tem de melhor, isto é, a sua competência essencial.

SKYRME (1996) sugere que os seguintes benefícios podem ser obtidos por meio da formação de EVs:

- Acesso a um amplo escopo de recursos especializados;

- Cada membro mantém sua independência e continua a desenvolver suas competências essenciais e

\footnotetext{
${ }^{2}$ Segundo PRAHALAD \& HAMEL (1990), uma competência é considerada essencial quando preenche os seguintes requisitos: proporciona acesso potencial para uma variedade ampla de mercados; traz uma contribuição significativa para os benefícios percebidos pelo cliente no produto final e é difícil para os competidores imitarem.

${ }^{3}$ Os custos de transação, segundo WIGAND et al. (1997), são os custos relacionados à coordenação de uma transação comercial, compreendendo as atividades de iniciação, negociação, realização, controle e adaptação da cooperação.
} 
- A EV é reconfigurada e troca seus parceiros de acordo com o projeto ou tarefa a ser realizada.

Segundo BROWNE \& ZHANG (1999), pequenas e médias empresas (PMEs) que participam de EVs têm acesso a recursos como se fossem uma grande empresa, mantendo a agilidade e independência de uma pequena. EVERSHEIM et al. (1996) declaram que a adoção da estratégia de formação de EVs é adequada aos países em desenvolvimento como o Brasil, pois permite às PMEs a oportunidade de globalizarem seus negócios. Além disso, esses autores ressaltam que a cultura dos empresários brasileiros é adequada à estratégia de EVs, pois devido à falta de recursos, é comum a formação de parcerias informais para o desenvolvimento de projetos e manufatura.

Para CAMARINHA-MATOS \& AFSARMANESH (1999), o conceito de EV representa uma área de pesquisa muito importante com um grande potencial de aplicação em indústrias e outros setores, mas ainda enfrenta muitos desafios e questões não respondidas. Entre essas questões pode-se incluir: uma melhor compreensão dos requisitos de uma EV e de seu comportamento, a elaboração de um modelo referência abrangente, políticas de gerenciamento de informação e ferramentas de apoio à tomada de decisão.

JAGDEV \& BROWNE (1998) consideram que a coordenação dos relacionamentos entre as entidades de uma $E V$, assim como a comunicação entre essas, são questões cruciais para o sucesso de uma EV. CAMARINHA-MATOS \& AFSARMANESH (1997) também citam que é importante notar que o conceito de EV cria novas necessidades em termos de métodos aplicados, tipos de atividades e habilidades apropriadas dos recursos humanos envolvidos. Portanto, os aspectos organizacionais de uma EV devem ser analisados simultaneamente ao desenvolvimento tecnológico.

Segundo CAMARINHA-MATOS \& AFSARMANESH (1999), o paradigma de EV desafia a forma que os atuais sistemas de manufaturas são planejados e gerenciados. As atividades de planejamento e controle da produção (PCP), ao se considerar uma $\mathrm{EV}$, tornam-se mais complexas, pois precisam ser realizadas tanto dentro das empresas, como em toda a cadeia produtiva, de forma integrada, a fim de atingir níveis exigidos de desempenho. 
Segundo CORRÊA (1999), o processo de PCP que em uma empresa já é fonte de várias dificuldades, passa a se tornar um grande desafio para o sucesso de uma EV devido a complexidade de integração de recursos de diferentes empresas. A maior dificuldade na integração de empresas parceiras em uma EV corresponde ao ajuste das capacidades dos parceiros e a definição comum de prazos. Assim, a integração dos processos de PCP entre as diferentes empresas é um requisito fundamental para formação de uma EV voltada a manufatura.

Considerando-se o contexto descrito acima, foi identificado que a formação de EVs se apresenta como uma tendência. No entanto, existe uma carência de métodos adequados para executar o planejamento e controle da produção de forma que as empresas, que constituem a EV, possam trabalhar como uma unidade integrada, embora mantendo sua autonomia.

Além disso, SHIN (1998) sugere que apesar de cada cooperação requerer uma forma específica de organização e fluxo de informações, padrões podem ser adotados, desde que adaptados para as reais necessidades. Assim, a adoção de modelos que auxiliem a formação e operação de uma EV, pode facilitar a exploração das oportunidades de mercado e gerar uma maior probabilidade de sucesso dessa forma de cooperação.

Em função dos tópicos descritos acima, foi identificado o problema abordado e definido o objetivo do trabalho, que são apresentados a seguir.

\subsection{Problema Abordado}

O problema abordado no trabalho é: quais são as atividades, informações e estrutura organizacional apropriadas para o Planejamento e Controle da Produção em Empresas Virtuais?

\subsection{Objetivo do Trabalho}

Em função do problema abordado, o objetivo deste trabalho é propor um modelo de referência para o Planejamento e Controle da Produção em Empresas Virtuais. O modelo visa dar suporte a operação distribuída, porém de forma integrada, das 
empresas parceiras que formam uma EV. Pretende-se com esse modelo definir um conjunto de atividades para o planejamento e controle da produção em EVs. O modelo também contempla as informações necessárias para a realização das atividades e determina a estrutura organizacional responsável por executá-las. Esses elementos são definidos a fim de atender às características das EVs e de sua gestão da produção.

Este trabalho é realizado junto ao grupo de pesquisa de Empresas Virtuais do Núcleo de Manufatura Avançada (NUMA) sediado no campus da Escola de Engenharia de São Carlos da Universidade de São Paulo (USP).

\subsection{Método de Pesquisa}

A seguir são apresentados os aspectos metodológicos considerados no desenvolvimento deste trabalho de pesquisa, tendo em vista o objetivo proposto. Inicialmente a pesquisa é classificada quanto ao seu objetivo, então é escolhido o método de pesquisa empregado e as etapas do trabalho são descritas.

\subsubsection{Definição do Método}

O método é o conjunto das atividades sistemáticas e racionais que, com maior segurança e economia, permite alcançar o objetivo e traçar o caminho a ser seguido, além de detectar erros e auxiliar as decisões do cientista (LAKATOS \& MARCONI, 1991).

Para definir o método da pesquisa, essa deve ser classificada quanto ao seu objetivo e determinados os métodos de procedimento a serem utilizados. De acordo com GIL (1988), as pesquisas podem ser classificadas em três grandes grupos quanto ao objetivo:

- Pesquisas Exploratórias: têm como objetivo proporcionar maior familiaridade com o problema, com vista a torná-lo mais explícito ou a construir hipóteses. Pode-se dizer que essas pesquisas têm como objetivo principal o aprimoramento de idéias ou a descobertas de intuições. 
- Pesquisas Descritivas: têm como objetivo primordial a descrição das características de determinada população ou fenômeno, podendo também estabelecer relações entre variáveis.

- Pesquisas Explicativas: têm como preocupação central identificar os fatores que determinam ou que contribuem para a ocorrência dos fenômenos. Esta é o tipo de pesquisa que mais aprofunda o conhecimento da realidade, porque explica a razão, o porquê das coisas.

Entre os possíveis métodos de procedimento pode-se citar os seguintes, sendo as suas descrições baseadas em GIL (1998):

- Pesquisa Bibliográfica: é desenvolvida a partir de material já elaborado, constituído principalmente de livros e artigos científicos;

- Pesquisa Documental: assemelha-se à pesquisa bibliográfica, no entanto a pesquisa documental vale-se de materiais que não receberam ainda tratamento analítico, tais como arquivos de órgãos públicos e instituições privadas;

- Pesquisa Experimental: consiste de determinar um objeto de estudo, selecionar as variáveis que seriam capazes de influencia-lo, definir as formas de controle e de observação dos efeitos que a variável produz no objeto;

- Levantamento: caracteriza-se pela interrogação direta das pessoas cujo comportamento se deseja conhecer;

- Estudo de caso: é caracterizado pelo estudo profundo e exaustivo de um ou de poucos objetos, de maneira que permita o seu amplo e detalhado conhecimento.

De acordo CERVO \& BERVIAN (1983), o estudo exploratório é recomendável nos caso em que há poucos conhecimentos sobre o problema a ser estudado. Considerando-se que o tema deste trabalho é recente e ainda pouco estudado na literatura cientifica, a pesquisa mais apropriada é a exploratória.

Segundo GIL (1988), tem-se que o planejamento de pesquisas exploratórias é bastante flexível, de modo que possibilite a consideração dos mais variados aspectos relativos ao fato estudado, sendo que na maioria dos casos, assume a forma de pesquisa bibliográfica ou de estudo de caso. 
O método adotado foi a pesquisa bibliográfica. Não foi possível realizar um estudo de caso por não haver acesso a uma EV durante o período de pesquisa. Porém, trabalhos futuros podem se basear nas conclusões apresentadas neste trabalho, e elaborar hipóteses objetivando aprofundar o estudo sobre o tema ou aspectos específicos relacionados.

A seguir são descritas as etapas do trabalho.

\subsubsection{Descrição das Etapas do Trabalho}

Sendo o objetivo do trabalho propor um modelo de referência para o Planejamento e Controle da Produção em Empresas Virtuais foram definidas etapas para atingí-lo.

Primeiramente foi identificada a necessidade de definir o método de modelagem a ser utilizado. Porém antes era necessário delimitar o escopo o modelo, assim como definir os requisitos que deveriam ser atendidos. Para definir o escopo e estabelecer os requisitos, é preciso entender onde o modelo se insere, isto é, compreender os processos de negócios envolvidos na operação de uma EV, assim como as atividades e questões relacionadas ao PCP. Para tal, também é necessário definir as características do PCP em EV. Uma forma de identificá-las é por meio de um estudo sobre de projetos relacionados ao tema e pesquisa sobre gestão da produção e EVs. No entanto, devido a diversidade de abordagens de EV na literatura, fez-se fundamental inicialmente definir as características da EV adotadas no trabalho.

Uma vez elaborado o modelo, visando ilustrar a sua utilização, optou-se por elaborar um exemplo de aplicação em um EV fictícia. Como última etapa, são avaliados os resultados obtidos por meio conclusões e considerações.

As etapas definidas para este trabalho são apresentadas na FIGURA 01. Uma descrição sobre cada etapa é feita a seguir. 


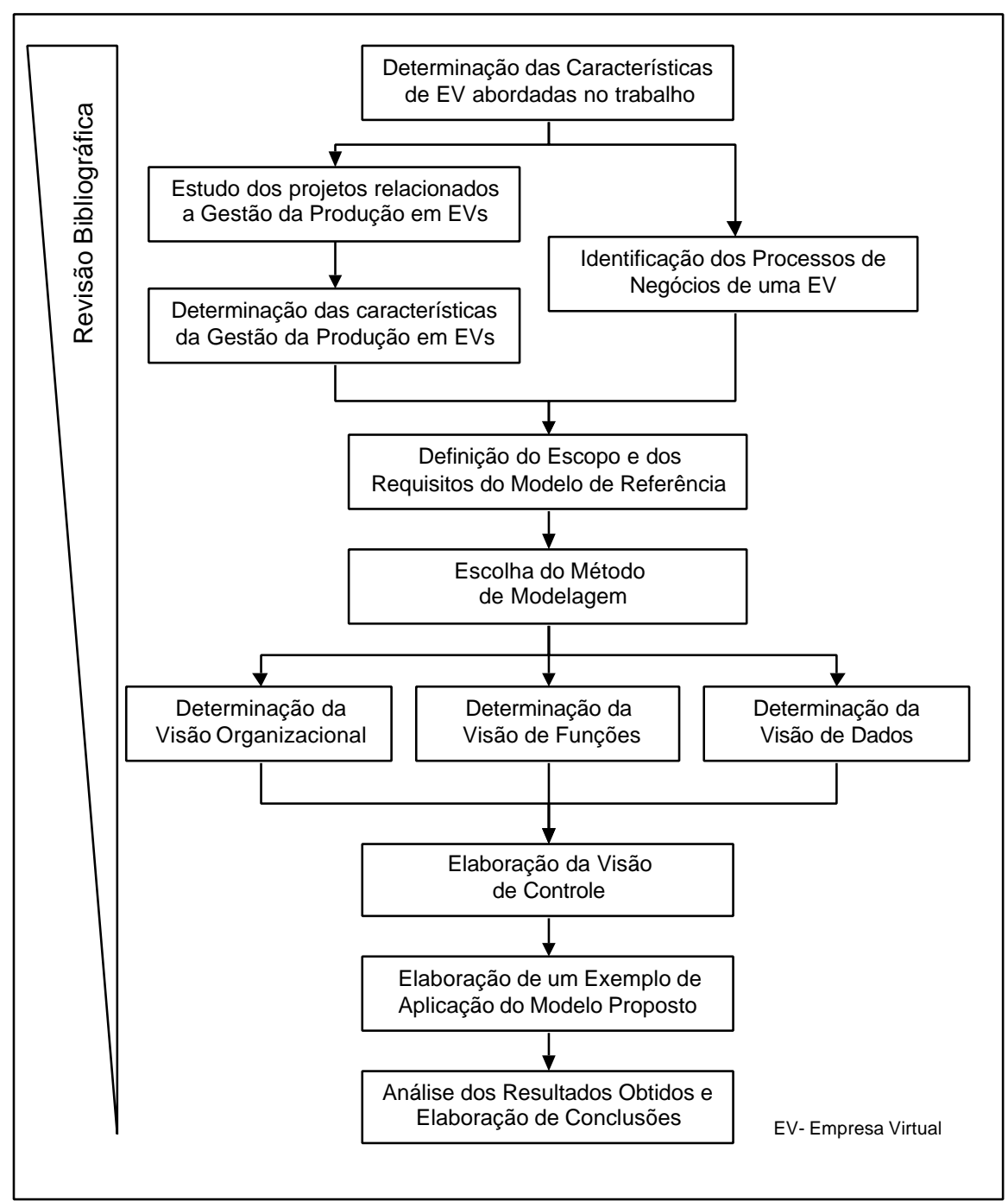

FIGURA 01 - Etapas do Trabalho

\section{Revisão Bibliográfica}

A revisão bibliográfica é realizada praticamente ao longo de todo o trabalho. Foram levantadas e estudadas referências bibliográficas relacionadas aos três principais tópicos que abrangem as áreas do conhecimento sobre as quais se baseia o trabalho: Modelagem de Processos de Negócio, Empresas Virtuais e Gestão da Produção. 


\section{Determinação das Características de Empresa Virtual abordadas no Trabalho}

Durante a revisão bibliográfica, verificou-se a existência de diferentes enfoques para descrever uma EV. O objetivo desta etapa é determinar quais das possíveis caraterísticas de uma EV serão consideradas no trabalho.

\section{Estudo dos Projetos Relacionados à Gestão da Produção em Empresas Virtuais}

Os principais projetos existentes que abordam a gestão da produção em EVs foram levantados e resumidos durante a revisão bibliográfica. Esta etapa determina alguns aspectos a fim de analisar e compará-los. Este estudo visa facilitar a determinação das características da gestão da produção em EVs e identificar conceitos que podem ser adotados para a definição do modelo.

\section{Determinação das Características da Gestão da Produção em Empresas Virtuais}

Considerando-se as atividades a serem normalmente executadas no planejamento e controle da produção, as características de EV adotadas no trabalho, juntamente com o estudo dos projetos realizado na etapa anterior, são determinadas as principais características da gestão da produção em EVs. Essas características serão consideradas tanto para a definição dos requisitos dos modelos como para a determinação do modelo.

\section{Identificação dos Processos de Negócio de uma Empresa Virtual}

Esta etapa visa identificar os processos de negócio envolvidos na operação de uma EV. O objetivo dessa etapa é entender melhor quais são os processos operacionais de uma EV e como esses são realizados. Essa identificação é baseada na classificação de processos proposta pela American Productivity \& Quality Center (APQC) e no ciclo de vida proposto para EV por GORANSON (1999).

\section{Determinação do Escopo e Requisitos do Modelo de Referência}

Em função dos resultados das etapas anteriores são determinados o escopo e os requisitos do modelo. Esta etapa visa focar a elaboração do modelo, definindo os limites do processos a ser detalhado e os aspectos a serem considerados na sua elaboração. 


\section{Escolha do Método de Modelagem}

Esta etapa define o método de modelagem a ser utilizado a fim de atender o objetivo e requisitos do trabalho.

\section{Determinação da Visão Organizacional}

Para a determinação da visão organizacional são definidas as entidades necessárias ao PCP em uma EV. Para cada entidade são descritos seus papéis e responsabilidade. Esta etapa gera um texto descritivo e um modelo da visão na ferramenta ARIS.

\section{Determinação da Visão de Funções}

Nesta etapa são determinadas as atividades envolvidas na gestão da produção de um EV assim como o relacionamento entre essas. O levantamento dessas atividades visa a determinação da visão de funções do modelo de referência. Essa etapa, assim como a anterior, gera um texto descritivo e um modelo na ferramenta ARIS.

\section{Determinação da Visão de Dados}

São definidas as informações necessárias para a realização das atividades, tais como as que são geradas. Essas informações e seus relacionamentos, são apresentadas em um modelo entidade-relacionamento (MER).

\section{Elaboração da Visão de Controle}

Uma vez descritas as visões organizacionais, de funções e de dados, essas são interligadas na visão de controle. Uma descrição do método utilizado na elaboração da visão e o modelo gerado na ferramenta ARIS é demonstrado.

\section{Elaboração de um Exemplo de Aplicação do Modelo Proposto}

Para ilustrar o modelo proposto é criado um exemplo de aplicação do modelo proposto em uma EV fictícia. São descritas as atividades desde a identificação de uma oportunidade até a execução das ordens de produção. No entanto, o enfoque maior é quanto ao processo descrito no modelo, onde são apresentadas opções de como executar suas atividades. 


\section{Análise dos Resultados Obtidos e Elaboração de Conclusões}

Nesta etapa final, são discutidos os resultados apresentados nas fases anteriores, apresentadas as conclusões obtidas e realizadas sugestões para trabalhos futuros.

\subsection{Estrutura do Trabalho}

Este trabalho é apresentado conforme a sistematização a seguir:

Capítulo 2 - Revisão Bibliográfica: contempla um resuma da revisão bibliográfica dos temas pertinentes ao escopo do trabalho.

Capítulo 3 - Proposta de um Modelo de Referência para Planejamento e Controle da Produção em Empresas Virtuais: apresenta as etapas do trabalhos realizadas a fim de propor o modelo de referência desde a determinação das características das EVs adotadas no trabalho até a elaboração da visão de controle.

Capítulo 4 - Elaboração de um Exemplo de Aplicação do Modelo Proposto: descreve a criação de um exemplo de aplicação do modelo proposto em uma EV fictícia.

Capítulo 5 - Considerações e Conclusões Finais: resume as considerações e conclusões finais sobre o presente trabalho de mestrado e apresenta proposta de futuras trabalhos. 


\section{Revisão Bibliográfica}

Neste capítulo é apresentada uma revisão bibliográfica dos principais assuntos relacionados a este trabalho.

\subsection{Modelagem de Processos de Negócio}

Inicialmente é descrito o conceito Processos de Negócio e a seguir são abordados os tópicos sobre Modelos de Referência e Arquiteturas de Referência.

\subsubsection{Processos de Negócio}

O modelo de gerenciamento que as empresas têm utilizado mais freqüentemente para administrar seus negócios tem com base uma estrutura funcional departamentalizada. No entanto, DAVENPORT (1994) indica como necessária para a sobrevivência das empresas que as atividades empresariais sejam vistas não em termos de funções, departamentos ou produtos, mas em termos de processos.

Para ROTONDARO (1997) processo é "uma seqüência organizada de atividades, que transforma as entradas dos fornecedores em saídas para os clientes, com um valor agregado pela unidade". Assim, a geração de um produto ou serviço para um cliente é realizada pela cadeia de um ou mais processos interligados. Esta visão de processo orientado a um tipo de negócio da empresa originou uma categoria de processos, os chamados Processos de Negócio (PN).

VERNADAT (1996) define um processo de negócio como uma seqüência de atividades de uma empresa, cuja execução é desencadeada por algum evento e resultará em um resultado final observável e quantificável. 
Segundo ROZENFELD (1996), um PN "é um fenômeno que ocorre dentro das empresas. Ele contém um conjunto de atividades, associadas às informações que manipula, utilizando os recursos e a organização da empresa. Forma uma unidade coesa e deve ser focalizado em um tipo de negócio, que normalmente está direcionado a um determinado mercado/cliente, com fornecedores bem definidos".

Como exemplos de PN que ocorrem em uma empresa, pode-se citar uma classificação proposta pela American Productivity \& Quality Center (APQC). Esta classificação é composta por treze PNs divididos em dois grupos: processos operacionais e processos de gerenciamento e suporte. Esses PNs são apresentados na FIGURA 02, a seguir:

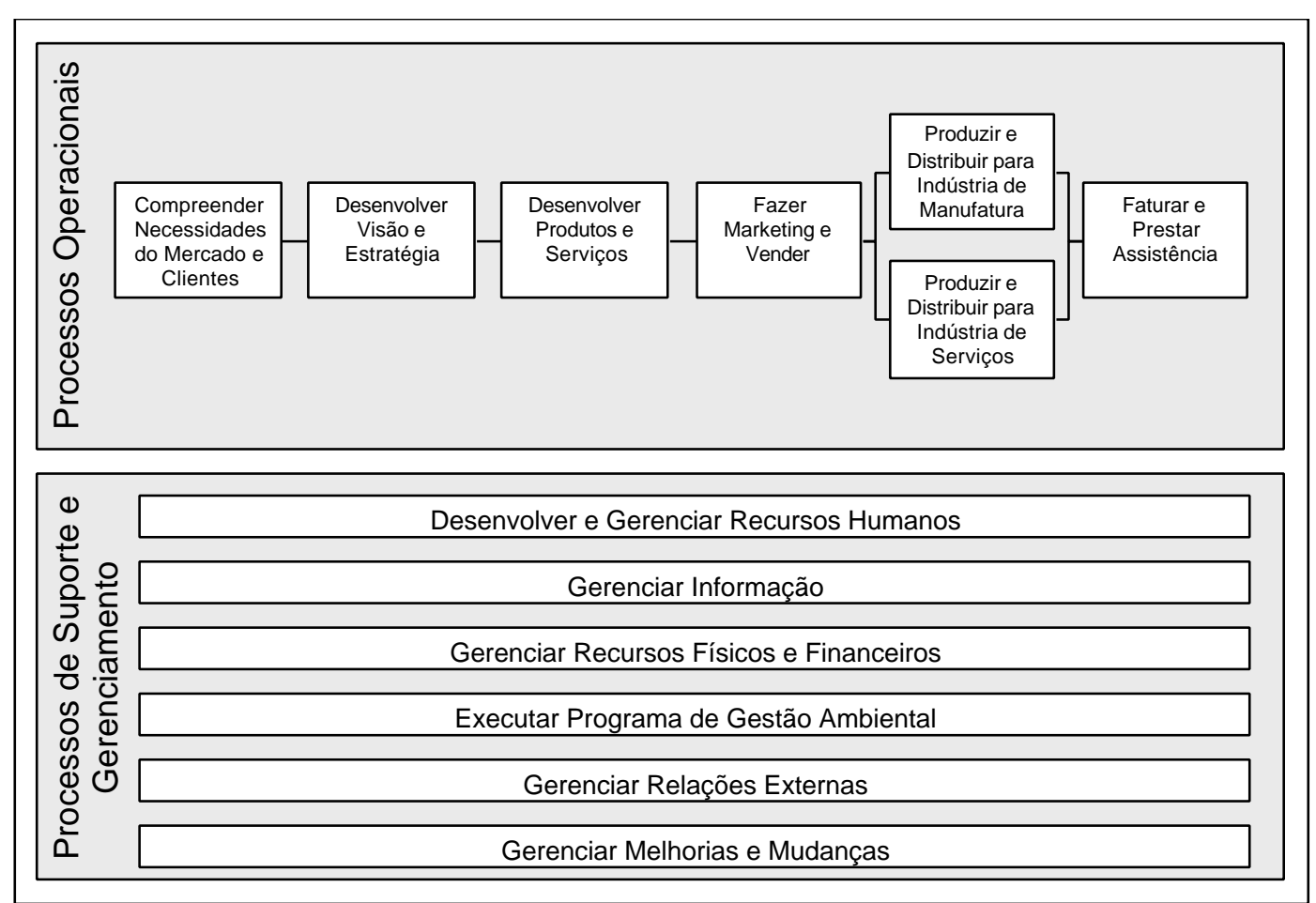

Adaptada de APQC (1998)

FIGURA 02 - Framework de Classificação de Processos de Negócio 


\subsubsection{Modelos de Referência}

Um modelo é uma representação útil de algum objeto. É uma abstração da realidade expressa em termos de algum formalismo (ou linguagem) definido por um método de modelagem em função do objetivo do usuário (VERNADAT, 1996).

Para KELLER \& TEUFEL (1998), os modelos têm os seguintes objetivos:

- apresentar os elementos de um sistema e seus respectivos relacionamentos;

- explicar como um sistema funciona e

- suportar a comunicação por meio de uma formalização consistente.

Assim, partindo do objetivo para o qual o modelo é desenvolvido, devem ser escolhidas quais informações da realidade devem ser representadas. Outra preocupação que deve ocorrer é o nível de detalhamento do modelo. Um modelo pouco detalhado pode omitir informações relevantes, assim como um modelo muito detalhado pode ser difícil de ser elaborado e algumas das informações podem não ser utilizadas. $O$ grau de detalhamento deve ser compatível com a necessidade.

Em SCHEER (1998), tem-se que para reduzir a complexidade de um modelo, classes com inter-relacionamentos de semântica similar são agrupadas em visões. Cada visão é um conjunto de um ou mais tipos de elementos. Essas visões podem ser complementares, apesar de representadas de formas distintas.

Algumas técnicas e ferramentas de modelagem apresentam visões definidas, que devem ser representadas através de modelos específicos. Alguns exemplos de visões são exemplificados no tópico 2.1.3.

Segundo VERNADAT (1996), modelos de referência devem conter um determinado grau de generalidade e ser customizável. Em outras palavras, um modelo de referência deve funcionar como uma base de discussão, uma sugestão formal ou semi-formal para a elaboração de modelos específicos, fazendo com que as informações referentes ao projeto de um processo de negócio sejam claras para as pessoas que participam deste. 
SCHEER (1998) diz que modelos de referência, os quais podem ser desenvolvidos a partir de situações reais ou teoricamente, documentam o know-how de um processo que pode ser utilizado para modelagem de outro.

KELLER \& TEUFEL (1998) comentam que o termo modelo da referência é freqüentemente usado em relação à criação de processos do negócio, podendo ser aplicados nos seguintes casos:

- experiência acumulada em um tipo negócio ou setor de indústria, representando as soluções mais gerais aplicáveis a estes e

- soluções de processos do negócio implementadas e executadas em software de gestão empresarial.

KELLER \& TEUFEL (1998) argumentam que com a ajuda da modelagem, é possível simplificar drasticamente a descrição dos processos abstraindo fatos complexos. O objetivo de modelar é aumentar a transparência dos relacionamentos nas organizações orientadas a processo de negócio, concentrando nos componentes relevantes à análise e seus respectivos relacionamentos.

Segundo CURTIS et al. (1992), as técnicas de modelagem devem ser capazes de representar quatro aspectos básicos que estão relacionados ao entendimento de como funcionam os processos de negócios de uma empresa, são eles:

- $\quad$ aspectos funcionais, descrevem o que tem que ser feito;

- aspectos seqüenciais e lógicos, descrevem o comportamento, isto é o como e quando;

- $\quad$ aspectos de informação, descrevem os dados que serão utilizados e produzidos e as relações entre eles;

- aspectos organizacionais, descrevem os responsáveis pelas funções.

Como conseqüência da necessidade de padronizar os conceitos e métodos de modelagem surgiram as arquiteturas de referência. 


\subsubsection{Arquiteturas de Referência}

Segundo VERNADAT (1996), arquiteturas de referencia são paradigmas intelectuais que facilitam a análise, discussão e especificação, provendo uma forma de examinar, conceber e tratar uma determinada questão. VERNADAT (1996) cita como arquiteturas mais representativas as seguintes:

- CIM-OSA (Computer Integrated Manufacturing - Open System Architecture),

- GRAI/GIM (Graphes à Rèsultats et Activitès Interreliés/GRAI Integrated Method);

- PERA (Purdue Enterprise Reference Architecture);

- GERAM (Generalized Enterprise Reference Architecture and Methodology);

- $\quad$ ARIS (Architecture for integrated Information System)

A seguir é descrita a ARIS que foi desenvolvida pelo Prof. Scheer. O conceito da ARIS é baseado em uma estrutura de referência em que as visões distintas de uma empresa são organizadas e ligadas uma as outras. O ponto inicial para criação das visões é a compreensão do processo de negócio como uma cadeia de atividades que estão interligadas e as quais são atribuídos dados ou status, pessoas, unidades organizacionais e recursos de tecnologia de informação (TI) como componentes descritivos adicionais (KELLER \& TEUFEL, 1998). O objetivo deste modelo por visões é atribuir objetos descritivos com um mínimo da interdependência às diferentes visões, e combinar aqueles com um grau elevado de interdependência em uma única visão.

As principais visões do ARIS são detalhadas a seguir (SCHEER (1994), SCHEER (1998), VERNADAT (1996), KELLER \& TEUFEL (1998)):

- Visão de funções: define uma hierarquia de funções. Apresenta uma descrição da função, enumerando as suas sub-funções e o relacionamento entre estas. As designações "função", "processo" e "atividade" são usadas como sinônimos, podendo ser definidas como ação executada para a realizar alguma tarefa, necessitando de tempo e recursos para tal, e transformando um input em output.

- Visão de dados: representa todos os elementos que modificam ou geram dados, que são os eventos e as condições. Um evento é a manifestação de uma mudança no estado do sistema indicando que algo aconteceu. Assim, um evento pode 
disparar funções tal como ser disparado por estas. As condições são referências, como por exemplo, o status de uma ordem de fabricação. Essa visão é caracterizada por representar o fluxo de dados.

- Visão organizacional: representa as unidades organizacionais e usuários, criando a estrutura organizacional.

- Visão de Controle: o relacionamento entre as diferentes visões, assim como o processo de negócio inteiro, é documentado pela visão de controle. A visão de controle é um componente essencial da ARIS que a distingue de outras arquiteturas propostas.

$\mathrm{Na}$ FIGURA 03 são representadas as visões de um modelo de processo na ferramenta ARIS.

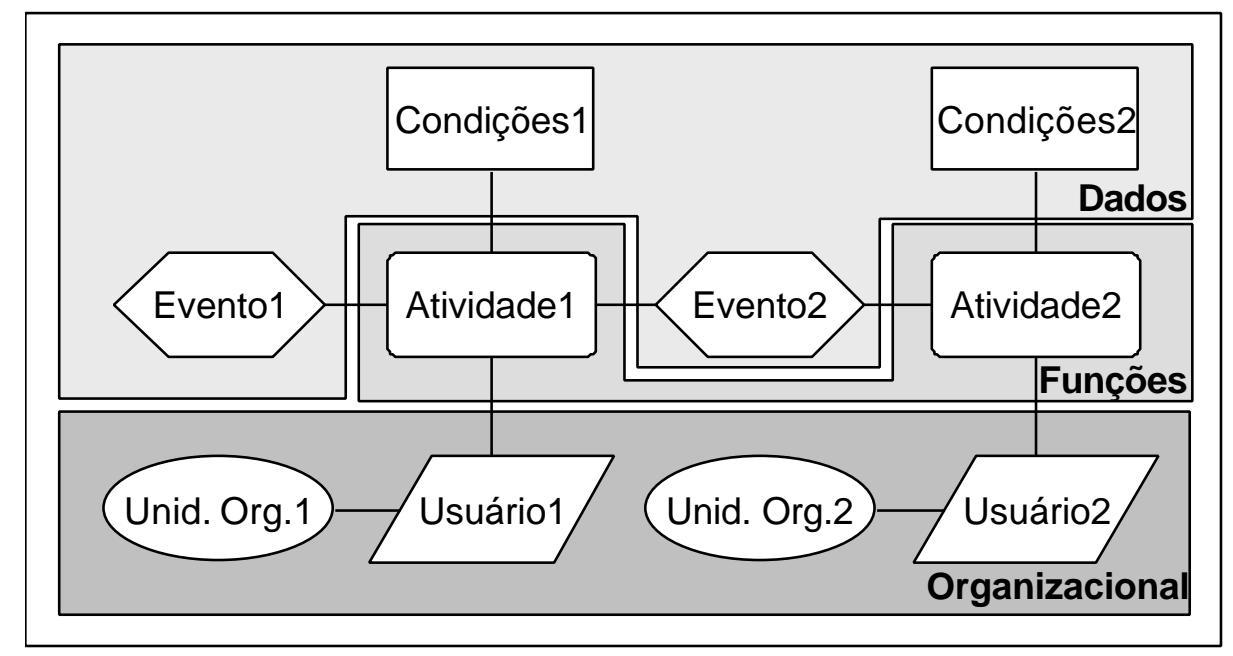

Adaptada de SCHEER (1994)

FIGURA 03 - Visões de um Modelo de Processo de Negócio

Para fazer a modelagem, primeiro deve-se descrever as três visões (dados, função e organizacional) independentemente. Depois, na visão de controle, utilizando o formalismo do EPC (Event Process Chain - Diagrama de Processos Controlado por Eventos), é desenvolvido o modelo de processo na visão de controle. Para tal, é feita a inserção das atividades (já modeladas na visão de funções) unindo-as através dos eventos que as disparam. Nesta fase, identifica-se o fluxo de atividades assim como paralelismo, probabilidade e freqüência de ocorrência destas. Uma vez encadeadas as 
atividades por eventos, essas são agregadas aos responsáveis pela sua execução (da visão organizacional) e às informações usadas e geradas (da visão de dados).

Além da divisão em visões a ARIS é composta por três níveis referentes ao ciclo de vida do modelo proposto, sendo esses os representados na FIGURA 04 e descritos a seguir (SCHEER, 1994; ARIS, 1998):

- Definição de requisitos: descreve a aplicação do negócio a qual deve ser suportada por uma linguagem formalizada de descrição tal que possa ser usada como ponto de partida para uma tradução consistente da definição dos requisitos para a $\mathrm{TI}$. Esse nível refere-se ao modelo semântico.

- Especificação do Projeto: o ambiente conceitual de definição dos requisitos é transferido para categorias de tecnologia de informação. Módulos e transações que executam as funções são definidos;

- Descrição da Implementação: a especificação do projeto é transferida para componentes de hardware e software, estabelecendo uma ligação física com a tecnologia da informação.

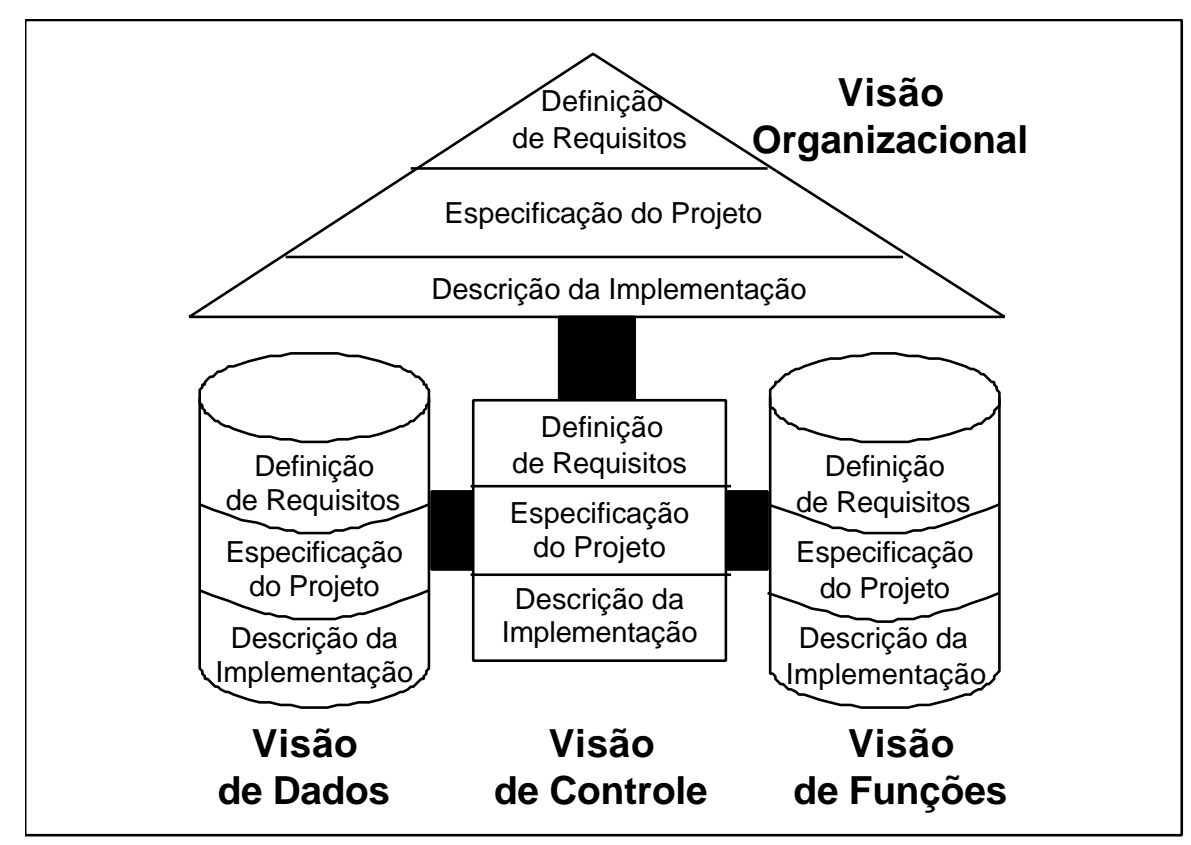

Adaptada de ARIS (1998)

FIGURA 04 - Arquitetura ARIS 
A ARIS foi a base para o desenvolvimento da ferramenta ARIS Toolset que permite a modelagem de processos e de dados em vários níveis, de forma exata, detalhada e integrada.

\subsection{Empresas Virtuais}

Este tópico primeiramente aborda os conceitos de virtualidade de forma introdutória para a definição de Empresa Virtual (EV). A seguir são apresentadas características e tipologias propostas para EVs. A fim de melhor entender o conceito de $E V$, são descritas outras formas de cooperação, assim como comparações entre essas. Por fim, são apresentadas propostas para a formação de EVs.

\subsubsection{Conceitos de Virtualidade}

Segundo JÄGERS et al. (1998), ser virtual é um modismo. Tornou-se comum o uso de termos como realidade virtual, organização virtual e escritório virtual. No entanto, nem sempre o uso dessas expressões corresponde ao seu significado verdadeiro. FERREIRA (1986) descreve virtual como o que "existe como faculdade, porém sem exercício ou efeito atual; suscetível de se realizar; potencial" ou ainda "dizse do que está predeterminado e contém todas as condições essenciais à sua realização".

MOWSHOWITZ (1997) define que a virtualidade pode ser entendida como o fato de todas as características principais de um objeto existirem, em forma digitalizada, apesar do objeto em si não existir fisicamente.

Virtualidade também pode ser definida como a habilidade de oferecer um produto ou serviço completo aos clientes, onde a empresa em si possui apenas algumas das competências envolvidas, sendo que as demais competências necessárias são obtidas através de cooperação (SIEBER ${ }^{4}$ apud BREMER et al, 1999a).

SKYRME (1998) lista tendências que induzem a virtualização:

\footnotetext{
${ }^{4}$ SIEBER, P. (1997). Virtuelle unternehmen: eine zasammenfassung. In: WORKSHOP VIRTUALITAT ALS ETTBEWERBSFAKTOR, Universität Bern.
} 
- produtos e serviços estão tornando-se mais baseados em informação e conhecimento, podendo ser comercializados e mesmo entregues de forma virtual;

- a revolução da Internet tem papel fundamental na redefinição da maneira em que os negócios são conduzidos, permitindo também que trabalhos e serviços sejam realizados a distância;

- networking, interdependência e novas formas de organização e colaboração possibilitam o acesso a recursos, combinando flexibilidade com rápido tempo de resposta e

- globalização de mercados e recursos à empresas vender mais facilmente seus produtos no mundo inteiro e lançar mão de especialistas de classe mundial, independentemente do local base de suas operações.

Ainda segundo SKYRME (1998), a virtualização oferece a diferentes tipos de organizações significativos benefícios:

- ganho de flexibilidade com estruturas dinâmicas,

- desenvolvimento de projetos ou solução de problemas que de outra maneira não seria possível;

- alcance ao mercado global sem uma presença local e

- redução significativa de custos em relação às maneiras convencionais de trabalhar.

BULTJE \& WIJK (2000) identificaram as seguintes quatro visões de virtualidade como as mais comuns:

- "irreal, parecendo real”: esse conceito é originado da Óptica. Essa disciplina científica faz a distinção de uma figura real e uma figura virtual. Ambas figuras parecem a mesma, mas a figura virtual não pode ser retratada em um papel fotográfico, ao contrário da figura real.

- “imaterial, suportado por TI”: nesta visão, o conceito de virtual é usado em expressões como biblioteca virtual, sala de aula virtual, etc. Funções que era usualmente executadas por pessoas, passam a ser são substituídas pelo uso do $\mathrm{TI}$.

- "potencialmente presente": torna-se somente ativa mediante o surgimento de uma oportunidade. 
- "existente, mas mudando": existente, mas a sua composição é temporária e possivelmente sofrendo alterações ao longo a sua existência.

BULTJE \& WIJK (2000) identificaram que diferentes definições de EV, dependem da visão dos autores quanto ao conceito de virtual. A seguir são apresentadas algumas definições selecionadas entre as diversas existentes na literatura.

\subsubsection{Definições de Empresas Virtuais}

Entre as definições encontradas na pesquisa bibliográfica foram selecionadas as apresentadas a seguir visando proporcionar uma visão de diferentes autores.

Em GOLDMAN et al. (1995), define-se EV "como uma aliança oportunista de competências essenciais distribuídas entre várias entidades operacionais distintas, dentro de uma única grande empresa ou um grupo de empresas independentes".

Para CAMARINHA-MATOS \& AFSARMANESH (1999), uma EV é uma aliança temporária de empresas que se unem para compartilhar habilidades ou competências essenciais e recursos a fim de responder melhor às oportunidades de negócios, e cuja cooperação é suportada por redes de computador.

Uma EV, segundo SIHN (1998), combina várias empresas enquanto mantêm uma grande flexibilidade e independência nos negócios. A característica crucial de uma EV é que essa se apresenta como uma única empresa para o mercado quando na verdade é constituída de várias, assim suas relações internas assemelham-se com as de uma empresa descentralizada. SIHN (1998) também alega que EVs possibilitam uma produção closed-to-the-customer com capacidades extremamente flexíveis e curtos tempos de entrega. Especialmente para as PMEs, esta é uma possibilidade de participar da competição global.

Para JAGDEV \& BROWNE (1998), EVs são uma resposta à velocidade e globalização da nova era digital. Novas necessidades de mercado surgem muito rapidamente e as empresas freqüentemente não possuem todas as competências necessárias para lidar com estas demandas. Entretanto, combinando as suas competências com competências complementares de outras empresas parcerias é possível criar uma EV, que seja capaz de prosperar e responder a estas exigências. Tal EV pode ser configurada com o objetivo de produzir um produto específico ou 
prover um tipo particular de serviço, e depois então a EV dissolve-se naturalmente permitindo que os parceiros encontrem novas oportunidades e novos parceiros para explorá-las.

\subsubsection{Características de Empresas Virtuais}

Como principais características das EVs pode-se citar (BYRNE, 1993; GOLDMAN et al., 1995; JÄGERS et al., 1998; SKYRME, 1998; TUMA, 1988):

- Foco em Competências Essenciais: cada empresa parceira participa com a sua competência, sendo essa complementar às competências das demais parceiras, e juntas tornam-se capazes de atender às demandas do mercado que não seriam possíveis de atender apenas através de uma única empresa;

- Direcionada a Oportunidade: a EV é um tipo de cooperação voltada a oportunidades de negócio. As empresas trabalham juntas para satisfazer uma oportunidade de negócio específica, separando-se após o fim desta. Cada EV é formada para explorar uma oportunidade de negócio por vez;

- Estrutura Organizacional Dinâmica e sem Hierárquica: a EV deve possuir uma estrutura organizacional dinâmica, com regras adaptáveis que possam torná-la flexível. Em uma EV, os elementos que a compõem não devem dominar os demais, obtendo assim um maior grau de flexibilidade.

- Baseada em Confiança: uma característica importante é o grau de confiança existente entre seus parceiros. A cultura baseada na vontade de compartilhar habilidades e informações toma o lugar da cultura baseada no controle. Assim arriscar e confiar são pré-requisitos para participar de uma EV;

- Infra-estrutura Tecnológica: as TI permitem que empresas geograficamente distribuídas possam unir suas competências complementares. Além de diminuir as fronteiras entre as empresas, essa infra-estrutura ajuda a reduzir os custos de transação e produção. 


\subsubsection{Tipologias de Empresas Virtuais}

O objetivo deste tópico é apresentar duas diferentes tipologias propostas de EVs, a fim de complementar as definições e características das EVs, possibilitando uma melhor visão das possíveis formas de EV existentes na literatura.

CAMARINHA-MATOS (1997) propôs uma tipologia de classes de EV baseada nos seguintes aspectos representados na FIGURA 05, cuja descrição é feita a seguir:

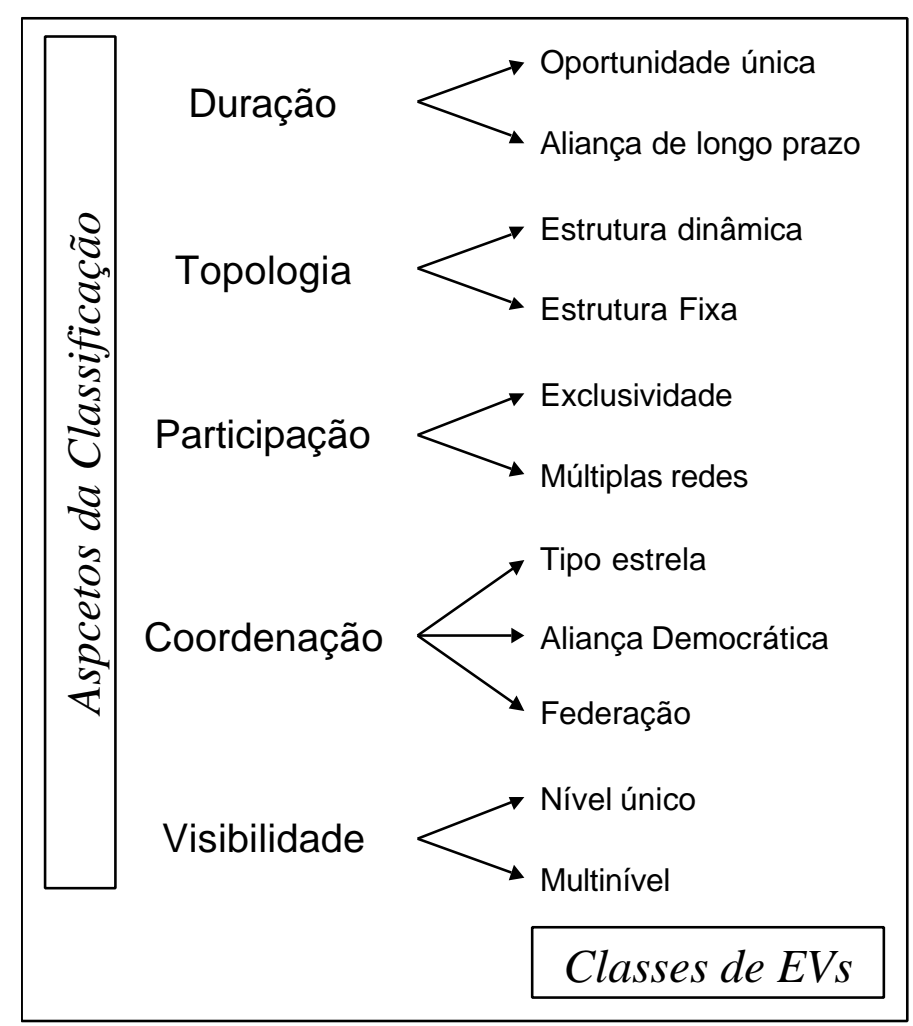

Adaptado de CAMARINHA-MATOS (1997)

FIGURA 05 - Classes de Empresas Virtuais

- Duração: algumas parcerias são constituídas para atender uma única oportunidade de negócio, sendo dissolvidas ao término de tal processo. Mas podem também ocorrer alianças de longa duração que podem durar por um número indefinido de oportunidades de negócios ou para um período de tempo especificado;

- Topologia: de acordo com a topologia da rede, há situações que mostram uma natureza dinâmica, na qual algumas empresas podem se unir rapidamente ou deixar a aliança de acordo com as fases do processo ou outros fatores de mercado. 
Mas pode haver também, cadeias de produtivas com uma estrutura quase fixa, com apenas uma pequena variação em termos de fornecedores ou clientes;

- Participação: este aspecto está relacionado com a possibilidade de uma empresa estar participando simultaneamente de várias redes ou sendo comprometida a uma única aliança (exclusividade);

- Coordenação: três formas são possíveis em termos de coordenação:

- Estrutura "tipo-estrela": há uma empresa dominante que define as regras do jogo e impõe seus próprios padrões;

- Aliança democrática: uma organização diferente poderia ocorrer em algumas redes de cooperação sem uma empresa dominante, na qual todos as empresas cooperam igualmente e mantêm sua autonomia, mas unindo suas competências essenciais;

- Federação: uma vez que uma aliança próspera é formada, essas empresas podem perceber os benefícios mútuos de ter uma administração comum ou compartilhamento de competências, infra-estruturas e processos de negócio podendo criar um tipo de estrutura de coordenação;

- Visibilidade: relacionado à topologia e à coordenação, o aspecto de visibilidade diz respeito a quão distante ao longo da cadeia cada empresa é vista. Em muitos casos uma empresa só enxerga seus parceiros diretos (fornecedores e clientes). Em situações de coordenação mais avançadas, uma empresa poderia ter a visibilidade dos outros níveis. A visibilidade de multinível é uma exigência para a ótima coordenação de várias atividades dentre os parceiros de uma EV. Por exemplo, na implementação de uma função de previsão de demanda, além dos dados históricos, é importante ter, com antecedência, informação sobre o consumo, níveis acionários ou até mesmo previsões de demanda pertinentes a diversos níveis da cadeia produtiva. 
BULTJE \& WIJK $(2000)^{5}$ definiram a seguinte tipologia a partir de uma pesquisa que levantou 27 características de EVs e as analisou em 6 casos de EVs existentes:

- EV estável: pode ser concluído a partir da pesquisa que as EVs estáveis são empresas grandes, o que resulta em inflexibilidade, comprometendo a sua agilidade em cooperar com outras organizações. As relações entre as organizações têm um caráter permanente por essa razão. Além disso, muitas EVs estáveis têm um parceiro principal o qual determina as regras da cooperação. A cooperação é dependente da escolha do parceiro principal, não sendo baseado em oportunismo Como exemplo, pode-se citar a Nike (projeto e venda de roupas e calçados esportivos - www.nike.com) e Airbus (projeto e venda de aeronaves www.airbus.com);

- EV dinâmica: consiste de uma rede dinâmica de natureza temporária. Essa EV é estabelecida por pequenas e médias empresas e/ou pequenas unidades autônomas de grandes empresas. A razão para cooperação é baseada em oportunidades. Além disso, não há um parceiro principal, o que resulta na igualdade dos parceiros e em uma liderança compartilhada, isto é, cada parceiro controla seus próprios recursos. São dados como exemplos a TMG (projetos e construção de produtos industrial multi-disciplinar) e Prolion (projetos de biomecatrônica e produtos para o setor agro-alimentício - www.prolion.nl) e

- Web-company: é uma rede que possui as demais características das EVs dinâmicas. Mas a sua principal diferença é a sua razão de existência, sendo totalmente baseada em tecnologia de informação. Assim, uma EV dinâmica pode existir sem TI, uma Web-company não. Como exemplo, tem-se a Amazon.com (a maior livraria da Internet - www.amazon.com).

Complementando a visão das possíveis formas de EV apresentadas nas tipologias, a seguir são descritas e comparadas outras formas de cooperação entre empresas.

\footnotetext{
${ }^{5}$ Esses autores utilizam o termo Organização Virtual (OV), tal como vários outros autores como sinônimo de EV. O termo OV é empregado de forma diferente neste trabalho, sendo descrito no tópico 2.2.6.
} 


\subsubsection{Comparação com outras Formas de Cooperação}

De acordo com a teoria de custo de transação de Willianson, existem várias formas de coordenação híbrida entre os extremos institucionais (mercado e hierarquia), sendo uma dessas formas, a EV (TUMA, 1997). Devido à diversidade de formas de cooperação, ocorre uma certa dificuldade em determinar os limites para caracterização dessas relações. Em especial, existem duas formas de cooperação que possuem tanto similaridades como diferenças, no que diz respeito ao conceito de EV, sendo estas as Cadeias de Suprimentos (CS) e as Empresas Estendidas (EE). Porém, não existe um consenso na literatura a respeito da diferenciação entre essas três formas de cooperação. Por exemplo, em ROLSTADAS (1998), tem-se que alguns autores entendem EV como um conceito mais abrangente incluindo também o conceito de $\mathrm{EE}$, enquanto outros vêem a EE como o termo geral do qual o conceito de EV é subordinado.

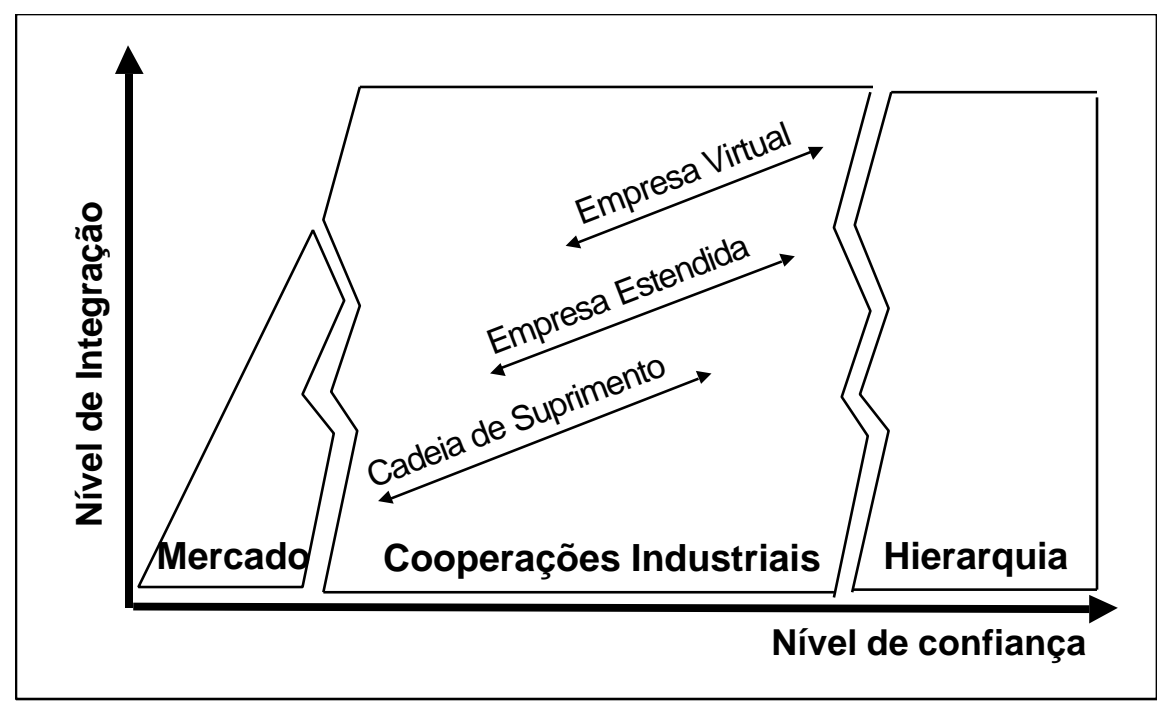

Adaptada de TROBEN \& JAGDEV (1999)

FIGURA 06 - Relações entre Cooperações de Empresas

A FIGURA 06 indica uma tendência na proximidade das relações entres as empresas, mas os limites entre cada forma de cooperação não são bem definidos. A seguir são descritos brevemente os conceitos sobre CS e EE e apresentadas comparações entre esses. 


\subsubsection{Cadeia de Suprimento}

Segundo PIRES (1999), uma CS refere-se à cadeia produtiva de um determinado produto, abrangendo desde a providência da matéria-prima, passando pelos processos de transformação até a entrega do produto ao consumidor final.

Uma CS também pode ser definida com o conjunto de processos integrados entre as empresas envolvidas na produção de um bem ou serviço, desde a matériaprima básica até o produto final, incluindo o fluxo de materiais e informações (LUMMUS \& VOKURKA, 1999).

Atualmente, não se pode descrever CS sem considerar os conceitos de Gestão da Cadeia de Suprimentos (SCM - Supply Chain Management). Para PIRES (1998), o SCM trata da integração holística dos processos de negócio através da cadeia produtiva, com o objetivo de atender o consumidor final mais efetivamente. Isso pode ocorrer tanto através da redução dos custos, como da adição de mais valor aos produtos finais.

Segundo PIRES (1998), práticas eficazes da SCM implementadas em todo mundo têm visado à simplificação e à obtenção de uma cadeia produtiva mais eficiente. Pode-se citar entre os principais resultados obtidos:

- Reestruturação e consolidação do número de fornecedores e clientes;

- Compartilhamento de informações e integração da infra-estrutura com clientes e fornecedores;

- Desenvolvimento conjunto de produtos;

- Considerações logísticas na fase de desenvolvimento dos produtos e

- Integração das estratégias competitivas na cadeia produtiva.

PIRES et al. (2000) apresentam comparações entre CS e EV, que são resumidas na TABELA 01. 
TABELA 01 - Comparação entre Cadeia de Suprimento e Empresa Virtual

Adaptado de PIRES et al. (2000)

\begin{tabular}{|c|l|l|}
\hline $\begin{array}{c}\text { Parceria } \\
\text { Paripal Objetivo da }\end{array}$ & $\begin{array}{l}\text { Aumentar a competitividade } \\
\text { através da cadeia de valor }\end{array}$ & $\begin{array}{l}\text { Explorar oportunidades } \\
\text { específicas de negócios }\end{array}$ \\
\hline $\begin{array}{c}\text { Estrutura } \\
\text { Organizacional }\end{array}$ & Organização estável & $\begin{array}{l}\text { Rede dinâmica e } \\
\text { temporária }\end{array}$ \\
\hline $\begin{array}{c}\text { Tipo de } \\
\text { Coordenação }\end{array}$ & $\begin{array}{l}\text { Usualmente uma empresa } \\
\text { principal assume a } \\
\text { coordenação }\end{array}$ & $\begin{array}{l}\text { Todas as empresas } \\
\text { participam ativamente na } \\
\text { coordenação e } \\
\text { planejamento }\end{array}$ \\
\hline Duração & $\begin{array}{l}\text { Cooperações de longo prazo } \\
\text { baseadas em contratos }\end{array}$ & $\begin{array}{l}\text { Rede temporária para } \\
\text { oportunidade específica } \\
\text { de negócios. }\end{array}$ \\
\hline $\begin{array}{c}\text { Participação } \\
\text { Relação ao Ciclo de } \\
\text { Vida do Produto }\end{array}$ & $\begin{array}{l}\text { Uma empresa pode participar } \\
\text { em diferentes CSs mas } \\
\text { exclusividade pode acontecer }\end{array}$ & $\begin{array}{l}\text { As empresas podem } \\
\text { participar de múltiplas } \\
\text { redes simultaneamente }\end{array}$ \\
\hline $\begin{array}{c}\text { Aplicabilidade do } \\
\text { (introdução, crescimento, }\end{array}$ & $\begin{array}{l}\text { Foco na fase de } \\
\text { introdução do produto }\end{array}$ \\
\hline
\end{tabular}

\subsubsection{Empresas Estendidas}

Para CHILDE (1998), o termo Empresa Estendida (EE) ultrapassa o conceito prévio de cadeia de suprimento para implicar em um relacionamento muito mais próximo dos fornecedores, pois esses passam a ser vistos como parte da empresa principal.

Segundo JAGDEV \& BROWNE (1998), os conceitos de EE surgem parcialmente de tentativas de empresas de manufatura, geograficamente dispersas, em construir 
parcerias formais para ganharem vantagem competitiva, sendo o ponto crucial desta lógica, a utilização de recursos externos e serviços sem possuí-los.

BROWNE \& ZHANG (1999) sugerem que o termo EE é freqüentemente usado na literatura para refletir o alto nível de interdependência que existe entre organizações ao administrar seus negócios.

Neste contexto, JAGDEV \& BROWNE (1998) definem EE como a formação de uma coordenação conjunta de empresas independentes que cooperam com seus parceiros de negócios no desenvolvimento de produto, determinação de custos e planejamento da produção. Essa forma de colaboração é representada pela formação de vínculos formais e mutuamente benéficos.

Segundo BROWNE \& ZHANG (1999), as principais características de uma EE são as seguintes:

- A empresa de manufatura foca em seu core business e atividades técnicas, repassando as atividades não essenciais para seus fornecedores externos ou prestadores de serviço. A prática de outsourcing encoraja o desenvolvimento das habilidades competitivas tanto da empresa como de seus fornecedores aumentando a dependência mútua entre eles;

- A empresa, que está no centro da EE, desenvolve relações de longo prazo com clientes-chave e os trata como importantes parceiros de negócios;

- Métodos, processos de negócios e tecnologias estão disponíveis para suportar atividades através dos limites tradicionais das empresas, em particular apoiar a integração cliente-fornecedor por meio do intercâmbio de informações técnicas e comerciais.

JAGDEV \& BROWNE (1999) afirmam de que a diferença entre EE e EV é até certo ponto uma questão de semântica. Segundo esses autores, uma EV possui maior grau de integração entre seus parceiros, além de maior escopo de cooperação, considerando inclusive que a EE é um caso particular de EV.

Para BROWNE \& ZHANG (1999), a principal de diferença é a natureza temporária ou dinâmica da EV contra a estabilidade relativa da EE. Esses autores 
elaboraram uma comparação entre EE e EV, cujo resultado é apresentado na TABELA 02.

TABELA 02 - Principais Diferenças entre Empresa Estendida e Empresa Virtual

Adaptado de BROWNE \& ZHANG (1999)

\begin{tabular}{|c|c|c|}
\hline & Empresa Estendida & Empresa Virtual \\
\hline $\begin{array}{c}\text { Questão } \\
\text { estratégica }\end{array}$ & Forte objetivo de longo prazo & Forte objetivo de curto prazo \\
\hline $\begin{array}{l}\text { Objetivo da } \\
\text { Parceria }\end{array}$ & $\begin{array}{l}\text { Cooperação de negócios de } \\
\text { longo prazo }\end{array}$ & $\begin{array}{l}\text { Trabalho conjunto } \\
\text { temporário visando projetos } \\
\text { ou produtos }\end{array}$ \\
\hline $\begin{array}{c}\text { Estabilidade da } \\
\text { Organização }\end{array}$ & $\begin{array}{l}\text { Organização estável de } \\
\text { empresas através da cadeia de } \\
\text { valor do produto }\end{array}$ & $\begin{array}{l}\text { Organização dinâmica de } \\
\text { empresas focada em } \\
\text { competências essenciais }\end{array}$ \\
\hline $\begin{array}{c}\text { Relacionamento na } \\
\text { Parceria }\end{array}$ & $\begin{array}{l}\text { Confiança e dependência } \\
\text { mútuas por longo prazo }\end{array}$ & Temporário e dinâmico \\
\hline $\begin{array}{c}\text { Tipo de fronteiras } \\
\text { entre as } \\
\text { organizações }\end{array}$ & $\begin{array}{l}\text { Completamente abertas por } \\
\text { longo prazo }\end{array}$ & $\begin{array}{l}\text { Parcialmente abertas por } \\
\text { curto prazo }\end{array}$ \\
\hline $\begin{array}{c}\text { Coordenação da } \\
\text { parceria }\end{array}$ & $\begin{array}{l}\text { Normalmente, a empresa } \\
\text { principal (montadora) gerencia a } \\
\text { parceria }\end{array}$ & $\begin{array}{l}\text { Um broker freqüentemente } \\
\text { gerencia a cooperação }\end{array}$ \\
\hline $\begin{array}{l}\text { Tecnologia de } \\
\text { Informação }\end{array}$ & Aspecto facilitador e habilitador & $\begin{array}{l}\text { Operação depende de Tls } \\
\text { sofisticadas }\end{array}$ \\
\hline
\end{tabular}

TROBEN \& JAGDEV (1999) propõe uma comparação entre transações de mercado, CS, EE e EV, apresentada na TABELA 03. Porém, segundo esses autores, os atributos da TABELA 03 devem ser considerados mais como tendências do que valores fixos. 
TABELA 03 - Atributos para Caracterizar Relacionamentos Bilaterais

Adaptado de TROBEN \& JAGDEV (1999)

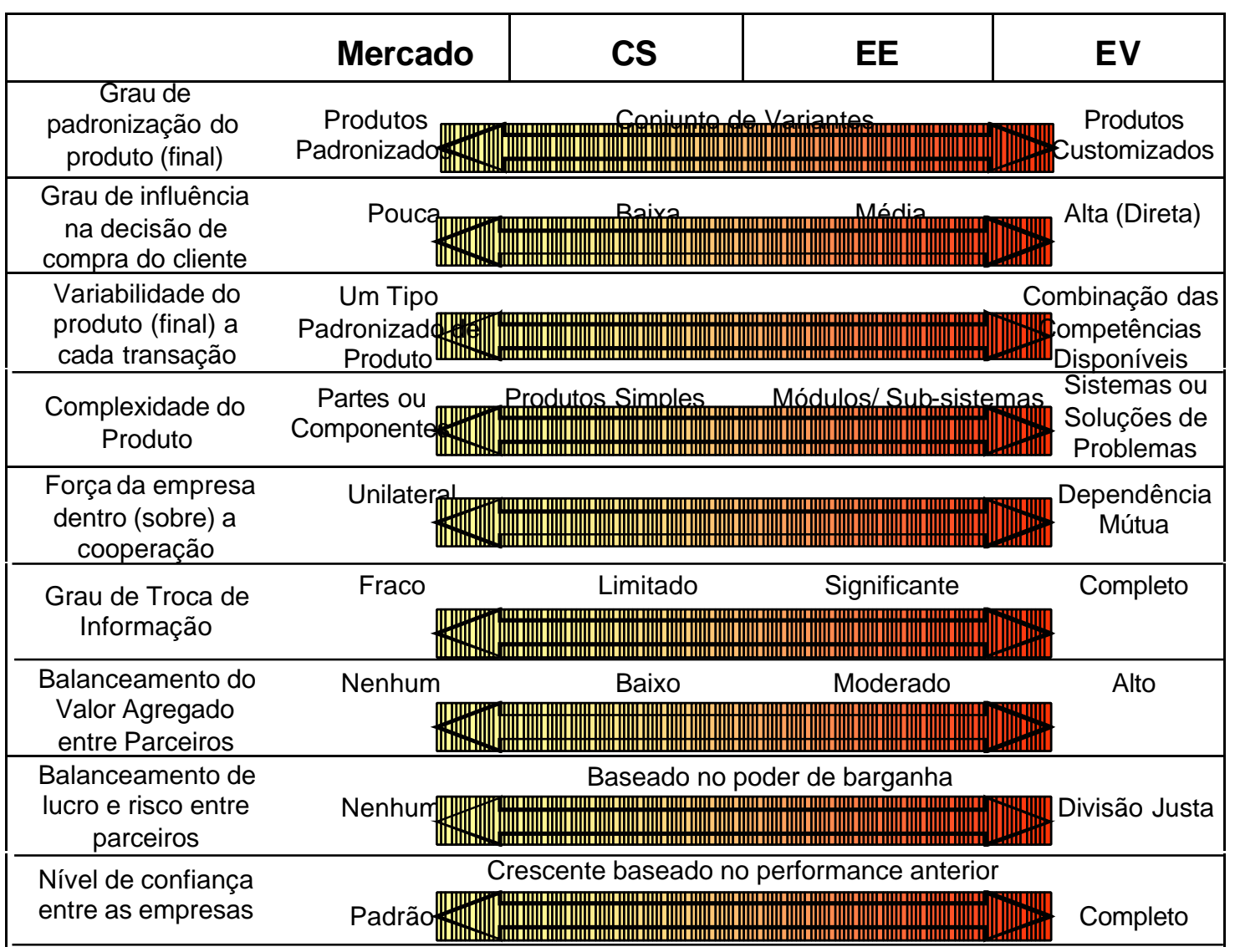

Nessa comparação, TROBEN \& JAGDEV (1999) consideram que o relacionamento bilateral entre duas empresas pode ser visto como o menor tipo de cooperação industrial. Assim, redes complexas de cooperação são compostas por relacionamentos bilaterais iguais ou diferentes, isto é, redes homogêneas ou heterogêneas, como ilustrado na FIGURA 07. Por exemplo, para CHILDE (1998), uma EE não necessariamente compreende toda a cadeia de suprimento, mas um grupo de empresas dentro dessa. 


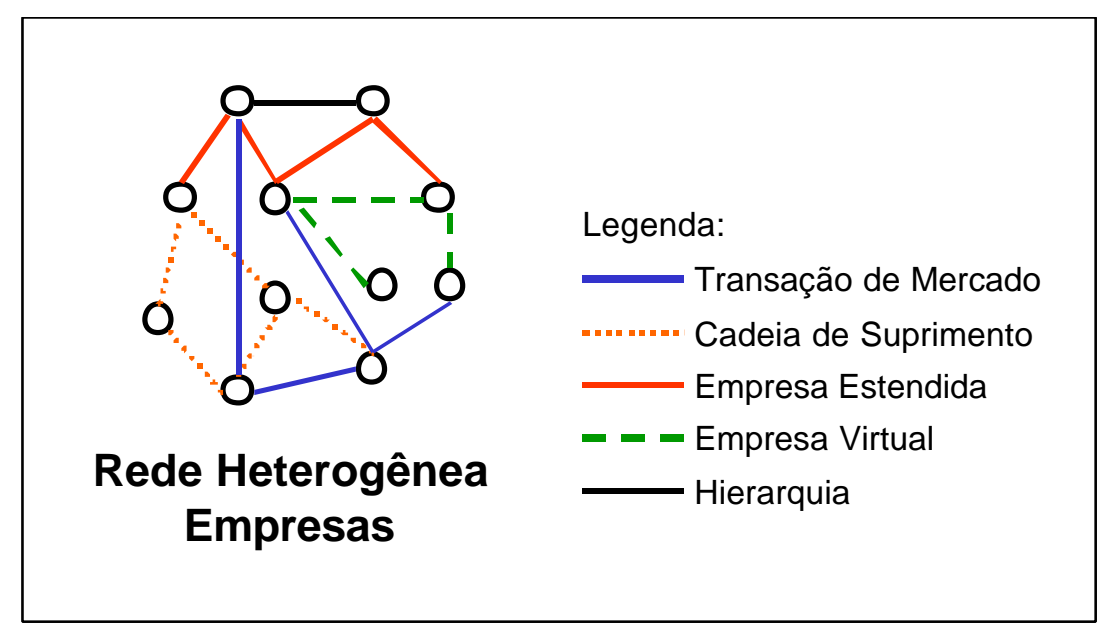

Adaptada de TROBEN \& JAGDEV (1999)

FIGURA 07 - Redes de Empresas e Relacionamento Bilateral

Vale ressaltar que além das formas de cooperação descritas acima, existem várias outras, tais como, joint ventures, franchising e alianças estratégicas, que não serão descritas nesse trabalho.

\subsubsection{Propostas para a Formação de Empresas Virtuais}

A seguir são apresentados três modelos propostos para a formação de Empresas Virtuais.

\subsubsection{Modelo Agile Virtual Enterprise}

Um importante trabalho nesta área de estudo é realizado pelo Agile Manufacturing Enterprise Forum (AMEF). Esse é um fórum de discussão e estudo do assunto do qual participam acadêmicos e empresários de importantes indústrias. $\mathrm{O}$ principal grupo de pesquisas do AMEF está na Universidade de Lehigh (EUA).

O AMEF propõe um framework (modelo genérico que serve como guia de referência) para a formação de EVs. Neste caso, o nome empregado é Empresas Virtuais Ágeis (Agile Virtual Enterprises - AVE), pois se pretende especificar um tipo particular de EV (MAVE, 1998). 
O modelo é uma matriz, de um lado estão os processos associados ao ciclo de vida da EV. Do outro lado, estão as chamadas infra-estruturas ou áreas de aplicação dentro da empresa (GORANSON, 1999). A FIGURA 08 representa essa matriz.

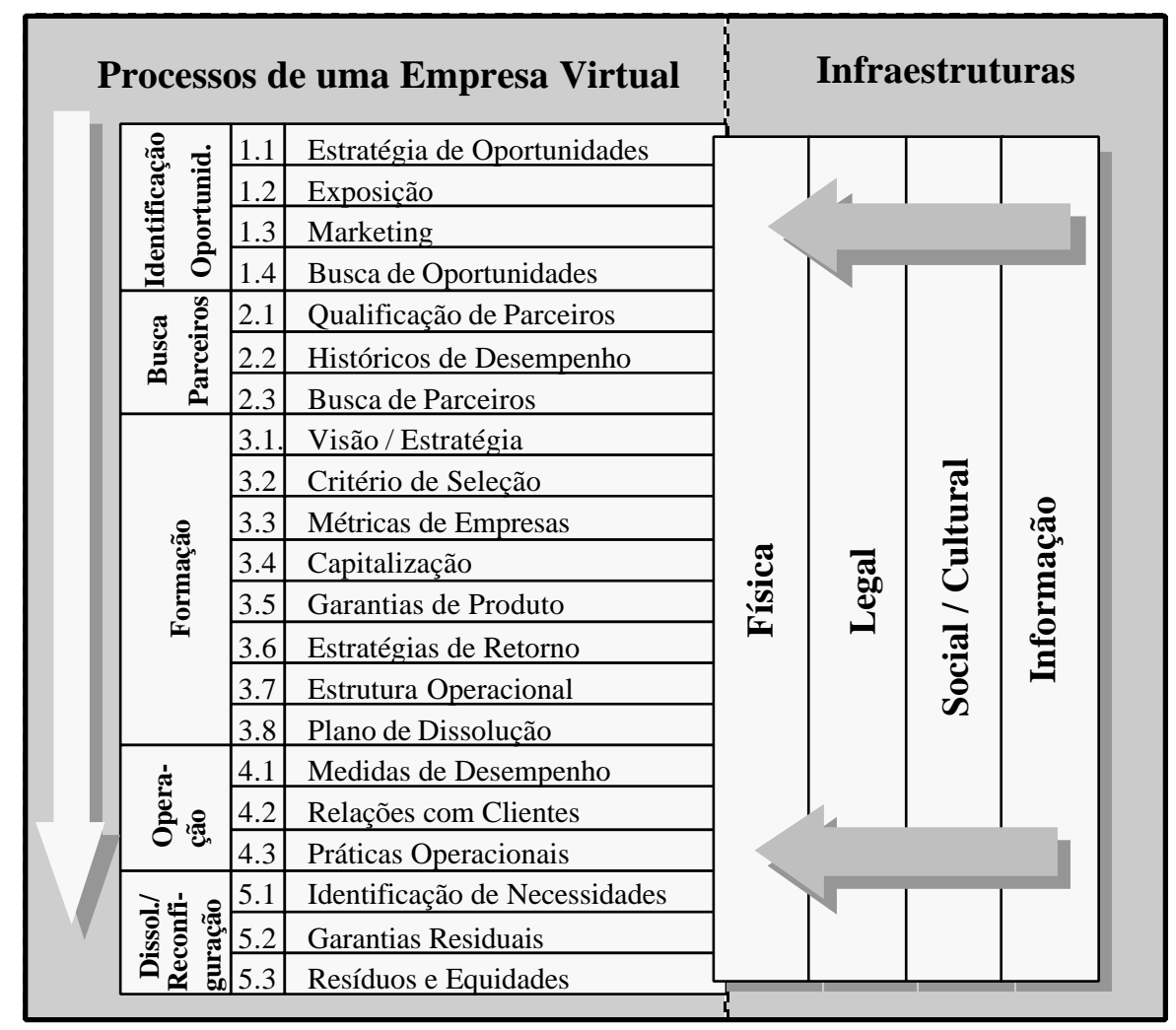

Adaptado de GORANSON (1999)

FIGURA 08 - Estrutura Agile Virtual Enterprise

As cinco principais categorias dos processos do ciclo de vida da EVs são os seguintes (GORANSON, 1999):

- Identificação da Oportunidade: nessa etapa algum agente, um líder em potencial da EV ou um grupo de especialistas, possui a responsabilidade de identificar, refinar e/ou caracterizar a oportunidade de negócio;

- Busca de Parceiros: uma vez que a oportunidade foi identificada, é necessário encontrar os parceiros adequados para atuar na EV; 
- Formação: tendo identificado a oportunidade e seus parceiros é necessário elaborar um Business Case detalhado, estabelecer comprometimentos mútuos e formar a EV;

- Operação: tendo estabelecido a EV, ela deve ser operacionalizada, ou seja, colocada em funcionamento. A impressão causada ao cliente deve ser a de uma única organização, sendo responsabilidade desta etapa criar uma visão externa semelhante à de uma organização convencional;

- Dissolução/Reconfiguração: em um certo ponto pré-determinado, a oportunidade terá sido explorada integralmente ou necessitará ser modificada. Neste momento, a EV deverá ser dissolvida ou reformulada.

As quatro infra-estruturas definidas no modelo são:

- Informação: inclui mecanismos usados para criar, administrar e comunicar informação na EV. Na prática, um conjunto de tecnologias de informação representa a infra-estrutura de informação das EVs. Além disso, os modelos adotados para a EV também fazem parte da infra-estrutura de informação.

- Social/Cultural: refere-se às regras implícitas e explícitas e questões políticas existentes na organização. As regras de negócio associadas à supervisão são partes desta infra-estrutura. A política, incluindo acordos trabalhistas e hábitos, é parte da cultura corporativa.

- Legal: relaciona-se com processos que lidam com instrumentos legais. Internamente tais instrumentos são cláusulas contratuais; externamente eles são formados pelos códigos, leis e regulamentações. Dentro desta questão, encontrase o problema de supervisão da programação e controle de atividades. Redes de supervisão e papéis de decisão são incluídos.

- Física: relaciona-se com a fabricação, equipamentos, layout, transporte, manipulação ou quaisquer características físicas da EV. Possui os seguintes componentes:

- Armazenagem/Logística: movimentação e armazenagem de mercadorias, equipamentos e pessoal,

- Equipamentos: recursos físicos usados pela EV; e 
- Físicos: processos que são restringidos ou limitados por leis físicas como, por exemplo, seqüência de montagem ou fatores geográficos que afetam as propriedades dos materiais.

\subsubsection{Modelo do Agile Aerospace Manufacturing Research Center}

O Agile Aerospace Manufacturing Research Center (AAMRC) propõe um modelo para dar suporte a visão de EV. Para a AAMRC, uma EV é um relacionamento temporário entre dois ou mais parceiros que é formado, operado e dissolvido visando objetivos específicos de curto prazo (REID et al., 1996a). Segundo esses autores, uma EV difere-se dos outros modelos interorganizacionais pelo grau de comprometimento, responsabilidade e estrutura compartilhada entre os participantes por meio da contribuição de suas competências.

O modelo proposto pela AAMRC assume que o ciclo de vida de uma EV é composto por seis etapas (FIGURA 09), que são descritos a seguir (REID et al., 1996b):

- Concepção: uma EV surge ao ser identificada uma necessidade de mercado e ao se estabelecer um objetivo. Nessa etapa, é necessário conhecer as expectativas e necessidades do cliente a fim de satisfazê-lo. Essa etapa é essencialmente o projeto de concepção de uma nova EV;

- Criação: a EV é criada com o estabelecimento de relacionamentos entre parceiros que possuem as competências requeridas ao se determinar a estratégia e conceber o produto que satisfaça a necessidade identificada. Nessa fase, a EV é detalhada e realização uma preparação completa para sua implementação;

- Competição: é feita a divulgação do produto no mercado. Essa etapa pode ser realizada de diferentes formas. A EV pode, por exemplo, oferecer soluções alternativas para necessidades imprevistas, cativando novos clientes. Por fim, a EV pode garantir clientes para os produtos propostos;

- Configuração: a EV é configurada a partir da aquisição dos ativos e competências necessárias. Nessa etapa, também são estabelecidos os processos e infraestruturas necessárias para a operação da EV; 
- Condução: a EV começa a operar produzindo e entregando seu produto, buscando a maximização de valor para seus stakeholder;

- Conclusão: ao alcançar os objetivos da EV, a cooperação é finalizada, ocorrendo a dispersão ou reaproveitamento dos ativos envolvidos.

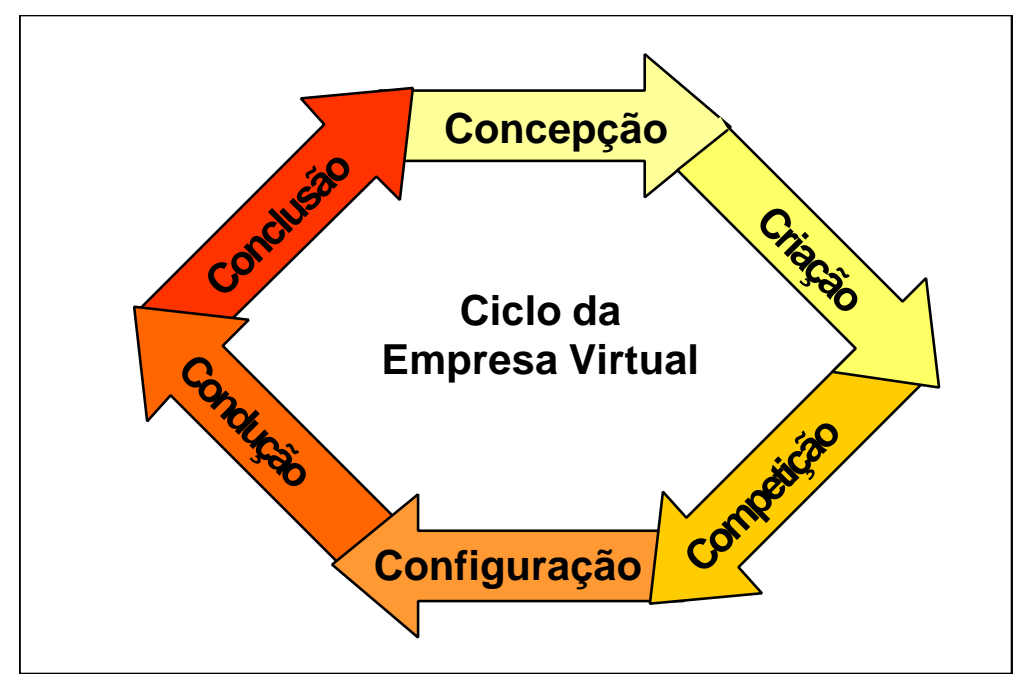

Adaptada de REID et al. (1996b).

FIGURA 09 - Ciclo de vida de uma Empresa Virtual - AMMRC

Segundo REID et al. (1996b), as atividades do ciclo de vida são desempenhadas por processos detidos e operados pelos membros da EV de forma individual, ou, por processos compartilhados entre empresas como uma única entidade. $O$ fato dos processos serem desempenhados de forma individual ou compartilhada depende dos objetivos estabelecidos e de como se deseja alcançá-los.

\subsubsection{Modelo de Negócios Virtuais Globais}

O framework para Negócios Virtuais Globais (NVG) foi elaborado com base no modelo de Empresas Virtuais Ágeis descrito anteriormente. O framework tem como objetivo identificar os processos e competências necessárias para a configuração de um EV (EVERSHEIM et al., 1998).

Em BREMER et al. (1999b) tem-se que o ambiente NVG é composto pelas seguintes entidades de negócio: Grupo Virtual de Indústrias, Agenciador de EV, Organização Virtual e Empresa Virtual (FIGURA 10): 


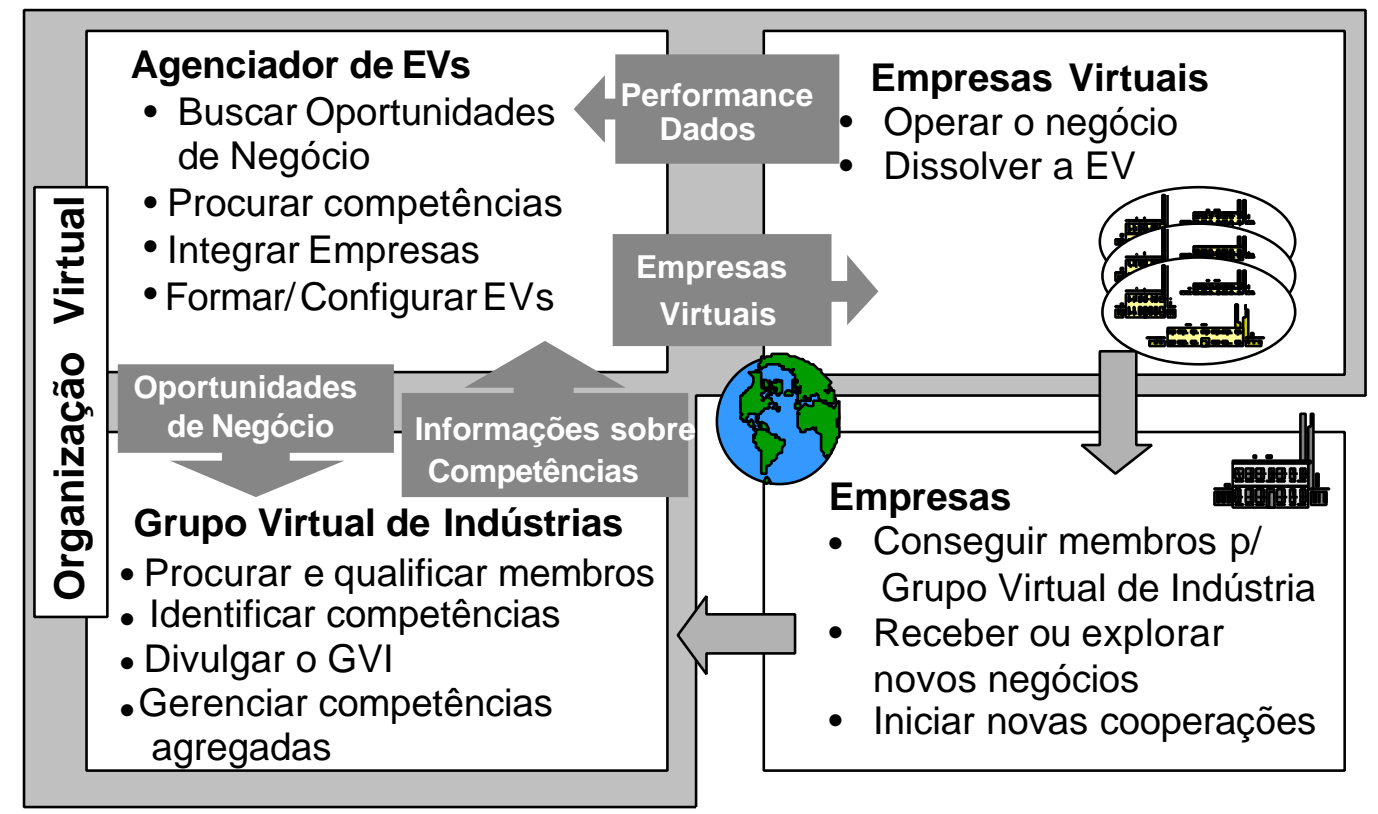

Fonte: Adaptado de (BREMER et al., 1999b)

FIGURA 10 - Relacionamentos no Ambiente de Negócios Virtuais Globais

\section{Grupo Virtual de Indústrias (GVI)}

Segundo BREMER et al. (1999b), o GVI é um agrupamento de empresas provenientes de diversas áreas de atuação, com competências bem definidas e focadas, com o propósito de obter acesso a novos mercados e a oportunidades de negócio por meio do nivelamento de seus recursos. As empresas podem ou não ser distribuídas geograficamente.

BREMER et al. (1999b) descrevem os dois principais processos do GVI:

- Gerenciamento do GVI: diz respeito à organização, formação e marketing do GVI, incluindo busca, seleção e qualificação das empresas para a formação do GVI.

- Gerenciamento das Competências: envolve a identificação, disponibilização e proteção das competências do GVI.

\section{Agenciador da Empresa Virtual (AEV)}

Segundo BREMER et al. (1999b), o AEV é responsável por buscar oportunidades visando a formação de EVs. O AEV realiza os processos de procura e seleção de 
parceiros para atender à oportunidade, além de configurar as infra-estruturas adequadas (física, legal, social/cultural e de informação) para a formação e comprometimento da EV.

\section{Organização Virtual (OV)}

As OVs podem ser definidas como uma rede estável de empresas, com a intenção de formar EVs, onde os parceiros são unidos por suas competências e estratégias de mercado (BREMER et al., 1999b). Segundo BREMER et al.(2000), caso o GVI possua seu próprio AEV, ele se torna uma OV. A competência essencial de uma OV é a agregação das competências de negócio do AEV e da competência tecnológica do GVI, que criam valor adicional aos clientes.

\section{Empresa Virtual (EV)}

EV é uma rede temporária de empresas independentes, normalmente ligadas por tecnologias de informação, que compartilham competências, infra-estruturas e processos de negócio, com o objetivo de atender a uma necessidade de mercado específica (BREMER et al, 1999b).

No framework NVG, uma EV é criada quando uma oportunidade de negócio é identificada pelo AEV e pode ser explorada pelas competências dos membros do GVI, ou seja, uma OV é a base para o surgimento de diversas EVs.

\section{Vantagens da formação de uma Organização Virtual}

WILDEMAN (1999) apresenta um estudo que mostrou que várias empresas vêm criando OVs para evitar os principais problemas das alianças mais convencionais. Quando pensam em formar alianças, as organizações geralmente enfrentam o seguinte dilema: elas devem ser constituídas rapidamente - em parte porque o ciclo de vida dos produtos é cada vez mais curto - mas o relacionamento com os parceiros, considerado vital, leva tempo. Para resolver esse dilema, algumas empresas vêm criando redes de relacionamento formadas por pessoas e/ou empresas que (WILDEMAN, 1999):

- possuem determinadas competências que poderão ser benéficas no futuro e

- não criam problemas de relacionamento. 
Assim que forem definidas as competências necessárias para determinado serviço ou produto, como a primeira seleção técnica e de relacionamento já ocorreu no momento em que alguém for aceito na rede, as escolhas poderão ser estabelecidas sem perder muito de tempo no estabelecimento da cooperação.

Segundo CORRÊA (1999), uma OV pode ser vista como uma plataforma estável onde empresas trocam informações a respeito de oportunidades de mercado e consequentemente utilizam-se dessa cooperação para a formação rápida de uma EV, uma vez que uma estrutura organizacional já esta presente. A FIGURA 11 ilustra a formação de EVs a partir de uma OV.

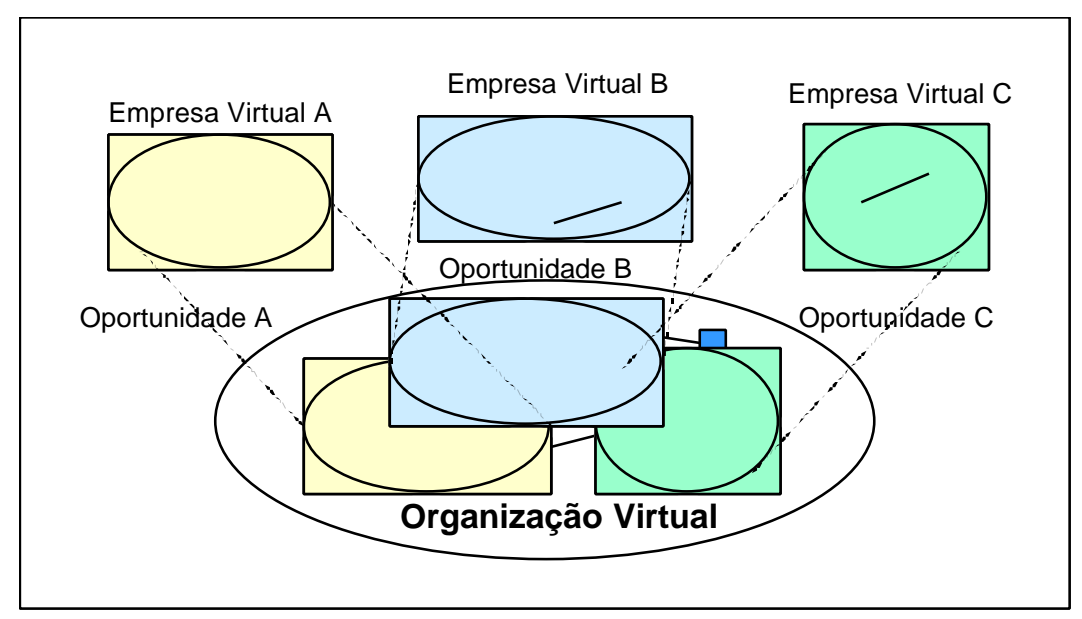

Adaptado de CORRÊA (1999)

FIGURA 11 - Formação de Empresas Virtuais a partir de uma Organização Virtual

As empresa que participam de OVs, segundo esse modelo, estão mais bem preparadas, pois uma característica fundamental das EVs é que a sua formação deve ser rápida, a fim de explorar oportunidade de mercado, e existência de OVs possibilita isto.

\subsection{Planejamento e Controle da Produção}

O termo Planejamento e Controle da Produção (PCP) pode ser definido como sendo um conjunto de atividades gerenciais a serem executadas, para que se concretize a produção de um produto (PIRES, 1995). Para VOLLMAN et al. (1997), um sistema de PCP fornece informações para um gerenciamento eficiente do fluxo de 
materiais, uma utilização eficaz de recursos, uma coordenação interna das atividades com fornecedores e uma comunicação com os clientes sobre os requisitos de mercado.

Vários termos são freqüentemente utilizados na língua portuguesa para tratar o mesmo assunto, tais como: gestão da produção, gerenciamento da produção, administração da produção e planejamento e controle da produção (PIRES, 1995). Neste trabalho são utilizados os termos planejamento e controle da produção e gestão da produção como sinônimos.

A seguir são apresentadas as principais atividades de PCP, algumas formas de classificação dos sistemas produtivos e abordagens de gestão da produção.

\subsubsection{Atividades do Planejamento e Controle da Produção}

Independentemente do sistema produtivo e abordagem utilizada pelo PCP, existem algumas atividades que são tradicionalmente inerentes à sua realização (PIRES, 1995). Isso significa que, em um nível de complexidade variável, essas atividades, descritas a seguir e representadas na FIGURA 12, sempre se farão necessárias.

PREVISÃO DE VENDAS e/ou CARTEIRA DE PEDIDOS - o planejamento praticamente se inicia com os dados fornecidos pela área de Vendas. Normalmente, esses dados dizem respeitos ao que produzir, em quais quantidades e em que prazo.

PLANEJAMENTO AGREGADO DA PRODUÇÃO - consiste no estabelecimento dos níveis gerais de produção e capacidade para um período de médio/longo prazo. Nesse nível de planejamento, uma macro comparação da carga de trabalho com a capacidade permite antecipar a tomada de decisões, tais como novos investimentos. 


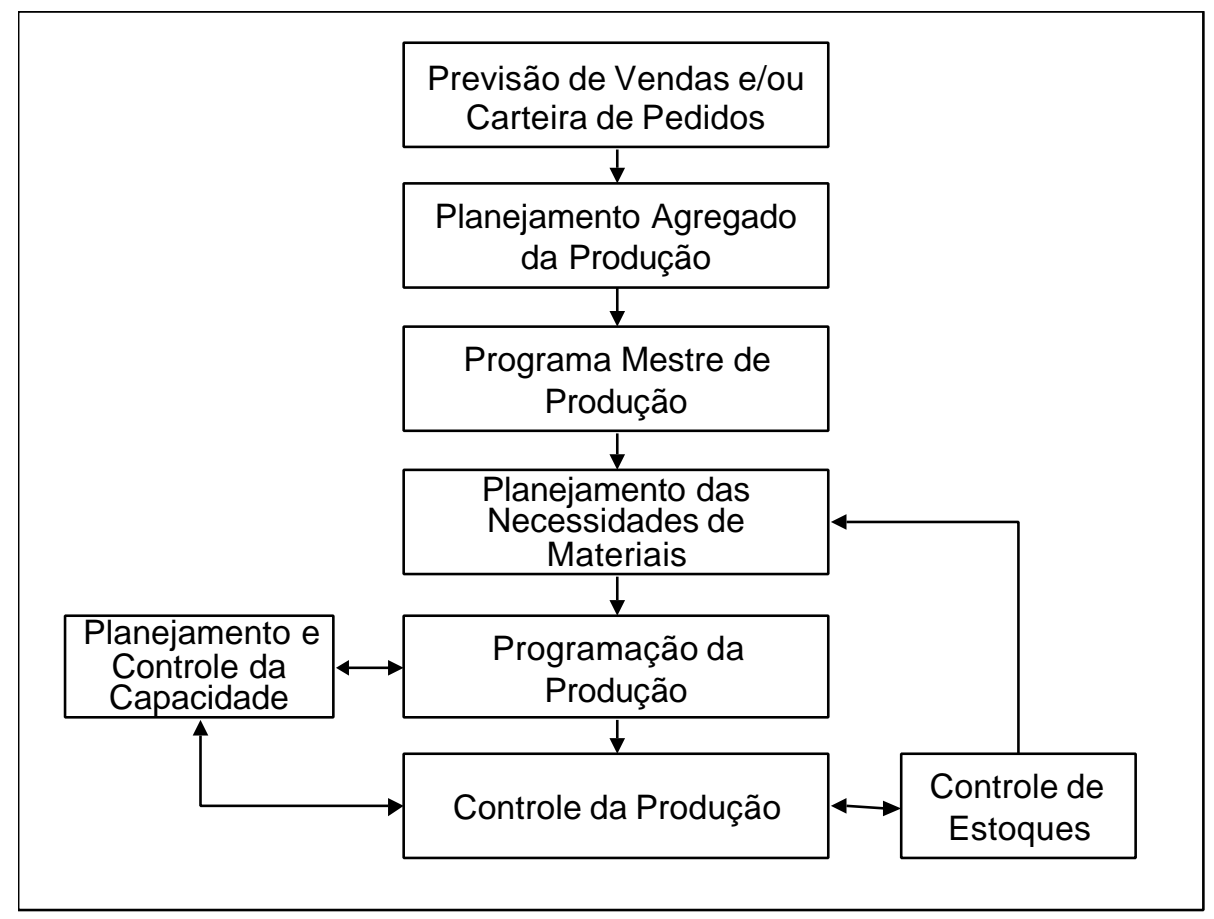

Adaptada de PIRES (1995)

FIGURA 12 - Atividades básica do Planejamento e Controle de Produção

PROGRAMA MESTRE DE PRODUÇÃO - consiste em um referencial básico para a produção, estabelecendo quando e em que quantidade cada produto deverá ser produzido dentro de um certo horizonte de planejamento. $\mathrm{Na}$ elaboração desse programa, as restrições impostas pela capacidade são verificadas em um nível macro, ou seja, geralmente é a etapa onde verificações mais detalhadas da capacidade podem nivelar a produção por restrições organizacionais e/ou econômicas.

PLANEJAMENTO DAS NECESSIDADES DE MATERIAIS - calcula as chamadas necessidades líquidas para cada produto ou componente a ser produzido. Essas necessidades líquidas são calculadas com base nas necessidades brutas vindas da lista de materiais, pelas exigências impostas pelo programa mestre e pelas informações do controle de estoques (itens em estoque e itens em processo de fabricação/compras).

CONTROLE DE ESTOQUES - trata basicamente do controle sobre todos os itens fabricados, comprados e utilizados pela indústria para a produção de seus produtos. O controle de estoques visa trabalhar com dois objetivos aparentemente 
conflitantes: minimizar os investimentos em estoques e maximizar os níveis de atendimento aos clientes e a produção da indústria.

PROGRAMAÇÃO DA PRODUÇÃO - consiste em determinar os prazos de entrega para os itens definidos, respectivamente como fabricados e comprados. Para os itens fabricados, muitas vezes são definidos também o centro produtivo e a seqüência das operações a serem realizadas. As restrições a essa tarefa são impostas pela capacidade disponível do centro produtivo, para o período em questão, bem como pelas exigências tecnológicas colocadas nos roteiros de produção.

PLANEJAMENTO E CONTROLE DA CAPACIDADE - estipula quais devem ser os níveis de produção máximos que os centros produtivos devem ter em um certo horizonte de planejamento. Cuida das providências para que a capacidade planejada seja realizada e das informações a serem utilizadas por outras atividades do PCP.

CONTROLE DA PRODUÇÃO - consiste em acompanhar a fabricação e compra dos itens planejados (programados), com o objetivo de que os prazos sejam cumpridos. O controle da produção costuma também atuar colhendo dados importantes para o sistema de custos, tomando decisões típicas de chão de fábrica (como mudanças de prioridades, necessidade de hora extras, etc.) e alimentando informações ao controle de estoques.

As atividades do PCP, segundo CONTADOR \& CONTADOR (1997), podem ser dividas em quatro fases, que são hierarquizadas no sentido de que a fase seguinte é iniciada após a implementação das decisões tomadas na fase anterior. Assim, a abordagem hierárquica considera diferentes horizontes de planejamento: longo, médio, curto e curtíssimo prazos (TABELA 04). 
TABELA 04 - Processo de Decisão no Planejamento da Produção

Adaptada de CONTADOR \& CONTADOR (1997)

\begin{tabular}{|c|c|c|c|}
\hline Horizonte & Entradas & Funções do PCP & Saídas \\
\hline $\begin{array}{l}\text { Longo } \\
\text { Prazo }\end{array}$ & $\begin{array}{l}\text { - Pesquisa de } \\
\text { Mercado } \\
\text { - } \quad \text { Previsões de } \\
\text { longo prazo }\end{array}$ & $\begin{array}{l}\text { Planejamento de } \\
\text { recursos } \\
\text { COMO } \\
\text { PRODUZIR }\end{array}$ & 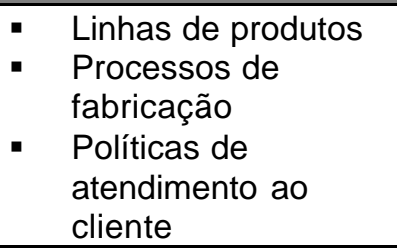 \\
\hline $\begin{array}{l}\text { Médio } \\
\text { Prazo }\end{array}$ & $\begin{array}{l}\text { - Previsões de } \\
\text { demanda de } \\
\text { médio prazo } \\
\text { - } \quad \begin{array}{l}\text { Planos de } \\
\text { emprego da mão } \\
\text { de obra }\end{array}\end{array}$ & $\begin{array}{l}\text { Plano de } \\
\text { produção } \\
\text { O QUE E } \\
\text { QUANTO } \\
\text { PRODUZIR }\end{array}$ & $\begin{array}{l}\text { - } \quad \text { Necessidades de } \\
\text { materiais } \\
\text { - Planos de } \\
\text { estocagem } \\
\text { - Planos de entrega } \\
\text { - Níveis de força de } \\
\text { trabalho } \\
\end{array}$ \\
\hline $\begin{array}{l}\text { Curto } \\
\text { Prazo }\end{array}$ & $\begin{array}{l}\text { - Prazos de entrega } \\
\text { - } \quad \text { Prioridades de } \\
\text { atendimento }\end{array}$ & $\begin{array}{l}\text { Programação da } \\
\text { produção } \\
\text { QUANDO } \\
\text { PRODUZIR }\end{array}$ & $\begin{array}{ll}\text { - } & \text { Ordens de } \\
& \text { fabricação } \\
\text { - } & \text { Tamanhos de lote } \\
\text { - } & \text { Utilização de horas } \\
& \text { extras } \\
\text { - } & \text { Reserva de material }\end{array}$ \\
\hline $\begin{array}{c}\text { Curtíssimo } \\
\text { Prazo }\end{array}$ & $\begin{array}{l}\text { - Ordens de } \\
\text { fabricação } \\
\text { - } \quad \text { Critérios de } \\
\text { sequenciamento }\end{array}$ & $\begin{array}{l}\text { Liberação da } \\
\text { produção } \\
\text { ONDE E QUEM } \\
\text { PRODUZIR }\end{array}$ & $\begin{array}{ll}\text { - } & \text { Seqüência de tarefas } \\
\text { - } & \text { Requisição de } \\
& \text { recursos } \\
\text { - } \quad \text { Designação de } & \text { tarefas } \\
\text { - } & \text { Coleta de dados } \\
\text { para controle }\end{array}$ \\
\hline
\end{tabular}

Embora essa divisão seja relativa, pois depende das características dos sistemas de produção, é uma tentativa de tratar as decisões de maneira apropriada ao nível de incertezas e importância inerentes à cada nível de planejamento.

\subsubsection{Classificação dos Sistemas Produtivos}

Um sistema produtivo pode ser definido genericamente como sendo um elemento capaz de transformar alguns recursos de entrada em produtos e/ou serviços como saídas (PIRES, 1995). A característica de cada sistema produtivo é fundamental para a definição estratégica de qual sistema de gestão da produção deve ser implementado. Dentro dessa visão, diversos autores propõem diferentes classificações, o que permitem identificar as características similares dos processos produtivos. Duas das possíveis formas de classificação são apresentadas a seguir. 
A primeira classificação considera os volumes de produção e a variedade com que os produtos são fabricados, dividindo inicialmente os sistemas produtivos em duas categorias: produção contínua e produção discreta ou intermitente.

Segundo APICS (1998), a produção contínua diz respeito a um sistema no qual o equipamento produtivo é organizado e sequenciado de acordo com as etapas envolvidas na fabricação do produto. Esse termo denota que o fluxo de material é contínuo durante o processo de produção, o roteiro de produção é fixo e mudanças de setup ocorrem raramente. Freqüentemente, a produção contínua é associada aos processos químicos envolvendo substâncias fluidas, mas também pode englobar a produção de itens sólidos produzidos de forma contínua.

A produção discreta é a produção de distintos itens em um sistema produtivo, que pode ser dividida em (PORTER et al., 1999):

- Produção em massa: grande volume de produção com uma pequena diversidade de produtos padronizados. É caracterizado por um lead-time curto e pela especialização dos equipamentos e mão-de-obra.

- Produção em lotes: os produtos são fabricados em lotes, apresentando valores intermediários de lead time. Os lotes podem ainda ser classificados em pequenos, médios e grandes, não existindo, porém um critério genérico para se fazer essa classificação, ou seja, o que é considerado pequeno lote numa indústria pode ser considerado grande em outra.

- Produção individual: é caracterizada pelo baixo volume de produção de uma grande variabilidade de produtos com demanda de difícil previsão, sendo normalmente desenvolvido sob encomenda.

Nessa classificação pode ser relacionado o volume de produção e variedade de produtos, tal como na FIGURA 13 (PORTER et al.,1999). 


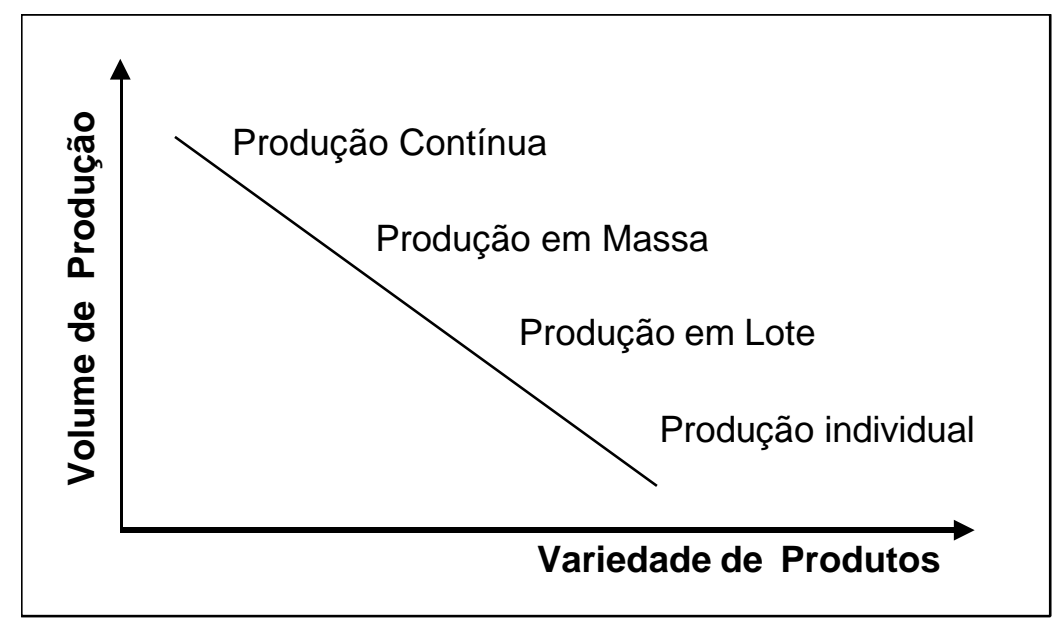

Adaptada de PORTER et al. (1999)

FIGURA 13 - Volume de produção x variedade de produtos

Nesse contexto, VOLLMAN et al. (1997) apresentam o relacionamento entre a complexidade do produto sendo expresso em número de componentes e a natureza repetitiva da produção representada como o intervalo de tempo entre unidades sucessivas. A FIGURA 14 também apresenta alguns exemplos de produtos que se enquadram nas escalas de tempo e complexidade.

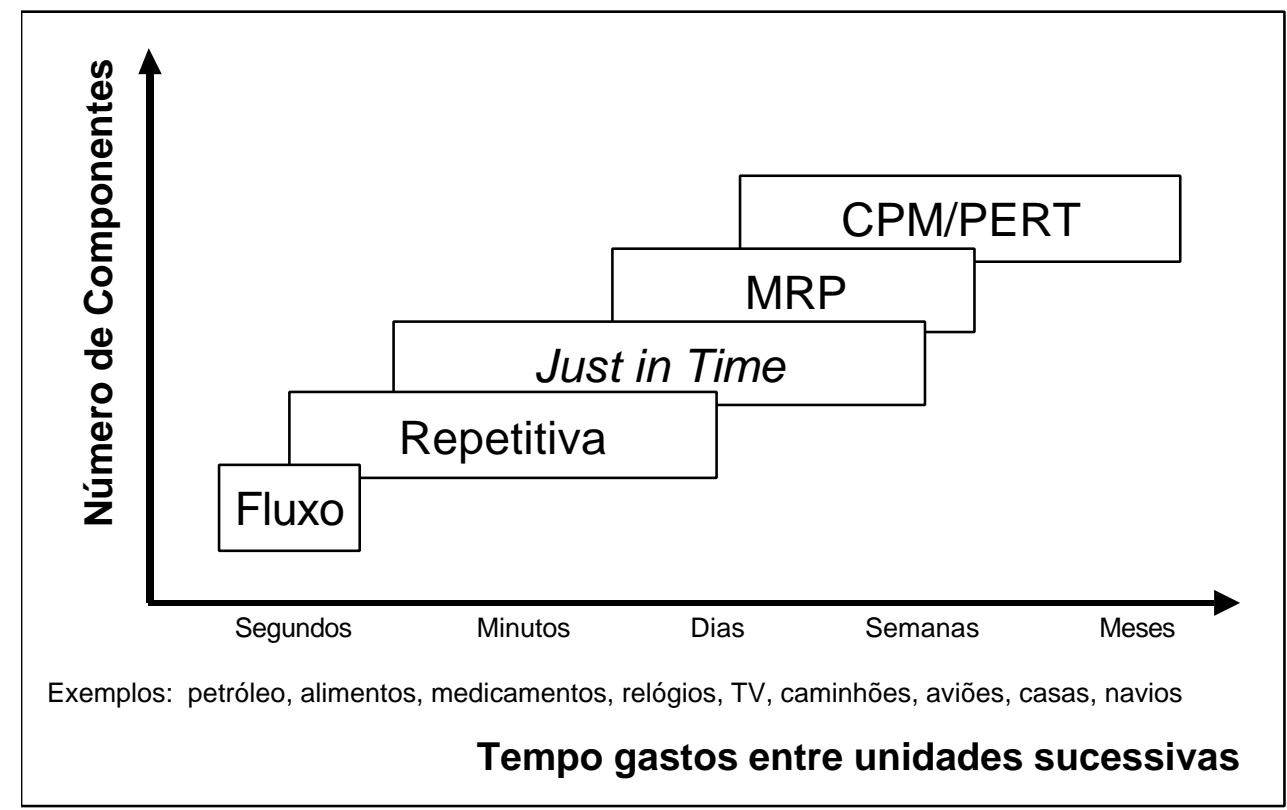

Adaptado de VOLLMAN et al. (1997)

FIGURA 14 - Número de componentes, lead-time e tipos de sistemas de produção 
De acordo com PORTER et al. (1999), um mecanismo alternativo para classificação é identificar e diferenciar os sistemas produtivos entre os direcionados a estoque ou a ordens/encomendas. PIRES (1995) complementa que o primeiro grupo engloba os sistemas onde a venda do produto geralmente é feita após a sua produção, enquanto que o segundo grupo ela é feita antes de sua produção. Essa classificação representa a forma de interação dos sistemas produtivos com os clientes, ou seja, o nível de interferência que o cliente tem no produto final.

PIRES (1995) apresenta quatro tipos básicos dessa classificação são descritos a seguir e representados na FIGURA 15:

- Produção para Estoque (MTS - Make to Stock): caracteriza os sistemas que produzem produtos padronizados, baseados principalmente em previsões de demanda. Nesse caso, nenhum produto é customizado, porque o pedido é feito com base no estoque de produtos acabados. Isso significa que a interação dos clientes com o projeto do produto é muito pequena ou inexistente. Os sistemas MTS têm como principal vantagem a rapidez na entrega dos produtos, mas os custos com estoques tendem a ser grandes e os clientes não têm como expressar suas necessidades a respeito dos produtos. Nesses sistemas, os ciclos de vida dos produtos tendem a ser relativamente longos e previsíveis.

- Montagem sob Encomenda (ATO - Assemble to Order): caracteriza os sistemas onde os subconjuntos, grandes componentes e materiais diversos são armazenados até o recebimento dos pedidos dos clientes contendo as especificações dos produtos finais. A interação dos clientes com o projeto do produto é limitada. Nos sistemas ATO, as entregas dos produtos tendem a ser de médio prazo e as incertezas da demanda (quanto ao mix e volume dos produtos) são gerenciadas através de um excesso no dimensionamento dos estoques de subconjuntos e capacidade das áreas de montagem.

- Produção sob Encomenda (MTO - Make to Order): o projeto básico pode ser desenvolvido a partir dos contatos iniciais com o cliente, mas a etapa de produção só se inicia após o recebimento formal do pedido. A interação com o cliente costuma ser extensiva e o produto está sujeito a algumas modificações mesmo durante a fase de produção. Num sistema MTO, os produtos geralmente não são 
um de cada tipo, porque usualmente os produtos são projetados a partir de especificações básicas. Os tempos de entrega tendem a ser de médio a longo prazo e as listas de materiais são usualmente únicas para cada produto.

- Engenharia sob Encomenda (ETO - Engineering to Order): é praticamente uma extensão do MTO, com o projeto do produto sendo feito quase que totalmente baseado nas especificações do cliente. Os produtos são altamente customizados e o nível de interação com o cliente é muito grande.

MARUCHECK \& McCLEKKAND ${ }^{6}$ apud PIRES (1995) diferenciam esses quatro sistemas por meio da definição do conceito de ciclo competitivo, que seria o tempo compreendido entre o recebimento do pedido e o despacho do produto final, ou seja, representaria o tempo de interação entre a manufatura e os clientes. A FIGURA 15 representa os ciclos competitivos para os quatro sistemas considerados.

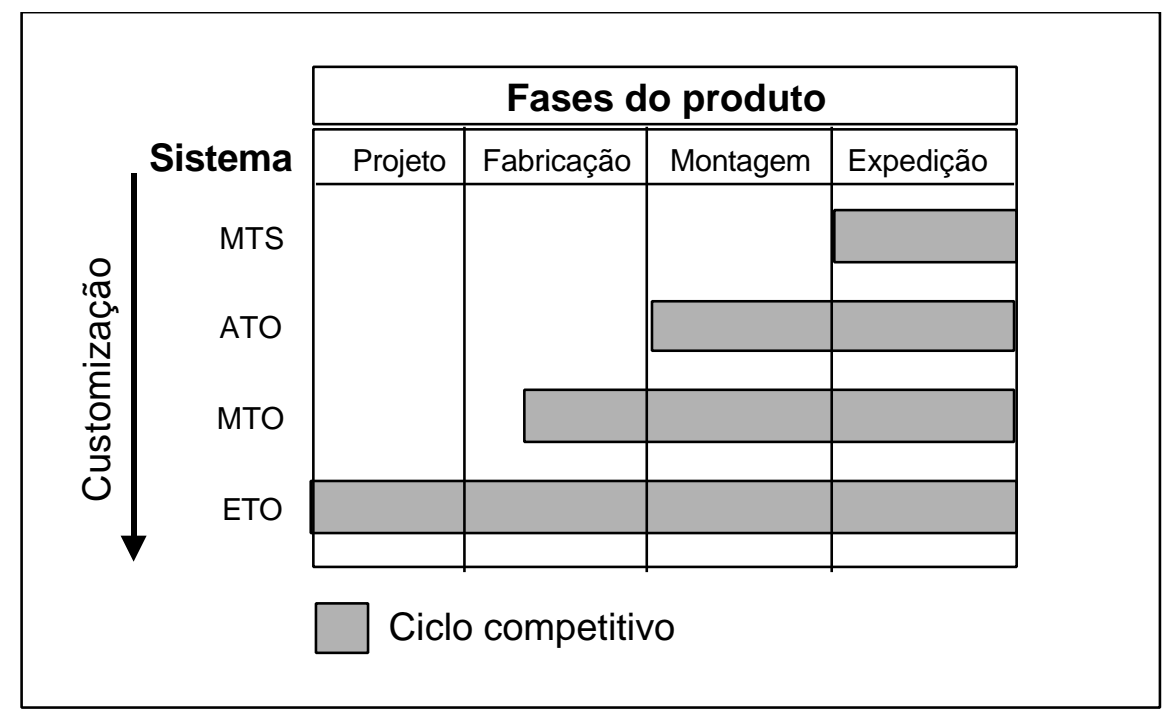

Fonte: PIRES (1995)

FIGURA 15 - Tipologias de produção

Essas quatro tipologias básicas de produção definem ou direcionam grande parte das características do processo de gestão da produção de uma empresa, independente do seu setor de negócio.

\footnotetext{
${ }^{6}$ MARUCHECK, A. S.; McCLEKKAND, M. K. (1986). Strategic Issues in Make-to-Order Manufacturing. Production and Inventory Management Journal. v.27, n.2, p.82-96.
} 


\subsubsection{Abordagens de Planejamento e Controle da Produção}

Neste tópico, as abordagens mais conhecidas de PCP são brevemente descritas em um resumo de suas principais características.

\subsubsection{MRP e suas derivações}

O termo MRP (Material Requirement Planning - Planejamento das Necessidades de Materiais) proposto por Joe Orlicky no começo dos anos 60 nos EUA surgiu com o objetivo de executar computacionalmente a atividade de planejamento das necessidades de materiais. Esse cálculo baseia-se na idéia de que, se são conhecidos todos os componentes de determinado produto e os tempos de obtenção de cada um deles, pode-se como base nas demandas futuras, calcular os momentos e as quantidades em que devem ser obtidos para que não haja falta nem excesso de suprimentos (CÔRREA et al., 1997).

Posteriormente, na década de 70, esse sistema que executava o cálculo das necessidades de materiais, evolui paralelamente ao desenvolvimento da informática, surgindo um sistema computacional com o pretensioso objetivo de realizar todas as principais atividades do PCP (PIRES, 1995). Esse novo sistema passou a se chamar MRP II (Manufacturing Resource Planning - Planejamento dos Recursos de Manufatura).

Em resumo, o MRP II pode ser descrito como um sistema hierárquico de gestão da produção, em que os planos de longo prazo de produção são sucessivamente detalhados até se chegar ao nível do planejamento de componentes e máquinas específicas (CORRÊA \& GIANESI, 1993).

Outros módulos começaram a ser acrescidos nos sistemas MRP II, tais como módulos de controladoria, compras e finanças. Esses sistemas integrados, capazes de atender às necessidades de informação de diversas áreas das empresas, passaram a ser chamados de ERP (Enterprise Resource Planning - Planejamento dos Recursos da Empresa). Segundo (CÔRREA et al., 1997), um ERP é basicamente composto de módulos que atendem a necessidade de informações para apoio à tomada de decisões de outros setores que não apenas aqueles ligados à manufatura a partir de uma base de dados única e não redundante. 


\subsubsection{Manufatura Enxuta}

O termo Manufatura Enxuta (do original Lean Manufacturing e também conhecido como Lean Production ou Lean Thinking) surgiu de estudos do MIT (Massachusetts Institute of Technology) para representar toda uma nova filosofia de manufatura baseada em técnicas originalmente nascidas no Japão após a segunda guerra mundial, pioneiramente introduzidas pelo engenheiro chefe da Toyota, Taiichi Ohno.

Segundo WOMACK \& JONES (1997), seu conceito parte do princípio de que existem desperdícios em uma organização e que a Manufatura Enxuta surge como um antídoto para se fazer cada vez mais com cada vez menos, e cada vez mais oferecer aos clientes o que eles realmente desejam.

O objetivo é tornar as empresas mais flexíveis e capazes de responder efetivamente às necessidades dos clientes e ainda conseguir desenvolver, produzir e distribuir produtos com menos esforço humano, espaço, recursos, tempo e despesas globais (WOMACK \& JONES, 1997). O conceito de Manufatura Enxuta baseia-se nas seguintes metas:

- eliminação das etapas desnecessárias dos processos;

- alinhamento das etapas de cada atividade em um fluxo contínuo;

- organização do pessoal em equipes interdisciplinares dedicadas a cada atividade;

- melhoria contínua dos processos.

A Manufatura Enxuta possui cinco princípios básicos quem deve ser seguidos como um guia de ação (WOMACK \& JONES, 1997). A seguir é apresentado um resumo de cada um dos princípios:

Especifique Valor: é o ponto de partida e só pode ser definido pelo cliente final. Deve-se começar com uma tentativa consciente de definir precisamente o valor em termos de produtos específicos, com capacidades específicas, oferecidas a preços específicos por meio de diálogo com clientes específicos.

Identifique a Cadeia de Valor: é o mapeamento do conjunto de todas as atividades para se levar um produto específico a passar pelas tarefas de desenvolvimento do produto (da concepção até o lançamento do produto), 
gerenciamento da informação (do recebimento do pedido até a entrega), e transformação física propriamente dita (da matéria-prima ao produto acabado nas mãos do cliente).

Fluxo: é necessário fazer com que as etapas que criam valor, fluam. Isso exige uma mudança completa de mentalidade, buscando quebrar a visão intuitiva de se enxergar as empresas por funções e departamentos. Essa abordagem é difícil de ser quebrada pela sua intuitividade e por justificar os membros de departamentos e equipamentos totalmente ocupados, dando a falsa sensação de eficiência. As coisas podem funcionar melhor quando se focaliza o produto e suas necessidades, e não a organização ou o equipamento, de modo que todas as atividades necessárias para se projetar, pedir e fornecer um produto ocorra em fluxo contínuo.

Produção Puxada: é fazer o que os clientes precisam no momento certo, permitindo que o cliente (interno ou externo) puxe o produto quando necessário, em vez de empurrar muitas vezes produtos indesejados.

Perfeição: fazer os quatro princípios anteriores interagirem em um círculo na eliminação de muda (palavra japonesa para desperdício) especificando valor com precisão, identificando a cadeia de valor como um todo, fazendo com que os passos da cadeia de valor fluam e os clientes puxem. Isso é possível porque, ao dar condições para que o valor flua, sempre ocorrerá uma exposição de desperdícios ocultos na cadeia de valor.

WOMACK \& JONES (1997) afirmam que, com base nas suas experiências, a Manufatura Enxuta traz, em termos específicos, benefícios como aumento da produtividade da mão-de-obra ao longo do sistema como um todo, redução do tempo de throughput, dos estoques no sistema, dos erros que chegam até o sistema, da sucata dentro do processo de produção e dos acidentes de trabalho, do tempo de lançamento de novos produtos, podendo-se ainda oferecer uma maior variedade de produtos a um custo adicional pequeno, tudo isso necessitando baixos investimentos.

\subsubsection{OPT-Optimized Production Technology}

A OPT (Optimized Production Technology - Tecnologia de Produção Otimizada) pode ser apresentada como uma abordagem de gestão da produção, orientada por 
gargalos produtivos e baseada em uma técnica de programação da produção que utiliza um software específico.

A premissa principal da OPT, segundo GOLDRATT \& COX (1988), é que a meta de qualquer organização é o lucro e baseando-se nessa premissa propuseram uma metodologia racionalizadora do sistema produtivo. Dentro desse enfoque, a manufatura contribui de três maneiras distintas para o atendimento dessa meta: agilizando o fluxo de materiais, reduzindo os estoques e reduzindo as despesas operacionais.

A OPT propõe que o PCP seja orientado pelos gargalos da produção, que são os recursos produtivos sobre os quais a demanda imposta é maior que a sua capacidade de processamento. Os recursos anteriores aos gargalos são 'puxados' (programação para trás) e os recursos posteriores são 'empurrados' (programação para frente) de acordo com as saídas do gargalo.

Segundo CORREAA \& GIANESI (1993), a OPT obedece a nove princípios básicos:

1- Balancear o fluxo e não a capacidade;

2- A utilização de um recurso não gargalo não é determinada por sua disponibilidade, mas por alguma outra restrição do sistema, por exemplo, um gargalo;

3- Utilização e ativação de um recurso não são sinônimos;

4- Uma hora ganha em um recurso gargalo é uma hora ganha para o sistema com um todo;

5- Uma hora ganha em um recurso não gargalo não é nada, apenas miragem;

6- O lote de transferência pode não ser, e não deveria ser, igual ao lote de processamento;

7- O lote de processamento deve ser variável e não fixo;

8- Os gargalos não só determinam o fluxo do sistema como também definem seus estoques;

9- A programação das atividades e a capacidade produtiva devem ser consideradas simultaneamente e não seqüencialmente. O lead time é resultado da programação e não pode ser assumido a priori. 
A OPT tem-se mostrado capaz de reduzir o estoque em processo na ordem de 40 a $75 \%$ e o lead time em até 30\% (CORRÊA \& GIANESI, 1993). No entanto, um fato desfavorável é que, por não ser público o algoritmo, cria uma dependência da empresa usuária com apenas um fornecedor do sistema. Outra questão importante é que a OPT não possui, nem formaliza, nenhuma forma de retroalimentação do sistema em função do que realmente tenha ocorrido no chão de fábrica, dificultando as funções de controle da produção.

\subsubsection{Manufatura Distribuída}

Por Manufatura Distribuída entende-se todo um elenco de conceitos emergentes voltados para o gerenciamento e controle distribuído da manufatura, que surgiu como tentativa de diminuir a complexidade dos sistemas, visando torná-los mais competitivos em um meio ambiente turbulento (LEPIKSON, 1997).

Existem diferentes abordagens e nomes para sistemas de manufatura distribuída que basicamente tratam da mesma idéia: uma rede flexível de cooperação de unidades produtivas autônomas (MEZGÁR \& KOVÁCS, 1998).

Recentemente três linhas de pesquisa nessa área têm chamado atenção: Sistema de Manufatura Holônico, Fábrica Fractal e Sistema de Manufatura Biônico. Esses três conceitos assumem que as mudanças de paradigmas na indústria da manufatura afetarão profundamente o projeto e a operação dos sistemas de fabricação, os quais serão substituídos por estruturas mais inovadoras. A proposta desses conceitos é na direção de conglomerados de unidades distribuídas que operem cooperativamente. A seguir é apresentado um resumo sobre o conceito do sistema de manufatura holônico $(\mathrm{SMH})$.

O conceito do SMH sistema de manufatura holônico vem do termo holon proposto na década de 60 pelo filósofo e autor húngaro Arthur Koestler para descrever a unidade básica de uma organização, seja num sistema biológico ou social (HMS, 2000). Holon significa uma entidade que é ao mesmo tempo o todo (holos, em grego) e parte de um todo (sufixo on significando partícula ou parte). O conceito parte de dois princípios: que um sistema complexo (um produto, por exemplo) evolui mais rápido e 
consistentemente se houverem formas intermediárias estáveis (sub-montagens ou subprocessos).

Atualmente existe um consórcio mundial que lidera as pesquisas feitas em Sistemas Holônicos de Manufatura, o Holonic Manufacturing Systems Consortia (HMSC). Esse consórcio é formado por países da Comunidade Européia, Suíça, Japão, EUA, Canadá e Austrália (HMS, 2000).

A tarefa do HMSC é traduzir os conceitos que Koestler desenvolveu para organizações sociais e organismos vivos em um conjunto de conceitos apropriados para indústrias de manufatura. A meta desse trabalho é atingir na manufatura os benefícios que organizações holônicas provêm a organismos vivos e sociedades, como por exemplo, estabilidade diante às perturbações, adaptabilidade e flexibilidade em face a mudança, e uso eficiente de recursos disponíveis.

Como passo inicial, o consórcio desenvolveu a seguinte lista de definições para ajudar a entender os conceitos holônicos em um ambiente industrial (HMS, 2000):

- Holon: um bloco autônomo e cooperativo de um sistema de manufatura capaz de transformar, transportar, armazenar e/ou validar informações e objetos físicos. O holon consiste de componente de informação e freqüentemente também possui um componente físico. Um holon pode ser parte de outro holon.

- Autonomia: a capacidade de uma entidade de criar e controlar a execução de seu próprio planejamento e/ou estratégias.

- Cooperação: processo pelo qual um conjunto de entidades desenvolve e executa planos mutuamente aceitáveis.

- Holarquia: um sistema de holons que pode cooperar para alcançar uma meta ou objetivo. A holarquia define as regras básicas para cooperação dos holons e também limites de autonomia destes.

- Sistema Holônico de Manufatura: uma holarquia que executa um conjunto de atividades de manufatura, englobando atividades de projeto, planejamento, produção e comercialização, possibilitando a existência de empresas ágeis de manufatura. 
O trabalho do HMSC é desenvolver e unificar os meios de incorporar comportamento holônico em sistemas de manufatura. A intenção é integrar a tecnologia baseada em holons com a capacidade de trabalhadores para aumentar o desempenho de ambos. Capacidades humanas são essenciais para garantir o funcionamento dos conceitos holônicos. Reciprocamente conceitos holônicos ajudarão os trabalhadores a enfocar suas competências permitindo que cada um faça o seu melhor.

A estabilidade a organização holônica advém dos holons serem unidades autosustentáveis, as quais têm um certo grau de independência e lidam com circunstâncias e problemas em seu nível de existência de forma autônoma em relação ao seu nível imediatamente superior. Holons podem também receber instruções de holons de nível superior, e de certa forma também serem controlados por estes. A característica de auto-sustentabilidade garante que os holons sejam estáveis, capazes de suportar distúrbios. A subordinação a holons de nível superior garante a operação efetiva do todo.

Segundo LEPIKSON (1997), essas três linhas de pesquisas possuem pontos em comum, que vão de encontro com as bases para a formação de Empresas Virtuais, sendo estas as seguintes características:

- Simplificação das estruturas produtivas (com implicações, em geral, na diminuição do porte das suas unidades);

- Minimização das atividades que não agregam valor e otimização das que agregam;

- Concentração nas competências essenciais, que passam a ser reconhecidas como elemento estratégico na organização da manufatura;

- Cooperação e autonomia entre as unidades que compõem o sistema.

\subsubsection{Projetos relacionados à Gestão da Produção em Empresas Virtuais}

Foram estudados os principais projetos existentes voltados a Gestão da Produção em Empresas Virtuais. Alguns dos projetos mais representativos são: PRODNET II, PLENT, MASSYVE e X-CITTIC. A seguir será apresentada uma descrição sobre cada um dos projetos. 


\subsubsection{PRODNET II - Production Planning and Management in an Extended Enterprise}

O projeto PRODNET II tem como objetivo principal conceber e desenvolver uma plataforma aberta, com protocolos adequados e mecanismos suportados por tecnologias de informação, que permitam o funcionamento de uma EV (PRODNET, 2000). É um projeto ESPRIT (European Union Information Technologies Program Programa de Tecnologia de Informação da União Européia) formado por parceiros de indústria, softwarehouses e universidades de Alemanha, Brasil, França, Holanda e Portugal.

A FIGURA 16 representa o ciclo de vida de uma EV, proposto no projeto, que inclui as fases: criação, operação, evolução e dissolução (CAMARINHA-MATOS \& AFSARMANESH,1999).

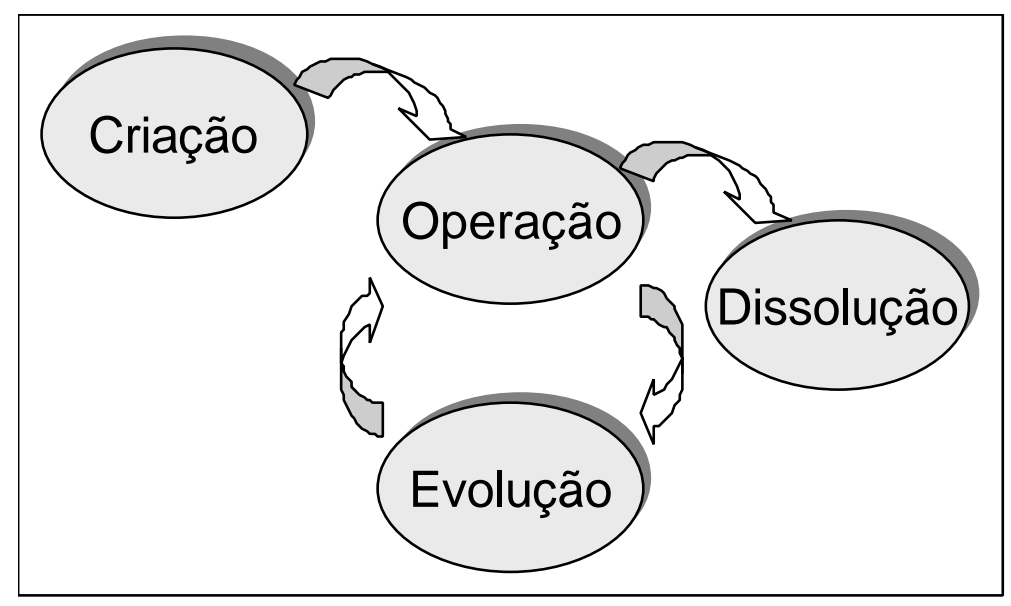

Adaptada de CAMARINHA-MATOS \& AFSARMANESH (1999)

FIGURA 16 - Ciclo de Vida de uma Empresa Virtual - PRODNET II

Uma descrição das atividades de cada fase do ciclo de vida é apresentada abaixo (SPINOSA et al.,1998; CAMARINHA-MATOS \& AFSARMANESH,1999):

- Criação da EV: visa formar um grupo de empresas para realizar um determinado PN. Esta fase é iniciada quando uma EV é criada/configurada e para tal, as principais funcionalidades necessárias são: seleção de parceiro, negociação de contrato, definição de direitos de acesso e nível de compartilhamento, definição de procedimentos de união/separação e configuração. 
- Operação da EV: as ações realizadas pela EV durante sua existência. As funcionalidades necessárias são: mecanismos de intercâmbio de dados, compartilhamento de informação e direitos de visibilidade, planejamento e programação distribuída e dinâmica, gestão das ordens e processamento de ordens incompletas.

- Evolução: pode ser necessário adicionar ou trocar um parceiro durante a operação da EV. Isso pode ocorrer em função de um evento, tal como a incapacidade temporária de um parceiro ou a necessidade de aumentar a carga de trabalho. Funcionalidades similares às especificadas nas fases de criação dão suporte a essa fase.

- Dissolução: a EV finaliza seus PNs e se desfaz. Duas situações podem causar a dissolução da EV, a realização de todos os objetivos com sucesso, ou a decisão dos parceiros envolvidos de interromper a operação da EV. A definição das obrigações de todos os parceiros é um importante aspecto que precisa ser negociado, pois a responsabilidade do fabricante permanece durante todo o ciclo de vida do produto, considerando até sua desmontagem e reciclagem.

Para suportar este ambiente e lidar com os sistemas legados das empresas, o PRODNET II propõe uma infra-estrutura composta por módulos, que são representados na FIGURA 17 e descritos a seguir (CAMARINHA-MATOS \& AFSARMANESH, 1997; KLEN et al., 1999): 


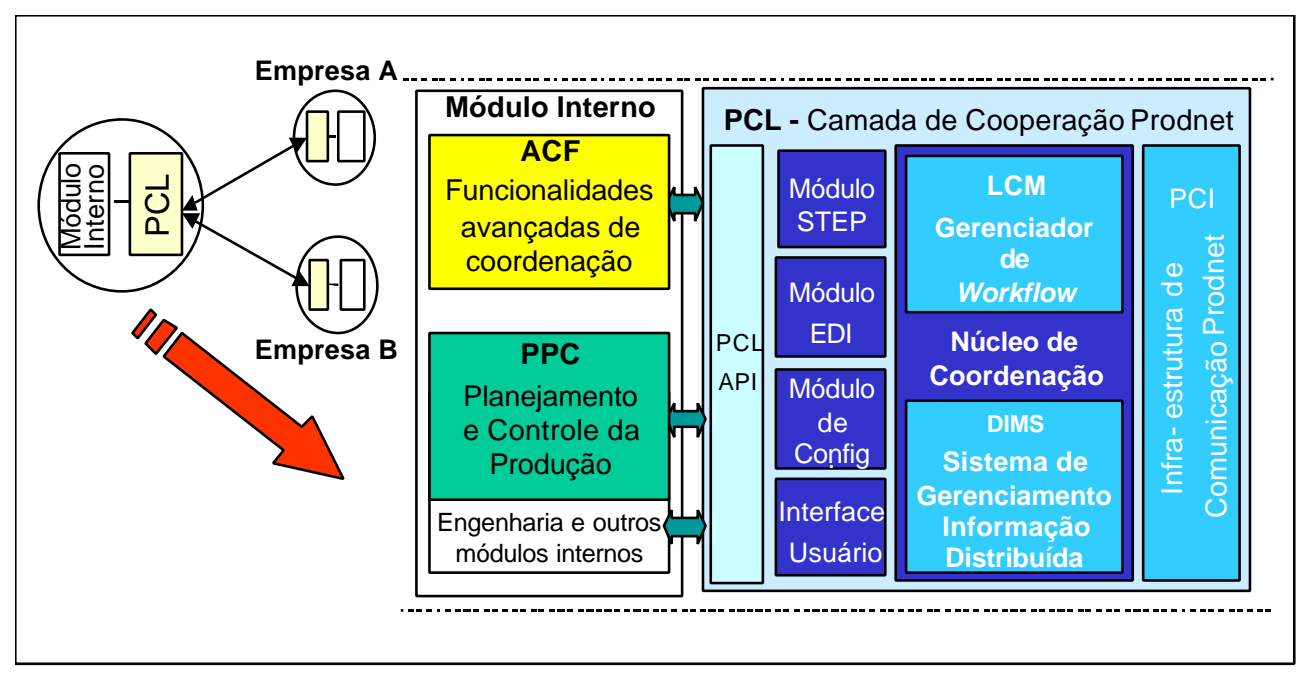

Adaptada de CAMARINHA-MATOS \& AFSARMANESH, 1997

FIGURA 17 - Arquitetura PRODNET-II

Camada de Cooperação (Prodnet Cooperation Layer - PCL): contém todas as funcionalidades para a conexão entre a empresa e os demais participantes da EV. Representa a função de comunicação e coordenação como um interlocutor da empresa com a rede, ou seja, como uma interface recebendo e enviando mensagens da EV). A PCL é composta pelos seguintes módulos:

- Sistema de Gerenciamento de Informação Distribuída (Distributed Information Management System - DIMS): é responsável por modelar e controlar a troca de informações da cooperação, visando preservar a autonomia e privacidade das empresas envolvidas.

- Módulo EDI (Eletronic Data Interchange - Troca Eletrônica de Dados): é responsável por receber e formatar, no formato EDIFACT (um dos possíveis formatos no qual mensagens podem ser trocadas via EDI), as mensagens referentes às ordens.

- Módulo STEP (Standard for the exchange of process and product model data Padrão para troca de dados de processo e produto): sua função é manipular dados técnicos de produtos. Idealmente todos os dados do produto deveriam ser transmitidos no formato STEP. Os serviços providos por este módulo permitem a transmissão e a recepção de arquivos STEP que foram codificados de acordo com um esquema definido. Os dados STEP existentes na arquitetura PRODNET podem 
ser acessados pelo uso de SDAI (Standard Data Access Interface - Interface Padrão de Acesso a Dados), ou por meio de uma interface SQL (Structure Query Language - Linguagem Estruturada de Busca).

- Infra-estrutura de Comunicação (PRODNET Communication Infrastructure PCI): é responsável por coordenar toda a comunicação com os parceiros da rede. Inclui funcionalidades como: seleção de protocolos e canais de comunicação, gerência básica de comunicação, mecanismos de privacidade (criptografia) e canais de comunicação seguros para enviar mensagens entre as empresas.

- Módulo de Configuração e Interface com o Usuário (Configuration and User Interface): a plataforma PRODNET visa suportar uma grande diversidade de empresas e de meios de interconexão. Isso significa uma heterogeneidade em termos de serviços disponíveis e instalados, tal como de procedimentos de gerência. Consequentemente, é necessário especificar o comportamento de cooperação de cada empresa. Assim, cada empresa tem que definir o fluxo de atividades que serão executadas/controladas pelo Módulo de Coordenação Local. Adicionalmente, o componente de configuração permitirá uma especificação da estrutura da EV e das características de participação de todos seus membros. A interface assegura uma relação entre o operador humano, responsável pela as interações com a EV, e o PCL. O nível da intervenção humana neste processo depende da política de cada empresa sendo especificado na fase da configuração.

- Módulo de Coordenação Local (Local Coordination Module - LCM): atua como workflow, é o executor/controlador do fluxo de atividades definidas pelo Módulo de Configuração. É o responsável pelo comportamento do PCL e interage com todos os módulos restantes. Controla todos os eventos da cooperação de acordo com as regras especificadas para cada empresa. Estes eventos têm uma natureza assíncrona e são provocados pelos outros integrantes da EV, pelo módulo interno de cada empresa ou por interface humana.

- Módulo de API (Application Program Interfaces): um componente importante em todo o sistema cooperativo é o conjunto dos protocolos para suportar as interações entre os agentes envolvidos. A arquitetura PRODNET define dois diferentes protocolos para suportar a comunicação tanto com o lado interno da empresa 
quanto com o exterior. São denominados, respectivamente, de PRODNET Internal Communication Protocol (PICP) e PRODNET External Communication Protocol (PECP), constituindo APIs específicas.

Módulo Interno (Internal Module): representa a unidade autônoma de cada empresa, incluindo toda a sua infra-estrutura de informação, como por exemplo, sistemas de planejamento e controle da produção, sistemas de apoio à engenharia sistemas de informação e bases de dados. O Módulo Interno tem os seguintes componentes:

\section{- Funcionalidades Avançadas de Coordenação (Advanced Coordination}

Funcionalities - $\boldsymbol{A C F}$ ): enfoca aspectos de coordenação como procura e seleção de parceiros, e sistema de suporte à decisão para logística integrada que visa fornecer às empresa informações em tempo real sobre o status atual das operações nas empresas envolvidas.

- Planejamento e Controle da Produção (Production Planning and Control PPC): constitui o componente mais importante do Módulo Interno, sendo parte dos sistemas legados de cada empresa pertencente à EV. Inclui as funções de Gerenciamento Logístico (gerenciamento do fluxo de ordens, de dados sobre produtos, de previsão de vendas e planejamento de necessidades), Programa Mestre da Produção, Controle da produção, Controle de qualidade e Custeio.

O projeto PRODNET foi finalizado em setembro de 1999. De acordo com a avaliação oficial, o projeto obteve sucesso tanto nas áreas técnicas e de negócios (PRODNET, 2000).

\subsubsection{MASSYVE - Multi-Agent Agile Manufacturing Scheduling System in Virtual Enterprise Industry \\ O projeto MASSYVE visa investigar o uso de sistemas multi-agente para} programação da produção em um ambiente de EV. Esse projeto é baseado no sistema HOLOS, que utiliza a abordagem multi-agente (RABELO \& CAMARINHA-MATOS, 1995). O sistema é representado por um grupo de agentes configurados para um chão de fábrica específico que processam e trocam informações sobre ordens de produção para gerar, executar e supervisionar a programação (RABELO et al., 1999). No entanto, esse sistema precisa adquirir novas funcionalidades para suportar os 
requisitos de uma EV. Assim, o MASSYVE avaliará os requisitos para esta extensão e realizará alguns desenvolvimentos experimentais considerado as necessidades das PMEs (MASSYVE, 2000).

Um sistema multi-agente é composto por um conjunto de processors, nós em uma rede de recursos de produção, que visam achar uma solução para os problemas de programação. Um processor é considerado um agente quando possui pelo menos as seguintes características (SICHMAN \& DEMAZEAU ${ }^{7}$ apud RABELO et al., 1999):

i) tem um certo grau de autonomia para tomar decisões por si próprio;

ii) tem a capacidade de interagir com outros agentes e

iii) tem o conhecimento para independentemente solucionar parte do problema global.

Considerando o ambiente de EV, algumas características já foram identificadas pelo projeto MASSYVE, tais como (RABELO et al., 1999):

- Cooperar com agentes que não são totalmente cooperativos: apesar de se tratar de uma cooperação, vários níveis de confiança devem ser considerados. Podem existir agentes egoístas (não interessados na otimização global, somente neles) ou ainda destrutivos (empresas concorrentes, que por exemplo, enviam informações erradas de propósito).

- Negociar com informações incompletas ou imprecisas: uma ordem pode ser recebida com dados imprecisos ou incompletos, para serem completados posteriormente.

- Benefícios da programação da EV versus programação individual das empresas: o cenário de EV requer relações mais cooperativas entre os membros, assim faz sentido considerar a programação global da EV (lucros globais) ao invés de um conjunto de programações individuais e independentes.

- Programação concorrente: cada empresa tem sua própria programação. No entanto, dependendo da tarefa a ser executada, cada programação local pode competir com a programação da EV, sem considerar o ganho global.

\footnotetext{
${ }^{7}$ SICHMAN, J.; DEMAZEAU, Y. (1992). When can knowledge-based systems be called agents? In: BRAZILIAN SYMPOSIUM ON ARTIFICIAL INTELLIGENCE, 9..
} 
- Análise de perturbações (mudanças no comportamento): a rede precisa ser constantemente monitorada para garantir a programação e manter o planejamento logístico atualizado. Para isso, os agentes/sistemas têm que ser sensíveis aos problemas e reagir para a solução de tais.

O projeto MASSYVE encontra-se em andamento e ainda não existem muitas publicações disponíveis.

\subsubsection{PLENT - PLanning small-medium Enterprise NeT works}

O objetivo do projeto é desenvolver um conjunto de ferramentas inovadoras para apoiar a coordenação e planejamento de redes de PMEs voltadas a manufaturas. No contexto desse projeto, o problema mais importante não é o estudo de uma técnica sofisticada de apoio a decisão, mas a definição de uma política de planejamento baseada em regras bem definidas, completamente visíveis e aplicáveis (PLENT, 2000).

O PLENT (ESPRIT n. 20723) é realizado por um consórcio de empresas e institutos de pesquisa da Espanha, Hungria, Itália e Grécia (PLENT, 2000). O projeto é subdivido em três principais fases: planejamento da rede; especificação, desenvolvimento e teste do software; e vadiação do sistema. O PLENT enfoca os requisitos para a gestão da produção em redes de PMEs, propondo o seguinte modelo organizacional (MALLIDI et al., 1999):

(i) os nós são empresas autônomas cooperando espontaneamente para atingir um objetivo comum, isto é, produzir e vender juntas um determinado produto;

(ii) cada nó tem basicamente direitos iguais;

(iii) uma unidade neutra de coordenação é estabelecida para planejar e supervisionar a execução das tarefas;

(iv) as decisões da unidade coordenadora são tomadas baseada em um critério transparente.

A operação da rede é suportada por um software de planejamento global e avaliação de desempenho na unidade coordenadora, e por um software de planejamento local em cada nó, para avaliar e confirmar as decisões do planejamento da rede (MALLIDI et al.,1999). 
Outra proposta do projeto é o NOS (network operational scheme), que pode ser traduzido como esquema operacional da rede. De acordo com MEZGÁR \& KOVÁCS (1999), o NOS é utilizado para descrever o processo produtivo de cada EV, definindo a seqüência de todas as etapas de produção e transporte necessárias para obter um determinado produto.

MEZGÁR \& KOVÁCS (1999) comparam as características consideradas para uma EV e a rede proposta no projeto, na TABELA 05. No entanto, segundo MEZGÁR \& KOVÁCS (1999), tendo em mente as distinções citadas, a rede PLENT pode ser considerada um caso especial de EV.

TABELA 05 - Diferenças significativas entre EV e a abordagem PLENT

\begin{tabular}{|l|c|c|}
\hline \multicolumn{1}{|c|}{$\begin{array}{c}\text { Principais } \\
\text { Características }\end{array}$} & $\begin{array}{c}\text { Empresa } \\
\text { Virtual }\end{array}$ & $\begin{array}{c}\text { Rede Cooperativa } \\
\text { de PMEs }\end{array}$ \\
\hline Base para rápida reação & Especialização funcional & Flexibilidade inerente \\
\hline Sistema organizacional & Duplicação de sistema & Preservação de identidade \\
\hline Agregação & Temporária & Estável \\
\hline Coordenação & Local & Global \\
\hline
\end{tabular}

O projeto já foi finalizado, porém não foram encontradas publicações com os resultados finais alcançados.

\subsubsection{X-CITTIC - Planning and Control System for Semiconductor Virtual Enterprises}

Este é um projeto ESPRIT (n. 20544) focado em EVs para o setor de semicondutores, sendo uma parceira de instituições acadêmicas da Alemanha, Inglaterra e Portugal juntamente como empresas de semicondutores e uma especialista em TI (MAKATSORIS et al., 1996). O projeto teve como objetivo o desenvolvimento de uma metodologia e um sistema de informação de apoio ao planejamento da produção de uma rede de empresas geograficamente distribuídas, com as seguintes funcionalidades (INESC PORTO, 2000):

- a negociação das ordens em tempo real, através de uma rápida avaliação da capacidade produtiva ao longo da rede de empresas; 
- planejamento otimizado e sincronizado das atividades das empresas;

- a monitorização do fluxo das ordens de produção e o apoio à tomada de decisões, por forma a garantir o cumprimento dos prazos de entrega.

A infra-estrutura proposta pelo X-CIITTIC consiste dos seguintes componentes (RICHARDS et al., 1997, AZEVEDO et al., 1998):

- Negociação de Ordens (Order Promise): este componente realiza a interação com os clientes, determinando datas de entrega realísticas e alocando as ordens de forma otimizada.

- Planejamento Macro da Capacidade (Rough Planner): este mecanismo é usado para dividir as ordens geradas no módulo anterior em várias sub-ordens, de acordo com a capabilidade das empresas parceiras da EV.

- Planejamento Fino da Programação (Fine Planner Scheduler): é uma aplicação baseada em multi-agentes que otimiza a programação das ordens da EV. Esse módulo utiliza modelos de capacidade que permite a identificação detalhada da capacidade disponível para determinar as datas de inicio e fim de cada ordem.

- Controle Reativo (Reactive Controller): tem a função de minimizar os possíveis impactos causados por atrasos em uma das empresas. O X-CITTIC considera quatro formas de reagir aos imprevistos:

- Replanejamento local: os desvios são minimizados por meio de alterações internas na empresa;

- Replanejamento baseado em negociação: quando só o replanejamento local não garante o atendimento da ordem, as empresas afetadas buscam um novo planejamento por meio de negociação;

- Replanejamento global: um novo planejamento para toda a EV torna-se necessário e os clientes são avisados no caso de alteração na data de entrega;

- Avisos: as empresas são avisadas sobre potenciais conflitos no momento mais cedo possível para que quaisquer ações de controle possam ser realizadas a tempo. 
- Gerenciador de Informação (Information Manager): a rápida transferência de dados entre software descentralizados e heterogêneos necessita de uma infraestrutura de TI apropriada. O X-CITTIC utiliza orientação a objeto e o padrão CORBA (Common Object Request Brokers Architecture) para as suas aplicações distribuídas.

O projeto X-CITTIC já foi finalizado, atingindo os seus objetivos, isto é, criando uma ferramenta de suporte ao planejamento e controle da produção de uma EV. Essa ferramenta foi testada em alguns dos parceiros, no entanto não foram encontrados relatos dessa implementação entre as referências estudadas. 


\section{Proposta de um Modelo de Referência para Planejamento e Controle da Produção em Empresas Virtuais}

Neste capítulo são apresentados os resultados obtidos em cada etapa do trabalho a fim de propor o modelo de referência. Inicialmente, são determinadas as características de EV abordadas no trabalho e as da sua gestão da produção, apresentado um estudo sobre os projetos descritos no tópico 2.2.7 e identificados os processos de regócio de uma Empresa Virtual. Em funções dessas etapas são definidos o escopo e requisitos do modelo de referência. Posteriormente, são determinadas as visões que compõe o modelo, sendo essas a visão de organização, dados, funções e controle.

\subsection{Determinação das Características de Empresa Virtual Abordadas no Trabalho}

Segundo as diversas referências levantadas e apresentadas no texto da revisão bibliográfica, diferentes conceitos de EVs podem ser encontrados, os quais variam em termos de organização, objetivos e princípios operacionais das parcerias.

As características de EV abordadas no trabalho são baseadas na tipologia proposta por BULTJE \& WIJK (2000) no que diz respeito a EVs dinâmicas. Assim, as EVs consideradas no trabalho são aquelas que consistem uma rede dinâmica, de natureza temporária, cujo objetivo da cooperação é atender uma oportunidade específica. Essa EV é estabelecida por pequenas e médias empresas e/ou pequenas unidades autônomas de grandes empresas. Além disso, não há um parceiro principal, o que resulta na igualdade dos parceiros e em uma liderança compartilhada, isto é, cada parceiro controla seus próprios recursos. 
Foi também definido que as EVs surgem de uma OV, segundo o ambiente proposto pelo framework NGV. Essa opção se deve ao fato de que as EVs dinâmicas possuem uma maior probabilidade de sucesso quando existe uma rede de relacionamentos pré-estabelecida, que visa preparar as empresas para cooperarem, como foi exposto por WILDEMAN (1999). É determinado também que essa OV é formada por PMEs voltadas a manufatura ${ }^{8}$.

Quanto ao aspecto de temporariedade, pode ocorrer que uma EV seja criada para explorar uma oportunidade específica, no entanto, continue em operação por um período maior, devido à existência de novos pedidos a serem realizados. Surge então, a necessidade de determinar até quando essa parceria se caracteriza como uma EV.

Para solucionar essa questão é proposto estabelecer um critério para reavaliar a parceria. Esse critério pode ser uma data, um nível de faturamento ou quantidade de produção. A partir do atendimento de um desses critérios deve-se verificar se a EV continua atendendo a suas características. Esses critérios devem estar formalizados no contrato estabelecido entre as empresas durante a configuração da EV.

A partir dessa verificação, podem ocorrer as seguintes situações (FIGURA 18):

- manter a EV com as suas principais características, mesmo que por um período maior que o inicialmente estabelecido;

- criar uma nova empresa focada no nicho de mercado que foi explorado pela EV;

- reconfigurar para uma aliança estável, como por exemplo, uma cadeia de suprimento ou

- dissolver a parceria e consequentemente a EV.

\footnotetext{
${ }^{8}$ A escolha dessas características de EV a ser considerada neste trabalho visa o alinhamento com os demais projetos que estão sendo realizados pelo grupo de Empresas Virtuais do NUMA, cuja pesquisa é focada principalmente neste tipo de EVs.
} 


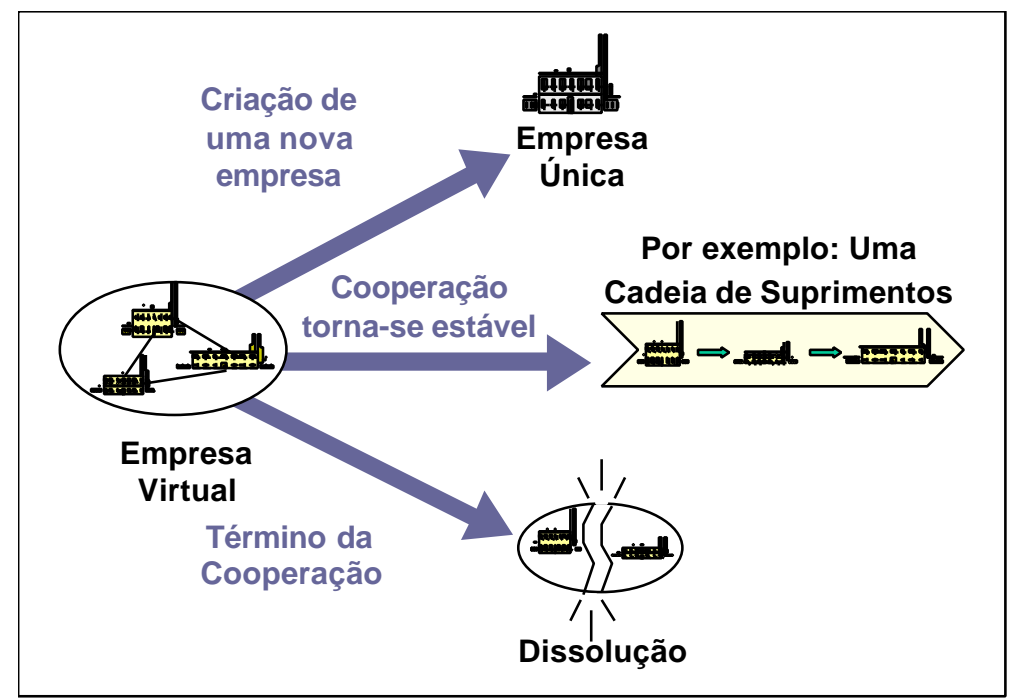

FIGURA 18 - Reconfiguração ou Dissolução da Empresa Virtual

A determinação das características abordadas no trabalho visa delimitar o escopo e possibilitar um maior foco em um tipo definido de EV.

\subsection{Estudo dos Projetos Relacionados à Gestão da Produção em Empresas Virtuais}

Foram estudados os principais projetos existentes voltados à Gestão da Produção em EVs, dos quais foi apresentado um resumo no tópico 2.3.5. Para comparar e analisar os projetos foram estabelecidos alguns aspectos com base nas etapas propostas neste trabalho e em pontos em comum entre os projetos. O estudo dos projetos, em função dos aspectos selecionados, é exposto nas TABELAS 06 e 07. Uma descrição dos aspectos abordados e síntese da comparação é apresentada a seguir. 
TABELA 06 - Estudo dos Projetos Relacionados à Gestão da Produção em Empresas Virtuais (Parte I)

\begin{tabular}{|c|c|c|c|c|}
\hline ASPECTOS & PLENT & X-CITTIC & PRODNET II & MASSYVE \\
\hline Objetivo & $\begin{array}{l}\text { Desenvolver um } \\
\text { conjunto de ferramentas } \\
\text { inovadoras para apoiar a } \\
\text { coordenação e } \\
\text { planejamento de redes } \\
\text { de PMEs voltadas a } \\
\text { manufatura }\end{array}$ & $\begin{array}{l}\text { Desenvolver uma } \\
\text { metodologia e um } \\
\text { sistema de informação } \\
\text { de apoio ao } \\
\text { planejamento da } \\
\text { produção de uma rede } \\
\text { de empresas } \\
\text { geograficamente } \\
\text { distribuídas. }\end{array}$ & $\begin{array}{l}\text { Conceber e desenvolver } \\
\text { uma plataforma aberta, } \\
\text { com protocolos } \\
\text { adequados e } \\
\text { mecanismos suportados } \\
\text { por TI, que permitam o } \\
\text { funcionamento de uma } \\
\text { EV. }\end{array}$ & $\begin{array}{l}\text { Investigar o uso de } \\
\text { sistemas multi-agentes } \\
\text { para programação da } \\
\text { produção em um } \\
\text { ambiente de EVs }\end{array}$ \\
\hline $\begin{array}{l}\text { Período de } \\
\text { Realização }\end{array}$ & \begin{tabular}{|l|} 
Janeiro $1996-$ \\
Julho 1998 \\
\end{tabular} & $\begin{array}{l}\text { Janeiro } 1996- \\
\text { Dezembro } 1998 \\
\end{array}$ & $\begin{array}{l}\text { Outubro } 1996 \text { - } \\
\text { Setembro } 1999 \\
\end{array}$ & $\begin{array}{l}\text { Outubro } 1997 \text { - } \\
\text { Agosto } 2000\end{array}$ \\
\hline $\begin{array}{c}\text { Definição } \\
\text { utilizada de EV }\end{array}$ & \begin{tabular}{|l} 
É uma agregação \\
temporária de diversas \\
empresas orientada a \\
um objetivo. Pode ser \\
considerada uma \\
instanciação prática do \\
paradigma holônico na \\
forma de uma rede \\
aberta e flexível, por \\
meio de reconfigurações \\
contínuas e dinâmicas.
\end{tabular} & $\begin{array}{l}\text { Um conjunto de } \\
\text { empresas que comporta- } \\
\text { se como uma única } \\
\text { empresa por meio de } \\
\text { uma forte coordenação } \\
\text { e cooperação visando } \\
\text { objetivos comuns. }\end{array}$ & $\begin{array}{l}\text { Uma aliança temporária } \\
\text { de empresas que se } \\
\text { unem para compartilhar } \\
\text { habilidades ou } \\
\text { competências essenciais } \\
\text { e recursos a fim de } \\
\text { responder melhor às } \\
\text { oportunidades de } \\
\text { negócios, e cuja } \\
\text { cooperação é suportada } \\
\text { por redes de } \\
\text { computador. }\end{array}$ & $\begin{array}{l}\text { Um grupo de empresas, } \\
\text { fisicamente e } \\
\text { geograficamente } \\
\text { distribuídas, que } \\
\text { precisam cooperar e } \\
\text { trocar informação a fim } \\
\text { de atender uma } \\
\text { oportunidade especifica } \\
\text { de negócios. }\end{array}$ \\
\hline $\begin{array}{l}\text { Exemplo } \\
\text { utilizado }\end{array}$ & $\begin{array}{l}\text { Rede de PMEs voltadas } \\
\text { a agricultura }\end{array}$ & $\begin{array}{l}\text { Fabricação de } \\
\text { semicondutores }\end{array}$ & Fabricação de bicicletas & $\begin{array}{l}\text { Não utiliza um exemplo } \\
\text { específico }\end{array}$ \\
\hline $\begin{array}{l}\text { Escopo do } \\
\text { Projeto }\end{array}$ & $\begin{array}{l}\text { Fase de Operação } \\
\text { (planejamento, } \\
\text { programação e controle } \\
\text { da produção) }\end{array}$ & $\begin{array}{l}\text { Fase de Operação } \\
\text { (recebimento de } \\
\text { pedidos, planejamento, } \\
\text { produção e controle da } \\
\text { produção) }\end{array}$ & $\begin{array}{l}\text { Fase de Formação } \\
\text { (seleção de parceiros, } \\
\text { negociação de contrato } \\
\text { e definição de } \\
\text { procedimentos) Fase } \\
\text { de Operação } \\
\text { (recebimento de } \\
\text { pedidos, planejamento, } \\
\text { programação e controle } \\
\text { da producão) } \\
\end{array}$ & $\begin{array}{l}\text { Fase de Operação } \\
\text { (programaçãa da } \\
\text { produção) }\end{array}$ \\
\hline $\begin{array}{l}\text { Infra-estrutura } \\
\text { de informação }\end{array}$ & $\begin{array}{l}\text { Desenvolveu uma } \\
\text { ferramenta } \\
\text { computacional para } \\
\text { modelar a rede visando } \\
\text { a sua coordenação. }\end{array}$ & $\begin{array}{l}\text { Desenvolveu uma infra- } \\
\text { estrutura para suportar } \\
\text { as atividades descritas } \\
\text { acima. }\end{array}$ & $\begin{array}{l}\text { Desenvolveu uma infra- } \\
\text { estrutura para suportar } \\
\text { as atividades descritas } \\
\text { acima. }\end{array}$ & $\begin{array}{l}\text { Adaptou para o } \\
\text { ambiente de EV, um } \\
\text { sistema multi-agentes } \\
\text { previamente } \\
\text { desenvolvido. }\end{array}$ \\
\hline
\end{tabular}

- Objetivo: visa explicitar o objetivo dos projetos. Pode-se concluir que o enfoque dos projetos é o desenvolvimento de sistemas de informação.

- Período de Realização: os projetos são praticamente contemporâneos, sendo os três primeiros projetos ESPRIT. Os projetos tiveram uma duração média de três anos.

- Definição utilizada de EV: expõe a definição de EV utilizada no projeto. Apesar das pequenas diferenças entre cada definição, dois itens são comuns a todas: um 
grupo (conjunto, agregação ou aliança) de empresas e orientado a um objetivo comum ou oportunidade de negócios. Entre as diferenças pode-se citar ser geograficamente distribuídas, suportadas por rede de computador e pertencer ao paradigma holônico.

- Exemplo utilizado: identifica qual o exemplo de EV utilizado na descrição e/ou implementação do projeto. O PLENT apresenta a aplicação da proposta do projeto em uma rede de PMEs húngaras voltadas a plantação de sementes para extração de óleo. O X-CITTIC é focado no setor de semicondutores e o PRODNET utiliza como exemplo a fabricação de bicicletas, que é o produto de uma das empresas parceiras do projeto. Já o MASSYVE não apresenta um exemplo especifico.

- Escopo do Projeto: considerando-se as etapas do ciclo de vida de EV proposto por GORANSON (1999), identifica as fases e principais atividades abordadas pelo projeto. O PRODNET apresenta-se como o projeto mais abrangente, cujo escopo começa na seleção dos parceiros, passa pela negociação de contrato até a produção do produto. Os demais projetos têm maior enfoque na fase de operação, mais especificamente no planejamento, programação e controle da produção.

- Infra-estrutura de informação: entende-se por infra-estrutura de informação, o conjunto de mecanismos (recursos de software, hardware e tecnologias de informação) usados para criar, gerenciar e transmitir informações na EV. O desenvolvimento de infra-estruturas de informação é o principal foco dos projetos. Tanto o X-CITTIC como o PRODNET desenvolveram infra-estruturas abrangentes para suportar todo o escopo do projeto, tal como apresentadas no tópico 2.3.5. O MASSYVE adaptou para o ambiente de EV, um sistema multi-agentes previamente desenvolvido. Já o PLENT desenvolveu uma ferramenta computacional que possibilita a modelagem das etapas produtivas da rede visando a sua coordenação, sem definir uma infra-estrutura de informação específica. 
TABELA 07 - Estudo dos Projetos Relacionados à Gestão da Produção em Empresas Virtuais (Parte II)

\begin{tabular}{|c|c|c|c|c|}
\hline ASPECTOS & PLENT & X-CITTIC & PRODNET II & MASSYVE \\
\hline $\begin{array}{l}\text { Regras de } \\
\text { cooperação e } \\
\text { coordenação }\end{array}$ & \begin{tabular}{|l|} 
Propõe um modelo \\
organizacional composto \\
por regras de \\
cooperação e \\
coordenacão.
\end{tabular} & Não explicita. & \begin{tabular}{|l} 
Propõe mecanismos \\
para coordenação e \\
define regras para \\
solução de problemas.
\end{tabular} & $\begin{array}{l}\text { Determina aspectos que } \\
\text { devem ser considerados } \\
\text { em relação à } \\
\text { cooperação em EV. }\end{array}$ \\
\hline $\begin{array}{c}\text { Descrição das } \\
\text { Atividades de } \\
\text { Planejamento e } \\
\text { Controle da } \\
\text { Producão }\end{array}$ & $\begin{array}{l}\text { Propõe um método para } \\
\text { modelar e descrever as } \\
\text { etapas dos processos } \\
\text { produtivos de cada EV. }\end{array}$ & $\begin{array}{l}\text { Descreve as } \\
\text { funcionalidades do } \\
\text { sistema. }\end{array}$ & $\begin{array}{l}\text { Descreve as } \\
\text { funcionalidades do } \\
\text { sistema. }\end{array}$ & $\begin{array}{l}\text { Descreve as } \\
\text { funcionalidades do } \\
\text { sistema. }\end{array}$ \\
\hline $\begin{array}{c}\text { Determinação } \\
\text { de Estrutura } \\
\text { Organizacional }\end{array}$ & $\begin{array}{l}\text { Propõe uma unidade } \\
\text { coordenadora neutra. }\end{array}$ & Não propõe & $\begin{array}{l}\text { Propõe que uma } \\
\text { empresa seja a } \\
\text { coordenadora da EV e } \\
\text { existência de um broker } \\
\text { responsável pela busca } \\
\text { de parceiros e criação } \\
\text { da EV. }\end{array}$ & $\begin{array}{l}\text { Os agentes são os } \\
\text { responsáveis pela } \\
\text { tomada de decisões. }\end{array}$ \\
\hline $\begin{array}{l}\text { Número de } \\
\text { referências } \\
\text { utilizadas no } \\
\text { estudo }\end{array}$ & $\begin{array}{l}2 \text { artigos e a home page } \\
\text { do projeto. }\end{array}$ & $\begin{array}{l}13 \text { artigos e a home } \\
\text { page do projeto. }\end{array}$ & $\begin{array}{l}14 \text { artigos e a home } \\
\text { page do projeto. }\end{array}$ & $\begin{array}{l}2 \text { artigos, } 1 \text { relatório } \\
\text { técnico e a home page } \\
\text { do projeto. }\end{array}$ \\
\hline
\end{tabular}

- Regras de cooperação e coordenação: identifica se o projeto propõe regras de cooperação e coordenação. O PLENT lista regras de cooperação e coordenação, citadas no tópico 2.3.5. O MASSYVE determina aspectos que devem ser considerados em relação à cooperação em EV para levantar os requisitos para o desenvolvimento do seu sistema. O PRODNET possibilita a criação de mecanismos para coordenação e definição de regras para solução de problemas ao configurar o sistema para cada EV. O X-CITTIC não explicita o uso de regras de cooperação e coordenação.

- Descrição das Atividades de Planejamento e Controle da Produção: os projetos X-CITTIC, PRODNET e MASSYVE descrevem as funcionalidades desenvolvidas para o planejamento e controle da produção. Não há uma descrição das atividades de forma independente dos sistemas de informação. O PLENT visa a descrição das atividades para cada rede, porém não propõe um modelo genérico.

- Determinação de Estrutura Organizacional: verifica a existência de uma descrição quanto a estrutura organizacional e respectivos papeis e responsabilidades dentro da EV. O PLENT propõe uma unidade coordenadora neutra responsável por planejar e supervisionar a execução das tarefas da EV. O 
PRODNET sugere que uma empresa das empresas parceiras seja a coordenadora e existência de um broker responsável pela busca de parceiros e criação da EV. No MASSYVE, os agentes são os responsáveis pela tomada de decisões, não havendo uma descrição de outras funções. O X-CITTIC não explicita nenhuma estrutura organizacional.

- Número de referências utilizadas no estudo: este não é o valor total de referências existentes, mas o número que foi encontrado durante a pesquisa bibliográfica por meio de pesquisas em base de dados de referência, sites de busca na Internet e nos próprias home pages dos projetos. Pode-se identificar que houve um amplo acesso às referências dos projetos PRODNET e X-CITTIC, já para os outros, as informações disponíveis foram em menor quantidade.

\subsection{Determinação das Características da Gestão da Produção em Empresas Virtuais}

Baseado nas características de EV adotadas neste trabalho, nos projetos anteriormente estudados, nas atividades a serem normalmente executadas no PCP em empresas de manufatura, pode-se citar as seguintes características como as de maior relevância para a gestão da produção em EVs:

- cooperação entre as empresas;

- necessidade de coordenação;

- existência de duas dimensões de planejamento;

- planejamento para oportunidades específicas e

- necessidade de troca de informações.

A seguir, para cada uma dessas caraterísticas, são descritos os fatos e questões que as tornam importantes para a gestão da produção em EVs, e posteriormente quais são as propostas definidas para abordá-las nesse trabalho. 


\subsubsection{Cooperação entre as Empresas}

Para que a EV tenha sucesso, as empresas precisam cooperar, isto é, participar de forma colaborativa a fim de atingir os objetivos comuns do grupo. EVERSHEIM et al. (1997) apresenta que a palavra cooperação tem como origem cooperatio do latim, significando a interação entre ou a união no desempenho de tarefas.

Apesar da forte necessidade de cooperação, as empresas parceiras da EV podem não agir de maneira totalmente cooperativa, pois cada empresa tem seus próprios objetivos e prioridades, que muitas vezes são concorrentes com o objetivo comum do grupo. Além disso, cada empresa possui um comportamento próprio, tal como regras particulares de conduta, o que pode acarretar em uma certa dificuldade de integração e consequentemente cooperação. É preciso, então, que o objetivo da EV esteja claro para todas as empresas parceiras, estando de acordo com o objetivo estabelecido e conscientes de suas responsabilidades para que possam realmente cooperar.

No entanto, segundo BYRNE (1993), antes das empresas poderem mais facilmente dedicar-se a cooperações, essas devem construir um alto nível de confiança entre si. Assim, como principal proposta para abordar esta característica, sugere-se a criação de uma OV visando o estabelecimento de uma cultura de cooperação e confiança. Como possíveis mecanismos para aumentar a cooperação e confiança entre as empresas, pode-se promover reuniões formais e informais, visitas nas empresas, dinâmicas de grupo, simulações de situações hipotéticas, desenvolvimento conjunto da estratégia do grupo.

Outra proposta é que cada OV defina suas próprias regras de cooperação. Essas regras podem variar em detalhes para cada $\mathrm{EV}$, mas algumas podem ser definidas como fundamentais. Assim, durante a sua fase de configuração, cada EV deve adaptar as regras de cooperação para as suas necessidades. Como exemplo, WIENDAHL \& HÖBIG (1998) propõem um conjunto de regras para cooperação em redes de produção, como as exemplificadas a seguir:

- compreensão de todos os parceiros sobre os objetivos da rede é fundamental;

- toda informação transmitida entre os parceiros deve atender aos objetivos de rede; 
- o parceiro que ocasionar algum problema relativo à execução das ordens de produção tem a responsabilidade sobre tais problemas, que não deve acarretar em nenhuma responsabilidade sobre outro parceiro da rede;

- a otimização de toda a rede tem prioridade sobre a otimização de um único processo ou de um único parceiro;

- todo parceiro concorda em seguir as instruções do coordenador.

Além disso, a OV pode desenvolver um sistema de medidas de desempenho para avaliar a participação das EPs e como essas têm se comportado no que tange as questões de cooperação na EV. Esta avaliação de desempenho pode servir de base para a seleção de EPs em futuras EVs.

\subsubsection{Necessidade de Coordenação}

Para uma efetiva cooperação é necessário haver coordenação e a coordenação da EV depende do grau de cooperação e confiança atingido pelas empresas. Assim, pode-se dizer que essas duas caraterísticas dependem uma da outra.

De acordo com CAMARINHA-MATOS \& LIMA (1999), a coordenação é necessária para prevenir uma anarquia ou ineficiência. A coordenação consiste em gerenciar o planejamento e execução de um conjunto de atividades e suas respectivas interdependências visando alcançar uma meta. Sendo os parceiros da EV responsáveis por diferentes partes do produto a serem desenvolvidas ou fabricadas, a questão da coordenação entre as empresas é fundamental.

Apesar da proposta da EV ser a formação de uma estrutura não hierárquica, é necessário considerar a existência de uma unidade coordenadora que concentre as informações, proponha soluções e intermedie eventuais conflitos. Essa unidade coordenadora não é necessariamente uma empresa, mas uma função que pode ser exercida por um profissional, uma equipe ou um sistema especialista que atenda os requisitos necessários para a função.

Devido à necessidade de uma unidade coordenadora, é proposta a existência de um Coordenador e um Time de Gestão da Produção da EV com funções previamente definidas. Essas funções e respectivos papéis são descritos no tópico 3.7 que 
apresenta a visão organizacional do modelo. Para a definição do perfil dessa função, BYRNE (1993) sugere que uma EV demande um conjunto de habilidades de "gerentes" que terão que construir relacionamentos, negociar acordos "ganha-ganha", achar parceiros adequados com objetivos e valores compatíveis e ainda saber balancear a liberdade e controle nessas organizações temporárias.

A fim de auxiliar a coordenação da EV, uma ferramenta que pode ser utilizada, no que diz respeito à gestão da produção, é o modelo de referência proposto nesse trabalho. O modelo possibilita uma visão de como o processo será realizado, deixando explícitas as atividades e responsabilidades de cada participante. O modelo também serve como uma base comum para discussão sobre como a EV deve operar, sendo então adaptado para as necessidades requeridas.

Algumas ferramentas computacionais também podem ser empregadas para dar suporte a coordenação, tais como, sistemas de gerenciamento de fluxo de trabalho, sistemas $\mathrm{CSCW}^{9}$ (Computer-Supported Co-operative Work - Trabalho Cooperativo Suportado por Computador), além de sistemas de informações utilizados durante a operação da EV.

\subsubsection{Existência de duas Dimensões de Planejamento}

Uma EV deve operar como uma empresa única, porém ter a intenção de controlar todas as atividades das EPs envolvidas é uma questão complexa que pode não agregar valor ao resultado final.

Considerando a existência de uma unidade coordenadora, uma forma adequada para o PCP de uma EV é o planejamento distribuído com coordenação. Assim, para o planejamento dentro do ambiente de EV foi adotada a abordagem de dividir o processo de planejamento em duas dimensões: planejamento da EV e a inserção do planejamento nas empresas parceiras, conforme FIGURA 19.

\footnotetext{
${ }^{9}$ Ver dissertação de mestrado de Ana Paula Freitas Mundim "Proposta de um Ambiente Cooperativo Suportado por Computador para a Participação de Pequenas e Médias Empresas em Organizações Virtuais" apresentada à Escola de Engenharia de São Carlos da Universidade de São Paulo.
} 


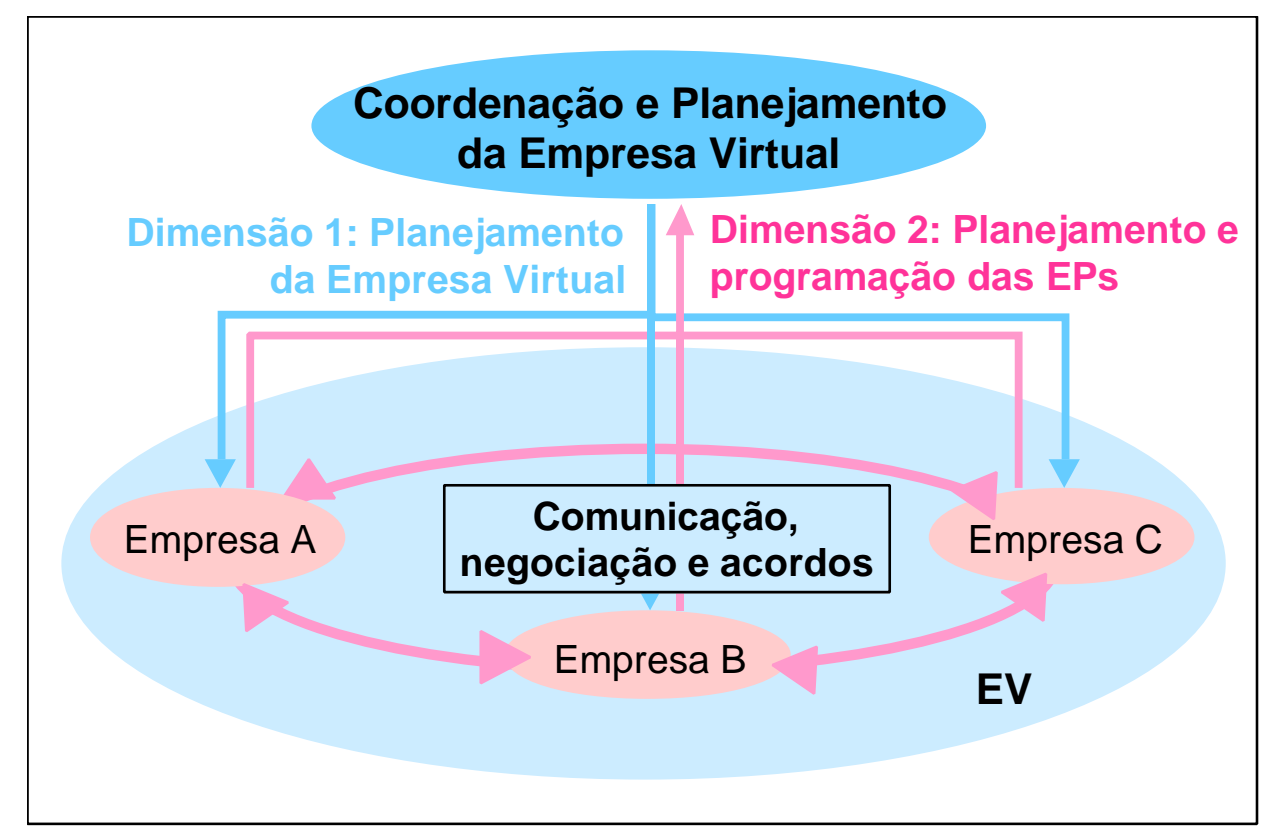

FIGURA 19 - Duas dimensões de planejamento

A primeira dimensão preocupa-se com a coordenação das várias partes da EV assim como seus resultados. Nessa dimensão são coletadas e sistematizadas as informações necessárias para propor o planejamento que estabelece as quantidades, prazos a serem atendidos e as ordens de responsabilidade de cada uma das empresas. Para tal planejamento, é necessário considerar a capacidade e restrições das empresas. Ainda nesta etapa, há uma validação do planejamento proposto junto às empresas parceiras para que cada parceiro possa trabalhar para atingir as metas estabelecidas.

Na segunda dimensão, o planejamento da EV deve ser inserido no planejamento de cada uma das empresas parceiras. Torna-se necessário determinar a programação detalhada das empresas a fim de cumprir o planejamento da EV. Nesta fase, deve-se buscar a melhor maneira de gerenciar possíveis conflitos advindos de superposições ou alterações dos programas de produção.

As atividades que compõe tanto a primeira como a segunda dimensão estão descritas e detalhadas na visão de funções no tópico 3.10 . 


\subsubsection{Planejamento para Oportunidades Específicas}

Dadas as características das EVs, observa-se que a sua criação visa atender a oportunidades específicas e às vezes únicas, onde ocorre um planejamento de curto prazo e fazem-se necessárias rápidas tomadas de decisão buscando um menor tempo de resposta ao mercado.

As EVs são normalmente orientadas a pedidos, onde a produção é executada mediante a existência de pedido. Uma EV pode ser criada para atender a um único pedido, fazendo com que o planejamento tome um caráter mais de gerenciamento de projeto do que planejamento da produção, tal como em uma ambiente ETO. Mas uma EV também pode atender a vários pedidos, e consequentemente planejar diversos lotes de produção. Dependendo do número de pedidos ou lotes a serem produzidos, diferentes aspectos podem ser abordados.

Por ser uma oportunidade nova, não há dados históricos, o que de certa forma dificulta a acuracidade dados, como também, tentativas de otimização. Outro problema reside no planejamento de capacidade da $E V$, pois as empresas envolvidas não trabalham exclusivamente para a EV, de forma que se deve considerar a capacidade disponível de todas as empresas para a determinação da capacidade da EV.

\subsubsection{Necessidade de Troca de Informações}

Segundo CAMARINHA-MATOS \& AFSARMANESH (1998), as empresas envolvidas em uma EV precisam compartilhar e trocar informações para atingir os objetivos comuns desta parceria e possibilitar a execução de suas funções como uma única organização. A necessidade de um fluxo eficiente de informações, assim como o de materiais, entre as empresas é um fator crítico para o sucesso da EV. Pode-se dizer que o fluxo de informações determina o fluxo de materiais, pois transmite as necessidades e prazos para a produção. A unidade coordenadora, assim como toda a $E V$, precisa de informações corretas e constantemente atualizadas sobre 0 planejamento, status das ordens, capacidade e desempenho em cada empresa.

Normalmente, cada empresa parceira desenvolveu e/ou usa diferentes sistemas de informação de acordo com suas necessidades. Essa situação pode acarretar em 
uma diversidade de sistemas de PCP, usualmente não propícios a conexões com outros sistemas fora da empresa.

Já existem alguns software que visam atender a cooperações possibilitando um planejamento colaborativo da produção, tal como os sistemas APS (Advanced Planning and Scheduling - Planejamento e Sequenciamento Avançado). Os sistemas APS são voltados a otimização dos processos de uma cadeia de suprimentos, isto é, cooperações mais estáveis. Segundo um relatório da AMR (1998), devido a tendência das empresas necessitarem de tecnologias para o planejamento de cadeia de suprimentos, o mercado de APS tem crescido consideravelmente. Esse relatório cita alguns fornecedores dessas soluções, tais como, Manugistics, i2 Technologies e Logitily e também os fornecedores de ERP, como SAP, Peoplesoft, Baan e J. D. Edwards, que estão desenvolvendo funcionalidades de otimização ou gerando parcerias para suprir esta necessidade. No entanto, o custo de compra e implementação dessas soluções ainda é muito alto.

Uma outra tendência emergente de uso de tecnologia de informação dentro e entre empresas, é o conceito de ASP (Application Service Provider - Provedor de Serviços de Aplicativos). Segundo PROMON IP (2000), o ASP é um novo modelo de negócio que possibilita às empresas obterem uma rápida e segura implantação de soluções com baixo investimento inicial. O ASP parte da premissa que o software não é um produto e sim um serviço e que o hardware desse aplicativo não precisa estar no interior da empresa e ainda cabendo à consultoria gerenciar o aplicativo, não apenas implementá-lo (PROMON IP, 2000). A empresa paga uma taxa mensal pela utilização do aplicativo, ao invés de despender recursos na compra do software, hardware, implementação e manutenção. Ainda em PROMON IP (2000), aplicações de todo tipo vêm sendo disponibilizadas através desse modelo, como: E-commerce, CRM (Customer Relationship Management), ERP (Enterprise Resource Planning), SCM (Supply Chain Management) e outras. O instituto Gartner Group apresenta que com o mercado de ASP, surge a necessidade de uma nova arquitetura para "WEB native software", isto é, software que existam apenas na Internet e possibilitam a realização de negócios entre as empresas (GARTNER, 2000). Essa mesma fonte prevê que em três anos essa será a principal forma de implantação de aplicativos nas empresas, 
especialmente graças ao crescimento vertiginoso da Internet e redução crescente dos custos para transmissão de dados.

Entre os projetos voltados a gestão da produção em EVs, o desenvolvimento de infra-estruturas de informação tem sido o principal objeto de estudo, como foi apresentado no tópico 3.2. CAMARINHA-MATOS (1997) cita que como requisito básico para uma infra-estrutura de informação suportar EVs, essa deve possibilitar a interoperabilidade e intercâmbio de informações em tempo real de forma que as empresas possam trabalhar como uma unidade integrada mantendo sua independência e autonomia.

Apesar da necessidade de integrar as informações, o custo associado ao desenvolvimento de interfaces ou seleção de soluções apropriadas para EV, assim como a implementação e treinamento, podem não compensar os benefícios, sendo necessária uma análise custo-benefício para tal conclusão. Esse aspecto torna-se mais crítico devido ao fato da EV ser uma oportunidade específica.

Assim, antes de propor uma infra-estrutura de informação para integrar as empresa é preciso levantar a situação atual de disponibilidade de TI de cada EP para então, avaliar as necessidade da EV e selecionar uma infra-estrutura adequada que seja condizente com a realidade das empresas parceiras.

MICHILINI (2000) propõe uma infra-estrutura de informação mínima e obrigatória, e outra recomendada para o suporte de OVs e EVs. A infra-estrutura mínima consiste apenas de tecnologias consideradas essenciais para que as empresas trabalhem de forma cooperativa sendo composta, basicamente, por tecnologias disponíveis pela Internet. Já a infra-estrutura recomendada inclui, além das tecnologias da infraestrutura mínima, um conjunto de padrões que procuram satisfazer as necessidades do ciclo de vida de uma EV, tais como, STEP, CORBA e EDI.

Outras questões que devem ser discutidas quanto à necessidade de troca de informações diz respeito ao grau de detalhamento e as regras de disponibilização e atualização dos dados.

Quanto ao grau de detalhamento dos dados, deve-se identificar um nível apropriado de forma a proporcionar a coordenação das atividades de cada empresa, e consequentemente da EV sem que haja uma grande quantidade de informações que 
são desnecessárias ao PCP da EV. Considerando a divisão do planejamento em duas dimensões, pode ser definido um nível de detalhamento mais abstrato para o planejamento da EV, isto é, informações sobre prazos, quantidades e capacidade macro. Já no nível da EP, utiliza-se um nível mais detalhado considerando as ordens e operações a serem alocadas a recursos específicos dentro da empresa. Vale ressaltar que cada uma das empresas parceiras pode ter um sistema de gestão próprio, que possibilita a sua programação de chão-de-fábrica detalhada e atualizada.

Também é preciso estabelecer regras para garantir o comprometimento das EPs quanto a veracidade e freqüência de atualização dos dados. Por exemplo, pode-se definir que caso esteja rodando uma ordem de produção, a EP responsável deve informar a cada intervalo de tempo estabelecido, o status das ordens para a unidade coordenadora, a fim de identificar potenciais desvios do planejamento o mais cedo possível para que ações de controle possam ser realizadas a tempo. Outra regra poderia ser o tempo máximo de resposta para informações solicitadas pela EV. O desempenho quanto ao cumprimento dessas regras deve ser analisado e armazenado na base de dados da OV.

As questões de detalhamento, atualização, confidencialidade e segurança na troca de informações entre as empresas, precisam ser estabelecidas ao configurar a EV.

A definição dessas características da gestão da produção juntamente como a identificação dos processos de negócio de uma EV geram o escopo e os requisitos a serem atendidos pelo modelo. A seguir, são apresentados os processos de negócios de uma EV.

\subsection{Identificação dos Processos de Negócio de uma Empresa Virtual}

Esta etapa visa identificar os processos de negócio envolvidos na operação de uma EV considerando o ciclo de vida proposto por GORANSON (1999) e baseando-se na classificação de processos de negócio proposta pela APQC.

GORANSON (1999) propõe as seguintes etapas para o ciclo de vida de uma EV, como representado na FIGURA 20: 


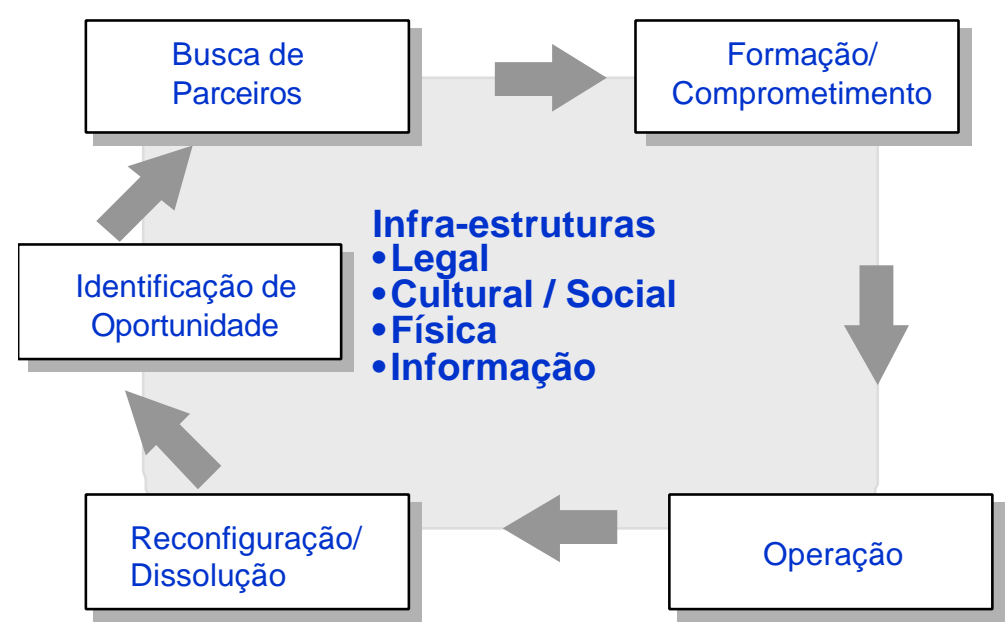

Adaptada de GORANSON (1999)

FIGURA 20 - Ciclo de Vida de uma Empresa Virtual

Não há uma descrição clara dos processos de negócio de uma EV na fase de operação. Para melhor detalhar a fase de operação foi adotado o modelo de referência desenvolvido pela APQC que fornece uma visão ampla e genérica dos processos de negócio geralmente encontrados em diferentes empresas e setores (APQC, 1998). Os processos propostos pela APQC foram apresentados anteriormente no tópico 2.1.1.

Dos processos propostos pela APQC nem todos são de responsabilidade da EV, sendo alguns de responsabilidade do GVI ou do AEV, ao considerar o framework NGV. Os processos relacionados a serviços foram desconsiderados nessa análise, pois o foco do trabalho é as empresas voltadas a manufatura. A designação dos processos operacionais às entidades responsáveis é representada na TABELA 08.

TABELA 08 - Processos Operacionais

\begin{tabular}{|l|c|c|c|}
\cline { 2 - 3 } \multicolumn{1}{c|}{} & \multicolumn{2}{c|}{ OV } & \multirow{2}{*}{ EV } \\
\hline Processos Operacionais & GVI & AEV & \\
\hline Compreender as Necessidades do Mercado e Clientes & & $\mathbf{x}$ & \\
\hline Desenvolver Visão e Estratégia & $\mathbf{X}$ & $\mathbf{x}$ & \\
\hline Desenvolver Produtos & & & $\mathbf{x}$ \\
\hline Realizar Marketing e Vender & & & $\mathbf{x}$ \\
\hline Produzir e Entregar & & & $\mathbf{x}$ \\
\hline Faturar e Prestar Assistência & & & $\mathbf{x}$ \\
\hline
\end{tabular}


Dos processos realizados pela EV, pode-se dividir a responsabilidade entre a Empresa Líder (EL) que faz a interface com o cliente e as Empresas Parceiras (EP) da EV. Assim, é proposta a seguinte divisão apresentada na TABELA 09.

TABELA 09 - Processos Operacionais da EV

\begin{tabular}{|l|c|c|}
\cline { 2 - 3 } \multicolumn{1}{c|}{} & \multicolumn{2}{c|}{ EV } \\
\hline Processos Operacionais da EV & EL & EP \\
\hline Resenvolver Produtos & $\mathbf{x}$ & $\mathbf{x}$ \\
\hline Vendizar Marketing & $\mathbf{x}$ & \\
\hline Produzir & $\mathbf{x}$ & \\
\hline Entregar & $\mathbf{x}$ & $\mathbf{x}$ \\
\hline Faturar & $\mathbf{x}$ & \\
\hline Prestar Assistência & $\mathbf{x}$ & \\
\hline
\end{tabular}

A seguir é descrito o que se compreende por cada um dos processos:

\section{Compreender as Necessidades do Mercado e Clientes}

Segundo a APQC, este processo compreende as atividades de determinar as necessidades dos clientes, acompanhar as mudanças nos mercados e nas expectativas dos clientes, assim como monitorar a sua satisfação.

Esse processo, no ambiente NGV, é de responsabilidade do AEV, que tem como função buscar oportunidades de negócio para a OV visando a formação de EVs. As oportunidades de negócio podem ser de dois tipos:

- interna, quando o AEV constata na OV uma potencial oportunidade de mercado a ser explorada, com base nas competências já detidas pelo grupo, ou

- externa, quando a oportunidade é trazida pelo AEV em função das necessidades de um cliente específico.

\section{Desenvolver Visão e Estratégia}

Este processo, segundo a APQC, diz respeito a monitorar o ambiente externo, analisando e entendendo a competição, identificando tendências econômicas e acesso a novas tecnologias. Também envolve a definição da estratégia organizacional, seleção dos mercados relevantes, desenvolvimento de uma visão de longo prazo e de metas da organização. 
Quando um GVI é formado, define-se a estratégia do grupo, tal como o seu foco. Por foco, entende-se determinar o setor de atuação, a abrangência geográfica e as competências das empresas. A estratégia do grupo juntamente com a estratégia do AEV determina as prioridades e metas quanto à busca de oportunidades.

\section{Desenvolver Produtos}

No processo de Desenvolver Produtos, as necessidades e desejos dos clientes são transformados em produto. Em uma EV, independente se a oportunidade é interna ou externa, pode haver dois tipos de produto:

- novo produto, sendo necessário o processo de desenvolvimento de produto;

- produto já existente, onde ao invés do desenvolvimento do produto, pode haver apenas adaptação do projeto para a produção.

$\mathrm{Na}$ fase de desenvolvimento do produto são determinadas as especificações técnicas tais como a estrutura do produto, quais materiais serão comprados ou produzidos e os roteiros de produção, sendo então geradas algumas das informações necessárias para a gestão da produção.

\section{Realizar Marketing}

Segundo a APQC, este processo envolve desenvolver estratégia de preços e propaganda, identificar clientes alvos específicos, elaborar previsão de vendas e negociar termos de contrato.

Este processo também ocorre no GVI visando expor em conjunto as competências das empresas membro a fim de buscar oportunidades de negócios.

\section{Vender}

A EL, sendo responsável pelo relacionamento com o cliente, tem como função realizar o processo Vender que corresponde a entrada dos pedidos dos clientes e a sua transmissão para o processo Produzir.

\section{Produzir}

Segundo a APQC, o processo Produzir é responsável por planejar e adquirir os recursos necessários a fim de converter inputs em produtos. O detalhamento do processo Produzir para EV é o resultado final desse trabalho de mestrado. 


\section{Entregar}

Entende-se por este processo a entrega do produto final, não incluindo o transporte entre as EPs durante a fase de produção. A EL é a responsável formal, mas a entrega pode ser realizada por uma firma especializada ou ainda ser designada a outra EP. O processo Entregar considera também as atividades de instalação do produto e confirmação das especificações dos requisitos do cliente.

\section{Faturar}

A EL é a empresa que emite a nota fiscal do produto sendo também responsável pelo recebimento do faturamento. $O$ valor recebido é divido segundo as regras estabelecidas na configuração da EV.

\section{Prestar Assistência}

Este processo abrange o serviço de pós-venda, assim como o atendimento de reclamações e garantias. Mesmo havendo a dissolução da EV, continua existindo a responsabilidade durante todo o ciclo de vida do produto. Entende-se que quando houver a necessidade de prestar assistência, o cliente deve entrar em contato com a EL, que deve analisar os requerimentos do cliente, podendo ocorrer duas situações:

- requerimento diz respeito a uma parte do produto que é de responsabilidade de apenas um EP, sendo então transmitido à EP responsável.

- necessidade de assistência envolve todo o produto, sendo preciso reconfigurar de novo a EV para atender o cliente.

Foram identificados os processos operacionais que podem ser realizados por uma EV. Os processos de suporte e gerenciamento, tais como Gerenciar Recursos Humanos e Gerenciar Melhorias e Mudanças, devem ser realizados de forma individual por cada uma das EPs.

Uma descrição dos processos do GVI e AEV tem sido realizada em um trabalho conjunto dos participantes do grupo de Empresas Virtuais do NUMA. Esses processos são apresentados no ANEXO A, porém em um maior macro de detalhamento. 


\subsection{Determinação do Escopo e Requisitos do Modelo de Referência}

Para determinar o escopo do modelo de referência são inicialmente consideradas as atividades tradicionalmente executadas no PCP. Essas podem ser divididas em diferentes níveis de planejamento: longo, médio e curto prazo, como na FIGURA 21. Sendo abordadas nesse trabalho as EVs dinâmicas, temporárias e oportunistas, o enfoque é o planejamento de curto prazo, englobando principalmente as atividades de Planejamento das Necessidades de Materiais, Programação da Produção e Controle da Produção. As atividades de Planejamento e Controle da Capacidade assim como de Controle de Estoques também são consideradas porém com um enfoque menor, pois essas dizem respeito mais ao PCP interno das EPs do que ao planejamento da EV.

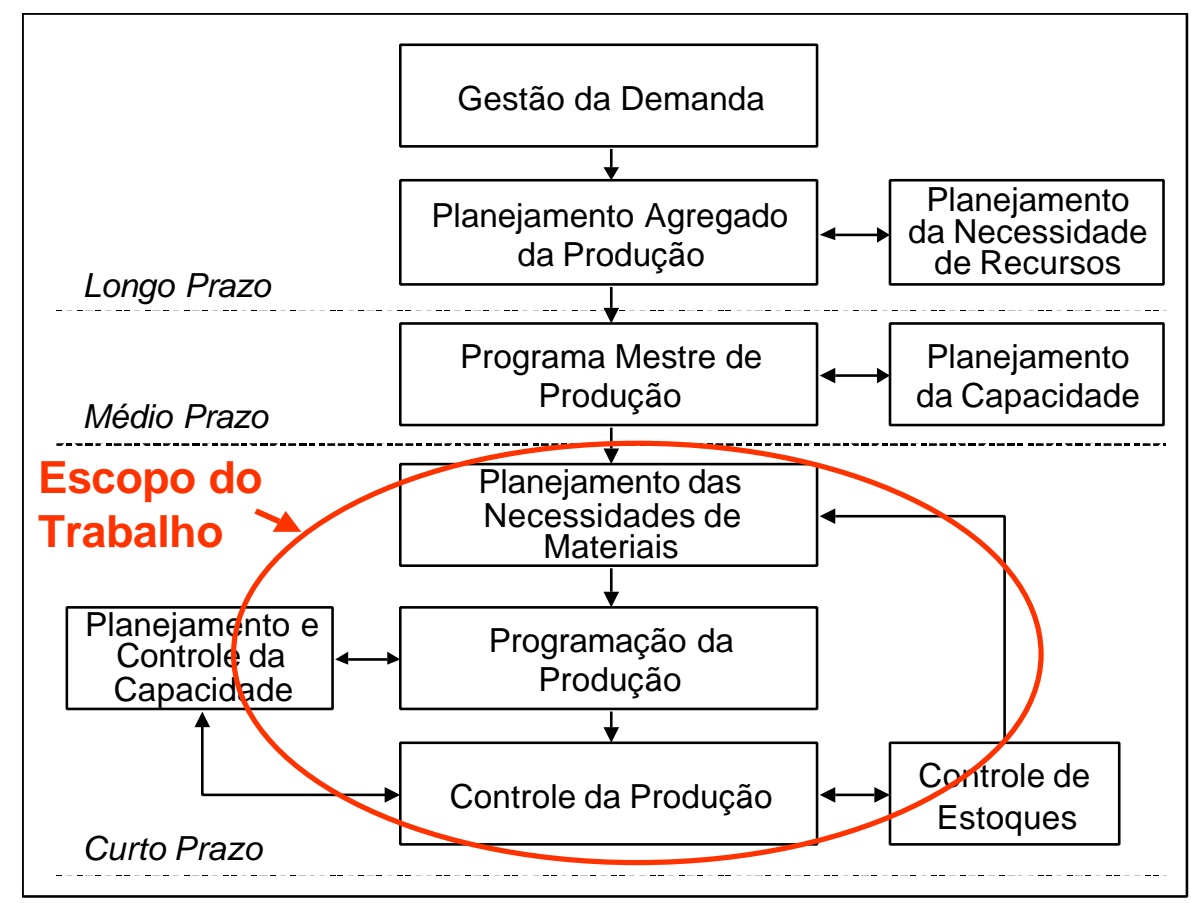

FIGURA 21 - Escopo de Atividades do PCP abordado no Modelo

Considerando os processos de negócio identificados na fase de operação de uma EV, como fronteiras do processo Produzir, que é detalhado no modelo, fica definido que se inicia a partir da existência de um pedido advindo do processo Vender e quando a especificação técnica, originada no processo Desenvolver Produto, já esteja disponível. O processo Produzir termina quando a fabricação do produto final da EV é finalizada e posteriormente entregue ao cliente. Durante o processo Produzir, 
cada empresa parceira gera as suas necessidades de compras de acordo com o planejamento da EV. A FIGURA 22 ilustra o relacionamento entre esses processos.

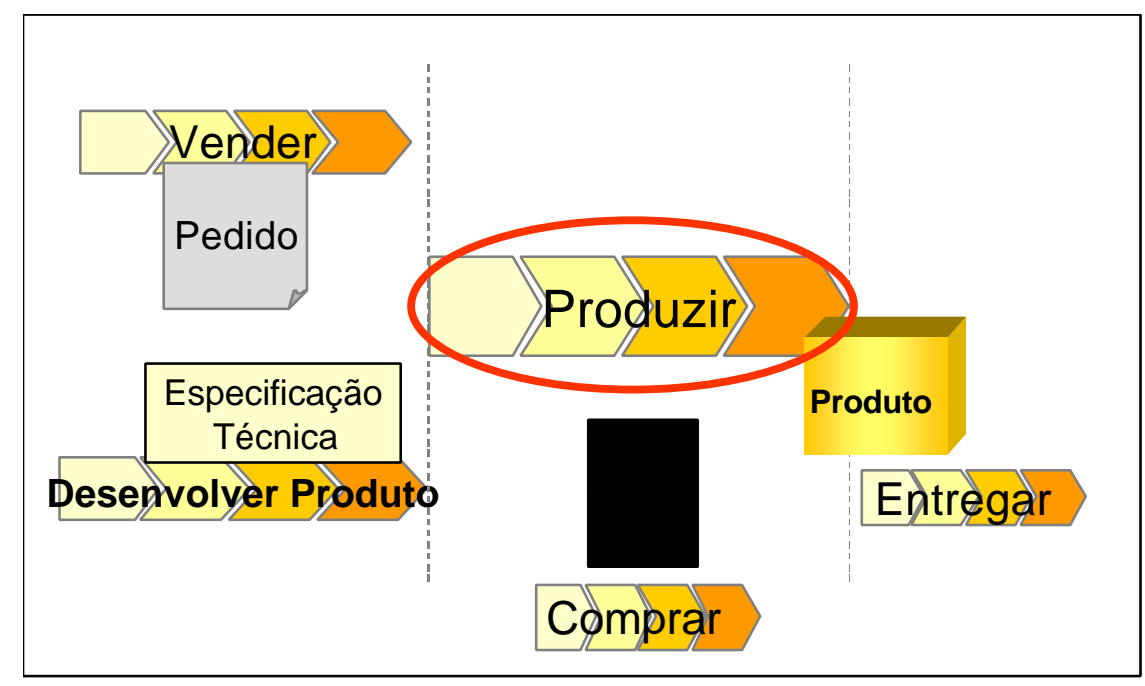

FIGURA 22 - Escopo do Processo Produzir

É determinado também que as EVs, nesse trabalho, operam em um ambiente orientado aos pedidos dos clientes, não havendo produção para estoque. Também é considerado que cada EV é voltada a uma oportunidade específica, isto é, produz apenas um tipo de produto por vez, contudo pode haver variações e diferentes configurações do produto.

Entre as prioridades competitivas da manufatura: custo, qualidade, desempenho das entregas e flexibilidade, este trabalho irá focar nas duas últimas prioridades. As questões de custo e qualidade não serão abordadas na elaboração do modelo.

Uma vez definido o escopo do modelo e as características a serem atendidas na gestão da produção da EV descritas anteriormente, os seguintes requisitos foram definidos para o desenvolvimento do modelo de referência:

- Propiciar a coordenação das atividades de planejamento da EV: o objetivo do modelo é propor como coordenar as atividades de PCP dentro da EV. É considerada a existência de uma unidade coordenadora e a divisão do planejamento em duas dimensões. A primeira dimensão trata da coordenação das atividades e do planejamento da EV e a segunda consiste da inserção do planejamento da EV nas EPs e de sua programação e controle. Não serão 
determinadas técnicas especificas de planejamento, programação ou controle. Essas técnicas devem ser definidas ao se utilizar o modelo em cada EV identificando quais se adequam melhor aos requisitos da EV em função das características do seu sistema de produção.

- Permitir a comunicação e negociação entre os responsáveis pelo planejamento da produção dos parceiros da EV: o planejamento gerado pelo modelo não é imposto às empresas e sim realizado em função da disponibilidade das EPs. Para que o planejamento seja passível de execução pela EPs, é preciso haver comunicação e negociação de soluções por meio de troca de informações entre as empresas.

- Ser independente de soluções computacionais específicas: o modelo deve definir quais as informações são utilizadas e geradas no PCP, porém de forma independente de ferramentas e infra-estruturas de informação. O modelo deve possibilitar a utilização de diferentes soluções computacionais desde ferramentas simples até a mais modernas.

- Viabilizar a operação da EV: o modelo deve por meio de uma seqüência de atividades, distribuição de responsabilidades e disponibilização de informações referentes à produção possibilitar o planejamento e controle da produção em uma EV.

Em função do escopo e requisitos especificados, são apresentadas a seguir a demais etapas a fim de elaborar o modelo de referência.

\subsection{Escolha do Método de Modelagem}

A ARIS foi escolhida como arquitetura de referência cujo formalismo de modelagem será seguido neste trabalho. Entre os motivos que levaram à escolha dessa arquitetura é a capacidade de representar os quatro aspectos básicos citados por CURTIS et al. (1992) para as técnicas de modelagem: funcionais, seqüenciais e lógicos, de informação e organizacionais. Outro motivo é o fato de existir uma ferramenta computacional, a ARIS Toolset, que suporta a modelagem dos processos segundo os conceitos da ARIS. 
Considerando a arquitetura escolhida, o modelo abrange as visões de funções, dados, organizacional e de controle no nível de definição de requisitos. Nos próximos tópicos, para cada uma das visões do modelo, é primeiramente explicado o método da ferramenta ARIS Toolset que foi utilizado e posteriormente são apresentados os resultados obtidos.

\subsection{Determinação da Visão Organizacional}

A determinação da visão organizacional tem como objetivo definir as responsabilidades dentro da EV no que diz respeito ao presente trabalho. Segundo SCHEER (1994), um organograma é uma forma típica de representar estruturas organizacionais. Um gráfico deste tipo reflete as unidades organizacionais e respectivos relacionamentos. Na ferramenta ARIS Toolset existem alguns elementos organizacionais para a composição da visão organizacional cujas representações gráficas e definições são apresentadas na FIGURA 23.

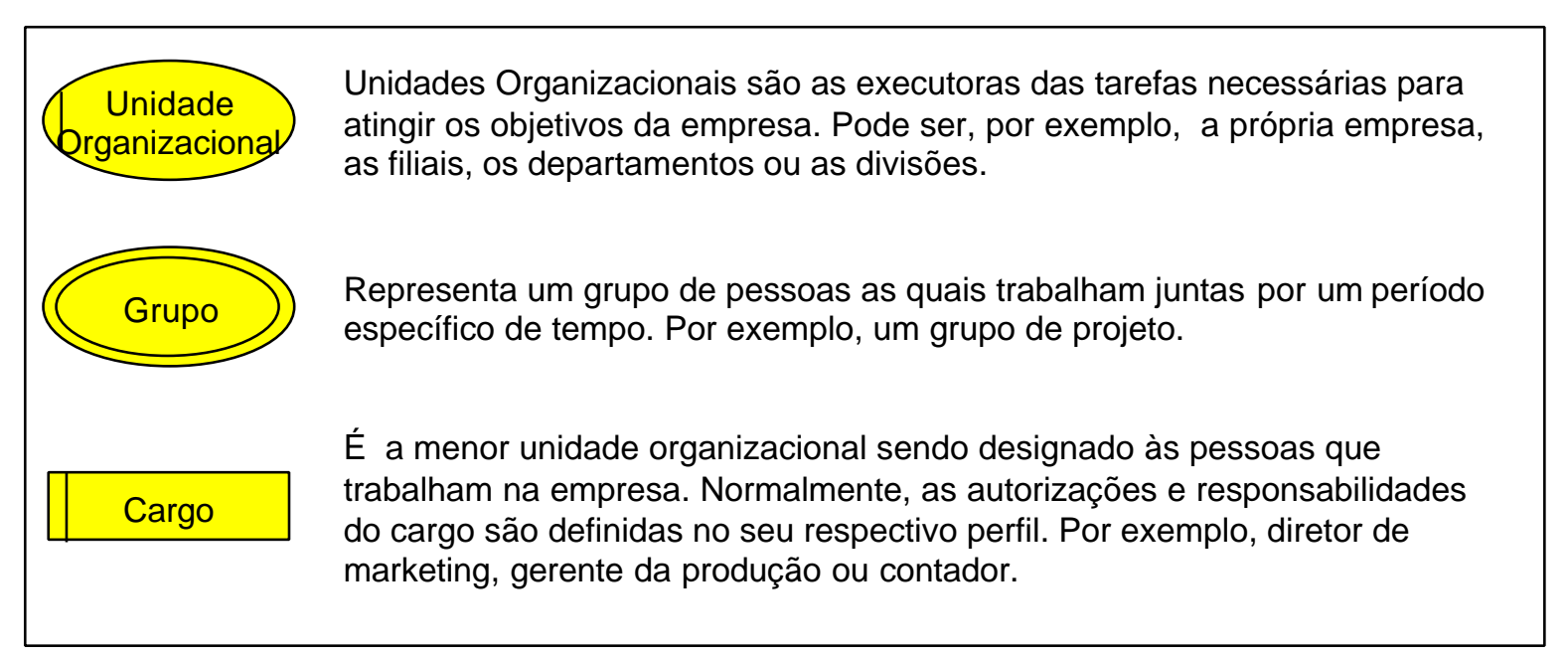

FIGURA 23 - Objetos da Visão Organizacional

Antes de apresentar o Organograma de Gestão da Produção da EV, são descritos o organograma da OV e da EV para um melhor entendimento das entidades envolvidas no processo. O organograma da OV é formado pelas entidades do framework NVG: a própria OV, o Grupo Virtual de Indústria (GVI), o Agenciador de Empresas Virtuais (AEV) e as Empresas-Membro (EM), que são as empresas que formam o GVI. A descrição dessas entidades foi feita no tópico 2.2.6.3. Existem outros 
elementos organizacionais na $\mathrm{OV}$, tais como o gerente do $\mathrm{GVI}$, que não serão detalhados pois não fazem parte do escopo desse trabalho. A FIGURA 24 apresenta o organograma da OV.

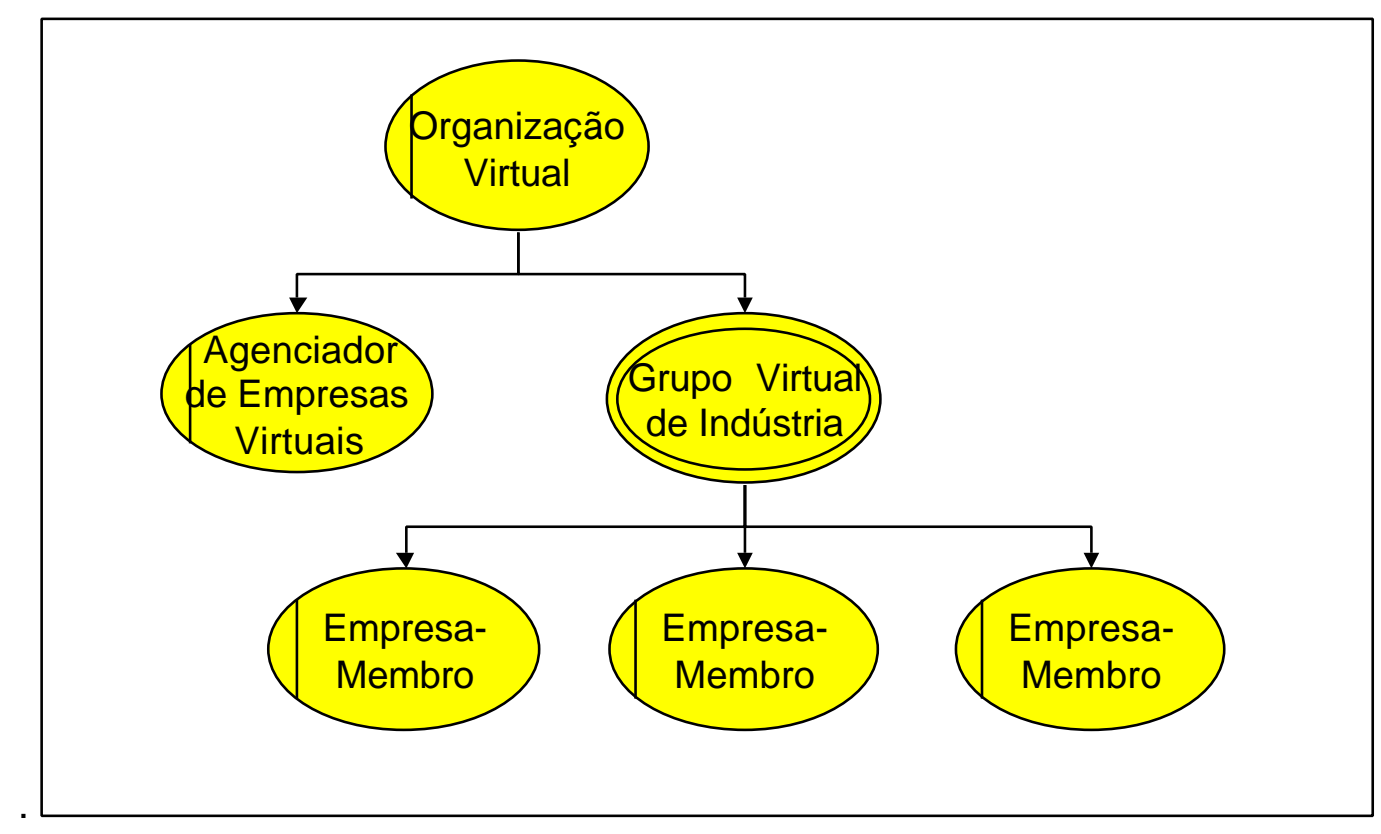

FIGURA 24 - Organograma Simplificado da Organização Virtual

Quando uma EV é formada, são definidas as empresas que a configurarão e determinada uma empresa responsável por representar a EV diante ao mercado. Para cada uma das empresas que formam a EV, são designadas pessoas que atuarão junto à EV. Seguindo a descrição acima, foi elaborado um organograma simplificado para a EV que é formado pelas entidades descritas a seguir e representadas na FIGURA 25.

- Empresas Parceiras (EP): são as empresas que constituem a EV, sendo essas preferencialmente EMs, mas também podem ser empresas externas à OV para complementar as competências necessárias à formação da EV.

- Empresa Líder (EL): é a empresa responsável pela interface e relacionamento com o cliente, como, por exemplo, nos processos de venda e entrega. Essa empresa é usualmente, mas não necessariamente, a responsável pela maior parte dos processos ou detentora da competência essencial mais relevante para exploração da oportunidade. A definição da EL é feita durante a configuração da EV. 
- Representante da Empresa Parceira (REP): o representante é a pessoa responsável pelo relacionamento da EP com a EV. Para os diferentes processos operacionais da EV, podem existir diferentes representantes. No processo de produção, é sugerido que o REP seja o gerente de produção da EP.

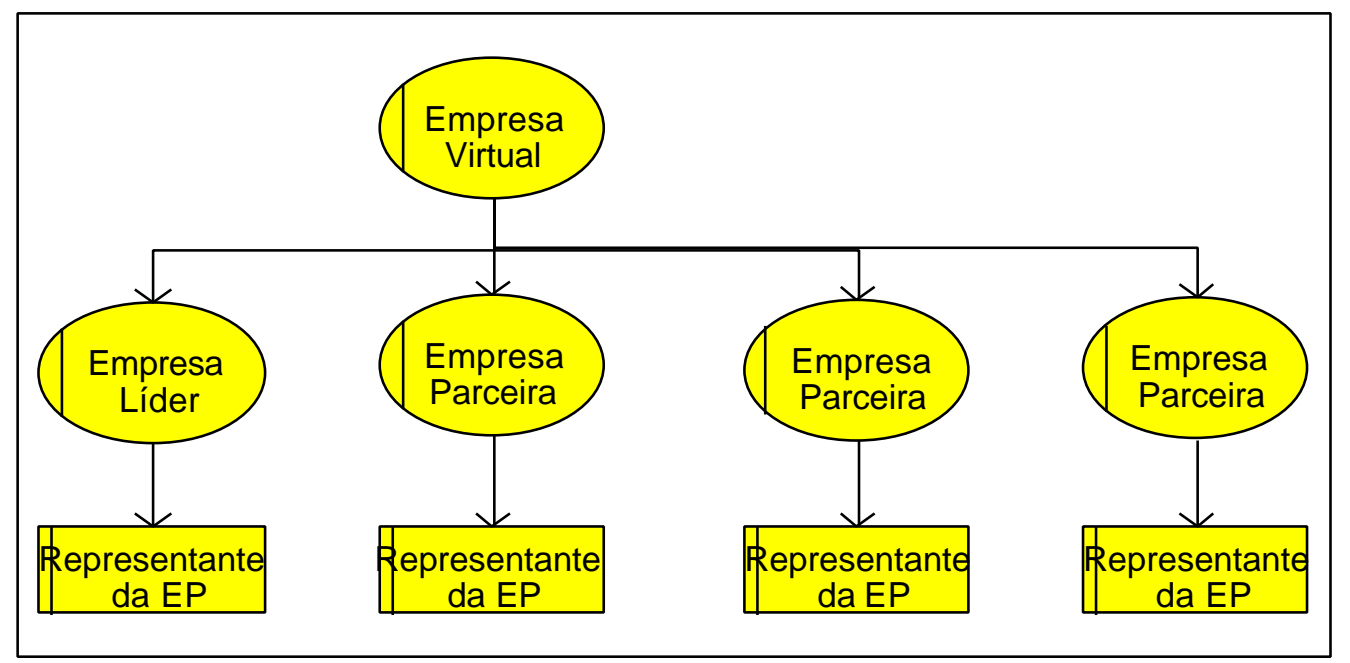

FIGURA 25 - Organograma Simplificado da Empresa Virtual

Considerando-se as necessidades de coordenação dentro da EV, para executar as atividades de PCP foram estabelecidos os seguintes papéis (FIGURA 26):

- Time de Produção da Empresa Virtual (TPEV): composto por pelo menos um representante (REP) de cada uma das EPs que formam a EV e participam da fase de produção. Entre suas funções estão: fornecer as informações necessárias para o planejamento, analisar e validar o planejamento, inserir as ordens da EV na programação da sua empresa de forma a cumprir os prazos estabelecidos e ser o responsável pela atualização do status das ordens de produção da sua empresa e informá-los à EV.

- Coordenador de Produção da Empresa Virtual (CPEV): é o responsável por liderar e coordenar o TPEV. O CPEV tem a função de elaborar o planejamento da EV, gerenciar a execução das ordens e propor solução para os possíveis conflitos no que se refere às decisões do planejamento da produção. O CPEV normalmente pertence à EL, no entanto pode ser um gerente de uma das outras EPs ou até mesmo um profissional autônomo com as habilidades necessárias para exercer a função. As responsabilidades descritas para o CPEV dizem respeito à fase de 
produção. Por exemplo, durante fase de desenvolvimento de produto, pode existir um coordenador de Desenvolvimento de Produto da EV com funções diferentes.

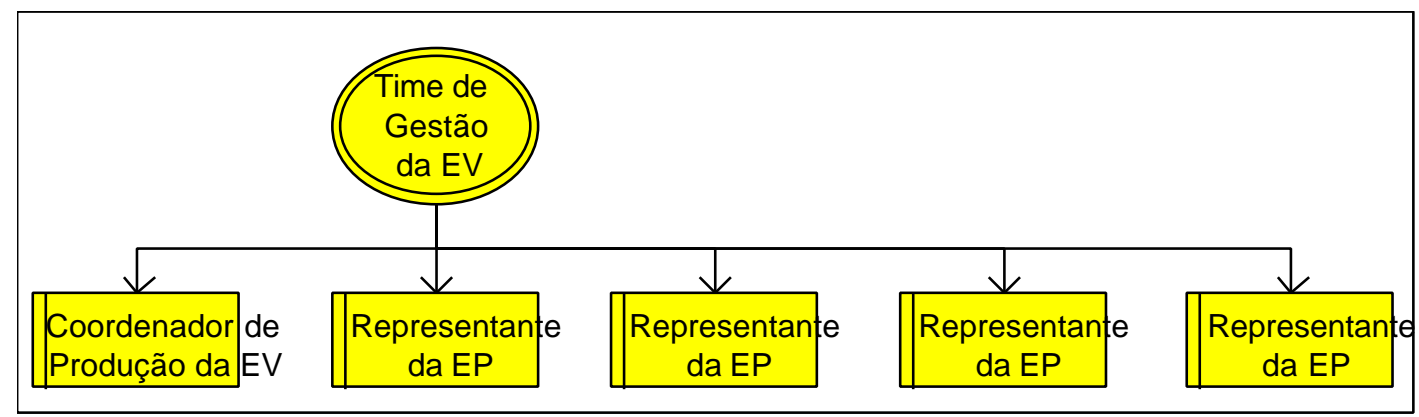

FIGURA 26 - Organograma de Gestão da Produção da Empresa Virtual

$\mathrm{Na}$ visão de controle (tópico 3.10), para cada atividade proposta no modelo é designado pelo menos um responsável, detalhando assim todas as funções para cada entidade.

\subsection{Determinação da Visão de Dados}

O objetivo da visão de dados é determinar quais informações são necessárias para a realização das atividades e as que são geradas durante a execução do processo definido no modelo. A definição dos requisitos da visão de dados inclui a descrição semântica do modelo de dados. Segundo ARIS (1998), o Modelo EntidadeRelacionamento (MER) é o mais difundido método para a determinação de modelos semânticos de dados, sendo este o adotado para a determinação da visão de dados desse modelo.

O MER baseia-se numa percepção de universo constituído por um grupo de objetos chamados de entidades e por relacionamentos entre esses objetos (CHEN, 1990). Uma entidade é a representação de um conjunto de objetos reais ou abstratos que são reconhecidos como sendo do mesmo tipo por compartilhar as mesmas características (FURLAN, 1997). A distinção entre as entidades é obtida associando-se a cada entidade um conjunto de atributos que descrevem o objeto. Um relacionamento é uma associação lógica entre duas ou mais entidades.

Além das entidades e relacionamentos, o MER representa certas restrições às quais o modelo e posteriormente o banco de dado deve-se adequar. Uma dessas 
restrições é a cardinalidade de mapeamento que expressa o número de entidades às quais outra entidade pode ser associada via um conjunto de relacionamentos.

A cardinalidade de mapeamento pode ser uma das seguintes formas (ARIS, 1998):

- Um-para-um (1 x 1): uma entidade em A está associada com no máximo uma entidade em $B$, e uma entidade em $B$ está associada com no máximo uma entidade em A;

- Um-para-muitos $(1 \times \mathrm{N})$ : uma entidade em A está associada a qualquer número de entidades em B. Todavia uma entidade em B pode estar associada a no máximo uma entidade em $A$;

- Muitos-para-muitos ( $\mathrm{N} \times \mathrm{M}$ ): uma entidade em $\mathrm{A}$ está associada a qualquer número de entidades em $B$ e uma entidade em $B$ pode estar associada qualquer número de entidades em $A$.

A representação gráfica de um MER consiste dos seguintes componentes:

- Retângulos: representam as entidades.

- Losangos: representam relacionamentos entre as entidades.

- Linhas: ligam atributos às entidades e entidades a relacionamentos.

- Elipses: representam os atributos.

Pode ocorrer que um relacionamento precise se relacionar com outro, neste caso tornar-se também uma entidade e é representado por um retângulo com um losango no centro. A seguir é apresentado um exemplo de MER na FIGURA 27.

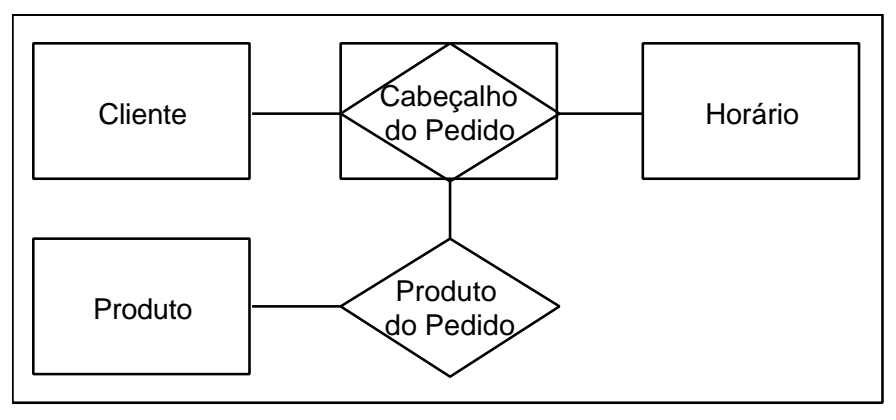

FIGURA 27 - Representação Gráfica de um MER 


\subsubsection{Entidades do Modelo Entidade-Relacionamento}

Na FIGURA 28, o MER é representado com todas as suas entidades e respectivos relacionamentos, assim como cardinalidades. A seguir, as entidades são apresentadas e descritas. Na descrição, os termos com letras maiúsculas representam as entidades. Os relacionamentos, que são descritos no próximo tópico, além de letras maiúsculas, estão sublinhados, como por exemplo: ENTIDADE e RELACIONAMENTO. 


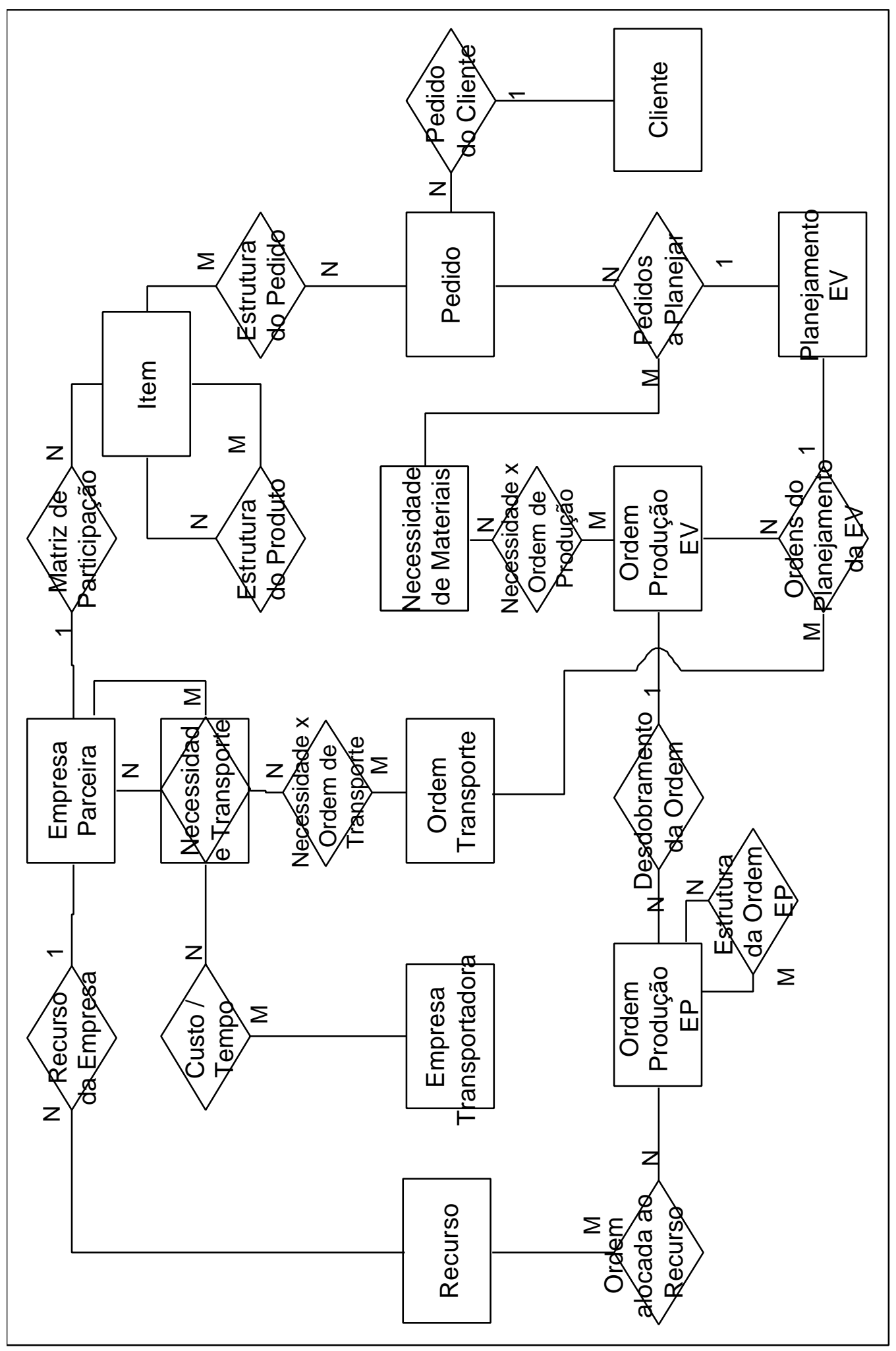

FIGURA 28 - Modelo Entidade-Relacionamento da Visão de Dados 
- EMPRESA PARCEIRA: são as empresas que constituem a EV.

- ITEM: são os itens que compõe a ESTRUTURA DO PRODUTO. Os itens podem ser dos seguintes tipos:

- Produto: é o produto final que será entregue ao cliente, sendo o conjunto total de todos os itens;

- Módulo: é o conjunto sob responsabilidade de uma EP. Uma EP pode fornecer um módulo para outra EP, assim um módulo pode ser composto por outros módulos.

- Componente: representa os itens que são processados pela EP e que compõe o módulo de sua responsabilidade.

- Elemento: refere-se aos itens comprados pela EP de fornecedores externos.

Essa classificação de itens não segue as normas usualmente utilizadas dentro da engenharia, mas foi proposta a fim de facilitar o tratamento diferenciado para cada tipo de itens, por exemplo, para os elementos haverá ordens de compra e para os componentes, ordens de produção. A FIGURA 29 apresenta uma exemplificação da proposta de classificação dos itens da estrutura do produto.

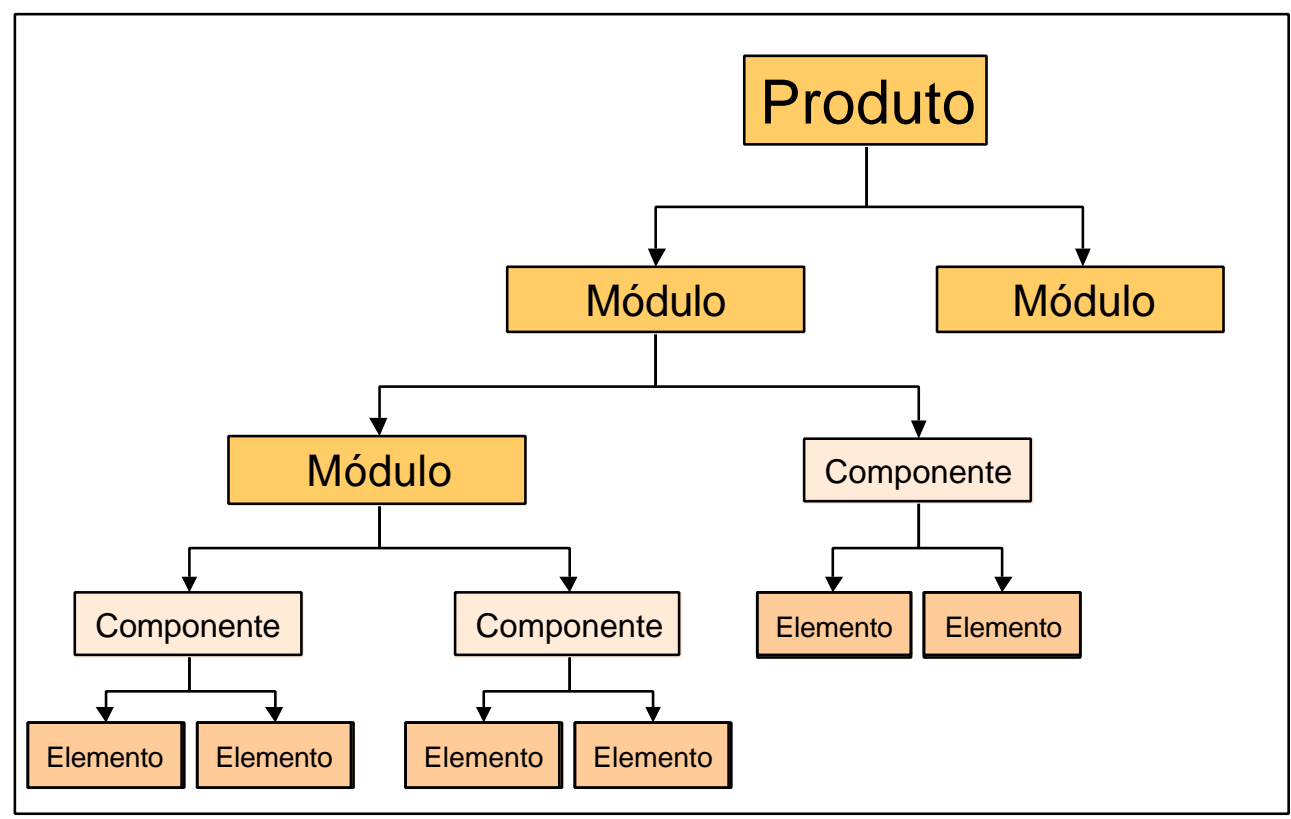

FIGURA 29 - Classificação da Estrutura do Produto por Item 
Normalmente, a EV é formada para produzir um único tipo de produto, no entanto pode ser necessário cadastrar as possíveis variações e configurações deste.

- CLIENTE: informações sobre os clientes da EV, tanto futuros clientes como clientes com pedidos em aberto ou já atendidos.

- PEDIDO: são os pedidos dos CLIENTES para um ou mais produtos. Cada PEDIDO tem uma ESTRUTURA DO PEDIDO.

- PLANEJAMENTO DA EV: estabelece o período que o planejamento atende e respectivos PEDIDOS A PLANEJAR. É composto por ORDENS DE PRODUÇÃO DA EV e ORDENS DE TRANSPORTE para o período determinado.

- NECESSIDADE DE MATERIAIS: define as quantidades brutas e líquidas das necessidades dos ITENS em função dos PEDIDOS A PLANEJAR, assim como os prazos que devem ser atendidos.

- ORDEM DE PRODUÇÃO DA EV: especifica a necessidade de fabricação de um ITEM, no caso um módulo de uma EP, determinando a quantidade a ser produzida e datas de início e término.

- ORDEM DE PRODUÇÃO DA EP: uma ORDEM DE PRODUÇÃO DA EV pode ser detalhada e/ou dividida em diferentes ORDENS DE PRODUÇÃO DA EP para serem inseridas no planejamento da EP.

- RECURSO: são os recursos produtivos das EMPRESAS PARCEIRAS.

- NECESSIDADE DE TRANSPORTE: determina a necessidade de transporte dos ITENS entre as EMPRESAS PARCEIRAS.

- ORDEM DE TRANSPORTE: a ORDENS DE TRANSPORTE representam as NECESSIDADES DE TRANSPORTE, determinando a EMPRESA TRANSPORTADORA e a data planejada para o transporte.

- EMPRESA TRANSPORTADORA: são as possíveis empresas responsáveis pelo atendimento das NECESSIDADES DE TRANSPORTE.

\subsubsection{Relacionamentos do Modelo Entidade-Relacionamento}

Os relacionamentos do modelo são descritos a seguir. 
- MATRIZ DE PARTICIPAÇÃO: relaciona as EMPRESAS PARCEIRAS e os ITENS que produzem.

- ESTRUTURA DO PRODUTO: relaciona os ITENS e respectiva hierarquia, representando as relações de item-pai e itens-filho, assim com suas quantidades.

- PEDIDO DO CLIENTE: relaciona um CLIENTE aos seus PEDIDOS.

- ESTRUTURA DO PEDIDO: relaciona um PEDIDO aos ITENS (produtos) que o compõem determinado as respectivas quantidades.

- PEDIDOS A PLANEJAR: define os PEDIDOS que serão planejados em um determinado PLANEJAMENTO DA EV

- NECESSIDADE X ORDEM DE PRODUÇÃO: relaciona as ORDENS DE PRODUÇÃO geradas em função de uma NECESSIDADE DE PRODUÇÃO, pode ocorrer NECESSIDADE DE PRODUÇÃO gerar mais de uma ORDEM DE PRODUÇÃO ou de uma ORDEM DE PRODUÇÃO ser gerada a partir da união de mais de uma NECESSIDADE DE PRODUÇÃO.

- NECESSIDADE X ORDEM DE TRANSPORTE: relaciona as ORDENS DE TRANSPORTE geradas em função de uma NECESSIDADE DE TRANSPORTE. Uma NECESSIDADE DE TRANSPORTE pode gerar mais de uma ORDEM DE TRANSPORTE como também uma ORDEM DE TRANSPORTE ser gerada a partir da união de mais de uma NECESSIDADE DE TRANSPORTE.

- ORDENS DO PLANEJAMENTO DA EV: determina as ORDENS DE PRODUÇÃO DA EV e as ORDENS DE TRANSPORTE DA EV que pertencem a um PLANEJAMENTO DA EV estabelecendo as precedências entre as ordens.

- DESDOBRAMENTO DA ORDEM: relaciona as ORDENS DE PRODUÇÃO DA EP a ORDEM DE PRODUÇÃO DA EV que as originou.

- ESTRUTURA DA ORDEM DA EP: estabelece as precedências entre as ORDENS DE PRODUÇÃO DA EP.

- ORDEM ALOCADA AO RECURSO: representa a alocação de uma ORDEM DE PRODUÇÃO DA EP a um RECURSO especifico capaz de realizá-la. 
- RECURSO DA EMPRESA: relaciona os RECURSOS pertencentes à EMPRESA PARCEIRA.

- CUSTO/TEMPO DE TRANSPORTE: determina o custo e o tempo para as NECESSIDADES DE TRANSPORTE estabelecidas pelas possíveis EMPRESAS TRANSPORTADORAS.

Os seus atributos das entidades e dos relacionamentos estão listados no ANEXO A.

\subsection{Determinação da Visão de Funções}

Esta etapa visa determinar as atividades do modelo que na nomenclatura ARIS são chamadas de funções (SCHEER, 1994). As funções são representadas por retângulos com quinas arredondadas, como na FIGURA 30.

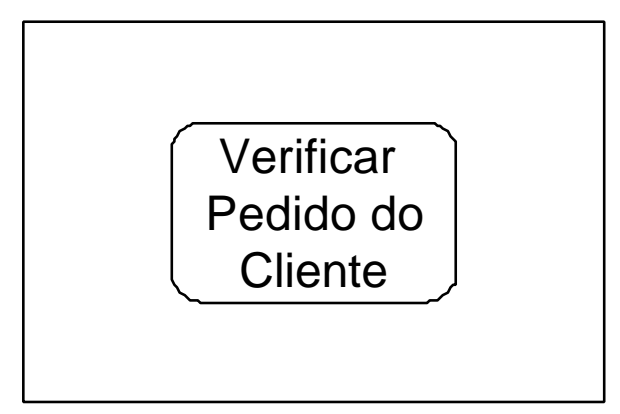

FIGURA 30 - Representação de uma função

Usualmente, o critério para estabelecer uma função é um objeto tal como Pedido do Cliente ou Ordem de Produção. O objeto deve ver visível no nome da função como ilustrado na FIGURA 30. Por exemplo, Pedido do Cliente define o objeto e Verificar define a atividade que é executada sobre o objeto.

Segundo ARIS (1998), as funções podem ser descritas em diferentes níveis de compreensão. O nível mais alto consiste de funções complexas tais como processos de negócio ou cadeias de processo. O termo função pode ser utilizado em todos os níveis hierárquicos. Porém, outros termos também são usados para descrever o nível hierárquico de forma mais apropriada, como por exemplo, processo, sub-função e função básica. Uma função básica é aquela que não pode ou não precisa ser mais detalhada em outras funções segundo o objetivo de análise de um processo de negócio (ARIS, 1998). 
Para representar os diferentes níveis das de funções são utilizadas as árvores de função, também chamadas de diagramas de hierarquia. Para agrupar as funções em uma árvore diferentes critérios podem ser empregados tais como: processar o mesmo objeto (orientado a objeto), pertencer ao mesmo processo (orientado a processo) ou envolver a mesma operação (orientado a operação). Na FIGURA 31 é apresentada uma árvore de cada tipo.

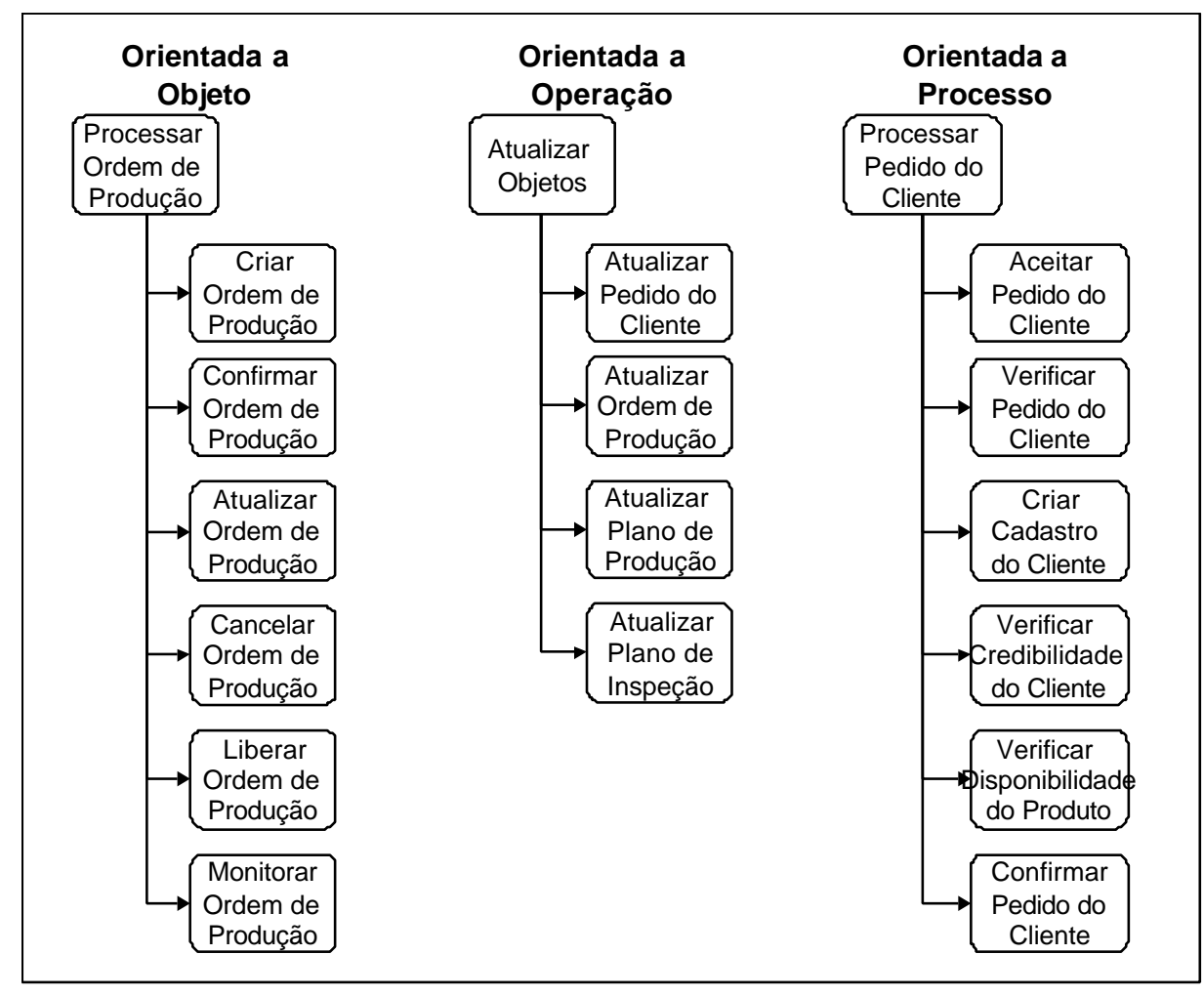

Adaptado de ARIS (1998)

FIGURA 31 - Tipos de Árvores de Funções

A primeira árvore da FIGURA 31 apresenta uma árvore orientada a objeto, na qual diferentes operações que são realizadas sobre o mesmo objeto, no caso a Ordem de Produção. A segundo árvore, que é orientada a operação, serve para agrupar funções de acordo com a operação, como por exemplo, Atualizar. Essas funções podem pertencer a diferentes processos e também envolver diferentes objetos.

A última árvore da FIGURA 31 é um exemplo de árvore orientada a processo. Se o objetivo da árvore de funções for representar os resultados obtidos por meio da modelagem de processos, a árvore orientada a processo deve ser o método escolhido. 
Assim, sendo o objetivo do modelo desse trabalho representar um processo de negócio, o método utilizado é o de árvore de funções orientada a processo. Para tal, é adotado a seguinte nomenclatura para a hierarquia de funções no modelo proposto: processo, sub-processo e funções.

O processo ao ser detalhado neste trabalho será denominado Produzir. Considerando a característica de dividir o planejamento em duas dimensões, inicialmente criou-se dois sub-processos: Planejar Produção da EV e Inserir Planejamento nas EPs.

Entre as funções do Planejar Produção da EV, as inicias tinham o objetivo de coletar informações para então gerar o planejamento. Assim, houve uma nova divisão, separando as atividades iniciais em um sub-processo chamado de Pré-Planejar Produção da EV. O sub-processo Inserir Planejamento nas EPs também foi divido em duas fases, gerando um novo sub-processo denominado Programar e Controlar a Produção.

O processo Produzir foi então dividido em quatros sub-processos: Pré-Planejar Produção da EV, Planejar Produção da EV, Inserir Planejamento nas EPs e Programar e Controlar a Produção, como apresentado na FIGURA 32:

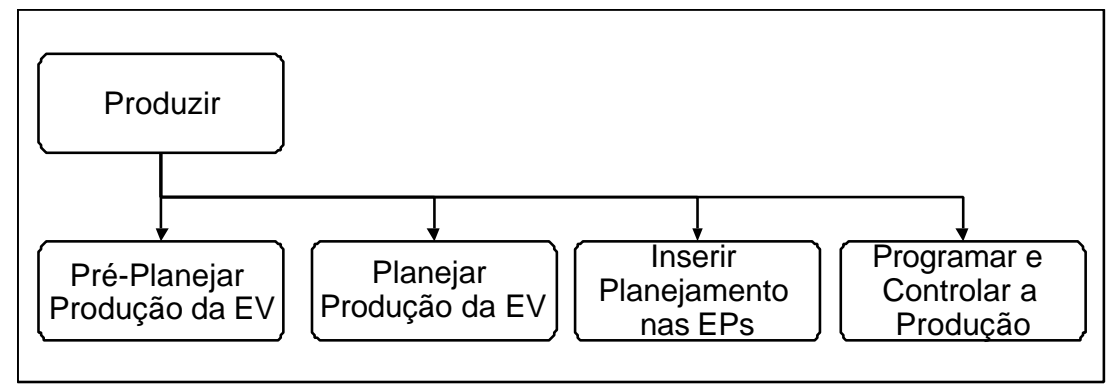

FIGURA 32 - Sub-Processos do Processo Produzir

Os próximos tópicos descrevem cada um destes sub-processos e suas respectivas funções apresentando uma árvore de funções parcial relativa ao subprocesso em questão. 


\subsubsection{Pré-Planejar Produção da EV}

O objetivo deste sub-processo é coletar e sistematizar as informações necessárias ao planejamento da produção de uma EV. Tal como foi considerado no escopo do processo, é considerado que parte dessas informações já estejam disponíveis, pois foram geradas em processos anteriores, tais como Desenvolver Produto e Vender. As atividades que compõe o sub-processo Pré-Planejar Produção da EV estão representadas na árvore de funções da FIGURA 33 e descritas a seguir.

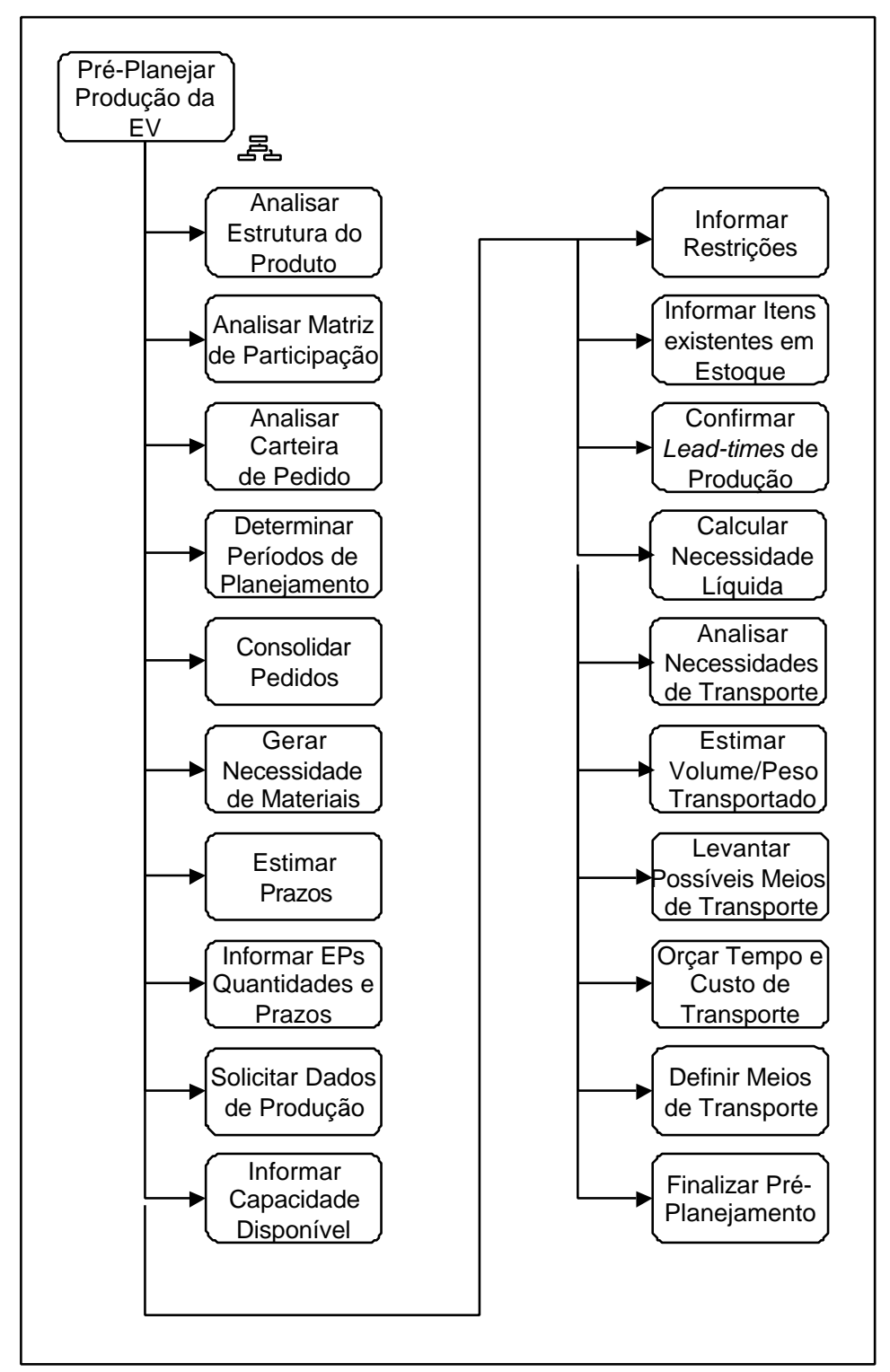

FIGURA 33 - Árvore de Funções do sub-processo Pré-Planejar Produção da EV 
- Analisar Estrutura do Produto: é preciso entender a estrutura do produto a ser produzido. É considerado que as informações sobre a estrutura do produto foram geradas no processo Desenvolver Produto e estão disponíveis.

- Analisar a Matriz de Participação: além de conhecer a estrutura do produto e necessário saber qual empresa é responsável pela produção de cada item do produto. A fonte desta informação é a matriz de participação que é gerada na fase de configuração da EV.

- Analisar Carteira de Pedido: consiste em verificar os pedidos existentes para a EV, verificando quantidades e prazos a serem atendidos.

- Determinar Períodos de Planejamento: estabelece qual será o período de planejamento baseado nos pedidos existentes, quantidade demandada e no leadtime de produção. Por exemplo, podem existir pedidos para os próximos quatro meses e optar por planejar apenas os pedidos dos dois primeiros meses, pois o lead-time de produção é de quatro semanas.

- Consolidar Pedidos: refinamento das atividades anteriores na qual são confirmados os pedidos que serão planejados no período determinado.

- Gerar Necessidade de Materiais: com base nas quantidades demandas nos pedidos e estrutura do produto, as necessidades de produtos são transformadas em necessidades de materiais, no caso, em necessidades de módulos produzidos pelas EPs.

- Estimar Prazos: em função do lead-time dos módulos são estimados os prazos nos quais as necessidades devem ser atendidas.

- Informar EPs sobre Quantidades e Prazos: as EPs são informadas quanto as quantidades de itens a serem produzidos e um prazo estimado para o atendimento dos pedidos.

- Solicitar Dados de Produção: para poder elaborar o planejamento, é necessário confirmar/atualizar alguns dados de produção de cada EP.

- Informar Capacidade Disponível: é preciso confirmar a disponibilidade de capacidade das EPs para realização das ordens. Como se trata de um planejamento macro da capacidade, essa pode ser informada, por exemplo, em 
horas/dia ou horas/semana da empresa, não precisando detalhar a capacidade de cada recurso envolvido.

- Informar Restrições: a intenção dessa atividade é identificar alguma restrição importante existente, isto é, tudo aquilo que limita o planejamento, como a não disponibilidade de material e recursos durante um determinado período.

- Informar Itens Existentes em Estoque: apesar da idéia de EV ser de trabalhar sem estoque, pode ocorrer que um dos itens produzidos na EP esteja disponível em estoque. Isso por que esse item pode ser utilizado em outros produtos da EPs ou em um pedido anterior da EV pode ter havido uma produção maior do que a necessária, o que gerou estoque do item.

- Confirmar Lead-times de Produção: apesar do lead-time ser um dos atributos já informados para cada item, deve ser confirmado uma vez que é fundamental para o estabelecimento das datas de planejamento, e o mesmo pode variar em função de melhorias no processo produtivo, da capacidade disponível e possíveis restrições.

- Calcular Necessidades Líquidas de Material: considerando o estoque existente informado pelas EPs, são calculadas as necessidades líquidas dos itens que compõe o produto.

- Analisar Necessidades de Transporte: conhecendo-se a estrutura do produto, necessidades de produção e as empresas responsáveis pelos itens, são analisadas as necessidades de transporte entre as EPs que precisam de transferência de itens. Essa atividade tem a sua importância aumentada proporcionalmente à distância entre as empresas da EV, e no caso de ser crítica pode ser realizada antes de estimar os prazos para que o tempo de transporte seja considerado.

- Calcular Volume/Peso Transportado: as EPs devem calcular e informar o volume e peso dos itens a serem transportados.

- Levantar Possíveis Meios de Transporte: pesquisar as possíveis formas de transporte e respectivos fornecedores de serviço que atendem as regiões onde estão localizadas a EPs considerando-se o volume e peso a ser transportado. As EPs também podem ser consideradas nesse levantamento. 
- Orçar Custos e Tempos de Transporte: requerer junto aos transportadores (podendo estes ser as próprias empresas parceiras) o tempo e custo de transporte;

- Definir Meios de Transporte: com base nos custos e no tempo necessário para o transporte são escolhidos os meios que melhor se adequem as necessidades de transporte entre as empresas. No entanto, os meios de transporte, e respecitivas empresas transportadoras, podem ser alterados, em situações tais como a atraso da produção de um dos itens, necessitando de um meio mais rápido de transporte mesmo que implique em aumento de custo.

- Finalizar Pré-Planejamento: após coletar as informações necessárias, o préplanejamento é finalizado. Essas informações são: o período de planejamento, os pedidos a planejar, a capacidade e restrições da cada EP, o lead-time e estoque dos itens, necessidades brutas e líquidas de material, necessidades de transporte e empresas responsáveis pelo transporte.

\subsubsection{Planejar Produção da EV}

A partir das informações coletadas no sub-processo anterior é iniciado o planejamento da produção da EV. O objetivo deste sub-processo é propor um planejamento que atenda as necessidades da EV e que também seja execução pelas EPs seja viável. As atividades para a realização do sub-processo Planejar Produção são apresentadas na FIGURA 34 e descritas a seguir. 


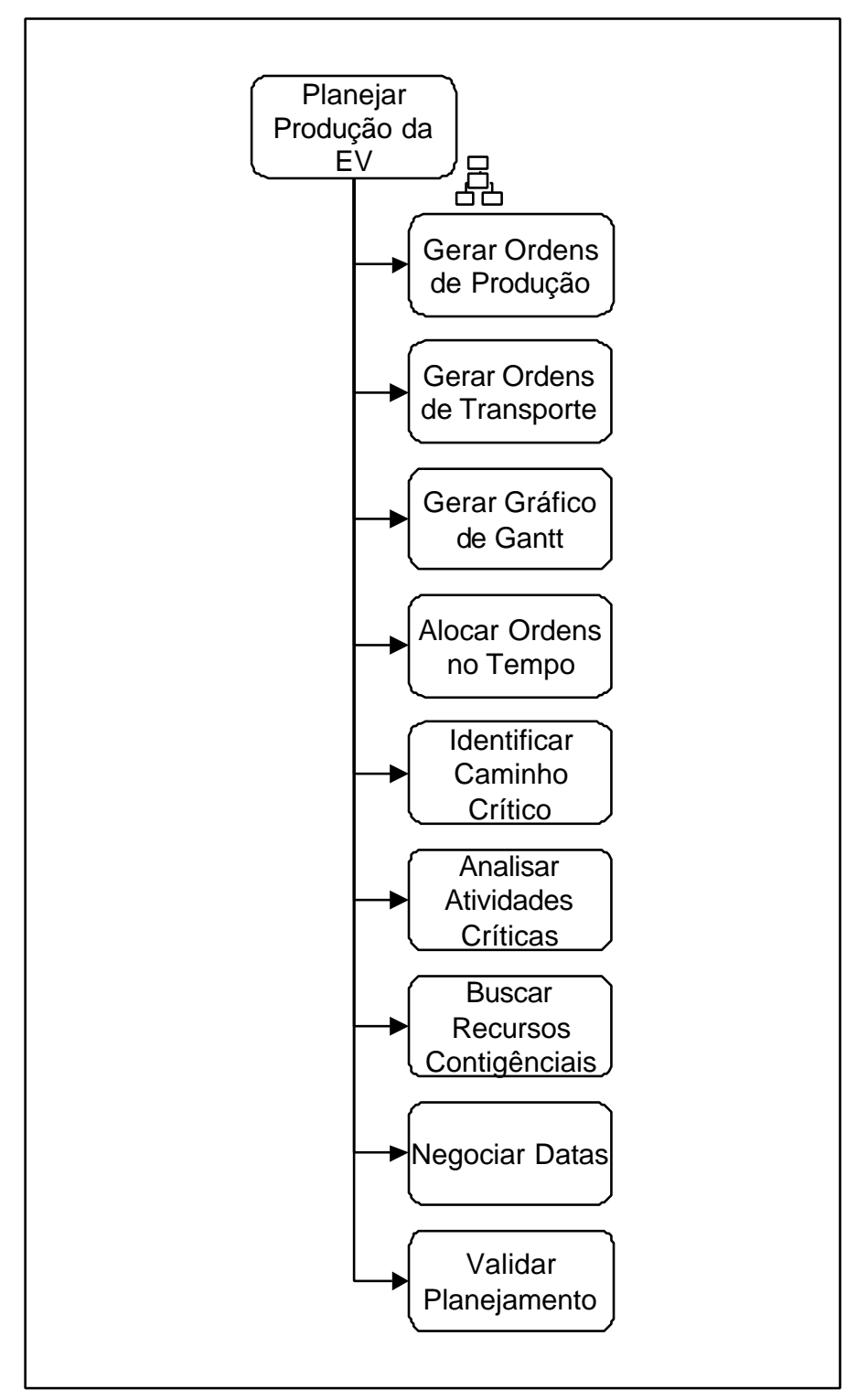

FIGURA 34 - Árvore de Funções do sub-processo Planejar Produção da EV

- Gerar Ordens de Produção: são geradas as ordens de produção baseadas no cálculo de necessidades líquidas realizado anteriormente. As ordens são geradas para os itens que pertencem ao tipo módulo.

- Gerar Ordens de Transporte: em função das ordens de produção e necessidades de transporte entre empresas são geradas ordens de transporte.

- Alocar Ordens para Empresas no Tempo: baseado na estrutura do produto e respectivos lead-times, as ordens de produção e transporte são distribuídas no 
tempo, considerando as precedências e definidas as datas mais cedo e mais tarde das ordens, determinando o intervalo no qual as EPs devem executar as ordens.

- Gerar Gráfico de Gantt: utilizando-se as informações geradas na atividade anterior, pode-se elaborar um gráfico de Gantt. Esse gráfico é uma representação gráfica da distribuição das ordens no tempo por empresa que permite a visualização do planejamento da EV assim como a sua atualização e alteração das ordens.

- Identificar Caminho Crítico: no planejamento existem ordens em seqüência e em paralelo, formando uma rede. A partir do Gráfico de Gantt, pode-se identificar qual o caminho crítico, isto é, qual a seqüência de ordens que contém a maior duração.

É chamado caminho crítico porque qualquer atraso em uma das ordens nesta seqüência reflete em atrasos no planejamento, pois não há folga entre as ordens.

- Analisar Atividades Críticas: caso o caminho crítico tenha uma duração superior ao tempo disponível para o atendimento dos pedidos, é preciso verificar se as atividades críticas realmente possuem lead-time longo ou é devido à falta de capacidade de produção de algumas EPs.

- Buscar Recursos Contingenciais: se o problema for falta de capacidade, pode-se então procurar recursos contingenciais para a realização das atividades alocadas inicialmente nos recursos sobre carregados. Esta busca pode ser realizada na base de dados das competências das empresas pertencentes à $O V^{10}$. Entre as informações dessa base estão os recursos produtivos de cada empresa pertence à OV. Assim, pode-se propor utilizar recursos de outras empresas a fim de melhorar o atendimento ao cliente. A utilização de outros recursos pode ser considerada apenas uma terceirização, mas também é possível que a empresa passa-se a fazer parte da EV.

\footnotetext{
${ }^{10}$ A especificação dessa base da dados foi realizada no trabalho de iniciação cientifica "Desenvolvimento de uma infraestrutra de informação para busca de competências para formação de empresas virtuais" de Christiane Peres Goulart e implementada no trabalho de mestrado "Definição de uma infra-estrutra de informação para suporte à gestão de organizações virtuais" de Flávia Valéria de Sousa Michilini.
} 
- Negociar Datas: tanto para o caso de falta de capacidade como para lead-times longos, deve-se negociar soluções para melhorar o tempo de processamento de das ordens a fim de atender os prazos estabelecidos.

- Validar Planejamento: o planejamento elaborado é apresentado a todo o TGEV, para que este dê seu aval com relação à realização deste. Neste momento, podese reajustar algumas datas, desde que seja de comum acordo do grupo.

Como resultado do Planejamento da EV, as EPs recebem as ordens de produção que são de sua responsabilidade.

\subsubsection{Inserir Planejamento nas Empresas Parceiras}

Uma vez validado o planejamento da produção da $E V$, esse é disponibilizado para as EPs, para que cumpram o que nele foi estabelecido. O sub-processo Inserir Planejamento nas Empresas Parceiras tem como objetivo transformar as ordens de produção da EV em ordens internas em cada uma das EPs. Para tal, as EPs devem inserir as ordens para serem utilizada internamente em seus sistemas de produção. Cada EP executa esse sub-processo em paralelo com as demais. As atividades que compõe o sub-processo são descritas a seguir e apresentada na FIGURA 35.

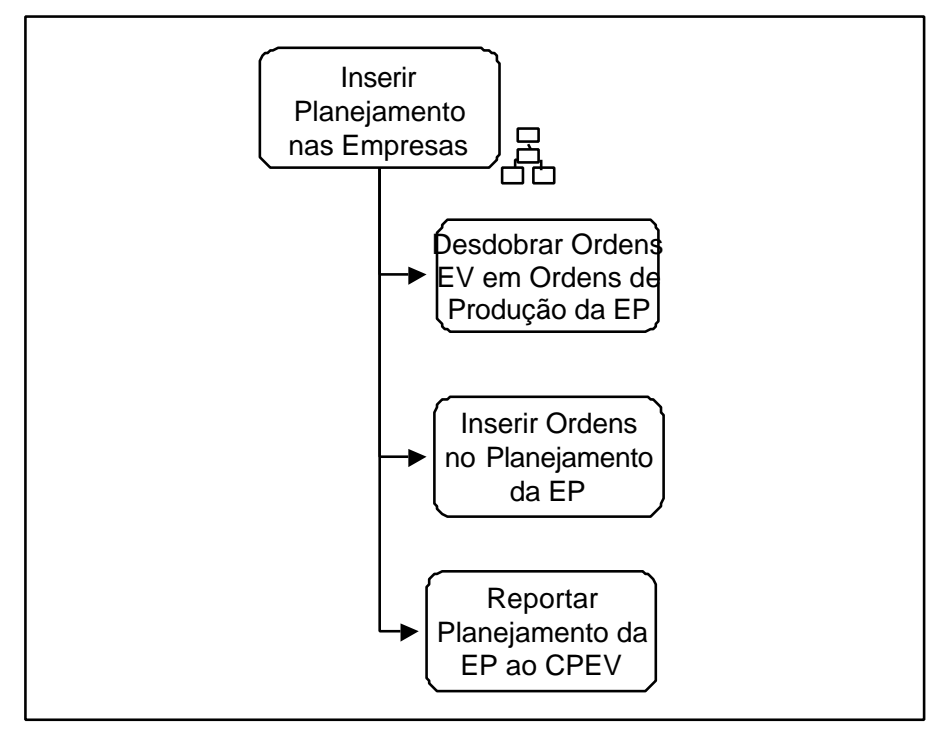

FIGURA 35 - Árvore de Funções do sub-processo Inserir Planejamento nas Empresas

- Desdobrar Ordens da EV em Ordens de Produção da EP: a ordem de produção da EV deve ser detalhada para o uso interno da empresa. Assim, uma ordem da 
EV pode ser dividida em diferentes ordens de produção da EP de forma que representem a produção dos itens que compõe o módulo de responsabilidade da EP e sejam alocadas para os recursos da empresa (FIGURA 36).

- Inserir Ordens no Planejamento da EP: as ordens que foram desdobradas são inseridas no sistema de planejamento da empresa.

- Reportar Planejamento da EP ao CPEV: após inserir as ordens no sistema da empresa, o REP deve reportar o planejamento ao CPEV.

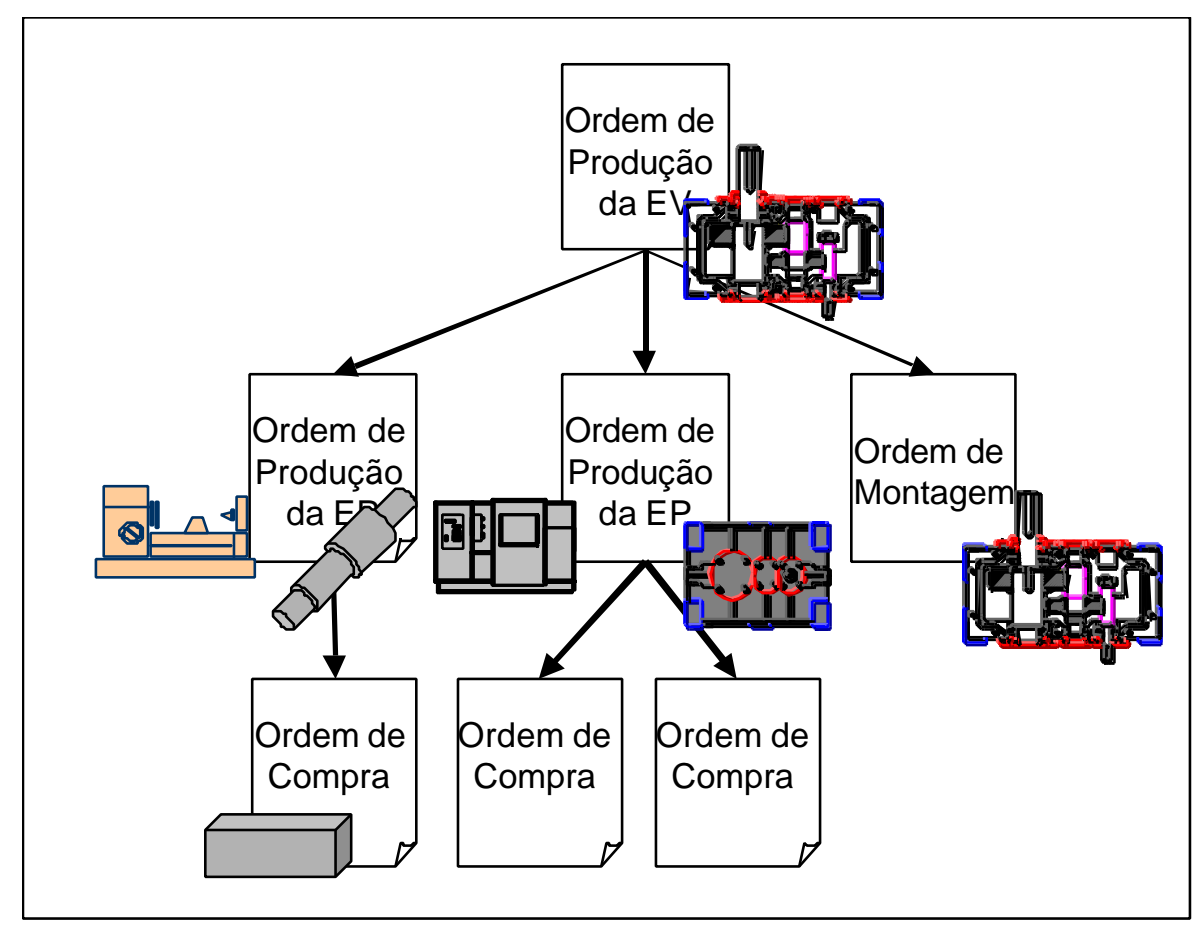

FIGURA 36 - Desdobramento de uma Ordem de Produção da EV em Ordens da EP

Após inserir as ordens no planejamento, o próximo passo é a programação e controle da produção.

\subsubsection{Programar e Controlar Produção}

Este sub-processo é responsabilidade de cada EP, tanto a programação e execução das ordens planejadas quanto o controle das atividades realizadas. $O$ subprocesso é realizado em cada EP, mas de forma a manter o CPEV atualizado do status das ordens. O sub-processo de Programar e Controlar envolve as seguintes atividades e é representado pela árvore da FIGURA 37. 


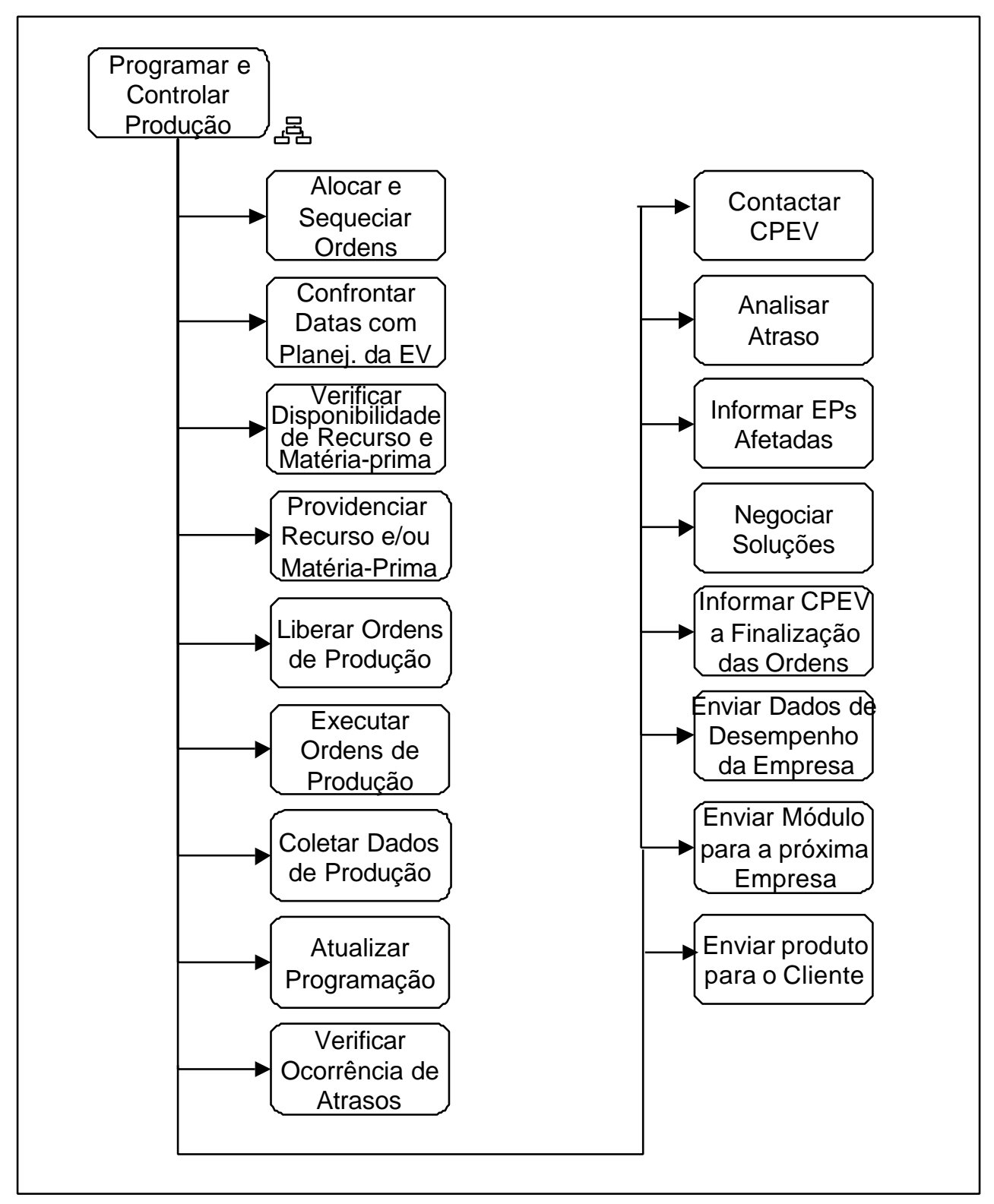

FIGURA 37 - Árvore de Funções do sub-processo Programar e Controlar Produção

- Alocar e Seqüenciar Ordens: ordens de produção da EP devem ser programadas no sistema interno de cada empresa. As ordens são alocadas aos recursos produtivos e seqüenciadas cronologicamente por critérios de prioridade, determinados pela empresa, respeitando as precedências tecnológicas.

- Confrontar Datas com Planejamento da EV: uma vez seqüenciadas as ordens, deve-se verificar se os prazos da programação estão dentro do planejado na EV. 
Caso não esteja, é necessário um novo seqüenciamento que respeite as datas limites do planejamento da EV.

- Verificar disponibilidade de recursos e matéria-prima: antes de liberar uma ordem, é preciso verificar a disponibilidade de recursos e matéria-prima.

- Providenciar recursos e/ou matéria-prima: caso não haja disponibilidade, é necessário tomar providência para que os recursos e matéria-prima estejam disponíveis a tempo de executar a ordem sem atrasos.

- Liberar Ordens de Produção: as ordens que foram alocadas e seqüenciadas são liberadas para produção.

- Executar Ordens de Produção: esta atividade representa a produção dos itens.

- Coletar Dados de Produção: é feito um acompanhamento da produção através do apontamento e coleta de dados do chão de fábrica.

- Atualizar Programação: com os dados coletados das ordens, a programação é atualizada. As informações coletadas geram o status das ordens programadas, liberadas, em execução ou executadas. A freqüência de coleta de dados e atualização da programação deve seguir as regras estabelecidas durante a fase de configuração da EV.

- Verificar Ocorrência de Desvios: a programação da EP é confrontada com o planejamento original da EV, a fim de identificar atrasos na produção.

- Contactar CPEV: caso ocorram atrasos, o CPEV deve ser mais cedo possível para que quaisquer ações de controle possam ser realizadas a tempo.

- Analisar Atraso: dependendo do impacto causado pelo atraso, pode-se executar uma reprogramação apenas na EP onde ocorreu o atraso ou se necessária uma reprogramação nas demais EPs afetadas.

- Informar EPs Afetadas: se a reprogramação for necessária, as EPs que dependem dos itens em atraso devem ser comunicadas.

- Negociar soluções: o CPEV e os participantes do TPEV devem discutir soluções para contornar o atraso. Pode-se, por exemplo, optar por um meio de transporte mais rápido, amortizando o impacto do atraso. No entanto, precisam ser analisadas 
as conseqüências da solução, tal como considerar possíveis aumentos de custo. Baseando-se nas propostas, pode-se negociar novas datas e simular novas programações.

- Verificar a existência de ordens não executadas: confere se todas as ordens relativas a ordem da EV foram executadas. Isto é, se o módulo sob responsabilidade da EP está pronto.

- Informar CPEV a Finalização das Ordens: avisar o CPEV sobre o término da produção da EP.

- Enviar Dados de Desempenho da Empresa: o desempenho da EP deve ser informado ao CPEV, para que estes dados sejam armazenados, servindo de referência para a seleção das EPs para futuras Evs. Os tipos de dados a serem avaliados devem ser definidos ao configurar a EV, pode-se, por exemplo, estipular medidas de desempenho quanto ao cumprimento dos prazos, relação entre os custos reais e planejados, participação do REP no time, disponibilização correta e pontual das informações necessárias entre outras.

- Enviar módulo para próxima EP: ao finalizar o módulo de sua responsabilidade a EP deve enviá-lo a EP que dará continuidade a fabricação do produto. O envio do módulo é feito de acordo como o que foi estabelecido na ordem de transporte para o módulo.

- Enviar produto para o cliente: a EP responsável pela montagem final do produto, deve disponibilizar o produto para entrega de acordo como o que foi estabelecido na pedido do cliente e na ordem de transporte para o produto.

Como essas funções o processo Produzir é finalizado, tal como definido no escopo, inicia-se o processo Entregar, que é responsável pelo envio do produto ao cliente.

\subsection{Elaboração da Visão de Controle}

As inter-relações entre os objetos das visões de dados, funções e organizacional são representadas na visão de controle (ARIS, 1998). O principal método para a representação da visão de controle é o EPC (Event Process Chain) que significa 
cadeia de processos orientada a evento. Os eventos representam tanto a causa como o resultado de funções, sendo representados por hexágonos, como na FIGURA 39 (SCHEER, 1994). Combinando-se os eventos e as funções em uma seqüência é criado um EPC.

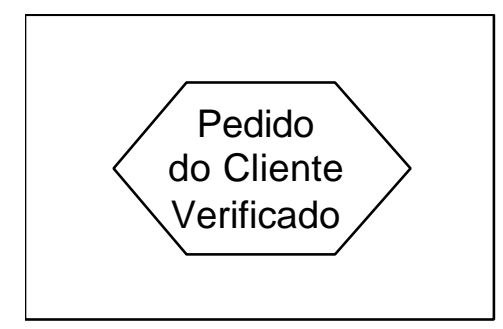

FIGURA 39 - Representação de um evento

Várias funções podem ser originadas simultaneamente a partir de um evento, como também, uma função pode ter como resultado vários eventos. Utilizando-se conectores é possível representar funções em paralelo e procedimentos de loop no EPC (ARIS, 1998). Esses conectores não servem apenas como conectores gráficos, mas definem as conexões lógicas entre os objetos. Os conectores utilizados no EPC e respectivas descrições são apresentados na TABELA 10.

TABELA 10 - Símbolo e Descrição dos Conectores

Representa o conector lógico E (AND), significa que todos os
eventos ou funções anteriores ligados ao conectores devem ter
ocorrido antes de atingir o próximo procedimento.

No EPC, os elementos da visão de dados podem ser representados por meio de Data Clusters. Um Data Cluster descreve uma visão lógica de um grupo de entidades e relacionamento de um modelo de dados necessários para a descrição de um objeto complexo, como também uma entidade, um relacionamento ou um de seus atributos. $A$ representação gráfica de um Data Cluster é ilustrada na FIGURA 40. 


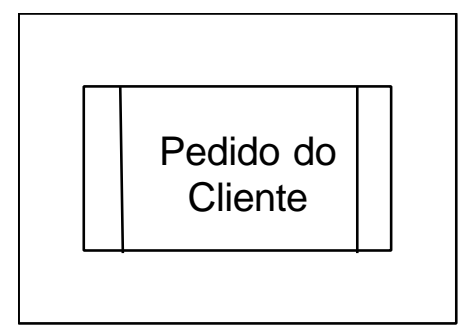

FIGURA 40 - Representação de um data cluster

Os EPCs gerados para cada sub-processos são apresentados no ANEXO C. Não é dada uma explicação dos EPCs, pois cada uma de suas partes já foi descrita separadamente e no próximo capítulo é apresentado um exemplo do modelo que ilustra a utilização do modelo. 


\section{Elaboração de um Exemplo de Aplicação do Modelo Proposto}

Este capítulo apresenta a elaboração de um exemplo do modelo proposto a fim de ilustrar a sua utilização. Inicialmente, foi criado um contexto que descreve a organização virtual e uma oportunidade de negócio a partir das quais uma EV fictícia é concebida. A seguir, são descritas, de forma sucinta, as atividades relacionadas à busca de parceiros e formação da EV. Para a fase de operação, é detalhado o processo de Planejamento e Controle da Produção segundo o modelo proposto.

Para dar suporte às atividades realizadas no planejamento da EV, optou-se por utilizar ferramentas da Microsoft normalmente disponíveis na maioria das empresas, tais como Excel e Project. As planilhas foram geradas a partir dos atributos especificados para as entidades e relacionamentos descritos na visão de dados e que se encontram detalhados no ANEXO B. Para ilustrar como cada EP pode usar o seu próprio sistema de informação para inserir o planejamento da EV, foi utilizado o sistema de gestão integrado R/3 da SAP, devido a sua disponibilidade no laboratório onde este trabalho foi realizado e por atender as necessidades do processo.

Este exemplo não tem como intenção discutir a viabilidade econômica nem tecnológica da EV a ser formada e seu respectivo produto.

\subsection{Descrição da Organização Virtual}

A organização virtual VirNet foi criada no ano de 1998, contando com a participação de 15 pequenas e médias empresas da região norte/nordeste do estado de São Paulo. A sede da organização fica no município de São Carlos, conhecido pólo de tecnologia do interior paulista. 
A OV visa explorar oportunidades no mercado brasileiro no ramo de transmissão de dados digital. A fim de buscar oportunidades de negócio para o grupo, a VirNet contratou um Agenciador. Esse Agenciador é um engenheiro eletrônico que trabalhou muitos anos na área comercial de uma indústria de bens de capital.

A VirNet contou com o auxílio de uma consultoria especializada em formação de OVs que acompanhou toda a sua formação. Essa consultoria propôs a utilização de modelos de referência para a realização dos processos das EVs a serem formadas. Todos os membros receberam treinamento necessário a fim de nivelar os conhecimentos, como por exemplo, em Desenvolvimento de Produtos e Gestão da Produção, e entender os conceitos envolvidos na formação e gerência de EVs.

Como infra-estrutura básica de informação, a OV utiliza a Internet. A VirNet desenvolveu uma Extranet para possibilitar a troca de informação entre suas empresas-membro, promovendo uma maior interatividade do grupo. São também realizadas reuniões para discutir as atividades a serem realizadas pelo grupo e possíveis oportunidades a serem exploradas.

\subsection{Identificação da Oportunidade}

O Agenciador obteve a informação de que algumas empresas de transportes públicos lançaram um programa de investimento em transmissão de dados. $O$ programa visa proporcionar informações on-line e acesso aos recursos disponíveis na Web para informação e lazer dos usuários de transportes públicos.

O produto proposto é um sistema de transmissão de dados digital a ser instalado em veículos públicos para viagens intermunicipais e estaduais. O sistema possui uma tela de cristal líquido e funciona como uma antena do sistema de transmissão de Internet, tanto podendo utilizar WAP (Wireless Application Protocol) como outra tecnologia, tendo como fontes satélites ou estações rádio base. A instalação de pontos de redes em veículos de transporte coletivo, para o acesso à Internet, será a principal atratividade do produto. O usuário poderá conectar notebooks ou palmpilots aos pontos de rede obtendo acesso rápido e barato à rede mundial de computadores.

A oportunidade está vinculada a uma licitação e o prazo de qualificação do edital demanda um curto ciclo de desenvolvimento de produto, trazendo a necessidade de 
agilildade e flexibilidade, características predominantes nas EVs. Essa oportunidade se enquadra na estratégia da OV, pois o produto contém alto valor agregado, está relacionado com a transmissão de dados digital e nenhuma das empresas conseguiria desenvolver e fabricar o produto sozinha.

\subsection{Busca por Parceiros}

A fim de identificar quais serão os parceiros da EV, inicialmente é preciso identificar as características técnicas do produto. As especificações técnicas do edital são analisadas pelo Agenciador juntamente com especialistas de algumas das empresas da VirNet. Baseando-se nas especificações técnicas, são identificadas as competências necessárias para explorar a oportunidade, sendo estas: projeto e montagem de componentes eletrônicos, desenvolvimento e fabricação de sistemas de amortecimento, injeção plástica e desenvolvimento de software para transmissão de dados.

O Agenciador filtra as competências necessárias, utilizando a base de dados da OV, já previamente preenchida com as competências de cada empresa. Identificadas as possíveis empresas, essas são comunicadas da oportunidade e se interessam em participar da EV. As empresas selecionadas foram as seguintes (TABELA 11):

TABELA 11 - Matriz de Participação

\begin{tabular}{|c|l|l|l|}
\hline Empresa & Competênica Utilizada & \multicolumn{1}{|c|}{ Módulo } & \multicolumn{1}{c|}{ Cidade } \\
\hline Amortece & $\begin{array}{l}\text { Desenvolvimento de sistemas de } \\
\text { amortecimento }\end{array}$ & Módulo Mecânico & Ribeirão Preto \\
\hline FIM & Usinagem & Módulo Mecânico & São Carlos \\
\hline InjetPlas & Injeção plástica & Caixa de Proteção & São Carlos \\
\hline MontaMicro & $\begin{array}{l}\text { Projeto e Montagem de } \\
\text { compontentes eletrônicos }\end{array}$ & Módulo Eletrônico & Araraquara \\
\hline TransSoft & $\begin{array}{l}\text { Desenvolvimento de software } \\
\text { para transmissão de dados }\end{array}$ & Módulo Software & Rio Claro \\
\hline
\end{tabular}

As empresas qualificadas possuem a capacidade e a competência necessária para cumprir os requisitos contidos no edital de licitação para este sistema de transmissão de dados. A empresa Amortece participa apenas do Desenvolvimento do 
Produto (DP) e as demais tanto do DP como da Produção. Uma vez selecionadas as empresas, inicia-se a etapa de formação da EV.

\subsection{Formação da EV}

As empresas parceiras assinam um contrato estipulando a responsabilidade de cada uma e os critérios para divisão dos resultados. É definido como duração inicial da EV, o prazo de um ano e que após esse período a cooperação será avaliada a fim de determinar a sua continuação ou dissolução. São também estabelecidas regras quanto a disponibilização, atualização e confidencialidade das informações transmitidas entre as empresas.

A empresa líder (EL) da EV escolhida pelo grupo é a MontaMicro, tornando-se responsável pela venda, montagem e emissão de faturas. As responsabilidades do produto perante aos órgãos de fiscalização e normalização ficam a cargo da EL.

\subsection{Operação da EV}

O primeiro processo da fase de operação é o desenvolvimento do produto $^{11}$. Durante o DP foram desenvolvidos e fabricados os protótipos que foram testados e aceitos pelas empresas cliente. O DP fornece a estrutura do produto e desenhos dos itens e do conjunto. Cada item pertencente ao produto possui um desenho criado em um sistema de CAD (Computer Aided Design) contendo suas dimensões, tolerâncias e material utilizado. Este arquivo é convertido em um arquivo de formato neutro para integração com outros software utilizados nas demais fases do desenvolvimento e para consultas na fase de produção. Também são disponibilizados os roteiros de produção e determinado o lead-time para cada item, tal como para os módulos. A seguir é apresentado um desenho do conjunto do produto da EV na FIGURA 41.

\footnotetext{
11 Esse processo não será detalhado neste texto, mas está sendo pesquisado no trabalho de mestrado de Luis Fernando Marques a ser defendido na Escola de Engenharia de São Carlos.
} 


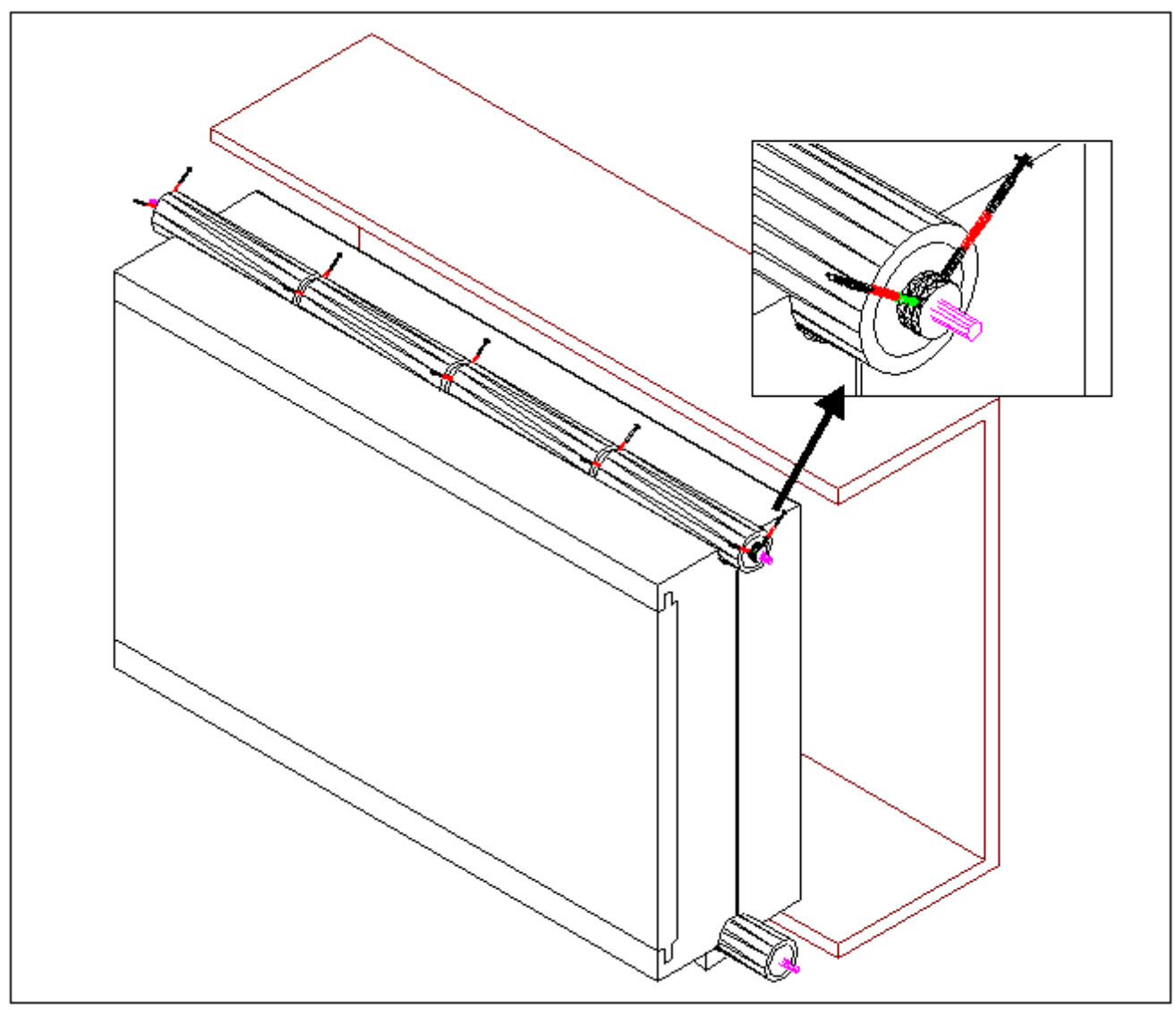

FIGURA 41 - Desenho do Conjunto

Para o Planejamento e Controle da Produção foram selecionados os integrantes do time de produção da EV (TPEV). O gerente de produção da EL foi indicado para coordenador de produção da EV (CPEV), e os gerentes de produção de cada EP formaram o TPEV. Todo o TPEV estudou detalhadamente o modelo de referência adotado pela OV. Não houve nenhuma alteração do modelo para atender a essa EV.

\subsubsection{Pré Planejar Produção da EV}

Primeiramente, o CPEV analisa a estrutura do produto (TABELA 12) a fim de conhecer o produto, pois não participou diretamente do time de desenvolvimento, apenas foi consultado sobre algumas questões relativas à produção. $\mathrm{Na}$ matriz de participação, que foi estabelecida na formação da EV, o CPEV identifica quais EPs são responsáveis por cada módulo. 
TABELA 12 - Estrutura do Produto

\begin{tabular}{|c|c|c|c|c|}
\hline Id. Item & Descrição Item & Tipo & Item-pai & Quant. \\
\hline 1 & $\begin{array}{l}\text { Sistema de Transmissão de Dados } \\
\text { para Veículos Coletivos (STDVC) }\end{array}$ & Produto & & \\
\hline 1.1 & Módulo Mecânico & Módulo & 1 & 1 \\
\hline 1.1 .1 & Sistema Amortecimento Superior & Sistema & 1.1 & 1 \\
\hline 1.1 .1 .1 & Borracha & Elemento & 1.1 .1 & 4 \\
\hline 1.1 .1 .2 & Eixo superior & Componente & 1.1 .1 & 1 \\
\hline 1.1.1.3 & Encosto cilíndrico & Elemento & 1.1 .1 & 4 \\
\hline 1.1.1.4 & Encosto central para haste & Componente & 1.1 .1 & 5 \\
\hline 1.1.1.5 & Encosto direito para haste & Componente & 1.1 .1 & 5 \\
\hline 1.1 .1 .6 & Encosto esquerdo para haste & Componente & 1.1 .1 & 5 \\
\hline 1.1 .1 .7 & Haste fixacão & Componente & 1.1 .1 & 10 \\
\hline 1.1.1.8 & Mola da haste & Elemento & 1.1 .1 & 10 \\
\hline 1.1.1.9 & Mola lateral & Elemento & 1.1 .1 & 2 \\
\hline 1.1 .1 .10 & Fecho roscado & Componente & 1.1 .1 & 2 \\
\hline 1.1 .2 & Sistema amortecimento inferior & Sistema & 1.1 & 1 \\
\hline 1.1 .2 .1 & Borracha & Elemento & 1.1 .2 & 4 \\
\hline 1.1 .2 .2 & Eixo inferior & Componente & 1.1 .2 & 1 \\
\hline 1.1 .2 .3 & Encosto cilíndrico & Elemento & 1.1 .2 & 4 \\
\hline 1.1 .2 .4 & Mancal & Elemento & 1.1 .2 & 4 \\
\hline 1.1 .2 .5 & Mola & Elemento & 1.1 .2 & 2 \\
\hline 1.1 .2 .6 & Fecho roscado & Componente & 1.1 .2 & 2 \\
\hline 1.2 & Caixa de Proteção & Módulo & 1 & 1 \\
\hline 1.2 .1 & Caixa interna dianteira & Componente & 1.2 & 1 \\
\hline 1.2 .2 & Caixa interna traseira & Componente & 1.2 & 1 \\
\hline 1.2 .3 & Presilha & Elemento & 1.2 & 4 \\
\hline 1.2 .4 & Tampa traseira & Componente & 1.2 & 1 \\
\hline 1.2 .5 & Tampa dianteira & Componente & 1.2 & 1 \\
\hline 1.2 .6 & Parafuso UNC M8 & Elemento & 1.2 & 4 \\
\hline 1.3 & Módulo Eletrônico & Módulo & 1 & 1 \\
\hline 1.3 .1 & Trasmissor de sinal & Componente & 1.3 & 1 \\
\hline 1.3 .2 & Painel LCD & Elemento & 1.3 & 1 \\
\hline 1.3 .3 & Processadores & Elemento & 1.3 & 3 \\
\hline 1.3 .4 & Processadores de imagem & Elemento & 1.3 & 1 \\
\hline 1.3 .5 & Receptor wap & Elemento & 1.3 & 10 \\
\hline 1.3 .6 & Decodificador wap & Elemento & 1.3 & 10 \\
\hline 1.3.7 & Fonte de alimentação & Elemento & 1.3 & 1 \\
\hline 1.3 .8 & Fusível & Elemento & 1.3 & 1 \\
\hline 1.4 & Módulo Software & Módulo & 1 & 1 \\
\hline
\end{tabular}

A seguir, O CPEV verifica os pedidos em carteira e determina o período de planejamento. A TABELA 13 apresenta os pedidos em carteira e respectivas quantidades e datas de entrega.

TABELA 13 - Pedidos em Carteira

\begin{tabular}{|c|r|c|l|l|r|}
\hline Id. Pedido & Data do Pedido & Quantidade & Descrição do Item & Id. Cliente & $\begin{array}{c}\text { Data de Entrega } \\
\text { Planejada }\end{array}$ \\
\hline 0001 & $21 / 07 / 00$ & 50 & STDVC & Empresa X & $01 / 11 / 00$ \\
\hline 0002 & $21 / 07 / 00$ & 50 & STDVC & Empresa X & $01 / 02 / 01$ \\
\hline 0003 & $21 / 07 / 00$ & 100 & STDVC & Empresa X & $01 / 05 / 01$ \\
\hline 0004 & $15 / 08 / 00$ & 50 & STDVC & Empresa $Y$ & $15 / 11 / 00$ \\
\hline 0005 & $15 / 08 / 00$ & 50 & STDVC & Empresa $Y$ & $15 / 12 / 00$ \\
\hline 0006 & $20 / 08 / 00$ & 10 & STDVC & Empresa J & $10 / 11 / 00$ \\
\hline
\end{tabular}


É determinado que serão planejados os pedidos para os próximos três meses, os pedidos 0001, 0004 e 0006. Para esses pedidos, são calculadas as necessidades de materiais e estimados os prazos, utilizando o lead-time já determinado para cada módulo. Na planilha representada na TABELA 14, é calculado o número total de horas e dias, considerando 8 horas disponíveis por dia e 5 dias por semana, para a produção de cada módulo.

TABELA 14 - Materiais e Tempos Necessários

\begin{tabular}{|l|c|c|c|c|c|c|}
\hline \multicolumn{1}{|c|}{ Item } & Pedido & Quant. & $\begin{array}{c}\text { Lead-time } \\
\text { unidade/hora }\end{array}$ & $\begin{array}{c}\text { Número de } \\
\text { horas }\end{array}$ & $\begin{array}{c}\text { Número de } \\
\text { dias (8 horas) }\end{array}$ & $\begin{array}{c}\text { Prazo } \\
\text { Pedido }\end{array}$ \\
\hline Módulo Mecânico & 0001 & 50 & 3 & 150 & 18,75 & $01 / 11 / 00$ \\
\hline Caixa de Protecão & 0001 & 50 & 1 & 50 & 6.25 & $01 / 11 / 00$ \\
\hline Módulo Eletrônico & 0001 & 50 & 2 & 100 & 12.5 & $01 / 11 / 00$ \\
\hline Módulo Software & 0001 & 50 & 1 & 50 & 6,25 & $01 / 11 / 00$ \\
\hline Módulo Mecânico & 0006 & 10 & 3 & 30 & 3,75 & $10 / 11 / 00$ \\
\hline Caixa de Protecão & 0006 & 10 & 1 & 10 & 1,25 & $10 / 11 / 00$ \\
\hline Módulo Eletrônico & 0006 & 10 & 2 & 20 & 2.5 & $10 / 11 / 00$ \\
\hline Módulo Software & 0006 & 10 & 1 & 10 & 1,25 & $10 / 11 / 00$ \\
\hline Módulo Mecânico & 0004 & 50 & 3 & 150 & 18.75 & $15 / 11 / 00$ \\
\hline Caixa de Protecão & 0004 & 50 & 1 & 50 & 6.25 & $15 / 11 / 00$ \\
\hline Módulo Eletrônico & 0004 & 50 & 2 & 100 & 12,5 & $15 / 11 / 00$ \\
\hline Módulo Software & 0004 & 50 & 1 & 50 & 6,25 & $15 / 11 / 00$ \\
\hline
\end{tabular}

As informações da planilha são transferidas para o Project. Nessa ferramenta são inseridas as precedências da seguinte forma: para o início de cada módulo é considerado o término da produção desse módulo para o pedido anterior, assim como dos módulos que o compõe.

Para estimar os prazos são considerados apenas os dias úteis. Foi inserida a data de início do primeiro módulo a ser produzido e as demais datas são calculadas automaticamente em função da duração e precedências. Houve um ajuste das datas de término das caixas de proteção para que coincidisse com o término do módulo mecânico, pois ambos são necessários para a montagem do módulo eletrônico. $O$ resultado do cálculo das datas pode ser verificado no Gráfico de Gantt na FIGURA 42. 


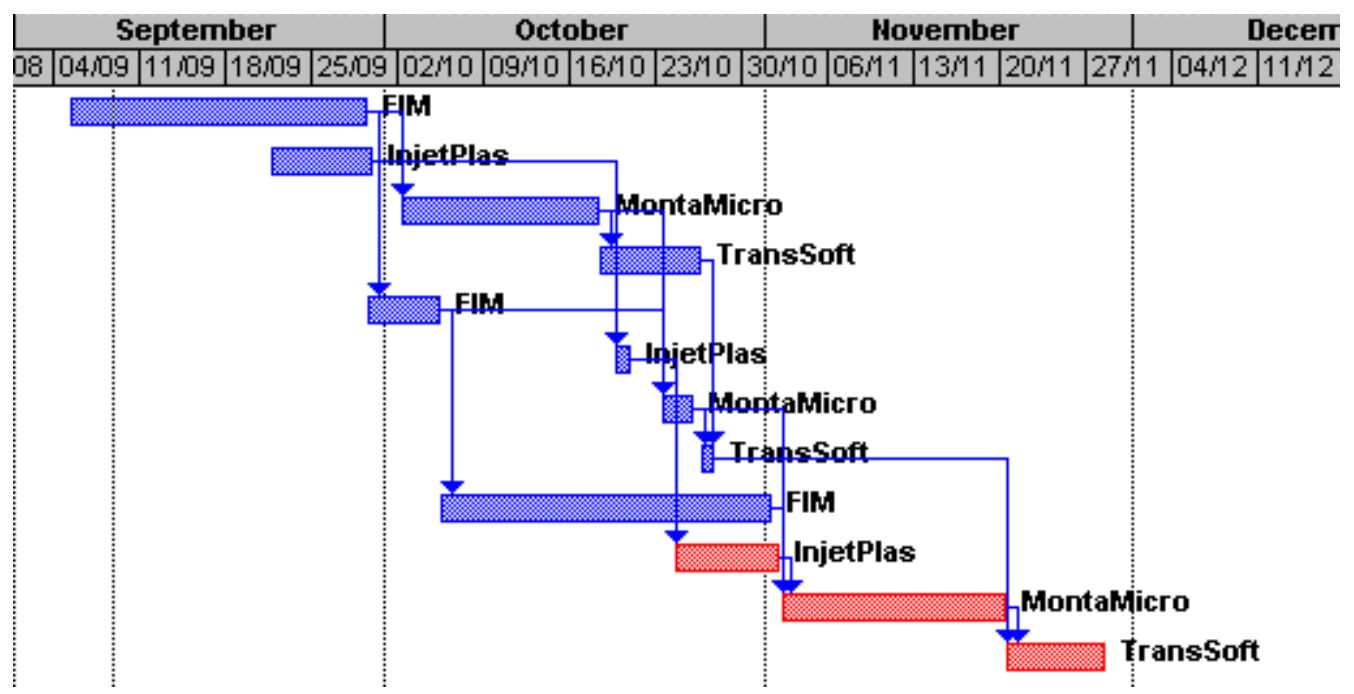

FIGURA 42 - Gráfico de Gantt: Quantidades e Prazos

É desconsiderado neste momento, o tempo gasto com transporte, pois não é um aspecto crítico devido à proximidade das empresas que estão localizadas na mesma região. Os pedidos 0001 e 0006 estão planejados dentro do prazo de entrega. $O$ pedido 0004 está com um provável atraso de 13 dias. Antes de tomar alguma decisão para evitar esse atraso, o CPEV solicita a confirmação dos dados de produção das EPs.

As EPs recebem um e-mail informando as quantidades a serem produzidas, os prazos inicialmente estimados, assim como um alerta do possível atraso no pedido 0004. As empresas também recebem uma planilha a ser preenchida confirmando a capacidade disponível no período, possíveis restrições, estoque existente e lead-time de produção. Essa planilha deve ser retornada para o CPEV dentro do prazo de resposta determinado para que ele consolide as informações de todas as EPs. $O$ resultado dessa consolidação é apresentado no TABELA 15.

TABELA 15 - Confirmação dos Dados de Produção

\begin{tabular}{|c|l|c|c|l|r|}
\hline Empresa & \multicolumn{1}{|c|}{ Módulo } & $\begin{array}{c}\text { Capacidade } \\
\text { (Horas/semana) }\end{array}$ & $\begin{array}{c}\text { Lead-Time } \\
\text { (Horas) }\end{array}$ & \multicolumn{1}{|c|}{ Restrição } & Estoque \\
\hline FIM & Módulo Mecânico & 50 & 3,00 & Nenhuma & 0 \\
\hline InjetPlas & Caixa de Protecão & 20 & 0,25 & Nenhuma & 10 \\
\hline MontaMicro & Módulo Eletrônico & 60 & 1,50 & $\begin{array}{l}\text { Matéria prima disponível } \\
\text { a partir de 01/10. }\end{array}$ & 0 \\
\hline TransSoft & Módulo Software & 40 & 0,50 & Nenhuma & 0 \\
\hline
\end{tabular}


Por ser o primeiro lote a ser produzido não há estoque existente, a não ser de 10 caixas que foram produzidas juntamente com o protótipo e que estão dentro das especificações. A única restrição informada foi a disponibilidade da matéria-prima para o módulo eletrônico apenas partir do dia 01/10. Os demais módulos utilizam como matéria-prima itens normalmente utilizados em outros produtos dentro das EPs, não sendo um aspecto crítico. Além disso, durante o DP, os fornecedores já haviam sido escolhidos e as compras de matéria-prima planejadas. Os lead-times são ajustados, assim como a capacidade de cada EP, segundo a TABELA 16:

TABELA 16 - Cálculo da Necessidade Líquida e Capacidade Necessária

\begin{tabular}{|l|c|c|c|c|c|c|c|}
\hline \multicolumn{1}{|c|}{ Item } & Pedido & Quant. & $\begin{array}{c}\text { Lead-time } \\
\text { (horas/unidade) }\end{array}$ & $\begin{array}{c}\text { Número de } \\
\text { horas }\end{array}$ & $\begin{array}{c}\text { Capacidade } \\
\text { (horas/semana) }\end{array}$ & $\begin{array}{c}\text { Número } \\
\text { de dias }\end{array}$ & $\begin{array}{c}\text { Prazo } \\
\text { Pedido }\end{array}$ \\
\hline Módulo Mecânico & 0001 & 50 & 3,00 & 150 & 50 & 15,00 & $01 / 11 / 00$ \\
\hline Caixa de Protecão & 0001 & 40 & 0,25 & 10 & 20 & 2,50 & $01 / 11 / 00$ \\
\hline Módulo Eletrônico & 0001 & 50 & 1,50 & 75 & 60 & 6,25 & $01 / 11 / 00$ \\
\hline Módulo Software & 0001 & 50 & 0,50 & 25 & 40 & 3,13 & $01 / 11 / 00$ \\
\hline Módulo Mecânico & 0006 & 10 & 3,00 & 30 & 50 & 3,00 & $10 / 11 / 00$ \\
\hline Caixa de Proteção & 0006 & 10 & 0,25 & 2,5 & 20 & 0,63 & $10 / 11 / 00$ \\
\hline Módulo Eletrônico & 0006 & 10 & 1,50 & 15 & 60 & 1,25 & $10 / 11 / 00$ \\
\hline Módulo Software & 0006 & 10 & 0,50 & 5 & 40 & 0,63 & $10 / 11 / 00$ \\
\hline Módulo Mecânico & 0004 & 50 & 3,00 & 150 & 50 & 15,00 & $15 / 11 / 00$ \\
\hline Caixa de Proteção & 0004 & 50 & 0,25 & 12,5 & 20 & 3,13 & $15 / 11 / 00$ \\
\hline Módulo Eletrônico & 0004 & 50 & 1,50 & 75 & 60 & 6,25 & $15 / 11 / 00$ \\
\hline Módulo Software & 0004 & 50 & 0,50 & 25 & 40 & 3,13 & $15 / 11 / 00$ \\
\hline
\end{tabular}

As necessidades de transporte são analisadas considerando-se o volume e o peso a ser transportado, assim como a distância a ser percorrida. Como o módulo mecânico e a caixa de proteção têm a mesma cidade origem e destino, além disso, precisam chegar na mesma data na empresa MontaMicro, optou-se por juntar as duas necessidades de transporte em uma única. A empresa InjetPlas que já atende a clientes na cidade de Araraquara, se candidatou como responsável pelo transporte, sendo aceita para tal. As necessidades de transporte são apresentadas na TABELA 17. 
TABELA 17 - Necessidade de Transporte

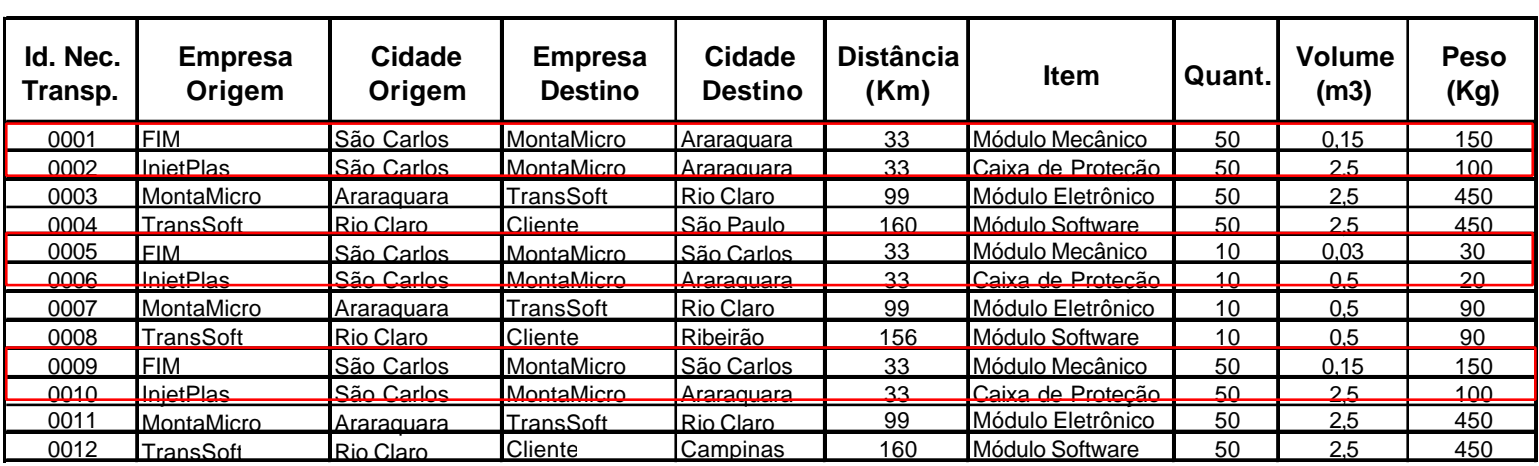

Para as demais necessidades de transporte, foram realizadas pesquisas em um site onde é possível encontrar diferentes opções de transporte com respectivas relações custo-benefício. As necessidades de transporte foram cadastradas no site e várias cotações recebidas, a partir das quais foram definidos os responsáveis pelo transporte. Assim, é finalizada a fase de pré-planejamento, sendo então iniciado o subprocesso de planejar a produção.

\subsubsection{Planejar Produção da EV}

A etapa de Planejamento da Produção é inicializada com a criação das ordens de produção e transporte para as necessidades anteriormente identificadas. Inicialmente, essas ordens são cadastradas em uma planilha. As informações contidas nas colunas Ordem, Item, Pedido, Duração e Empresa são transferidas para o Project. Tal como foi realizado ao calcular os prazos anteriormente, são inseridas as precedências e ajustadas algumas datas, como apresentado na TABELA 18. 
TABELA 18 - Ordens de Produção e Transporte

\begin{tabular}{|c|c|c|c|c|c|c|c|}
\hline Ordem & Item & Pedido & Duração & Início & Fim & Prec. & EP \\
\hline OP 0002 & Caixa de Proteçẫo & 0001 & $2,5 d$ & Wed 27/09,00 & Fri $29,09,00$ & & InjetPlas \\
\hline OT 0001 & Transporte & 0001 & $0,13 d$ & Mon 02/10,00 & Mon 02/10,00 & $1 ; 2$ & InjetPlas \\
\hline OP 0003 & Módulo Eletrônico & 0001 & $6,25 d$ & Mon 02/10,00 & Tue $10 / 10,00$ & 3 & MontaMicro \\
\hline OT 0003 & Transporte & 0001 & $0,25 d$ & Tue $10 / 10,00$ & Tue $10 / 10,00$ & 4 & TransportaT \\
\hline OP 0004 & Módulo Software & 0001 & $3,13 d$ & Tue $10 / 10,00$ & Fri $13 M 0,00$ & 5 & TransSoft \\
\hline OT 0004 & Transporte & 0001 & $0,5 \mathrm{~d}$ & Fri $13 M 0,00$ & Mon $16 / 10,00$ & 6 & Leva e Traz \\
\hline OP 0005 & Módulo Mecânico & 0006 & $3 d$ & Mon 02/10/00 & Wed 04/10,00 & 1 & FIM \\
\hline OP 0006 & Caixa de Proteçẫo & 0006 & $0,63 d$ & Wed $04 / 10 / 00$ & Wed $04 / 10 / 00$ & 2 & InjetPlas \\
\hline OT 0005 & Transporte & 0006 & $0,13 d$ & Thu $05 / 10,00$ & Thu $05 / 10,00$ & $8 ; 9$ & InjetPlas \\
\hline OP 0007 & Módulo Eletrônico & 0006 & $1,25 \mathrm{~d}$ & Tue $10 / 10,00$ & Wed $11 / 10,00$ & $4 ; 10$ & MontalMicro \\
\hline OT 0007 & Transporte & 0006 & $0,25 d$ & Wed $11 / 10,00$ & Wed 1119000 & 11 & TransportaT \\
\hline OP 0008 & Módulo Software & 0006 & $0,63 \mathrm{~d}$ & Fri $13 / 10,00$ & Mon 16/10,00 & $6 ; 12$ & TransSoft \\
\hline OT 0008 & Transporte & 0006 & $0,5 d$ & Mon 16/10/00 & Mon $16 / 10,00$ & 13 & Leva e Traz \\
\hline OP 0009 & Módulo Mecânico & 0004 & $15 d$ & Thu $05 / 10,00$ & Wed 25/10,00 & 8 & FIM \\
\hline OP 0010 & Caixa de Proteçẫo & 0004 & $3,13 d$ & Fri $20 / 10,00$ & Wed 25/10,00 & 9 & InjetPlas \\
\hline OT 0009 & Transporte & 0004 & $0,13 \mathrm{~d}$ & Thu $26 / 10,00$ & Thu $26 / 10,00$ & $15 ; 16$ & InjetPlas \\
\hline OP 0011 & Módulo Eletrônico & 0004 & $6,25 d$ & Thu $26 / 10,00$ & Fri $03 / 1100$ & $11 ; 17$ & MontalMicro \\
\hline OT 0011 & Transporte & 0004 & $0,25 \mathrm{~d}$ & Fri $03 / 11,00$ & Fri $03 / 11,00$ & 18 & TransportaT \\
\hline OP 0012 & Módulo Software & 0004 & $3,13 d$ & Fri $03 / 11,00$ & Wed 08/1100 & $13 ; 19$ & TransSoft \\
\hline OT 0012 & Transporte & 0004 & $0,5 d$ & Wed 08/11,00 & Thu $09 / 11,00$ & 20 & Leva e Traz \\
\hline
\end{tabular}

Como resultado da inserção das informações no Project, é gerado um Gráfico de Gantt, representando na FIGURA 43. As ordens representadas por barras em vermelho, são as pertencentes ao caminho crítico, que são identificadas automaticamente pelo Project. Como os pedidos estão sendo planejados dentro do prazo, não será necessário tomar nenhuma providência quanto ao caminho crítico, mas as ordens pertencentes ao caminho crítico devem ser controladas com maior rigor. 


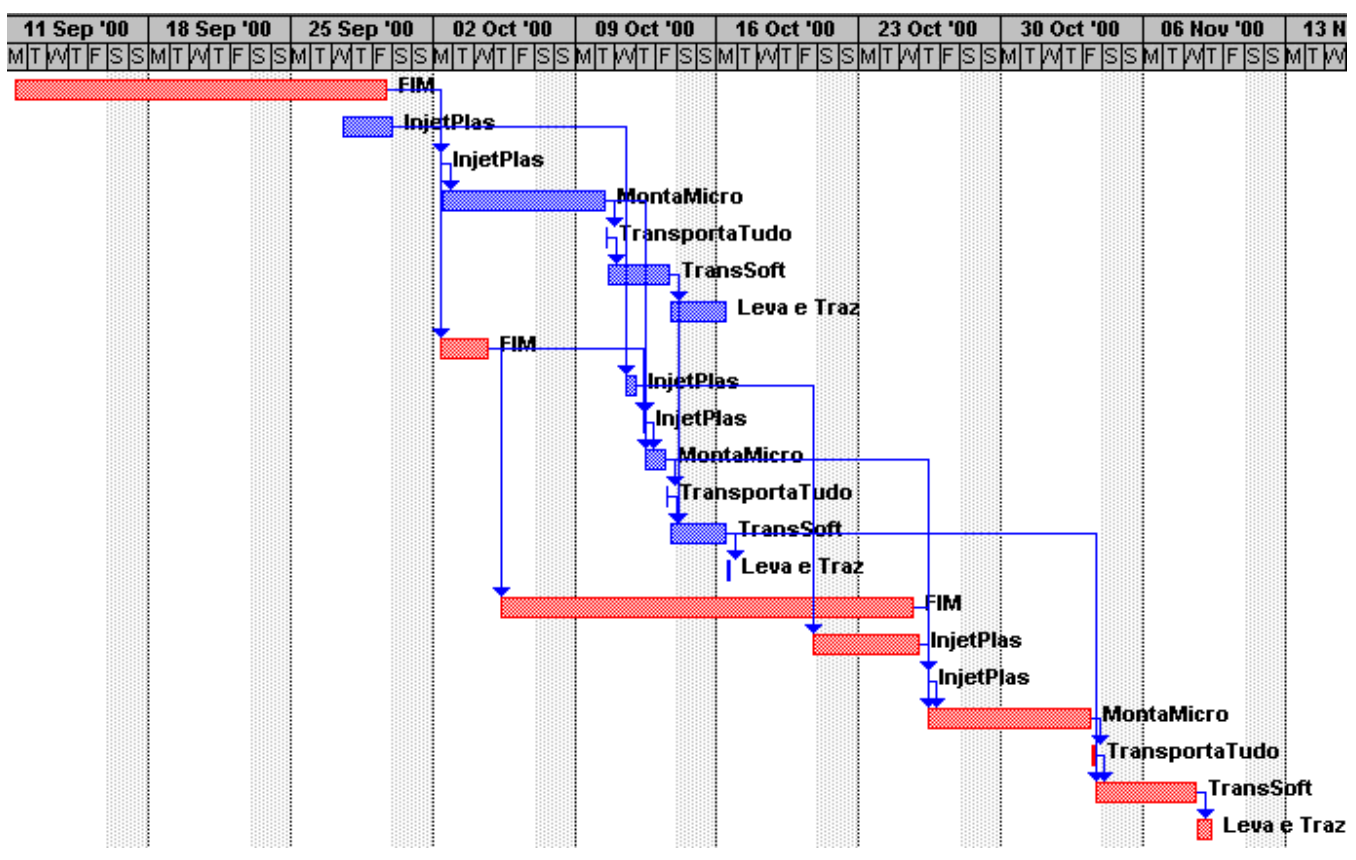

FIGURA 43 - Gráfico de Gantt: Planejamento da EV

Esse planejamento gerado é enviado às EPs e no fórum de discussão da Extranet da OV analisam as possíveis alterações. Algumas sugestões são feitas, no entanto com pouco impacto no planejamento inicial que é validado pelo TPEV.

\subsubsection{Inserir Planejamento nas Empresas Parceiras}

A inserção do planejamento é realizada em cada empresa parceira, mas será demonstrado para apenas em uma das EPs, a FIM. Essa EP utiliza o sistema R/3 da SAP, no qual já estão cadastrados a estrutura do módulo mecânico e os roteiros de produção que foram definidos durante o DP. A FIGURA 44 apresenta telas do sistema contendo a estrutura do módulo e um exemplo de roteiro de produção. 


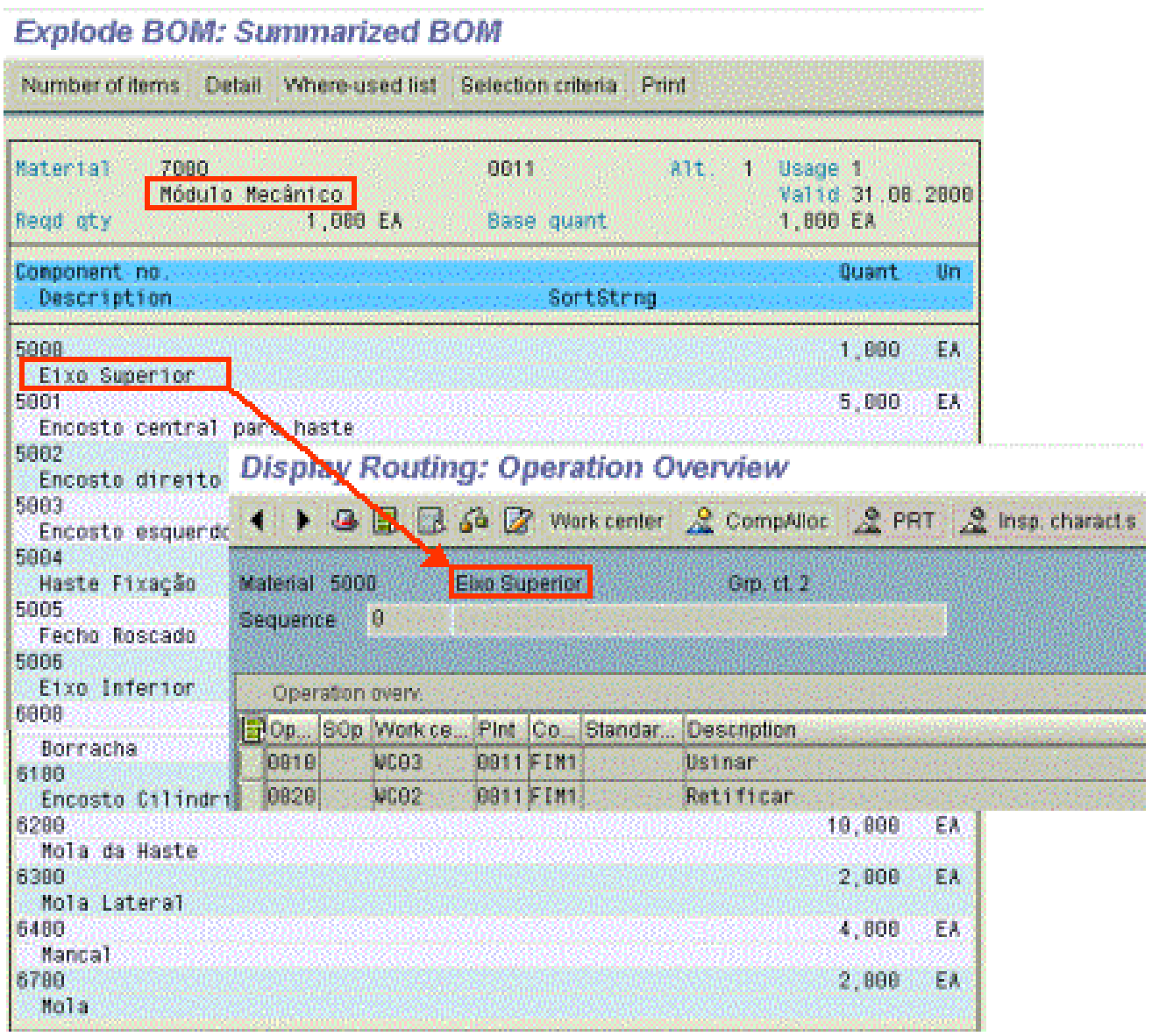

FIGURA 44 - Estrutura do Módulo Mecânico e Roteiro de Produção

O gerente de produção da FIM inicia a inserção das ordens de produção recebidas criando no sistema $\mathrm{R} / 3$ uma ordem de produção para 50 unidades do módulo mecânico a ser realizada entre 11/09 e 29/09 (FIGURA 45). 


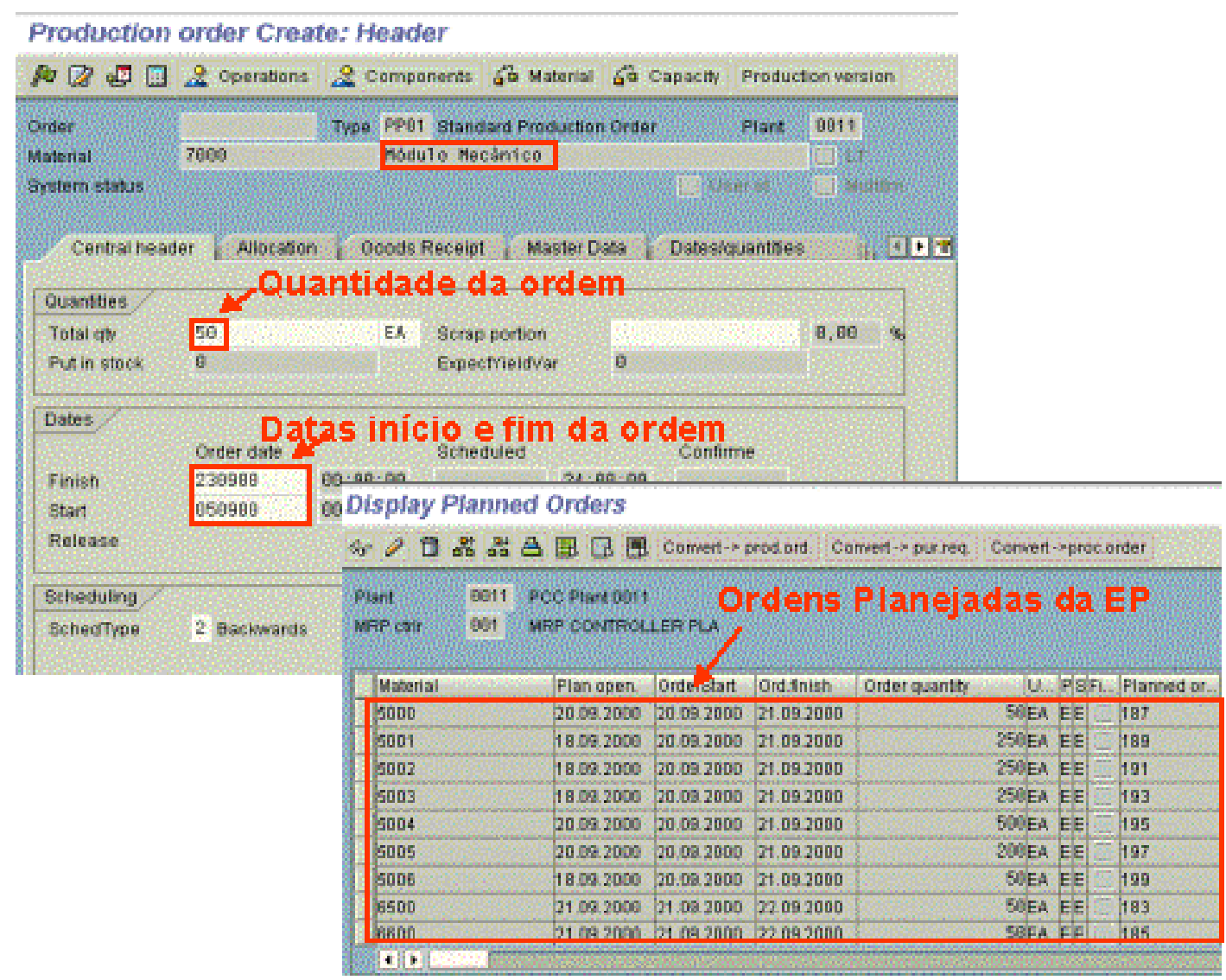

FIGURA 45 - Inserção da Ordem de Produção da EV na EP

Para essa ordem é rodado o MRP que gera as ordens de produção para os itens que compõe o módulo. Assim, a ordem de produção da EV é desdobrada em várias ordens de produção no planejamento da EP, como representado na tela do sistema na FIGURA 45.

Após inserir as ordens no sistema da empresa, a FIM assim como as demais empresas, reportam o planejamento ao CPEV, tornando o status de suas ordens como planejado.

\subsubsection{Programar e Controlar Produção}

Uma vez inseridas as ordens no planejamento da EP, o próximo passo é alocar as ordens aos recursos produtivos capazes de realizá-las, seqüenciadas por critérios de prioridade. Ao programar as ordens, são confrontadas as datas programadas com o planejamento da EV, pois caso as ordens programadas não estejam dentro das datas 
limite, um novo seqüenciamento é realizado para que o planejamento da EV seja respeitado.

Antes de liberar ordens para a produção, é verificada a disponibilidade dos recursos produtivos, isto é, se há capacidade disponível, e matéria-prima necessária para o processo. Sendo o resultado da verificação positivo, as ordens são liberadas, tal como o representado na FIGURA 46.

\begin{tabular}{|c|c|c|c|c|c|c|c|c|}
\hline \multicolumn{9}{|c|}{ Release Production Orders: List } \\
\hline \multicolumn{9}{|c|}{ 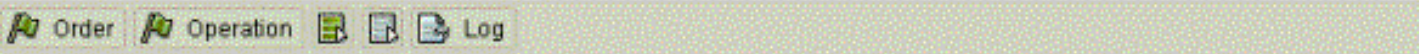 } \\
\hline Piant & 0011 & MRP controller & 001 & dScheduler & & & & \\
\hline \multicolumn{9}{|l|}{ Order list } \\
\hline Order & Material & Short tent & & Quantity & Un & OrdCat & t Release & Status \\
\hline 3000054 & 5001 & \multicolumn{2}{|c|}{ Encosto central para haste } & & 250EA & PP01 & 18.09 .2800 & CRTD PRC \\
\hline 3000055 & 5002 & \multicolumn{2}{|c|}{ Encosto direito para haste } & & $250 E A$ & PP01 & 18.09 .2800 & CRTD PRC \\
\hline 3000057 & 5003 & \multicolumn{2}{|c|}{ Encosto esquerdo para haste } & & $250 E A$ & PP01 & 18.09 .2000 & CRTD PRC \\
\hline 3000059 & 5008 & \multicolumn{2}{|c|}{ Eixo Inferior } & & $50 E A$ & PP01 & 18.09 .2800 & CRTD PRC \\
\hline 3000053 & 5000 & \multicolumn{2}{|c|}{ Ekxo Superior } & & $50 E A$ & PP01 & 21.09 .2000 & CRTD PRC \\
\hline 3000058 & 5004 & \multicolumn{2}{|c|}{ Haste Fixação } & & $500 E A$ & PP01 & 21.09 .2800 & CRTD PRC \\
\hline 3000056 & 5005 & \multicolumn{2}{|c|}{ Fecho Roscado } & & $200 E A$ & PP01 & $21,09,2800$ & CRTD PRC \\
\hline 3000060 & 8500 & \multicolumn{2}{|c|}{ Sistema de Amortecimento .. } & & $50 E A$ & PP01 & 21.09 .2000 & CRTD PRC \\
\hline 3000061 & 6600 & \multicolumn{2}{|c|}{ Sistema de Amortecimento l. } & & $50 E A$ & PP01 & 21.09 .2000 & CRTD PRC \\
\hline 3000052 & 7000 & \multicolumn{2}{|c|}{ Módulo Mecảnico } & & $50 E A$ & PP01 & 22.09 .2000 & CRTD PRC \\
\hline
\end{tabular}

FIGURA 46 - Liberação das Ordens de Produção

Uma vez liberadas, a execução das ordens é inicializada de acordo com as datas programadas seguindo o roteiro de produção. As ordens são monitoradas durante a sua execução e coletados dados sobre o seu status e quantidades produzidas. Este controle é realizado a fim de manter atualizada a programação da EP. Quando uma EP está executando ordens da EV, de acordo com o que foi estabelecido durante a configuração, deve enviar o status atual da programação seguindo a freqüência determinada. Um padrão para o controle das ordens é adotado, de acordo com os atributos definidos para a entidade ORDEM DE PRODUÇÃO DA EP.

A cada atualização da $E P$, é verificado se há algum desvio em relação ao planejamento original da EV. Caso ocorra algum desvio, o CPEV deve ser informado para que possa analisar os atrasos a fim de tomar as providências necessárias.

As ordens para os três pedidos foram executadas com sucesso, houve pequenos atrasos que não prejudicaram o atendimento do pedido no prazo estabelecido. Os 
dados de desempenho das EPs foram armazenados na base de dados da OV para serem utilizado na seleção das EPs para futuras EVs.

Espera-se com o exemplo apresentado ter possibilitado um melhor entendimento do modelo proposto neste trabalho. De certa forma, esse exemplo serviu como uma validação parcial do modelo, pois pode-se verificar a consistência da informações e atividades propostas. 


\section{Conclusões e Considerações Finais}

As EVs têm se apresentado como uma evolução das formas de cooperação, em função do seu ágil ciclo de vida, para atender a dinamicidade do mercado. Todavia, não se trata de um conceito totalmente novo. Cooperações temporárias entre empresas unindo o que cada uma tem de melhor para explorar uma oportunidade, vêm ocorrendo a muito tempo. GORANSON (1999) cita como exemplos a pesca baleeira e a indústria cinematográfica como casos antigos de EVs. O que é recente é o termo Empresas Virtuais que inicialmente foi utilizado por Byrne em 1993. O termo EV tem grande apelo na era digital e vem sendo utilizado por diversos autores com diferentes abordagens e contexto.

A falta de uma clara distinção entre outras formas de cooperação e o conceito de EV, foi identificada como uma barreira para o bom desempenho desse trabalho. Assim, tentou-se elaborar uma comparação entre as duas formas de cooperação mais próxima da EV, as empresas estendidas e as cadeias de suprimentos. Contudo ainda é necessário um estudo mais aprofundado, a fim de propor uma taxonomia para diferenciar as formas de cooperação e identificar qual a melhor forma de cooperação para diferentes tipos de negócios, processos, produtos e suas respectivas fases do ciclo de vida.

De qualquer forma, o conceito de Empresas Virtuais tem sido amplamente discutido para os seus diferentes tipos e a sua atualidade pode ser verificada pela data recente das referências utilizadas. Apesar da grande difusão e discussão sobre o conceito, ainda não existem dados significativos sobre a representatividade das EVs no mundo industrial, faltando exemplos tanto de sucesso como de fracasso. Encontra-se muitos trabalhos no âmbito acadêmico, mas poucos casos práticos.

Acredita-se que uma grande barreira para a formação de EVs se encontra na cultura organizacional, pois as empresas depois de muitos anos de competição 
passam a ter que cooperar para competir, podendo ainda não estar preparadas para tal. Como já foi exposto, a formação de OVs, que são grupos estáveis de empresas, pode aumentar a viabilidade de sucesso das cooperações temporárias por meio de um trabalho prévio a fim de gerar maior confiança, integração e nivelamento dos conhecimentos e estratégia da rede.

Assim, para que o conceito de EV seja realmente colocado em prática torna-se necessário um melhor detalhamento das infra-estruturas para o seu suporte, tais como a cultural, legal e de informação. Trabalhos sobre esses temas vêm sendo realizados no Grupo de Empresas Virtuais do NUMA, visando elaborar um modelo de referência completo para a formação e gerência de EVs tanto no que diz respeito aos processos como às infra-estruturas envolvidas.

Quanto às características de gestão da produção determinadas no trabalho, essas não são exclusivas de EVs, podendo ser também válidas para outras formas de cooperações ou até mesmo ao considerar uma única empresa. Pode-se por exemplo se dizer que para toda cadeia de suprimento é fundamental que haja cooperação, coordenação e troca de informações. Outra característica como o planejamento para oportunidades específicas é comum para empresa que trabalham em ambiente ETO.

O intuito de determinar essas características é deixar claro alguns cuidados especiais que se deve ter ao tratar de EVs e da sua gestão. No entanto, a gestão da produção em EV depende de variáveis tal como outros sistemas de produção, entre as quais pode-se citar:

- Volume de produção: uma EV pode atender a um único pedido, tendo mais um caráter de gestão de projeto ou a um conjunto de pedidos e diferentes lotes a serem planejados.

- Forma de interação com o cliente: os produtos da EV podem ser configurados ou desenvolvidos especialmente para um cliente, como também serem padronizados e oferecidos ao mercado.

Outro fator importante é como cada EP é estruturada e gerencia sua produção. É fundamental considerar a situação interna de cada empresa antes de selecioná-la para formar uma EV. Um levantamento da situação atual das empresas pertencentes à OV é proposto a fim de nivelar os principais conceitos envolvidos na gestão da produção 
de forma geral e em especial para EV. Esse nivelamento é importante para que cada empresa entenda o que é proposto no modelo a ser adotado para o PCP da EV.

Quanto ao uso de TI, esse é um facilitador muito importante, pois a troca de informações entre as empresas é fundamental para o planejamento e controle da produção, tal como para todo o ciclo de vida da EV. Porém o uso de modernas TIs não deve ser visto como requisito essencial. Como foi apresentado no exemplo do capítulo 5, foram utilizadas para o planejamento da EV tecnologias usualmente disponíveis na maioria das empresas, tal como Office e Internet e permitindo que cada EP use seu próprio sistema de gestão, no caso o R/3 da SAP.

Antes de definir a infra-estrutura de informação para a EV deve-se tentar nivelar suas necessidades da gestão da produção com a disponibilidade de sistemas da EPs. Em um levantamento realizado com oito empresas do projeto VIRTEC (ANEXO D), identificou-se a seguinte situação (TABELA 19) como exemplificação da situação de PMEs quanto ao uso de TI para a gestão da produção:

TABELA 19 - Uso de TI para a Gestão da Produção na Empresas do Projeto VIRTEC

\begin{tabular}{|c|c|c|c|c|}
\cline { 2 - 5 } \multicolumn{1}{c|}{} & $\begin{array}{c}\text { Sistema } \\
\text { Integrado }\end{array}$ & $\begin{array}{c}\text { Planilha } \\
\text { Eletrônica }\end{array}$ & $\begin{array}{c}\text { Não } \\
\text { Informatizado }\end{array}$ & Não Realiza \\
\hline $\begin{array}{c}\text { Planejar } \\
\text { producão }\end{array}$ & $42,9 \%$ & $28,6 \%$ & $14,3 \%$ & $14,3 \%$ \\
\hline $\begin{array}{c}\text { Programar } \\
\text { produção }\end{array}$ & $28,6 \%$ & $28,6 \%$ & $42,9 \%$ & $0,0 \%$ \\
\hline $\begin{array}{c}\text { Controlar } \\
\text { produção }\end{array}$ & $14,3 \%$ & $28,6 \%$ & $28,6 \%$ & $28,6 \%$ \\
\hline
\end{tabular}

Outro levantamento realizado com PMEs inglesas identificou que das 39 empresas que responderam ao questionário, 19 utilizam sistemas manuais de PCP (49\% das empresas) e das 13 que utilizam MRP/MRP II, apenas 3 trabalham com programação finita (LITTLE et al., 1997).

Assim, antes de propor a integração entre os sistemas das empresas, precisa-se primeiro analisar as necessidades das empresas e incentivar o uso de TI para suportálas. Contudo, pode-se ao inserir uma empresa membro em uma OV exigir uma infraestrutura de informação mínima tal como a proposta em MICHILIN (2000).

Quanto ao objetivo do trabalho, entende-se que foi atingido ao propor e gerar um modelo de referência para o planejamento e controle da produção em EVs. Esse 
modelo pode ser considerado de referência no sentido de ser um modelo genérico e um ponto de partida para a definição de como o processo pode ser realizado em uma EV.

Foram definidas todas as visões propostas no objetivo de forma a atender as características das EVs adotadas no trabalho e das características definidas para a sua gestão da produção.

O modelo não aborda alguns aspectos relacionados à produção, tais com controle da qualidade, custo e medidas de desempenho, podendo ser complementado em trabalhos futuros.

Para o seu uso em cada EV, o modelo deve ser adaptado aos requisitos das oportunidades de negócios e do ambiente da cooperação. Assim, faz-se necessário determinar em trabalhos futuros como adaptar o modelo para cada EV especifica, definindo critério a serem analisados e requisitos a atender.

Como resultado complementar, obteve-se um levantamento e sistematização de conceitos envolvidos relacionados a EVs e ao planejamento e controle de sua produção.

Como trabalhos futuros propostos estão:

- Desenvolvimento de um cenário completo do ciclo de vida de uma EV, expandindo o exemplo proposto.

- Definir como adaptar o modelo para cada EV específica, definindo critérios e requisitos em função das características da oportunidade e do ambiente da EV.

- Determinação de aspectos como determinação de custos, controle de qualidade e medidas de desempenho para a gestão da produção em EVs.

- Levantamento de sistemas computacionais que suportem o modelo proposto. 


\section{Anexos}

\section{ANEXO A - Processos do Framework Negócios Virtuais Globais}

Nas TABELAS 20 e 21 são apresentadas as atividades que compõe os processos do Grupo Virtual de Indústria e do Agenciador de Empresas Virtuais. As atividades são descritas em um detalhamento macro. Vale ressaltar que a definição dos processos se encontra em desenvolvimento pelo grupo de EV do NUMA.

TABELA 20 - Processos do Grupo Virtual de Indústria

\begin{tabular}{|l|}
\hline Formar Cluster \\
\hline Identificar o foco do Cluster \\
\hline Criar comite de formaccão do cluster \\
\hline Pré-estabelecer Estratégia do Cluster \\
\hline Procurar Empresas Interessadas \\
\hline Avaliar Empresas \\
\hline Definir Empresas do Cluster \\
\hline Consolidar a Estratégia do Cluster \\
\hline Formalizar Cluster \\
\hline Gerenciar o Cluster \\
\hline Divulgar o Cluster \\
\hline Promover Interatividade do Cluster (manter cluster informado) \\
\hline Gerenciar Conflitos \\
\hline Avaliar Membros \\
\hline Qualificar Membros \\
\hline Gerenciar as Informações sobre Competências Essenciais \\
\hline Identificar as Competências das Empresas \\
\hline Cadastrar as Competências das Empresas \\
\hline Gerenciar as Informações sobre as Empresas Virtuais \\
\hline Determinar indicadores de desempenho de EV \\
\hline Monitorar desempenho da EV \\
\hline Armazenar indicadores de desempenho \\
\hline Avaliar indicadores de desempenho \\
\hline
\end{tabular}


TABELA 21 - Processos do Agenciador de Empresas Virtuais

\begin{tabular}{|l|}
\hline Identificar Oportunidades de Mercado \\
\hline Rastrear Mercado \\
\hline Gerar Idéias \\
\hline Propor Estudo da Oportunidade \\
\hline Adaptar Análise de Atratividade \\
\hline Selecionar Grupo de Análise de Atratividade \\
\hline Realizar Análise de Atratividade \\
\hline Analisar resultado \\
\hline Identificar Competências Necessárias \\
\hline Definir Características Técnicas \\
\hline Determinar Competências Necessárias \\
\hline Identificar Empresas Detentoras das Competências \\
\hline Pré-Configurar EV \\
\hline Elaborar Plano de Negócios \\
\hline Configurar/Integrar EV \\
\hline Configurar Parceiros \\
\hline Configurar Infra-estrutura \\
\hline Estabelecer Contrato da EV \\
\hline
\end{tabular}




\section{ANEXO B - Descrição das Entidades e Relacionamentos}

A seguir, as entidades do MER e respectivos atributos são apresentados.

\section{Empresa Parceira}

\begin{tabular}{|l|l|}
\hline Atributo & Descrição \\
\hline Identificação & Identificação da Empresa Parceira \\
\hline Nome & Nome da Empresa Parceira \\
\hline Endereço & Endereço da Empresa Parceira \\
\hline Bairro & Bairro da Empresa Parceira \\
\hline Cidade & Cidade da Empresa Parceira \\
\hline Estado & Estado da Empresa Parceira \\
\hline CEP & CEP da Empresa Parceira \\
\hline E-mail & E-mail geral da Empresa Parceira \\
\hline Telefone & Telefone geral da Empresa Parceira \\
\hline Fax & Fax geral da Empresa Parceira \\
\hline Contato & Nome do Contato dentro da Empresa Parceira \\
\hline Cargo do contato & Cargo do Contato \\
\hline E-mail do contato & E-mail do Contato \\
\hline Telefone do contato & Telefone do Contato \\
\hline Nome do representante & Nome do representante da Empresa Parceira \\
\hline Cargo do representante & Cargo do representante \\
\hline E-mail do representante & E-mail do representante \\
\hline Telefone do representante & Telefone do representante \\
\hline Histórico & Breve histórico sobre a empresa \\
\hline
\end{tabular}

Item

\begin{tabular}{|l|l|}
\hline Atributo & Descrição \\
\hline Identificação & Identificação do Item \\
\hline Descrição & Descrição do Item \\
\hline Tipo & $\begin{array}{l}\text { Tipo do item } \\
1-\text { Produto } \\
2 \text { - Módulo } \\
3 \text { - Componente } \\
4 \text { - Elemento }\end{array}$ \\
\hline Lead-time & Tempo de obtenção total do item, considerando os \\
& tempos de preparação, fila, processamento e \\
& movimentação. \\
\hline Roteiro & Identificação roteiro de produção do item \\
\hline
\end{tabular}




\begin{tabular}{|l|l|}
\hline Desenho & Identificação do desenho do item \\
\hline Estoque & Quantidade disponível em estoque do item \\
\hline Data Estoque & Data da última atualização da quantidade em estoque \\
\hline
\end{tabular}

\section{Cliente}

\begin{tabular}{|l|l|}
\hline Atributo & Descrição \\
\hline Identificação & Identificação do Cliente \\
\hline Nome & Nome do Cliente \\
\hline Endereço & Endereço do Cliente \\
\hline Bairro & Bairro do Cliente \\
\hline Cidade & Cidade do Cliente \\
\hline Estado & Estado do Cliente \\
\hline CEP & CEP do Cliente \\
\hline E-mail & E-mail geral do Cliente \\
\hline Telefone & Telefone geral do Cliente \\
\hline Fax & Fax do Cliente \\
\hline Contato & Nome do Contato dentro do Cliente \\
\hline Cargo do contato & Cargo do contato \\
\hline E-mail do contato & E-mail do contato \\
\hline Telefone do contato & Telefone do contato \\
\hline Histórico & Breve histórico sobre a empresa \\
\hline
\end{tabular}

\section{Pedido}

\begin{tabular}{|c|c|}
\hline Atributo & Descrição \\
\hline Identificação & Identificação do Pedido \\
\hline Data do Pedido & Data na qual o pedido foi feito \\
\hline Data de Entrega Planejada & Data de entrega planejada \\
\hline Data de Entrega Realizada & Data de entrega realizada \\
\hline Status & $\begin{array}{l}\text { Status do pedido } \\
1 \text { - Não Planejado } \\
2 \text { - Planejado } \\
3 \text { - Em execução } \\
4 \text { - Executado } \\
5 \text { - Entregue }\end{array}$ \\
\hline
\end{tabular}

\section{Planejamento da EV}

\begin{tabular}{|l|l|}
\hline Atributo & Descrição \\
\hline Identificação & Identificação do Planejamento da EV \\
\hline Início do Período & $\begin{array}{l}\text { Determinação do início do período do planejamento do } \\
\text { EV }\end{array}$ \\
\hline Fim do Período & Determinação do fim do período do planejamento do EV \\
\hline
\end{tabular}


Responsável Identificação do responsável pelo Planejamento da EV

\section{Necessidade de Materiais}

\begin{tabular}{|l|l|}
\hline Atributo & Descrição \\
\hline Identificação & Identificação da Necessidade de Materiais \\
\hline Item & Identificação do Item a produzir \\
\hline Quantidade Bruta & Quantidade da Bruta demandada do Item \\
\hline Quantidade Líquida & Quantidade Líquida a produzir do Item \\
\hline Prazo & Data que a necessidade deve ser atendida \\
\hline
\end{tabular}

\section{Ordem de Produção da EV}

\begin{tabular}{|l|l|}
\hline Atributo & Descrição \\
\hline Identificação & Identificação da Ordem de Produção da EV \\
\hline Item & Identificação do Item a ser produzido \\
\hline Empresa Parceira & $\begin{array}{l}\text { Identificação da Empresa Parceira responsável pela } \\
\text { produção do Item }\end{array}$ \\
\hline Data de início planejada & Data de início planejada \\
\hline Data de término planejada & Data de término planejada \\
\hline Quantidade planejada & Quantidade planejada \\
\hline Crítica & $\begin{array}{l}\text { Atividade Crítica } \\
1\end{array}$ \\
& 2 - Crítica \\
\hline Status & Status da Oríca \\
& 1 - Planejada \\
& 2 - Programada \\
& 3 - Liberada \\
& 4 - Em execução \\
& 5 - Executada \\
\hline Atraso & Respeito ao prazo \\
& 1 - Dentro do Prazo \\
& 2 - Atrasada \\
\hline Motivo Atraso & Descrição do motivo do atraso \\
\hline
\end{tabular}

\section{Ordem de Produção da EP}

\begin{tabular}{|l|l|}
\hline Atributo & Descrição \\
\hline Identificação & Identificação da Ordem de Produção \\
\hline Item & Identificação do Item a ser produzido \\
\hline Data de início planejada & Data de início planejada \\
\hline Data de término planejada & Data de término planejada \\
\hline $\begin{array}{l}\text { Tempo de processamento } \\
\text { planejado }\end{array}$ & Tempo de processamento planejado \\
\hline
\end{tabular}




\begin{tabular}{|l|l|}
\hline $\begin{array}{l}\text { Tempo de preparação } \\
\text { planejado }\end{array}$ & Tempo de preparação planejado \\
\hline Tempo de espera planejado & Tempo de espera planejado \\
\hline $\begin{array}{l}\text { Tempo de transporte } \\
\text { planejado }\end{array}$ & Tempo de transporte planejado \\
\hline Data de início programada & Data de início programada \\
\hline $\begin{array}{l}\text { Data de término } \\
\text { programada }\end{array}$ & Data de término programada \\
\hline $\begin{array}{l}\text { Tempo de processamento } \\
\text { programado }\end{array}$ & Tempo de processamento programado \\
\hline $\begin{array}{l}\text { Tempo de preparação } \\
\text { programado }\end{array}$ & Tempo de preparação programado \\
\hline $\begin{array}{l}\text { Tempo de espera } \\
\text { programado }\end{array}$ & Tempo de espera programado \\
\hline $\begin{array}{l}\text { Tempo de transporte } \\
\text { programado }\end{array}$ & Tempo de transporte programado \\
\hline Data de início executada & Data de início executada \\
\hline Data de término executada & Data de término executada \\
\hline $\begin{array}{l}\text { Tempo de processamento } \\
\text { executado }\end{array}$ & Tempo de processamento executado \\
\hline $\begin{array}{l}\text { Tempo de preparação } \\
\text { executado }\end{array}$ & Tempo de preparação executado \\
\hline Tempo de espera executado & Tempo de espera executado \\
\hline $\begin{array}{l}\text { Tempo de transporte } \\
\text { executado }\end{array}$ & Tempo de transporte executado \\
\hline Quantidade planejada & Quantidade planejada \\
\hline Quantidade produzida & Quantidade produzida \\
\hline Quantidade rejeitada & Quantidade rejeitada \\
\hline Crítica & $\begin{array}{l}\text { Atividade Crítica } \\
1 \text { - Crítica } \\
2 \text { - Não Crítica }\end{array}$ \\
\hline Status & $\begin{array}{l}\text { Status da Ordem } \\
1 \text { - Planejada } \\
2 \text { - Programada } \\
3 \text { - Liberada } \\
4 \\
5 \text { - Em execução } \\
5 \text { - Executada }\end{array}$ \\
\hline $\begin{array}{l}\text { Atraso - Dentro do Prazo } \\
2 \text { - Atrasada }\end{array}$ \\
\hline
\end{tabular}

\section{Necessidade de Transporte}

\begin{tabular}{|l|l|}
\hline Atributo & Descrição \\
\hline Identificação & Identificação da Necessidade de Transporte \\
\hline
\end{tabular}




\begin{tabular}{|l|l|}
\hline Item & Identificação do item a ser transportado \\
\hline Empresa Origem & Identificação da empresa origem \\
\hline Empresa Destino & Identificação da empresa destino \\
\hline Distância & Distância entre as empresas \\
\hline Quantidade & Quantidade de itens a ser transportada \\
\hline Volume & Volume a ser transportado (por item) \\
\hline Peso & Peso a ser transportado (por item) \\
\hline
\end{tabular}

\section{Ordem de Transporte}

\begin{tabular}{|c|c|}
\hline Atributo & Descrição \\
\hline Identificação & Identificação da Ordem de Produção \\
\hline Empresa Transportadora & $\begin{array}{l}\text { Identificação da Empresa Transportadora escolhida para } \\
\text { realizar a ordem de transporte }\end{array}$ \\
\hline Data de início planejada & Data de início planejada \\
\hline Data de término planejada & Data de término planejada \\
\hline Data de início programada & Data de início programada \\
\hline $\begin{array}{l}\text { Data de término } \\
\text { programada }\end{array}$ & Data de término programada \\
\hline Data de início realizada & Data de início realizada \\
\hline Data de término realizada & Data de término realizada \\
\hline Crítica & $\begin{array}{l}\text { Atividade Crítica } \\
1 \text { - Crítica } \\
2 \text { - Não Crítica }\end{array}$ \\
\hline Status & $\begin{array}{l}\text { Status da Ordem } \\
1 \text { - Planejada } \\
2 \text { - Programada } \\
3 \text { - Liberada } \\
4 \text { - Em execução } \\
5 \text { - Executada }\end{array}$ \\
\hline Atraso & $\begin{array}{l}\text { Respeito ao prazo } \\
1 \text { - Dentro do Prazo } \\
2 \text { - Atrasada }\end{array}$ \\
\hline Motivo Atraso & Descrição do motivo do atraso \\
\hline
\end{tabular}

\section{Empresa Transportadora}

\begin{tabular}{|l|l|}
\hline Atributo & Descrição \\
\hline Identificação & Identificação da Empresa Transportadora \\
\hline Nome & Nome da Empresa Transportadora \\
\hline Endereço & Endereço da Empresa Transportadora \\
\hline Bairro & Bairro da Empresa Transportadora \\
\hline Cidade & Cidade da Empresa Transportadora \\
\hline Estado & Estado da Empresa Transportadora \\
\hline CEP & CEP da Empresa Transportadora \\
\hline
\end{tabular}




\begin{tabular}{|l|l|}
\hline E-mail & E-mail da Empresa Transportadora \\
\hline Telefone & Telefone geral da Empresa Transportadora \\
\hline Fax & Fax geral da Empresa Transportadora \\
\hline Contato & Contato na Empresa Transportadora \\
\hline E-mail Contato & E-mail do Contato \\
\hline Telefone Contato & Telefone do Contato \\
\hline
\end{tabular}

A seguir, os relacionamentos existentes no MER são apresentados, assim como sua cardinalidade e atributos.

\section{Matriz de Participação}

Cardinalidade $1 \times \mathrm{N}$ : uma EMPRESA PARCEIRA pode fornecer vários ITENS, mas um ITEM somente pode ser provido por uma EMPRESA PARCEIRA. São relacionados os ITENS do tipo módulo às EMPRESAS PARCEIRAS.

\section{Estrutura do Produto}

Cardinalidade N x M: um ITEM-pai é composto por até N ITENS-filho e um ITEM-filho pode fazer parte de até $M$ diferentes ITENS-pai.

\begin{tabular}{|l|l|}
\hline Atributo & Descrição \\
\hline Identificação do item-pai & Identificação do item-pai \\
\hline Identificação do item-filho & Identificação do item-filho \\
\hline Quantidade & Quantidade do item-filho \\
\hline Unidade & Unidade de medida do item-filho \\
\hline
\end{tabular}

\section{Pedido do Cliente}

Cardinalidade $1 \times \mathrm{N}$ : um CLIENTE pode solicitar até $\mathrm{N}$ diferentes PEDIDOS, um PEDIDO pode pertence a apenas um CLIENTE.

\section{Estrutura do Pedido}

Cardinalidade $\mathrm{N} \times \mathrm{M}$ : um PEDIDO pode ter $\mathrm{N}$ até ITENS e um ITEM pode estar presente em $\mathrm{M}$ diferentes PEDIDOS.

\begin{tabular}{|l|l|}
\hline Atributo & Descrição \\
\hline Identificação do pedido & Identificação do pedido \\
\hline
\end{tabular}




\begin{tabular}{|l|l|}
\hline Identificação do item & Identificação do item \\
\hline Quantidade & Quantidade do item \\
\hline
\end{tabular}

\section{Pedidos a Planejar}

Cardinalidade $1 \times \mathrm{N} \times \mathrm{M}$ : um PLANEJAMENTO DA EV atende a até $\mathrm{N}$ diferentes PEDIDOS podendo gerar M NECESSIDADES DE MATERIAIS.

\begin{tabular}{|l|l|}
\hline Atributo & Descrição \\
\hline $\begin{array}{l}\text { Identificação do } \\
\text { planejamento }\end{array}$ & Identificação do planejamento \\
\hline Identificação do pedido & Identificação do pedido \\
\hline $\begin{array}{l}\text { Identificação da } \\
\text { necessidade de materiais }\end{array}$ & Identificação d necessidade de materiais \\
\hline
\end{tabular}

\section{Necessidade x Ordem de Produção}

Cardinalidade $\mathrm{N} \times \mathrm{M}$ : uma NECESSIDADE DE PRODUÇÃO pode gerar até $\mathrm{N}$ diferentes ORDENS DE PRODUÇÃO e uma ORDEM DE PRODUÇÃO pode ter sido gerada por até $M$ diferentes NECESSIDADES DE PRODUÇÃO.

\section{Necessidade $\mathrm{x}$ Ordem de Transporte}

Cardinalidade $\mathrm{N} \times \mathrm{M}$ : uma NECESSIDADE DE TRANSPORTE pode gerar até $\mathrm{N}$ diferentes ORDENS DE TRANSPORTE e uma ORDEM DE TRANSPORTE pode ter sido gerada por até $M$ diferentes NECESSIDADES DE TRANSPORTE.

\section{Ordens do Planejamento da EV}

Cardinalidade $1 \times \mathrm{N} \times \mathrm{M}$ : um PLANEJAMENTO DA EV pode possuir $\mathrm{N}$ diferentes ORDENS DE PRODUÇÃO DA EV e também até $M$ diferentes ORDENS DE PRODUÇÃO. Nesse relacionamento são indicadas as precedências entre as ordens, tanto de produção como de transporte. Uma ordem pode ter desde nenhuma com várias ordens precedentes.

\begin{tabular}{|l|l|}
\hline Atributo & Descrição \\
\hline $\begin{array}{l}\text { Identificação do } \\
\text { planejamento }\end{array}$ & Identificação do planejamento da EV \\
\hline
\end{tabular}




\begin{tabular}{|l|l|}
\hline Identificação da ordem & Identificação da ordem de produção ou transporte da EV \\
\hline $\begin{array}{l}\text { Identificação da ordem } \\
\text { precedente }\end{array}$ & Identificação da ordem precedente \\
\hline
\end{tabular}

\section{Desdobramento da Ordem}

Cardinalidade $1 \times \mathrm{N}$ : uma ORDEM DE PRODUÇÃO DA EP pertence a apenas uma ORDEM DE PRODUÇÃO DA EV, mas uma ORDEM DE PRODUÇÃO DA EV pode ser constituída por até $\mathrm{N}$ diferentes ORDENS DE PRODUÇÃO DA EP.

\section{Ordem alocada ao Recurso}

Cardinalidade $\mathrm{N}$ x M: uma ORDEM DE PRODUÇÃO DA EP pode ser alocada até $\mathrm{N}$ diferentes RECURSOS e um RECURSO pode ter até M ORDEM DE PRODUÇÃO DA EP alocadas.

\section{Recurso da Empresa}

Cardinalidade $1 \times \mathrm{N}$ : uma EMPRESA PARCEIRA pode ter até $\mathrm{N}$ diferentes RECURSOS, mas um RECURSO só pode pertencer a uma EMPRESA PARCEIRA.

\section{Custo / Tempo de Transporte}

Cardinalidade $\mathrm{N}$ x M: uma NECESSIDADE DE TRANSPORTE pode ser realizada por até $\mathrm{N}$ diferentes EMPRESAS TRANSPORTADORAS, e uma EMPRESA TRANSPORTADORA pode atender a até M NECESSIDADES DE TRANSPORTE. Para cada uma desses relacionamentos existe um custo e tempo de transporte associado.

\begin{tabular}{|l|l|}
\hline Atributo & Descrição \\
\hline Identificação & Identificação do Custo/Tempo de Transporte \\
\hline $\begin{array}{l}\text { Identificação da } \\
\text { Necessidade de Transporte }\end{array}$ & Identificação da Necessidade de Transporte \\
\hline $\begin{array}{l}\text { Identificação da Empresa } \\
\text { Transportadora }\end{array}$ & Identificação da Empresa Transportadora \\
\hline Tipo & Tipo de transporte \\
\hline Tempo & Tempo de transporte (em minutos) \\
\hline Custo & Custo de transporte \\
\hline
\end{tabular}


ANEXO C - Modelos gerados na Visão de Controle 


\section{ANEXO D - Levantamento do uso de Tecnologia de Informação nas Empresas do Projeto VIRTEC}

O projeto VIRTEC ${ }^{12}$ teve início no NUMA, como um projeto pioneiro de uma Organização Virtual (OV) brasileira em outubro de 1998. O projeto VIRTEC é formado por nove PMEs, todas de São Carlos, provendo produtos e serviços tecnológicos, com alto valor agregado. A VIRTEC possui as competências em materiais recicláveis, fundição de aços especiais, automação, desenvolvimento de materiais poliméricos especiais, dispositivos hidráulicos, montagem e assistência técnica, usinagem e mecatrônica, instrumentação e software, equipamentos odontológicos e fornos especiais.

Uma vez que o projeto VIRTEC foi proposto, existem diferentes objetivos sendo visados. Estes objetivos podem, mas não necessariamente devem, ser alcançados em paralelo, e sua completa realização é uma questão de como aprender a operar virtualmente. Estes objetivos são:

1. Fornecer aos membros da VIRTEC uma melhor visibilidade de mercado e acesso a novos clientes;

2. Intensificar a cooperação informal entre os membros da VIRTEC;

3. Prover integração entre a universidade e o ambiente industrial;

4. Possibilitar uma melhor utilização das competências das empresas, como um todo;

5. Obter uma maior taxa de aquisição de know how através do compartilhamento de idéias e conceitos,

6. Viabilizar a formação de EVs.

No momento, alguns membros da VIRTEC já estão usufruindo os benefícios de fazer parte do projeto. No entanto, um benefício comum obtido por todos os membros foi a maior exposição ao mercado. Desde o lançamento da VIRTEC no mercado tem

\footnotetext{
${ }^{12}$ www.virtec.com.br
} 
havido um interesse da mídia técnica brasileira, refletida por artigos publicados (Gazeta Mercantil, Estado de São Paulo, Revista Máquinas e Metais, entre outros)).

Outros benefícios são brevemente descritos a seguir:

- Martelo reciclável de poliuretano (objetivos 2, 4 e 5): um dos membros da VIRTEC (Kehl) possui competência em borracha e espumas poliméricas, especificamente naquelas de natureza biodegradável. Como resultado de sete anos de pesquisa auto-patrocinada, foi desenvolvido um tipo de borracha vegetal em poliuretano. Esta borracha possui diversas aplicações tais como: montagem mecânica, acabamento de peças, diagnósticos médicos e assim por diante. Devido às características deste material é possível obter diversos graus de rigidez da borracha, dependendo do seu uso. Considerando este potencial a empresa tentou desenvolver um martelo totalmente feito de borracha vegetal em poliuretano. No entanto, os altos custos associados à produção do cabo e seu ciclo de vida não satisfatório foram fatores determinantes na procura por novas soluções. A empresa A procurou ajuda na VIRTEC onde ela encontrou a empresa Fultec - um produtor make-to-order de pedaços de ligas de aço especial - a fim de desenvolver um cabo barato, leve e reciclável para o martelo. Como resultado desta cooperação, o cabo desenvolvido é mais barato, mais leve e possui um maior ciclo de vida. Atualmente, este martelo está sendo vendido para a Comunidade Européia e para os Estados Unidos.

- amortecedor de borracha para uma secadora de roupas (objetivos 2, 3, 4 e 5): outro membro da VIRTEC, empresa Latina Eletrodomésticos, estava procurando um tipo de amortecedor eficiente para ser usado na coluna de um motor elétrico de uma nova secadora de roupas. A questão é que a empresa $C$ queria uma solução customizada para seu problema e não havia uma solução disponível no mercado capaz de atender aos requisitos. Através da VIRTEC, em conseqüência do compartilhamento de idéias e conhecimentos, a Latina e a empresa Kehl uniram-se a fim de desenvolver um novo amortecedor feito de borracha vegetal de poliuretano. Entretanto, havia uma falta de conhecimento no que se refere à absorção de vibração, uma questão primordial para o desenvolvimento do amortecedor. Para solucionar tal carência, um especialista do Departamento de 
Engenharia Mecânica da Escola de Engenharia de São Carlos foi contatado. O amortecedor, até agora, está em sua fase de testes/aprovação.

- Venda de produção (objetivo 1): Para seus membros, a VIRTEC oferece uma maior visibilidade e atuação no mercado. Um exemplo dos resultados que a VIRTEC traz para seus membros é a Kehl, que teve a produção anual de um de seus produtos totalmente vendida por meio de um contato proporcionado pela VIRTEC.

Foi realizado um levantamento junto a oito empresas participante do Projeto VIRTEC, com objetivo de identificar quais recursos de TI eram utilizados como parte do trabalho de MICHILIN (2000). A autora do presente trabalho de mestrado acompanhou esse levantamento enfoncando em como eram realizadas as atividades de PCP nas empresas. Os resultados do levantamento estão apresentados nas TABELAS 22 e 23. 
TABELA 22 - Levantamento do uso de TI nas Empresas do Projeto VIRTEC (Parte I)

\begin{tabular}{|c|c|c|c|c|}
\hline & Empresa 1 & Empresa 2 & Empresa 3 & Empresa 4 \\
\hline Número de Funcionários & 30 & 36 & 160 & 4 \\
\hline Faturamento (em 1999) & $\mathrm{R} \$ 2.300 .000,00$ & $\mathrm{R} \$ 1.200 .000,00$ & $\mathrm{R} \$ 8.830 .930,00$ & $\mathrm{R} \$ 240.000,00$ \\
\hline Tipologia de Produção & $\begin{array}{l}50 \% \text { sob encomenda (CTO) } \\
50 \% \text { itens de série (MTO) }\end{array}$ & $100 \%$ sob encomenda & $\begin{array}{l}\text { Sob encomenda, algumas } \\
\text { máquinas são produzidas } \\
\text { acompanhado os pedidos } \\
\text { existentes }\end{array}$ & Não produz (terceiriza) \\
\hline $\begin{array}{l}\text { Sistema Computacional } \\
\text { Utilizado }\end{array}$ & $\begin{array}{l}\text { Sistema comercial Sistec } \\
\text { Módulos: Contabilidade, } \\
\text { Financeiro, Compras, Estoques }\end{array}$ & $\begin{array}{l}\text { Não possui sistema } \\
\text { Utiliza planilhas Excel }\end{array}$ & $\begin{array}{l}\text { Sistema caseiro-Unix/Dataflex } \\
\text { Módulos: Vendas, Esoque, } \\
\text { PCP, Assistência Técnica } \\
\text { Sistemas comerciais para RH e } \\
\text { Contabilidade }\end{array}$ & Não utiliza \\
\hline Prever demanda/vendas & \begin{tabular}{|l|} 
Previsão de Vendas feita no \\
começo do ano baseada na \\
experiência e faturamento do \\
ano anterior. Não informatizado
\end{tabular} & Não realiza & Não informatizado & Não produz (terceiriza) \\
\hline Receber pedido & $80 \%$ fax, $20 \%$ e-mail & $\begin{array}{l}\text { Maioria por fax, e-mail apenas } \\
\text { para empresas maiores }\end{array}$ & $\begin{array}{l}40 \% \text { telefone, } 30 \% \text { visitas, } \\
\text { formalizacão do pedido por fax }\end{array}$ & $\begin{array}{l}\text { Maioria e-mail, restante por fax } \\
\text { e telefone }\end{array}$ \\
\hline Armazenar pedido & $\begin{array}{l}\text { Arquiva em uma pasta de } \\
\text { clientes e no sistema } \\
\text { comercial }\end{array}$ & $\begin{array}{l}\text { Arquiva em uma pasta de } \\
\text { clientes }\end{array}$ & Utiliza o sistema caseiro & $\begin{array}{l}\text { Emite três vias internas } \\
\text { (Cliente, Produção e Vendas) } \\
\text { Não informatizado }\end{array}$ \\
\hline Planejar produção & Não realiza & $\begin{array}{l}\text { Cria ordem a partir dos dados } \\
\text { do pedido do cliente }\end{array}$ & $\begin{array}{l}\text { Planejamento trimestral junto } \\
\text { com vendas }\end{array}$ & Não produz (terceiriza) \\
\hline Controlar estoques & Mantém estoque mínimo & Não informatizado & Utiliza sistema caseiro & Não produz (terceiriza) \\
\hline Planejar materiais & $\begin{array}{l}\text { Utiliza sistema integrado para } \\
\text { identificar itens abaixo do } \\
\text { estoque mínimo }\end{array}$ & Não informatizado & $\begin{array}{l}\text { Utiliza sistema caseiro mais } \\
\text { análise pessoal baseada na } \\
\text { experiência. }\end{array}$ & Não produz (terceiriza) \\
\hline Programar produção & $\begin{array}{l}\text { Ordens de produção são } \\
\text { fixadas em um mural, não há } \\
\text { críterios para sequenciamento } \\
\text { ou alocação das ordens }\end{array}$ & $\begin{array}{l}\text { Ordens de produção são } \\
\text { liberadas, no entanto não há } \\
\text { críterios para sequenciamento } \\
\text { ou alocação das ordens } \\
\end{array}$ & $\begin{array}{l}\text { A produção acampanha as } \\
\text { necessidades de montagem da } \\
\text { máquina. }\end{array}$ & Não produz (terceiriza) \\
\hline Controlar produção & Não realiza & Não realiza & Utiliza sistema caseiro & Não produz (terceiriza) \\
\hline
\end{tabular}


TABELA 23 - Levantamento do uso de TI nas Empresas do Projeto VIRTEC (Parte II)

\begin{tabular}{|c|c|c|c|c|}
\hline & Empresa 5 & Empresa 6 & Empresa 7 & Empresa 8 \\
\hline Número de Funcionários & 69 & 35 & 20 & 160 \\
\hline Faturamento & $\mathrm{R} \$ 22.400 .000,00$ & $\mathrm{R} \$ 3.443 .726,00$ & $\mathrm{R} \$ 980.000,00$ & $\mathrm{R} \$ 11.000 .000,00$ \\
\hline Tipologia de Produção & Itens de série (MTS) & Sob encomenda & Sob encomenda & Sob encomenda \\
\hline $\begin{array}{l}\text { Sistema Computacional } \\
\text { Utilizado }\end{array}$ & $\begin{array}{l}\text { Sistema caseiro Dataflex } \\
\text { Módulos: Contabilidade, } \\
\text { Financeiro, Estoque Utiliza } \\
\text { também planilhas Excel }\end{array}$ & $\begin{array}{l}\text { Em fase de implementação de } \\
\text { sistema integrado Colombus }\end{array}$ & Planilhas Excel & $\begin{array}{l}\text { Sistema comercial Sistec } \\
\text { Módulos: Contabilidade, } \\
\text { Financeiro, Compras, } \\
\text { Estoques, Vendas, Produção }\end{array}$ \\
\hline Prever demanda/vendas & Planilha Excel & Não realiza & Não realiza & Não informatizado \\
\hline Receber pedido & Fax, e-mail, telemarketing & Fax, e-mail & Fax, e-mail & Fax, correio \\
\hline Armazenar pedido & $\begin{array}{l}\text { Cadastra em planilha Excel e no } \\
\text { sistema caseiro }\end{array}$ & $\begin{array}{l}\text { Arquiva em uma pasta de } \\
\text { clientes e em planilha Excel }\end{array}$ & Utiliza Planilha Excel & Sistema comercial Sistec \\
\hline Planejar produção & Planilha Excel & $\begin{array}{l}\text { Planeja evitanto limpeza de } \\
\text { máquina. }\end{array}$ & Planilha Excel & Sistema comercial Sistec \\
\hline Controlar estoques & Planilha Excel & $\begin{array}{l}\text { Sistema integrado em fase de } \\
\text { implementação }\end{array}$ & Planilha Excel & Sistema comercial Sistec \\
\hline Planejar materiais & $\begin{array}{l}\text { Planilha Excel Manualmente } \\
\text { através da B.O.M. dia/fax }\end{array}$ & $\begin{array}{l}\text { Sistema integrado em fase de } \\
\text { implementação }\end{array}$ & Planilha Excel & Sistema comercial Sistec \\
\hline Programar produção & Planilha Excel & $\begin{array}{l}\text { Programação em função de } \\
\text { urgência da cliente. }\end{array}$ & Planilha Excel & $\begin{array}{l}\text { Não informatizado. } \\
\text { apenas montagem. }\end{array}$ \\
\hline Controlar produção & Planilha Excel & $\begin{array}{l}\text { Ficha de controle de produção. } \\
\text { Não informatizado. }\end{array}$ & Planilha Excel & Não informatizado. \\
\hline
\end{tabular}




\section{Referências Bibliográficas}

- APICS (1998). APICS dictionary. eds. COX, J.F.; BLACKSTONE, J.H. 9.ed. EUA, APICS.

- AMR (1998). Supply Chain Planning Optimization: just the facts. The Supply Chain Report. . http://www.amr.research.org (05 dez)

- APQC (1998). Process classification framework. http://www.apqc.com. (16 ago)

- ARIS method manual: versão 4.0. (1998). s.n.t. /Arquivo disponibilizado junto a ferramenta computacional ARIS Toolset.

- AZEVEDO, A.L.; SOUSA, J.P.; BASTOS, J.A., TOSCANO, C. (1998). A distributed order promise and planning system for the virtual enterprise. In: INTERNATIONAL IFIP WG 5.2/5.3 CONFERENCE - PROLAMAT, 10., Trento, 1998. /Enviado pelo autor/

- BREMER C.F.; MICHILINI, F.V.S.; ORTEGA, L.M.; SIQUEIRA, J.E.M. (2000). VIRTEC: um caso prático de formação e gestão de uma organização virtual. In: SIMPÓSIO DE GESTÃO DA INOVAÇÃO TECNOLÓGICA , 21., São Paulo, 2000. Anais. São Paulo, FEA/USP. /no prelo/

- BREMER, C.F.; MUNDIM, A.P.F.; MICHILINI, F.V.S.; SIQUEIRA, J.E.M.; ORTEGA, L.M. (1999a). A Brazilian case of VE coordination. In: WORKING CONFERENCE ON INFRASTRUCTURE FOR VIRTUAL ENTERPRISE (PROVE'99), Porto, 1999. Infrastructures for Virtual Enterprise - Networking Industrial Enterprise. Massachusetts, Kluwer Academic. p.377-386.

- BREMER, C.F.; EVERSHEIM, W.; WALZ, M.; MOLINA, A. (1999b). Global virtual business: a systematic approach for exploiting business opportunities in dynamic markets. International Journal of Agile Manufacturing, v.2, n.1, p.1-11, Jan./Feb. 
- BROWNE, J.; ZHANG, J. (1999). Extended and virtual enterprises - similarities and differences. International Journal of Agile Management Systems, v.1, p.30-36.

- BULTJE, R.; WIJK, J. (2000). Taxonomy of virtual organisations, based on definitions, characteristics and typology. The Eletronic Journal of Organizational Virtualness (www.virtual-organization.net), v.2, n.3, p.7-21.

- BYRNE, J.A. (1993). The virtual corporation. Business Week, p.98-103, 8 Fev.

- CAMARINHA-MATOS, L.M. (1997). A platform to support production planning and management in a virtual enterprise. s.n.t.

(http://www.uninova.pt/ prodnet/papers, 01/dez/1999). In: INTERNATIONAL CONFERENCE ON COMPUTER APPLICATIONS IN PRODUCTION AND ENGINEERING, Detroit, 1997.

- CAMARINHA-MATOS, L.M.; AFSARMANESH, H. (1997). s.n.t (http://www.uninova.pt/ prodnet/papers, 01/mai). Virtual enterprises: life cycle supporting tools and technologies. In: MOLINA, A.; SANCHEZ, J.; KUSIAK, A., ed. Handbook of life cycle engineering: concepts, tools and techniques. Chapman \& Hall. Cap. 1.

- CAMARINHA-MATOS, L.M.; AFSARMANESH, H. (1998). s.n.t (http://www.uninova.pt/ prodnet/papers, 01/ma/1999). Cooperative systems challenges in virtual enterprises. In: INTERNATIONAL MULTICONFERENCE ON COMPUTATIONAL ENGINEERING IN SYSTEMS APPLICATIONS, 2., Tunisia, 1998.

- CAMARINHA-MATOS, L.M.; AFSARMANESH, H. (1999). The Virtual enterprise concept. In: WORKING CONFERENCE ON INFRASTRUCTURE FOR VIRTUAL ENTERPRISE (PRO-VE'99), Porto, 1999. Infrastructures for Virtual Enterprise - Networking Industrial Enterprise. Massachusetts, Kluwer Academic. p.3-14.

- CAMARINHA-MATOS, L.M.; LIMA, C.P. (1999). Coordination and configuration requirements in a virtual enterprise. In: WORKING CONFERENCE ON INFRASTRUCTURE FOR VIRTUAL ENTERPRISE (PRO-VE'99), Porto, 1999. 
Infrastructures for Virtual Enterprise - Networking Industrial Enterprise. Massachusetts, Kluwer Academic. p.49-64.

- CeRVO, A.L.; BERVIAN, P.A. (1983). Metodologia científica. São Paulo, McGraw-Hill do Brasil.

- CHEN, P. (1990). Modelagem de dados: a abordagem entidade-relacionamento para projeto lógico. São Paulo, McGraw-Hill do Brasil.

- CHILDE, S.J. (1998). The extended enterprise - a concept of co-operation. Production Planning \& Control, v.9, n.4, p.320-327.

- CONTAdOR, J. C.; CONTADOR, J. L. (1997). Programação e Controle da Produção para Indústria Intermitente. In: CONTADOR, J.C., coord. Gestão de operações : a engenharia de produção a serviço da modernização da empresa. São Paulo, Edgard Blucher/Fundação Vanzolini.

- CORRÊA, G. N. (1999). Proposta de otimização da integração de parceiros na formação e gerência de empresas virtuais. São Carlos. 149p. Tese (Doutorado) - Escola de Engenharia de São Carlos, Universidade de São Paulo.

- CORREAA, H.; GIANESI, I. (1993). Just in time, MRP II e OPT: um enfoque estratégico. 2.ed. São Paulo, Atlas.

- CORRÊA, H.; GIANESI, I.; CAON, M. (1997). Planejamento, programação e controle da produção - MRP II/ERP, conceitos, uso e implementação. São Paulo, Atlas.

- CURTIS, B.; KELLNER, M. I.; OVER, J. (1992). Process Modeling. Comunications of ACM, v. 35, n. 9, p.75-90.

- DAVENPORT, T.H. (1994). Reengenharia de processos. Rio de Janeiro, Campus.

- EVERSheIM, W.; BAUERNHANSL, T.; BREMER, C.; MOLINA, A.; SCHUTH, S.; WALZ, M. (1998). Configuration of virtual enterprises based on a framework for global virtual business. In: ORGANIZATIONAL VIRTUALNESS AND ELECTRONIC COMMERCE, Bern, 1998. Proceedings. Bern, Simowa Verlag. p.77-84. 
- EVERSHEIM, W.; KLOCKE, F.; PFEIFER, T.; WECK, M. (1997). Manufacturing excellence in global markets. Aachen, Chapman \& Hall.

- EVERSHEIM, W.; BREMER, C.F.; KAMPMEYER, J. (1996). Requeriments for virtual enterprise management in developing countries. In: INTERNATIONAL CONFERENCE ON ENGINEERING AND TECHNOLOGY MANAGEMENT, Vancouver, 1996. Proccedings. Vancouver, Managing Virtual Enterprises. p. $84-88$.

- FERREIRA, A.B.H. (1986). Novo dicionário da língua portuguesa. Rio de Janeiro, Nova Fronteira.

- FURLAN, J. D. (1997). Modelagem de negócio. São Paulo, Makron.

- GARTNER (2000). Gartner's Dataquest Forecasts Worldwide ASP Market to Surpass $\$ 25$ Billion in 2004. www.gartner.com, 09/ago/2000.

- GIL, A.C. (1988). Como elaborar projetos de pesquisa. São Paulo, Atlas.

- GOldMAN, S.L.; NAGEL, R.N.; PREISS, K. (1995). Agile competitors: concorrência, organizações virtuais e estratégias para valorizar o cliente. São Paulo, Érica.

- GOldRATT, E. M.; COX, J. (1993). A Meta. São Paulo, Educator.

- GORANSON, H.T. (1999). The Agile virtual enterprise: cases, metrics, tools. Quorum Books.

- HAMEL, G.; PRAHALAD, C.K. (1995). Competindo pelo futuro: estratégias inovadoras para obter o controle do seu setor e criar os mercados de amanhã. Rio de Janeiro, Campus.

- HMS (2000). Holonic Manufacturing Systems. http://hms.ifw.uni-hannover.de/, 10/04/2000.

- INESC PORTO (2000). Unidade de Engenharia de Sistemas de Produção, Projetos de I\&D. http://www2.inescporto.pt/pt/html/mapa.htm, 10/abr/2000.

- JAGDEV, H.S.; BROWNE, J. (1998). The Extended enterprise - a context for manufacturing. Production Planning \& Control, v.9, n.3, p. 216-229.

- JÄGERS, H.; JANSE, W.; STEENBAKKERS, W. (1998). Characteristics of virtual organizations. In: ORGANIZATIONAL VIRTUALNESS AND ELECTRONIC COMMERCE, Bern, 1998. Proceedings. Bern, Simowa Verlag. p.65-76. 
- KELLER, G.; TEUFEL, T. (1998). SAP R/3 process oriented implementation. Harlow, Addison-Wesley.

- KLEN, A.P.; RABELO, R.J.; SPINOSA, L.M.; FERREIRA, A.C. (1999). s.n.t. (http://www.gsigma-grucon.ufsc.br/portugues/ vti bin/shtml.dll/publica.htm, 01 Mai). The PRODNET-II: approach for managing distributed business processes. In: WORKSHOP INTERNACIONAL DE AVALIAÇÃO DOS PROJETOS PRO TEM-CC FASE III, Rio de Janeiro, 1999.

- LAKATOS, E. M.; MARCONI, M. A. (1991). Metodologia Científica. 2ed., São Paulo, Atlas.

- LEPIKSON, H. A. (1997). Uma nova abordagem distribuída para o gerenciamento do chão de fábrica em um sistema integrado de manufatura. Florianópolis. p. Tese (Doutorado) - Universidade Federal de Santa Catarina.

- LITTLE, D.; GAVIN, C.; HODGSON, N.; GUENAOUI, D. (1997). Survey of SME information systems for planning and operations. Institute of Operation Management, n. 5, p. 17-20.

- LUMMUS, R.R.; VOKURKA, R.J. (1999). Defining supply chain management: a historical perspective and practical guidelines. Industrial Management \& Data Systems, v. 99, n. 1, p.11-17.

- MAKATSORIS, C.; LEACH, N. P.; RICHARDS, H. D.; BESANT, C.; RISTIC, M. (1996). s.n.t. (http://www.nimblesite.com/xcittic/, 01/set/1998) Addressing the planning and control gap in semiconductor virtual enterprise. In: ESPRIT INTEGRATION IN MANUFACTURING CONFERENCE, Galway, 1996.

- MALLIDI, K.; PARASKEVOPOULOS, A.T.; PAGANELLI, P. (1999). Process modelling in small-medium enterprise networks. Computer in Industry, v.38, p.149-158.

- MASSYVE. (2000). Multiagent manufacturing agile scheduling systems for virtual enterprises. http://centaurus.dee.fct.unl.pt/ massyve/ (01 mai)

- MAVE. (1998). Manufacturing agile virtual enterprise. http://absu.amef.lehigh.edu/Ex Proj/MAVE. (10 Ago)

- MEZGÁR, I.; KOVÁCS, G.L. (1999). Co-ordination of SME production through a co-operative network. Journal of Intelligent Manufacturing, n. 9, p.167-172. 
- MICHILINI, F. V. S. (2000). Definição de uma Infra-estrutura de informação para Suporte à Gestão de Organizações Virtuais. Trabalho de mestrado, 155p. Escola de Engenharia de São Carlos, Universidade de São Paulo. /a ser defendida em 20/10/2000/.

- MOWSHOWITZ, A. (1997). Virtual organization. Communications of the ACM, v.40, n.9, p.30-37.

- PIRES, S.R.I. (1995). Gestão estratégica da produção. Piracicaba, Unimep.

- PIRES, S.R.I. (1998). Gestão da cadeia de suprimentos e o modelo de consórcio modular. Revista de Administração, v.33, n. 3, p.5-15.

- PIRES, S.R.I. (199). Notas de Aula, Curso Supply Chain Management, PPGEP, UNIMEP, Piracicaba.

- PIRES, S.R.I. ;BREMER, C.F.; SANTA EULALIA, L.A.; GOULART, C.P. (2000). Supply chain and virtual enterprises: comparisons, migration and the brazilian experience of VIRTEC. In: LOGISTICS RESEARCH NETWOK CONFERENCE, 5. , Cardiff, 2000. Proceedings. Cardiff, Lean Enterprise Research Centre, v. 1, p. 463-470.

- PLENT. (2000). Planning small medium enterprise networks. http://www.cordis.lu/esprit/src/20723.htm. (01 Mai).

- PORTER, K.; LITTLE, D.; PECK, M.; ROLLINS, R. (1999). Manufacturing classifications: relationships with production control systems. Integrated Manufacturing Systems, v. 10, n. 3-4, p.189-198

- PREISS, K.; GOLDMAN, S. L.; NAGEL, R. N. (1998). Cooperar para Competir: Construindo Parcerias Eficazes. São Paulo, Ed. Futura.

- PRODNET (2000). PRODNET Production Planning and Management in an Extended Enterprise. http://www.uninova.pt/ prodnet/. (01 mai).

- PROMON IP, (2000). ASP - Application Service Provider. http://www.promonip.com.br/servicos/asp/frame asp solucoes.asp, (08 ago)

- RABELO, R.J.; CAMARINHA-MATOS, L.M. (1995). s.n.t. (http://www.gsigmagrucon.ufsc.br/Rabelo/publica.htm, 22/set/1999). HOLOS: a methodology for 
deriving scheduling systems. In: CAMARINHA-MATOS, L.M.; AFSARMANESH, H., ed. Balanced automation systems: architecture and design methods.

- RABElO, R.J.; CAMARINHA-MATOS, L.M.; AFSARMANESH, H. (1999). Multiagent-based agile scheduling. International Journal of Robotics and Autonomous Systems, Special Issue on Multi-Agent Systems Applications, p.15-28.

- REID, R. L.; ROGERS, K. J.; JOHNSON, M. E.; LILES, D. H. (1996a). Engineering the Virtual Enterprise. In: INDUSTRIAL ENGINEERING RESEARCH CONFERENCE, 5., Minneapolis, $1996 . \quad$ Proceedings. Minneapolis, Institute of Industrial Engineers. p. 485-490.

- REID, R.L.; TAPP, J.B.; LILES, D.H.; ROGERS, K.J.; JOHNSON, M.E. (1996b). An Integrated model for virtual enterprise: vision, strategy and strucutre. In: INTERNATIONAL CONFERENCE ON ENGINEERING AND TECHNOLOGY MANAGEMET, Vancouver, 1996. Proccedings. Vancouver, Managing Virtual Enterprises. p. 522-527.

- RICHARDS, H.D.; DUDENHAUSEN, H.M.; MAKATSORIS,C.; RIDDER, L. (1997). s.n.t. (http://www.nimblesite.com/xcittic/, 01/set/1998). Flow of orders through a virtual enterprise: their proactive planning \& scheduling and reactive control. Computing \& Control Engineering Journal, v.8, n.4, p.173-179.

- ROLSTADAS (1998). Editorial virtual and extended enterprise definition. Production Planning \& Control, v.9, n.4, p.215.

- ROTONDARO, R.G. (1997). Gerenciamento por processo. In: CONTADOR, J.C., coord. Gestão de operações : a engenharia de produção a serviço da modernização da empresa. São Paulo, Edgard Blucher/Fundação Vanzolini.

- ROZENFELD, H. (1996). Reflexões sobre a manufatura integrada por computador. In: WORKSHOP MANUFATURA CLASSE MUNDIAL, São Paulo, 1996. Mitos \& Realidade. São Paulo, EPUSP. р.25-38.

- SCHEER, A.W. (1994). Business process engineering: reference models of industrial enterprises. Berlin, Springer Verlag. 
- SCHEER, A.W. (1998). ARIS - business process frameworks. Berlin, Springer Verlag.

- SIHN, W. (1998). Manufacturing in networks - competitive advantages for virtual enterprise. In: INTERNATIONAL CONFERENCE OF THE MANUFACTURING VALUE CHAIN, Troon, 1998. Proceedings. Troon, Kluwer Academic. p.249257.

- SKYRME, D.J. (1998). The Reality of virtually. In: ORGANIZATIONAL VIRTUALNESS AND ELECTRONIC COMMERCE, Bern, 1998. Proceedings. Bern, Simowa Verlag. p.25-34.

- SPINOSA L.M.; RABELO R.J.; KLEN A.P. (1998). s.n.t. (http://www.uninova.pt/ prodnet/papers, 16/set/1999). High-level coordination of business processes in the virtual enterprise. In: INTERNATIONAL IFIP WG 5.2/5.3 CONFERENCE - PROLAMAT, 10., Trento, 1998.

- THOBEN, K.-D.; JAGDEV, H.S. (1999). Typological issues in industrial collaboration. In: INTERNATIONAL CONFERENCE ON CONCURRENT ENTERPRISING, 5., The Hague, 1999. IArquivo enviado pelo autor/

- TUMA, A. (1998). Configuration and coordination of virtual production networks. International Journal of Production Economics, v.56-57, p.641-648.

- VERNADAT, F.B. (1996). Enterprise modeling and integration: principles and applications. London, Chapman \& Hall.

- VOLLMANN, T.E.; BERRY, W.L.; WHYBARK, D.C. (1997). Manufacturing planning and control systems. 4.ed. New York, McGraw-Hill.

- WIENDAHL, H.P.; HÖBIG, M. (1998). Balanced production planning and control in production networks. In: STRATEGIC MANUFACTURING OF THE MANUFACTURING VALUE CHAIN, Troon, 1998. Proceedings. Troon, Kluwer Academic. p.401-410.

- WIGAND, R.; PICOT, A.; REICHWALD, R. (1997). Information, organization and management: expanding markets and corporate boundaries. Chichester, John Wiley \& Sons. 
- WILDEMAN, L. (1999). Organização virtual. HSM Management, n.15, p.74-80, jul./ago.

- WOMACK, J. P.; JONES, D. T. (1998). A mentalidade enxuta nas empresas: elimine o desperdício e crie riqueza. Rio de Janeiro, Campus.

- ZHANG, W. J.; LI, Q. (1999). Information modeling for made-to-order virtual enterprise manufacturing systems. Computer-Aided Design, v.31, p.611619. 


\section{Bibliográfia Consultada}

- AZEVEDO, A.L.; SOUSA, J.P. (1998). s.n.t. (http://www.nimblesite.com/xcittic/, 11/dez/1998). An order promise system for distributed enterprise. In: INTERNATIONAL CONMFERENCE ON ENGINEERING DESIGN AND AUTOMATION, 2., Maui, 1998.

- BALLOU, R.H. (1998). Business logistics management: planning, optimizing and controlling the supply chain. Rio de Janeiro, Prentice-Hall do Brasil.

- BREMER, C.F.; MUNDIM, A.P.F.; MICHILINI, F.V.S.; SIQUEIRA, J.E.M.; ORTEGA, L.M. (1999). New product search and development as trigger to competencies integration in virtual enterprises. The Electronic Journal of Organization Virtualness. Bern, Suiça, (www.virtual-organization.net), v.1, n.1, p.213-222.

- CAMARINHA-MATOS, L.M.; AFSARMANESH, H. (1999). The PRODNET goals and approach. In: WORKING CONFERENCE ON INFRASTRUCTURE FOR VIRTUAL ENTERPRISE (PRO-VE'99), Porto, 1999. Infrastructures for Virtual Enterprise - Networking Industrial Enterprise. Massachusetts, Kluwer Academic. p.97-108.

- CAMARINHA-MATOS, L.M.; SILVA, V.S.; RABELO, R.J. (1999). Production planning and control in a virtual enterprise. In: WORKING CONFERENCE ON INFRASTRUCTURE FOR VIRTUAL ENTERPRISE (PRO-VE'99), Porto, 1999. Infrastructures for Virtual Enterprise - Networking Industrial Enterprise. Massachusetts, Kluwer Academic. p.219-232.

- CAMPEÃO, P. (1997). Proposta de um método para desenvolvimento de processos de negócios integrados a uma metodologia de integração de empresas. São Carlos. 181p. Dissertação (Mestrado) - Escola de Engenharia de São Carlos, Universidade de São Paulo. 
- D'AMOURS, S.; MONTREUIL, B.; LEFRANÇOIS, P.; SOUMIS, F. (1999). Networked manufacturing: the impact of information sharing. International Journal of Production Economics, v.58, p.63-79.

- FREDERIX, F. (1996). Planning and scheduling multi-site semiconductor production chains. s.n.t. (http://www.nimblesite.com/xcittic/, 01 mai.). In: ESPRIT - INTEGRATION IN MANUFACTURING CONFERENCE, Galway, 1996.

- HE, D.; KUSIAK, A. (1996). Production planning and scheduling in virtual manufacturing. In: INDUSTRIAL ENGINEERING RESEARCH CONFERENCE, 5., Minneapolis, 1996. Proceedings. Minneapolis, Institute of Industrial Engineers. p. 491-502.

- KLEN, A.P.; RABELO, R.J.; SPINOSA, L.M.; FERREIRA, A.C. (1999). Distributed business process management. In: WORKING CONFERENCE ON INFRASTRUCTURE FOR VIRTUAL ENTERPRISE (PRO-VE'99), Porto, 1999. Infrastructures for Virtual Enterprise - Networking Industrial Enterprise. Massachusetts, Kluwer Academic. p.241-258.

- PORTER, M. (1998). Cluster e Competitividade. HSM Management, n. 15, p.100-110, jul-ago.

- SoARES, A.L., AZEVEdo, A.L.; SOUSA, J.P.; BASTOS, J.A., TOSCANO, C. (2000). Distributed planning and control systems for the virtual enterprise : organizational requirements and development life-cycle. Intelligent Manufacturing Journal. /no prelo/.

- SOARES, A.L.; SOUSA, J.P.; AZEVEDO, A.L.; BASTOS, J.A. (1997). s.n.t (http://www.nimblesite.com/xcittic/, 19/set/1998). Using an informal ontology in the development of a planning and control system - the case of the virtual enterprise. In: INTERNATIONAL CONFERENCE ON INTEGRATED AND SUSTAINABLE INDUSTRIAL PRODUCTION, Lisboa, 1997.

- SPINOSA L.M.; KLEN, A.P.; RABELO, R.J.; FERREIRA, A.C. (1999). s.n.t. (http://www.gsigma-grucon.ufsc.br/portugues/ vti bin/shtml.dll/publica.htm, 06/jun/1999). The PRODNET II - approach for managing distributed business 
processes. In: WORKSHOP INTERNACIONAL DE DE AVALIAÇÃO DO PROJETOS PRO TEM-CC FASE III, Rio de Janeiro, 1999.

- VOLLMANN, T.E.; BERRY, W.L.; WHYBARK, D.C. (1993). Integrated production and inventory management. Illinois, EUA, Business One Irwin. 